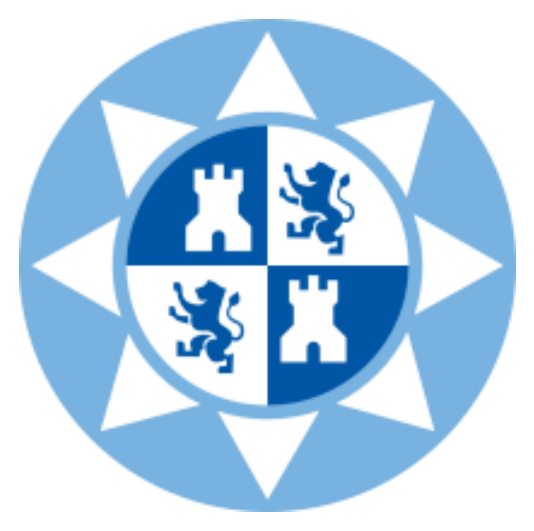

Universidad Politécnica de Cartagena

Departamento de Ingeniería de Alimentos

y del Equipamiento Agrícola

\title{
Estudio de la evolución de los regadíos mediante técnicas de benchmarking. Aplicación en la Región de Murcia
}

Mariano Soto García 


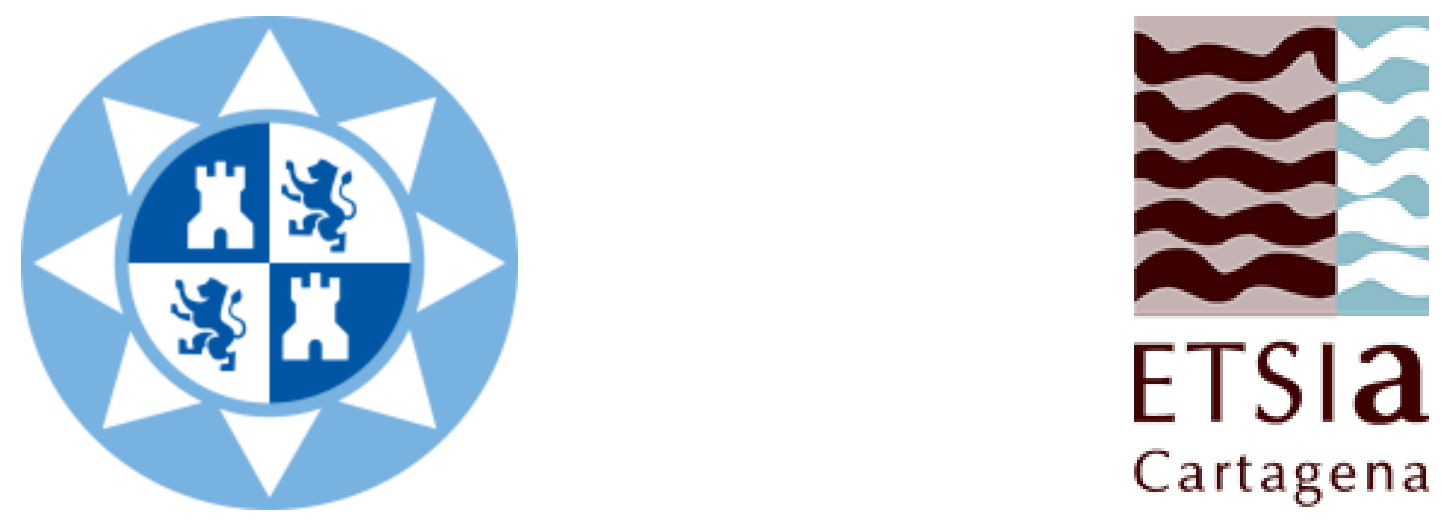

Universidad Politécnica de Cartagena

Departamento de Ingeniería de Alimentos

y del Equipamiento Agrícola

\section{Estudio de la evolución de los regadíos mediante técnicas de benchmarking. Aplicación en la Región de Murcia}

Mariano Soto García

Directores:

Dr. Bernardo Martín Górriz

Dr. Victoriano Martínez Álvarez 

A María Jesús, mis padres, familia y amigos 



\section{Resumen}

La competencia por el uso del agua aumenta día a día debido tanto al crecimiento demográfico como al aumento de la demanda de los distintos sectores económicos. Esta competencia se agudiza en zonas áridas y semiáridas, donde el cambio climático está produciendo una disminución de los recursos hídricos disponibles. En este contexto se desarrolla la presente tesis, enmarcada en el proyecto europeo SIRRIMED, en concreto en el Workpackage $n^{o} 3$, que tiene por objeto tanto la caracterización de distintas zonas regables del mediterráneo como su evaluación comparativa mediante la aplicación de técnicas de benchmarking. Con este fin se han analizado cinco comunidades de regantes (CCRRs) de la Región de Murcia en un periodo de diez años (2002-2011), que representan el 38,5\% de la superficie regable regional. Las principales aportaciones de esta tesis son el estudio del nexo agua-energía en CCRRs, así como de los efectos de la escasez de agua y de la modernización sobre los indicadores de gestión de zonas regables durante un periodo de tiempo tan prologando.

El empleo de técnicas de benchmarking ha permitido determinar que estas CCRRs tienen un valor de la producción agrícola muy alto, con una gran eficiencia de distribución, pero también con unos elevados costes de manejo del sistema y una gran irregularidad en la disponibilidad de recursos hídricos. De este trabajo se desprende que el factor que más influye en el consumo energético en el regadío es el origen de los recursos hídricos. Además, la escasez de agua produce grandes fluctuaciones anuales en los indicadores de gestión de las CCRRs, de importancia sensiblemente mayor que los asociados a las actuaciones de modernización de regadíos.

Por último, indicar que en los procesos de modernización de las CCRRs se han identificado dos grados (o niveles) de modernización: el denominado de "primera generación", caracterizado por la presurización de las redes de distribución; y el de "segunda generación", que se caracteriza por la incorporación de las Tecnologías de la Información y Comunicaciones (TICs) a la gestión de las CCRRs, automatizando las infraestructuras hidráulicas presurizada ya existente, lo que proporciona un mejor servicio al regante, permite conocer la trazabilidad del agua, y una distribución de agua transparente, eficiente y equitativa. Sin embargo, los indicadores de gestión tradicionales no son capaces de reflejar estas mejoras, por lo que se proponen nuevos indicadores que permitan cuantificar esta realidad. 


\section{Abstract}

Competition for water use increases daily as a consequence of the growing world population, climate change and the ever increasing demands of the various economic sectors. In this context, the present thesis, framed in the European project SIRRIMED and more specifically in Workpackage $n^{o} 3$, deals directly with the characterization of the irrigated areas by applying benchmarking techniques in order to propose the best management practices. For this study five Irrigation Districts (IDs) in the Region of Murcia, which represent $38.5 \%$ of the regional irrigable area, have been analyzed for a period of ten years (2002-11). The main contributions of the thesis are the study of the water-energy nexus in IDs, as well as the effect of water scarcity and the modernization of performance indicators on irrigable lands over such a long period.

The use of benchmarking techniques has revealed that the studied IDs have had very hight agricultural production, with very hight distribution efficiency, but aasociated to high system operating costs. The study IDs also were subjected to frequent water sortages and irregular supply; water sortages produced large annual fluctuations in indicators IDs. The results clearly show that water supply restrictions contributed to the important performance changes observed over time to a much greater extent than the modernisation process did.

The results of the study also highlight the two differents types of modernisation processes: "First generation" modernisation, involving the pressurisation of distribution networks, and "Second generation" modernisation, whose fundamental characteristics focus on the automation of hydraulic infrastructure and the incorporation of Information Technology and Communications (ICTs). The latter provides an improved service to irrigators, the provision of water traceability information, and a transparent, efficient and equitable water distribution. Traditional performance indicators are no able to reflect these improvements and as a result new indicators are proposed to quantify adequately this reality. 


\section{Índice}

1. INTRODUCCIÓN

1.1. LA AGRICULTURA DE REGADÍO 1

1.2. INDICADORES DE GESTIÓN Y TÉCNICAS DE BENCHMARKING 4

1.2.1. Introducción a las técnicas de Benchmarking 4

1.2.2. Aplicación de las técnicas de Benchmarking en el regadío 4

1.3. EL REGADÍO EN LA REGIÓN DE MURCIA 5

1.3.1. Situación actual del regadío 6

$\begin{array}{ll}\text { 1.3.2. Recursos disponibles } & 7\end{array}$

1.4. OBJETIVOS Y ESTRUCTURA DE LA PRESENTE TESIS 8

1.4.1. Objetivos 9

$\begin{array}{ll}\text { 1.4.2. Estructura } & 10\end{array}$

2. ANTECEDENTES Y ESTADO DEL ARTE 13

2.1. EL REGADÍO EN LA REGIÓN DE MURCIA 13

2.1.1. Antecedentes históricos 13

$\begin{array}{ll}\text { 2.1.2. La agricultura de regadío } & 15\end{array}$

2.1.3. Demanda hídrica 19

2.1.4. Recursos hídricos $\quad 21$

2.1.4.1. Agua superficial de la Cuenca 22

2.1.4.2. Aguas subterráneas 23

2.1.4.3. Trasvase Tajo-Segura 24

2.1.4.4. Desalinización 26

2.1.4.5. Reutilización $\quad 27$

2.1.5. La escasez de agua 28

2.1.6. Impacto medioambiental del regadío 32

2.2. COMUNIDADES DE REGANTES 34

2.2.1. Antecedentes históricos y base legal 35

2.2.2. Importancia y régimen de funcionamiento 36

2.3. ZONA DE ESTUDIO 38

2.3.1. Comunidad de Regantes del Campo de Cartagena (CRCC) 39

2.3.2. Comunidad de Regantes de Lorca (CRLO) 41 
2.3.3. Comunidad de Regantes Trasvase Tajo Segura Calasparra-Cieza (CRTCC)

2.3.4. Comunidad de Regantes Pantano de la Cierva (CRPC) 45

2.3.5. Comunidad de Regantes de Miraflores (CRM) 47

2.4. INDICADORES DE GESTIÓN Y TÉCNICAS DE BENCHMARKING 49

2.4.1. Introducción 49

2.4.2. Fases en el proceso de benchmarking aplicado al regadío 50

2.4.3. Indicadores de gestión 53

2.4.4. Aplicaciones del benchmarking en los regadíos 57

2.4.5. Indicadores de gestión del regadío de la Región de Murcia

2.5. ANÁLISIS DE LA RELACIÓN ENTRE EL AGUA Y LA ENERGÍA EN EL REGADÍO

2.5.1. Nexo agua-energía 63

2.5.2. Coste de energía 66

2.6. LA MODERNIZACIÓN DE LOS REGADÍOS 68

2.6.1. Plan Nacional de Regadíos 68

2.6.2. Aplicación de las TICs en la gestión de las comunidades de regantes 71

2.6.3. Modernización de regadíos en la Región de Murcia

3. CARACTERIZACIÓN DE LAS COMUNIDADES DE REGANTES DE LA REGIÓN DE MURCIA

3.1. INTRODUCCIÓN

3.2. METODOLOGÍA 78

$\begin{array}{ll}\text { 3.2.1. Indicadores de gestión aplicados } & 79\end{array}$

3.2.2. Comunidades de regantes seleccionadas $\quad 80$

$\begin{array}{ll}\text { 3.2.3. Adquisición de datos } & 81\end{array}$

3.2.4. Fiabilidad de los datos e Índice General de Fiabilidad (IGF) 83

3.2.5. Indicadores de gestión de otros estudios previos $\quad 84$

3.3. RESULTADOS 86

3.3.1. Análisis de la fiabilidad de los datos $\quad 86$

3.3.2. Indicadores de rendimiento 86

3.3.3. Indicadores financieros $\quad 89$

3.3.4. Indicadores de eficiencia de producción 95 
4. RELACIÓN AGUA-ENERGÍA EN EL REGADÍO 103

4.1. INTRODUCCIÓN 103

4.2. METODOLOGÍA 104

4.2.1. Indicadores aplicados 106

$\begin{array}{ll}\text { 4.2.2. Nivel de cuenca } & 107\end{array}$

4.2.2.1. Agua superficial 107

4.2.2.2. Aguas subterráneas 107

4.2.2.3. Trasvase Tajo-Segura 108

4.2.2.4. Desalinización 108

4.2.2.5. Reutilización 109

4.2.3. Niveles de comunidad de regantes y de parcela 110

4.3. RESULTADOS 112

4.3.1. Consumo agua y energía 112

4.3.1.1. Nivel de cuenca 113

4.3.1.2. Niveles de comunidad de regantes y de parcela 115

4.3.1.3. Consumo global de energía 117

4.3.2. Relación entre el consumo de energía y agua 119

4.3.3. Efectos de la modernización en los indicadores energéticos $\quad 124$

$\begin{array}{ll}\text { 4.4. DISCUSIÓN } & 125\end{array}$

5. EFECTOS DE LA ESCASEZ DE AGUA 129

5.1. INTRODUCCIÓN 129

5.2. METODOLOGÍA 131

5.2.1. Indicadores seleccionados 132

5.2.2. Zona de estudio a nivel parcela 133

5.2.3. Adquisición de datos y encuestas 134

5.3. RESULTADOS 136

5.3.1. Sensibilidad de los indicadores de gestión a la escasez de agua $\quad 136$

5.3.2. Patrón de cultivo y manejo del agua a nivel de parcela 145

5.3.3. Estrategias de los agricultores bajo restricciones de agua 149

5.4. DISCUSIÓN 153 
6. EFECTOS DE LA MODERNIZACIÓN 155

6.1. INTRODUCCIÓN 155

6.2. METODOLOGÍA 156

6.2.1. Indicadores seleccionados 157

6.2.2. Zona de estudio 158

6.2.3. Sistema de asignación y distribución del agua 160

6.2.4. Arquitectura del sistema de gestión 162

6.2.4.1. Aplicaciones para los usuarios en local 165

6.2.4.2. Aplicaciones para los usuarios en remoto 166

6.2.4.3. SCADA 168

6.3. RESULTADOS 169

6.3.1. Efecto de la modernización sobre los indicadores de gestión $\quad 169$

6.3.2. Efectos sobre la gestión y el servicio de la CRCC 172

6.3.3. Adaptación de los agricultores a las TICs 176

$\begin{array}{ll}\text { 6.4. DISCUSIÓN } & 178\end{array}$

7. CONCLUSIONES

$\begin{array}{ll}\text { 7.1. CONCLUSIONES } & 181\end{array}$

7.2. PROPUESTA DE FUTUROS TRABAJOS DE INVESTIGACIÓN QUE SE PUEDAN DERIVAR DE ESTA TESIS 183

$\begin{array}{ll}\text { BIBLIOGRAFÍA } & 185\end{array}$ 


\section{Índice de tablas}

Tabla 2.1. Agrupación de UDAs por comarcas agrarias en la Región de Murcia. Elaboración propia (CARM, 2013; CHS, 2013)........................20

Tabla 2.2. Dotaciones para riego en la $1^{\mathrm{a}}$ fase del Postravase (Gómez et al., 2011)...25

Tabla 2.3. Descripción y método de cálculo de los indicadores de gestión empleados .54

Tabla 2.4. Principales indicadores de gestión del regadío de la Región de Murcia durante el periodo 2002-11. Elaboración propia (ESYRCE, 2011; INE, 2012; CARM, 2013)

Tabla 2.5. Actuaciones en el ámbito del PNR y PCH (MAGRAMA, 2013)............70

Tabla 3.1. Principales características de las CCRRs analizadas en el periodo 2002-

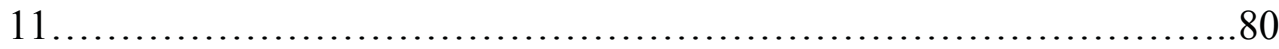

Tabla 3.2. Índice General de Fiabilidad (Rodríguez, 2003)............................84

Tabla 3.3. Valores de indicadores de gestión de otros estudios previos................85

Tabla 3.4. Valores del Índice General de Fiabilidad para las CCRRs objeto del estudio............................................................... 86

Tabla 3.5. Indicadores de rendimiento más significativos en el periodo $2002-11 \ldots \ldots . .87$

Tabla 3.6. Indicadores financieros más significativos en el periodo $2002-11 \ldots \ldots \ldots \ldots . . .89$

Tabla 3.7. Tarifas Trasvase Tajo-Segura y de peaje de la Cuenca (SCRATS, 2013)...90

Tabla 3.8. Indicadores de eficiencia de producción más significativos en el periodo $2002-11$ .95

Tabla 3.9. Comparativa de los resultados obtenidos en esta tesis con otros estudios previos 100

Tabla 4.1. Descripción y método de cálculo de los indicadores de gestión empleados..................................................... 106

Tabla 4.2. Principales características de las CCRRs analizadas en el periodo 20022011 110

Tabla 4.3. Energía específica (EacVs) por CCRR. Valor medio y rango en el período 2002-2011 
Tabla 5.1. Descripción y método de cálculo de los indicadores de gestión empleados..................................................... 132

Tabla 6.1. Descripción y método de cálculo de los indicadores de gestión empleados..................................................... 158

Tabla 6.2. Análisis comparativo de tiempo empleado para la realización de diferentes tareas antes y después de la modernización. 175 


\section{Índice de figuras}

Figura 2.1. Distribución territorial de la Cuenca Hidrográfica del Segura (CHS,

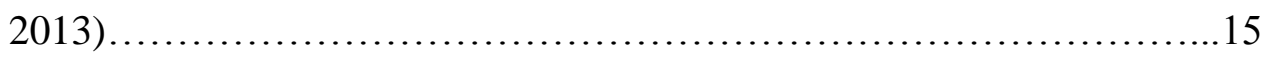

Figura 2.2. Comarcas agrarias y municipios de la Región de Murcia (CARM, 2013).17

Figura 2.3. Grupos de cultivos por comarcas agrarias. Elaboración propia con datos propuesta PHCS y estadística regional (CARM, 2013; CHS, 2013)......18

Figura 2.4. Sistemas de riego por comarcas agrarias. Elaboración propia con datos propuesta PHCS y estadística regional (CARM, 2013; CHS, 2013)......19

Figura 2.5. Balance de la Cuenca del Segura del PHCS (CHS, 2013)................22

Figura 2.6. Aportación anual de la Cuenca y el Trasvase Tajo-Segura (CHS, 2013)..23

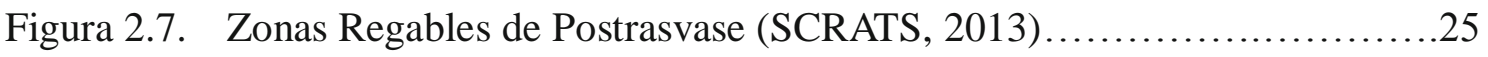

Figura 2.8. Trasvase Tajo-Segura. Volúmenes trasvasados. Elaboración propia (CHS, 2013)

Figura 2.9. Volúmenes de agua depurados durante el periodo 2002-11 en la Región de Murcia. Elaboración propia (INE 2012; ESAMUR 2013)...............28

Figura 2.10. Relación entre la precipitación anual respecto a la superficie regada (Sr) en la Región de Murcia durante el periodo 2002-11. Elaboración propia (CARM, 2013; ECONET, 2013)..................................30

Figura 2.11. Relación entre el volumen anual trasvasado para riego respecto a la superficie regada (Sr) en la Región de Murcia durante el periodo 2002-11. Elaboración propia (CARM, 2013; CHS, 2013).......................31

Figura 2.12. Evolución de las fuentes de agua para riego en la Cuenca del Segura. Elaboración propia (CHS, 2013; ESAMUR, 2013; INE, 2012; SCRATS,

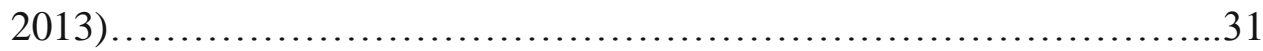

Figura 2.13. Localización de las CCRRs estudiadas en la Región de Murcia.............38

Figura 2.14. Mapa de la Zona Regable de la Comunidad de Regantes del Campo de Cartagena (CRCC, 2013) 39

Figura 2.15. Mapa de la Zona Regable de la Comunidad de Regantes de Lorca (CRLORCA, 2013) .42

Figura 2.16. Mapa de la Zona Regable de la Comunidad de Regantes del Trasvase Tajo Segura Calasparra-Cieza (SCRATS, 2013).... 
Figura 2.17. Mapa de la Zona Regable de la Comunidad de Regantes Pantano de la Cierva (SCRATS, 2013) .46

Figura 2.18. Mapa de la Zona Regable de la Comunidad de Regantes Miraflores.......48

Figura 2.19. Fases en el proceso de benchmarking aplicado al regadío. .51

Figura 2.20. Evolución de la superficie regada (Sr) en la Región de Murcia por grupos de cultivos. Elaboración propia (CARM, 2013)

Figura 2.21. Evolución suministro de agua por unidad de área regada (VsSr) en la Región de Murcia y España. Elaboración propia (ESYRCE, 2011; INE, 2012; CARM, 2013).

Figura 2.22. Evolución del valor de la producción agrícola por unidad de superficie regada (VPSr) en la Región de Murcia por grupos de cultivos. Elaboración propia (CARM, 2013).

Figura 3.1. Evolución de los indicadores de rendimiento: a) SrSa, b) ED, c) VsSr y d) ARIS.

Figura 3.2. Evolución de los indicadores financieros: a) CMSSr, b) CMSVs, c) GGSr, d) GGVs, e) CPSr, f) CPVs, g) CMSr y h) CMVs

Figura 3.3. Evolución de los indicadores financieros energéticos: a) CENSr y b) CENVs .94

Figura 3.4. Evolución de los indicadores de eficiencia de la producción: a) VPSr, b) VPVs, c) MBSr y d) MBVs. .96

Figura 4.1. Resumen de los niveles de gestión para obtener el consumo de energía global para el riego en la Región de Murcia.

Figura 4.2. Evolución de las fuentes de agua y la energía específica (EacVs) por CCRRs en el periodo estudiado. a) CRCC; b) CRTCC; c) CRM.

Figura 4.3. Evolución del suministro de agua por unidad de área regada (VsSr) y la energía activa consumida por unidad de superficie regada (EacSr) del 2002 al 2011 en la CRCC (a), la CRTCC (c) y la CRM (e). Relación entre el volumen suministrado de agua por unidad de área regada (VsSr) y la energía específica (EacVs) en la CRCC (b), la CRTCC (d) y la CRM (f). 120 
Figura 4.4. Relación entre la energía activa consumida por unidad de superficie regada (EacSr) y el suministro de agua por unidad de área regada (VsSr) por CCRR. 122

Figura 4.5. Evolución de la energía activa consumida por unidad de superficie regada (EacSr) por niveles de gestión desde el 2002 al 2011 en la CRCC (a), la CRM (b), y la CRTCC (c). 123

Figura 4.6. Consumo de energía específica (EacVs) en los diferentes niveles de gestión del agua para riego en la Región de Murcia 126

Figura 5.1. Mapa de las Zonas Regables de la CRCC y de las parcelas que fueron encuestadas. El histograma de frecuencia muestra el número de parcelas estudiadas por grupo de cultivos...............................136

Figura 5.2. Análisis de regresión lineal entre los indicadores SrSa y VsSr. a) CRCC, b) CRLO, c) CRTCC, d) CRPC, y e) CRM.

Figura 5.3. Análisis de regresión potencial entre los indicadores ED y VsSr. a) CRCC, b) CRLO, c) CRTCC, d) CRPC, y e) CRM. .138

Figura 5.4. Análisis de regresión lineal entre los indicadores ARIS y VsSr. a) CRCC, b) CRLO, c) CRTCC, d) CRPC, y e) CRM. 139

Figura 5.5. Análisis de regresión potencial entre los indicadores CMSVs y VsSr. a) CRCC, b) CRLO, c) CRTCC, d) CRPC, y e) CRM 140

Figura 5.6. Análisis de regresión potencial entre los indicadores CENVs y VsSr. a) CRCC, b) CRLO, c) CRTCC, d) CRPC, y e) CRM 141

Figura 5.7. Análisis de regresión lineal entre los indicadores CENSr y VsSr. a) CRCC, b) CRLO, c) CRTCC, d) CRPC, y e) CRM. 142

Figura 5.8. Análisis de regresión potencial entre los indicadores VPVs y VsSr. a) CRCC, b) CRLO, c) CRTCC, d) CRPC, y e) CRM 143

Figura 5.9. Análisis de regresión lineal entre indicadores VPSr y VsSr. a) CRCC, b) CRLO, c) CRTCC, d) CRPC, y e) CRM. 144

Figura 5.10. Evolución de la superficie total regada (Sr) y por grupos de cultivos en la CRCC durante el período 2002-2011. 146 
Figura 5.11. Evolución de: (a) el volumen anual de agua suministrada por la CRCC (Vs), (b) la evapotranspiración total anual de los cultivos (ETc), (c) el volumen total anual de agua de riego aplicada (Vi), (d) el agua en las explotaciones agrícolas disponible $(\mathrm{Vs}+\mathrm{Gw})$, y (e) el volumen total anual de agua aplicada a los cultivos (Vs+ Gw + Pef).

Figura 5.12. Necesidades brutas de agua de riego calculadas como describen en FAO24 (Nb FAO-24); evapotranspiración del cultivo calculada como se describe en FAO-56 (ETc FAO-56), y agua de riego aplicada según las encuestas de los agricultores por grupos de cultivos en 2011(Vi

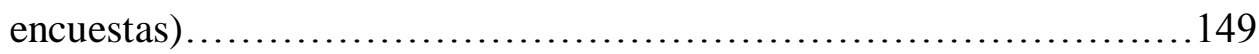

Figura 6.1. Diagrama de flujo de la distribución de agua............................161

Figura 6.2. Los tres niveles del sistema de gestión de la CRCC 163

Figura 6.3. Esquema general de comunicaciones entre el centro de control y las RTUs. Las oficinas de atención al regante en el campo están representadas como una persona y una caseta. 169

Figura 6.4. Variación de los indicadores de gestión en la CRCC antes (2002) y después (2011) de la modernización.

Figura 6.5. Ejemplo de la aplicación GIS donde se muestra la distribución del agua disponible $\left(\mathrm{m}^{3}\right)$ por parcela. El color de la parcela indica el volumen de agua disponible

Figura 6.6. Consulta de los datos registrados en un contador de una toma de riego a través del SCADA. Se representa caudal (línea verde) y volumen de agua suministrado (línea azul) 174

Figura 6.7. Evolución del uso de las aplicaciones web: a) porcentaje de agricultores que usaron el servicio web entre 2003 y 2012, y b) porcentaje que usaron el servicio web en 2012 por tamaño de explotación agrícola .177 


\section{Lista de los símbolos principales y acrónimos}

AMOPA Asociación Murciana de Organizaciones de Productores Agrarios

ANCID Australian National Committee on Irrigation and Drainage

ARIS Aporte relativo de agua de riego

ARWS Aporte relativo de agua suministrada

CARM Comunidad Autónoma de la Región de Murcia

CCRR Comunidad de regantes

CE Conductividad eléctrica $\mathrm{dS} \mathrm{m}^{-1}$

CEN Costes energéticos $€$

CENSr Coste energético por unidad de área regada $€ \mathrm{ha}^{-1}$

CENVs Coste energético por unidad de agua de riego suministrada $€ \mathrm{~m}^{-3}$

CHS Confederación Hidrográfica del Segura

CM Costes mantenimiento $€$

CMS Costes de manejo del sistema $€$

$\mathrm{CMSr} \quad$ Costes mantenimiento por unidad de área regada $\quad € \mathrm{ha}^{-1}$

CMSSr Costes de manejo del sistema por unidad de área regada $\quad € \mathrm{ha}^{-1}$

CMSVs Costes de manejo del sistema por unidad de agua de riego $€ \mathrm{~m}^{-3}$ suministrada

CMVs Costes mantenimiento por unidad de agua de riego suministrada $€ \mathrm{~m}^{-3}$

CP Costes personal $€$

CPSr Costes personal por unidad de área regada $\quad € \mathrm{ha}^{-1}$

CPVs Costes personal por unidad de agua de riego suministrada $€ \mathrm{~m}^{-3}$

CRCC Comunidad de Regantes del Campo de Cartagena

CRLO Comunidad de Regantes de Lorca

CRM Comunidad de Regantes de Miraflores

CRPC Comunidad de Regantes Pantano de la Cierva

CRTCC Comunidad de Regantes del Trasvase Tajo Segura CalasparraCieza

Eac Energía activa consumida kWh

EacSr Energía activa consumida por unidad de superficie regada $\mathrm{kWh} \mathrm{ha}^{-1}$

$\begin{array}{lll}\text { EacVs Energía específica } & \mathrm{kWh} \mathrm{m}^{-3}\end{array}$

Ear Energía reactiva consumida $\quad \mathrm{VAr}$

EarSr Energía reactiva consumida por unidad de superficie regada $\quad \mathrm{VAr} \mathrm{ha}^{-1}$ 
EarVs Energía reactiva consumida por unidad de volumen suministrado $\mathrm{VAr} \mathrm{m}^{-3}$

ED Eficiencia de distribución \%

ESAMUR Entidad de Saneamiento y Depuración de Aguas Residuales de la Región de Murcia

ETo Evapotranspiración del cultivo de referencia

$\mathrm{m}^{3}$

ETc Evapotranspiración del cultivo bajo condiciones estándar

$\mathrm{m}^{3}$

FAO Food and Agricultural Organisation

FEOGA Fondo Europeo de Orientación y Garantía Agrícola

GG Gastos generales del sistema $€$

GGSr Gastos generales del sistema por unidad de área regada $\quad € \mathrm{ha}^{-1}$

GGVs Gastos generales del sistema por unidad de agua de riego $€ \mathrm{~m}^{-3}$ suministrada

GIS Sistemas de información geográfica

Gw Volumen aguas subterráneas $\mathrm{m}^{3}$

ICID International Commission on Irrigation and Drainage

IDAE Instituto para Diversificación y Ahorro de la Energía

IGF Índice General De Fiabilidad

Ing Ingresos $€$

Inv Inversiones $€$

IPC Índice de Precios de Consumo

IPTRID International Program for Technology and Research in Irrigation and Drainage

ITRC Irrigation Training and Research Center

IWMI International Water Management Institute

Kc Coeficiente del cultivo

MB Margen bruto $€$

MBETc Margen bruto por unidad de agua demandada por los cultivos $€ \mathrm{~m}^{-3}$

MBSr Margen bruto por unidad de superficie regada $€ \mathrm{ha}^{-1}$

MBVs Margen bruto por unidad de agua de riego suministrada $€ \mathrm{~m}^{-3}$

$\mathrm{Nb} \quad$ Necesidades brutas de agua de riego $\mathrm{m}^{3}$

Nc Potencia Contratada kW

$\mathrm{NcSr} \quad$ Potencia Contratada por unidad de área regada $\quad \mathrm{kW} \mathrm{ha}^{-1}$

NP Número de trabajadores 
OCA Oficinas Comarcales Agrarias

O.M. Orden Ministerial

PA Precio del agua $€ \mathrm{~m}^{-3}$

PCH Plan de Choque de Modernización de Regadíos

Pef Precipitación efectiva $\mathrm{m}^{3}$

PHCS Plan Hidrológico de la Cuenca del Segura

PNR Plan Nacional de Regadíos

RAS Relación de adsorción del sodio mmol $\mathrm{l}^{-1}$

$\mathrm{Rb} \quad$ Retornos brutos $€$

RC Recuperación de Costes \%

RTU Unidad de terminal remoto

$\mathrm{Sa} \quad$ Superficie regable ha

SCADA Sistemas de supervisión y adquisición de datos

SCRATS Sindicato Central de Regantes del Acueducto Tajo-Segura

$\mathrm{Sg} \quad$ Garantía de suministro \%

$\mathrm{Sr} \quad$ Superficie regada ha

SrNP Superficie regada por trabajador ha empleado ${ }^{-1}$

$\mathrm{SrSa} \quad$ Intensidad de cultivo $\%$

SSD Sistemas de soporte a la decisión

TICs Tecnologías de la información y la comunicación

UDA Unidad de demanda agraria

UFN Unidad de fertilizante de nitrógeno UF

UFNSr Unidad de fertilizante de nitrógeno por unidad de superficie $\quad \mathrm{UF} \mathrm{ha}^{-1}$ regada

UFNVs Unidad de fertilizante de nitrógeno por unidad de agua $\quad \mathrm{UF} \mathrm{m}^{-3}$ suministrada

VP Valor producción agrícola $\quad €$

VPETc Valor producción agrícola por unidad de agua demandada por los $€ \mathrm{~m}^{-3}$ cultivos

VPSr Valor producción agrícola por unidad de superficie regada $€ \mathrm{ha}^{-1}$

VPVs Valor producción agrícola por unidad de agua de riego $€ \mathrm{~m}^{-3}$ suministrada

Vi Volumen total de agua de riego aplicada en parcela $\mathrm{m}^{3}$ 
$\mathrm{Vr} \quad$ Volumen total correspondiente a las concesiones

$\mathrm{m}^{3}$

Vs Volumen suministrado

$\mathrm{m}^{3}$

$\mathrm{VsSr} \quad$ Suministro de agua por unidad de área regada

$\mathrm{m}^{3} \mathrm{ha}^{-1}$

VT Volumen de agua que entra al sistema de la CCRR

$\mathrm{m}^{3}$

VTT Volumen total que entra a la zona regable

$\mathrm{m}^{3}$

WAP Wireless Application Protocol

WMS Servidor Web Map Server

$\sigma$

Desviación estándar 


\section{Agradecimientos}

A mis directores de tesis el Dr. Bernardo Martín Górriz y el Dr. Victoriano Martínez Álvarez, muchas gracias por vuestra generosidad, paciencia, dedicación, esfuerzo, apoyo, y por haberme transmitido parte de vuestro conocimiento.

A D. Pedro Antonio García, compañero en la toma y análisis de datos, espero que pronto siga mis pasos y pueda finalizar su tesis. Sin olvidar a D. Eduardo Nicolás.

A todos mis compañeros de la Escuela Técnica Superior de Ingeniería Agronómica y en especial a los del Área de Ingeniería Agroforestal.

Al proyecto Europeo de Cooperación del VII Programa Marco: SIRRIMED (Sustainable use of IRRIgation water in the MEDiterranean region).

A D. Manuel Martínez Madrid por su colaboración, y sobre todo por abrirme en 1996 las puertas de mi casa: la Comunidad de Regantes del Campo de Cartagena. Desde entonces estoy muy agradecido de poder desarrollar mi labor profesional junto a mis compañeros y amigos (Miguel Ángel, Antonio, Manolo, Silvestre, Paco, Jesús, Gustavo, Pablo, Pedro,...). También agradezco a los presidentes y junta de gobierno de la Comunidad de Regantes del Campo de Cartagena las facilidades dadas para realizar mi actividad profesional durante estos años: D. Francisco Sáez, D. Manuel León y sobre todo un recuerdo muy especial para D. Antonio Bolea y D. Manuel Martínez Roca (Manolo del Pino), que ya no se encuentran entre nosotros.

A D. Francisco Del Amor, mi gran maestro.

A D. José Manuel Claver, presidente del SCRATS, por su ayuda, asesoramiento, colaboración y la gran cantidad de información facilitada. Y a Alfonso, Blanca y María Dolores por vuestra asistencia.

A los presidentes, juntas de gobierno, personal y regantes de la Comunidad de Regantes de Lorca, Comunidad de Regantes del Trasvase Tajo Segura Calasparra-Cieza, Comunidad de Regantes Pantano de la Cierva, Comunidad de Regantes de Miraflores y la Comunidad de Regantes del Campo de Cartagena: Antonio, Pedro, Manolo, Francisco, Eladio, ... Sin vuestra colaboración no hubiera sido posible este trabajo.

A todos aquellos grandes profesionales de diferentes organismos (Consejería de Agricultura y Agua, SEIASA, IMIDA, CEBAS, CHS, IGME, ESAMUR, Universidad de Murcia, UPCT, UMH, ARADA, Intecsa-Inarsa, CEDEX...) que he tenido la suerte de conocer y que me han prestado en todo momento su ayuda y apoyo: D. Fulgencio Pérez, D. David Velarde, D. Miguel Ángel Del Amor, D. Manuel Erena, D. Manuel 
Abellán, D. Juan Maldonado, Dr. Francisco Alcón, Dr. José María Gómez, Dr. Ricardo Abadía, Dra. María Dolores De Miguel, Dr. José Luis García, Dr. Javier Calatrava, Dr. José Francisco Maestre, Dr. Francisco Pedrero, Da Beatriz Martí, D. Joaquín Rodríguez, D. Pedro Álvarez, D. José Gimeno, D. Juan Manuel Fernández,... Gracias a todos, incluidos a los que no he nombrado por no hacer interminable este documento.

A mi familia y amigos, lo mejor es tenerlos y poder compartir mi vida con ellos. En especial quiero agradecer la colaboración directa de: el Dr. Víctor León, D. Diego Sánchez, Mr. Andrew Camburn, D. Miguel Ángel Plazuelo y D. Antonio Rosique.

A mis padres, Juan y María, me lo han dado todo a cambio de nada.

Finalmente a María Jesús, mi compañera, por su infatigable ayuda y por tantas otras cosas. 


\section{Capítulo 1}

\section{INTRODUCCIÓN}

El agua es esencial para la vida, para un desarrollo socioeconómico óptimo y para el medio ambiente (Al-Ismaily y Probert, 1998; Molina et al., 2009; Rasouliazar, 2011). Sin embargo, poder satisfacer la demanda hídrica existente y garantizar su calidad se ha convertido en un problema mundial (Pedrero et al., 2010), debido a que se trata de un recurso limitado y su consumo mundial se duplica cada 20 años (Clothier, 2008).

\subsection{LA AGRICULTURA DE REGADÍO}

Históricamente el agua ha sido el catalizador más importante para el desarrollo humano, prueba de ello es que diversas civilizaciones de la antigüedad se desarrollaron en los valles de los grandes ríos, como el Tigris y Éufrates, el Nilo, el Indo y el Hwang Ho (Grindlay et al., 2011).

En la actualidad los recursos hídricos se encuentran bajo una fuerte presión debido a causas como el crecimiento demográfico mundial, el cambio climático y la competencia por estos recursos entre los diversos sectores: la agricultura, el abastecimiento de la población, la producción de energía, la industria, el turismo y el medioambiente (Romero et al., 2012). Esta competencia está provocando una mayor competitividad entre países y regiones por los recursos hídricos disponibles, afectando incluso al desarrollo de muchos de ellos (Moreno-Pérez y Roldán-Cañas, 2013).

A nivel mundial el sector agrícola es el mayor consumidor de agua dulce, ya que emplea un $70 \%$ del total. En este sentido es importante reseñar que la agricultura de regadío desempeña un papel esencial en la producción mundial de alimentos, dado que produce el $40 \%$ de los mismos con menos de un $20 \%$ de las tierras cultivadas, siendo un 
reto importante para las próximas décadas garantizar la seguridad alimentaria para una población creciente. Hay que tener en cuenta que a escala mundial los cultivos de regadío presentan un rendimiento de aproximadamente 2,7 veces superior a los de secano. Por lo tanto, en el futuro el regadío deberá seguir desempeñando un papel fundamental en la producción de alimentos (Zwart et al., 2010; WWAP, 2012).

La superficie regable en el mundo ha pasado de 170 millones de hectáreas en 1970 a 304 millones de hectáreas en 2008, y con posibilidades de seguir creciendo, sobre todo en el África Subsahariana y América del Sur (WWAP, 2012). A nivel regional, se pueden observar grandes diferencias, mientras que en el Norte de África la superficie regada representa aproximadamente el $30 \%$ del total de las tierras cultivables, en Europa esta proporción no es mayor de un 7\% (Schaldach et al., 2012). Respecto a España, en 2011 la superficie de regadío fue de 3.473 .474 ha, un $20 \%$ de la tierra cultivada (ESYRCE, 2011), con un consumo del 75\% del agua dulce (INE, 2012). En la gestión del regadío español juegan un papel muy importante las comunidades de regantes (CCRRs), dado que distribuyen el agua al 70\% de la superficie regable del país (Berbel et al., 2007).

Para mejorar la gestión y la eficiencia del uso del agua en el regadío, la administración española ha promovido la modernización de muchas zonas regables (Playán y Mateos, 2006; Plusquellec, 2009). Estos procesos se han caracterizado principalmente por el cambio de los sistemas tradicionales de riego por gravedad por sistemas presurizados, y con la incorporación de las tecnologías de la información y la comunicación (TICs) en la gestión de las CCRRs. Aunque la modernización ha reducido considerablemente la cantidad de agua consumida, ha supuesto un aumento notable del consumo energético debido a la sustitución de los sistemas tradicionales de riego por gravedad (Jackson et al., 2010; Rodríguez et al., 2011a; Abadía et al., 2012). 
Por otra parte, diversos autores (Sánchez-Moreno et al., 2011; Martínez-Fernández et al., 2013) defienden el regadío tradicional por considerar que: (a) promueve la conservación y uso sostenible del suelo, (b) mantiene una alta diversidad biológica, y (c) garantiza la agrobiodiversidad.

Además, algunos sectores de la opinión pública están cuestionando el papel actual de la agricultura de regadío por ser el mayor consumidor de agua, exigiendo que se aumente el caudal ecológico en los ríos y que se preserve para otros sectores, para reducir de esta manera la presión sobre los sistemas acuáticos (López-Gunn et al., 2012). Sin embargo, es necesario tener en cuenta que la agricultura de regadío juega un papel trascendental para la provisión de alimentos, y es también muy importante desde el punto de vista del paisaje, la biodiversidad y el desarrollo rural (Castañón, 2009; De Stefano y Llamas, 2013).

En este contexto, el regadío se enfrenta a los siguientes retos: (a) aumentar la producción de alimentos; (b) reducir el consumo de agua, gestionando de una manera conjunta y más eficiente los recursos hídricos y energéticos para asegurar la conservación del medio ambiente; y (c) garantizar la cantidad y calidad del agua para las generaciones venideras (García-Vila y Fereres, 2012; Huang et al., 2012; Jacobsen et al., 2012).

De todo lo expuesto se desprende la necesidad de mejorar el manejo del agua en el regadío con la aplicación de nuevas herramientas en su gestión. Una de estas técnicas es el benchmarking (Malano y Burton, 2001; Rodríguez et al., 2008; Córcoles et al., 2010). 


\subsection{INDICADORES DE GESTIÓN Y TÉCNICAS DE BENCHMARKING}

\subsubsection{Introducción a las técnicas de benchmarking}

El uso de la técnica de benchmarking tiene su origen en la actividad empresarial, se trata de una herramienta para mejorar los procesos y la excelencia de una organización, que emplea la experiencia adquirida en el estudio de organizaciones o procesos similares (Gurutze y Ochoa, 2005).

El Centro de Calidad y Productividad Americano (APQC, 2006) define el benchmarking como "el proceso de identificar y aprender a partir de las mejores prácticas en cualquier parte del mundo, es una herramienta poderosa en la búsqueda de una mejora continua y de avances importantes". Por todo ello se puede considerar que el objetivo principal del benchmarking es una mejora continua de la organización a lo largo del tiempo.

\subsubsection{Aplicación de las técnicas de benchmarking en el regadío}

La aplicación de las técnicas de benchmarking para mejorar el funcionamiento del regadío es un fenómeno relativamente reciente (Malano y Burton, 2001; Cakmak et al., 2004; Ghazalli, 2004; Jayatillake, 2004; Borgia et al., 2013), siendo una herramienta muy útil para optimizar el uso del agua y la energía en este sector (Malano et al., 2004; Rodríguez et al., 2008; Córcoles et al., 2010).

El objetivo principal de las técnicas de benchmarking es mejorar a la CCRR analizada mediante la comparación de su funcionamiento actual con el de otras CCRRs o con ella misma a lo largo del tiempo. De esta manera, es posible determinar qué prácticas conducen al mejor aprovechamiento y posteriormente adaptar estas prácticas a las CCRRs que sean menos eficientes. Estas técnicas se han utilizado en esta tesis para caracterizar los regadios en la Región de Murcia. 
El análisis de indicadores de gestión es la principal herramienta del benchmarking. Estos indicadores se obtienen a partir de la combinación de una o varias variables primarias, generalmente disponibles en las CCRRs, con el fin de describir las características principales de las zonas regables estudiadas. La interpretación de los valores obtenidos para cada indicador permite realizar el diagnóstico de una situación, a partir del cual se podrá realizar la toma de decisiones. Este método de comparación de indicadores de gestión ha sido empleado en numerosos trabajos y para distintas zonas regables situadas en diferentes partes del mundo (Melián-Navarro et al., 2010), pero muy pocos investigadores lo han empleado para analizar periodos prolongados.

Los indicadores de gestión empleados en esta tesis se basan en la propuesta del "International Program for Technology and Research on Irrigation and Drainage" IPTRID (Malano y Burton, 2001), considerando también indicadores adicionales propuestos por autores que han aplicado previamente técnicas de benchmarking en España (Rodríguez, 2003; Córcoles, 2009; Abadía et al., 2010). Los factores que se consideran en los indicadores son los relacionados con los flujos económicos, la producción agrícola, el medioambiente, el uso del agua y la energía. Los indicadores empleados se han agrupado en cinco grupos: de rendimiento, financieros, de eficiencia de producción, energéticos y ambientales.

\subsection{EL REGADÍO EN LA REGIÓN DE MURCIA}

La Región de Murcia sufre en las últimas décadas una escasez estructural de recursos hídricos, resultado de su régimen climático semiárido y del crecimiento de la demanda de agua para la agricultura y otros sectores de gran importancia económica como el turismo. La gran variabilidad climática produce además frecuentes y prolongados periodos de sequía. También presenta grandes riesgos de desertificación 
por sus bajas precipitaciones anuales, la torrencialidad de las mismas y el empleo de agua de riego con alta salinidad (Pérez-Sirvent et al., 2003; Acosta et al., 2011).

Esta escasez de agua en la Región de Murcia es un aspecto muy relevante a la hora de garantizar el futuro de la agricultura de regadío, dado que suele ser el primer sector al que se le aplican restricciones en el suministro de agua en los periodos de escasez (García-Vila y Fereres, 2012).

\subsubsection{Situación actual del regadío}

El sector agrícola es un pilar fundamental de la economía de la Región de Murcia. El valor de las exportaciones debidas a este sector fueron de 3.007 M€ en 2011, representando el 55\% del total, la producción vegetal contribuyó de forma exclusiva con 1.852 M€ (ECONET 2013). Respecto a la población empleada directamente en el sector agrario, ésta fue de 76.100 personas en 2011, lo que representó el 13,8\% de la población activa ocupada (CARM, 2013).

En el año 2011 la superficie total de las tierras cultivadas en la Región de Murcia fue de 550.948 ha, de esta superficie 187.064 ha fueron de regadío, lo que representó el 34\% (CARM, 2013). Por otro lado, el volumen de agua consumido por el regadío en 2010 fue de $508 \mathrm{hm}^{3}$, representado un 79\% del consumo total (INE, 2012). Los cuatro tipos de regadíos característicos que nos podemos encontrar en esta región según Alcón (2007) son: (a) los tradicionales, legalizaciones y ampliaciones de las Vegas del Segura; (b) los creados o redotados con aguas procedentes del Trasvase Tajo-Segura; (c) los que se abastecen con aguas subterráneas; y (d) los abastecidos con la reutilización o desalación. 


\subsubsection{Recursos disponibles}

Los recursos hídricos de la Región de Murcia dependen de los disponibles en la Cuenca del Segura en cada momento, dado que el $99 \%$ de su superficie se encuentra ubicada en la misma. A pesar de las limitaciones en los recursos hídricos, el regadío de esta cuenca es muy rentable, generando un margen neto de 879 M€ al año (Calatrava y Martinez-Granados, 2012).

Actualmente existe un déficit estructural de agua en la cuenca de $460 \mathrm{hm}^{3} \mathrm{año}^{-1}$, dado que sus recursos no son suficientes para satisfacer la demanda estimada: (a) urbana de $217 \mathrm{hm}^{3} \mathrm{año}^{-1}$, (b) industrial no conectada a las redes municipales de $23 \mathrm{hm}^{3} \mathrm{año}^{-1}$, y (c) agrícola de $1.571 \mathrm{hm}^{3}$ año $^{-1}$ (CHS, 2013). Los recursos hídricos de la cuenca provienen de diferentes fuentes:

- Superficiales. La estimación total de recursos superficiales de la Cuenca del Segura es de $640 \mathrm{hm}^{3}$ año $^{-1}$ (CHS, 2013), pero la disponibilidad de este tipo de recursos sufre gran variabilidad a lo largo del tiempo.

- Aguas subterráneas. Muchos de los acuíferos se encuentran sobreexplotados (Molina et al., 2011), con unos consumos de aguas subterráneas medios anuales de $570 \mathrm{hm}^{3}$ en la cuenca para el periodo 1980-2009, según estimaciones de la Fundación Instituto Euromediterráneo del Agua y del Instituto Geológico y Minero de España.

- Trasvase Tajo-Segura. La puesta en marcha de este trasvase en 1979 permitió convertir a la Región de Murcia en una de las zonas de mayor producción de hortalizas de Europa (Martínez-Carrasco y Martínez, 2011). El volumen anual asignado para riego agrícola del Trasvase Tajo-Segura es de $400 \mathrm{hm}^{3}$, pero en la práctica el valor medio anual ha sido de $196 \mathrm{hm}^{3}$ (CHS, 2013), apenas la mitad del volumen previsto. 
- Desalación. Desde la administración, la desalación se ha planteado en los últimos años como una alternativa para aumentar los recursos hídricos de la Cuenca del Segura, siendo una de las principales actuaciones el Programa AGUA (Maestre-Valero, 2011). Por otro lado, existen agricultores, que para garantizar la disponibilidad de agua, han instalado pequeñas plantas desalobradoras en sus explotaciones agrícolas (Soto-García et al., 2013a).

- Reutilización. Los volúmenes de agua depurados durante el periodo 2002-11 en la Región de Murcia han tenido un valor anual medio de $103 \mathrm{hm}^{3}$ (ESAMUR, 2013).

\subsection{OBJETIVOS Y ESTRUCTURA DE LA PRESENTE TESIS}

Este trabajo de investigación se ha desarrollado en el proyecto europeo SIRRIMED, "Sustainable use of IRRigation water in the MEDiterranean region" (SIRRIMED, 2013), en el que participan grupos de investigación de 9 países (Egipto, España, Francia, Gran Bretaña, Grecia, Holanda, Italia, El Líbano y Marruecos). En concreto se enmarca dentro del Workpackage $n^{\circ} 3$ "Caracterización de las zonas regables y evaluación comparativa". El objetivo de este Workpackage es evaluar y comparar, mediante la aplicación de técnicas de benchmarking, las zonas regables seleccionadas de los diferentes países participantes, para así proponer las mejores prácticas de gestión.

En nuestro caso se han seleccionado cinco CCRRs de la Región de Murcia, con una superficie total de 71.954 ha, lo que representó el 38,5 \% de la superficie regable regional en 2011. Por tanto, la muestra analizada se puede considerar representativa del regadío de esta región. 


\subsubsection{Objetivos}

El objetivo general de la presente tesis es "la ampliación del conocimiento científico sobre el estudio de la evolución de los regadíos mediante técnicas de benchmarking con su aplicación en zonas regables de la Región de Murcia”, incluyendo los siguientes objetivos específicos:

I. Caracterizar los regadíos de la Región de Murcia mediante el empleo de los indicadores de gestión, incluyendo el análisis de su evolución y la comparación tanto entre las CCRRs seleccionadas como con otros estudios previos. Se pretende aportar valores de referencia para los gestores de CCRRs o para futuros estudios.

II. Analizar la relación entre el consumo de agua y energía en los tres niveles de gestión del agua de riego: cuenca hidrográfica, CCRR y parcela o explotación.

III. Estudiar, a nivel CCRR, la sensibilidad de los indicadores de gestión a la escasez de agua. Analizar la relación entre la variación de los indicadores y las estrategias seguidas por los agricultores a nivel de parcela (riego deficitario, desalinización de aguas salobres, cambios en el patrón de cultivo, etc.) durante los periodos de sequía.

IV. Estudiar los efectos de la modernización sobre las CCRRs, analizando el papel de las TICs en la gestión moderna de estas organizaciones y la adaptación de los regantes a los nuevos servicios proporcionados por las mismas. 


\subsubsection{Estructura}

Para lograr estos objetivos, la presente tesis se ha estructurado en cinco partes. A continuación se realiza una breve descripción de cada una de ellas.

El Capítulo 2 es una síntesis del estado del conocimiento actual sobre: (a) los regadíos de la Región de Murcia, (b) las CCRRs, (c) las técnicas de benchmarking, (d) la relación entre el consumo de agua y energía en el regadío, y (e) la modernización de los regadíos. En este Capítulo también se describen las principales características de las cinco CCRRs seleccionadas durante el periodo de estudio 2002-11: Comunidad de Regantes del Campo de Cartagena (CRCC), Comunidad de Regantes de Lorca (CRLO), Comunidad de Regantes del Trasvase Tajo Segura Calasparra-Cieza (CRTCC), Comunidad de Regantes Pantano de la Cierva (CRPC) y Comunidad de Regantes de Miraflores (CRM).

En el Capítulo 3 se caracterizan los regadíos de la Región de Murcia mediante el análisis de la evolución de numerosos indicadores de gestión y su comparación durante un periodo de diez años. Hasta la fecha ningún trabajo ha analizado las zonas regables de la Región de Murcia con profundidad mediante las técnicas de benchmarking, aunque esta técnica ya se había empleado previamente a otras regiones españolas (Rodríguez, 2003; Córcoles, 2009). Con este análisis se complementa el estudio de las áreas más importantes del regadío español mediante la técnica de benchmarking, permitiendo la comparación con otras regiones y aportando valores de referencia a los gestores de las CCRRs o para futuros estudios.

En el Capítulo 4 se analiza la relación entre el consumo de agua y energía en la zona de estudio durante el periodo 2002-11. Se analizan tres CCRRs cuyos recursos proceden de diferentes fuentes (aguas superficiales, aguas subterráneas, trasvase, reutilización y desalación), seleccionando un conjunto de indicadores para caracterizar 
la interrelación entre el consumo de agua y energía en los tres niveles de gestión (cuenca, CCRR, y parcela); las otras dos CCRRs estudiadas en la tesis no han sido evaluadas dado que no disponían de los datos energéticos necesarios para realizar el ánalisis. La interrelación entre el consumo de agua y energía, es denominado frecuentemente como el "nexo agua-energía", siendo su estudio en el regadío interesante para los encargados de la planificación en el ámbito de las diferentes administraciones y los gestores de las CCRRs.

En el Capítulo 5 se evalúan los efectos de las restricciones en el suministro de agua sobre las CCRRs. Para ello se analiza la sensibilidad de los indicadores de gestión de las cinco CCRRs seleccionadas a la escasez de agua. Simultáneamente también se estudia las estrategias seguidas por los agricultores a nivel parcela (riego deficitario, desalinización de aguas salobres, cambios en el patrón de cultivo, etc.) para cada grupo de cultivos durante estos periodos, con el fin de disponer de la información necesaria para la correcta interpretación de las tendencias de estos indicadores de gestión (Tanaka y Sato, 2005; García-Vila et al., 2008; Salvador et al., 2011). Para los gestores de las CCRRs es muy interesante identificar cómo contribuye la escasez de agua a los cambios observados en los indicadores de gestión de su organización.

En el Capítulo 6 se estudian los efectos de la modernización en la CRCC, comparando los indicadores de gestión antes y después del proceso, considerando años con suministro hídrico similar. Esta CCRR disponía de las redes presurizadas de distribución previas a la modernización, al contrario que lo sucedido por lo general en otras CCRRs de España, caracterizada la modernización por la sustitución de los tradicionales sistema de distribución por gravedad por conducciones presurizadas mucho más eficientes (Rodríguez et al., 2011a). Además se analiza el papel de las tecnologías de la información y la comunicación (TICs) en la gestión de estas 
organizaciones y cómo se han adaptado los regantes a los nuevos servicios proporcionados por las mismas. La CRCC está aplicando las TICs en la gestión de su zona regable desde 1999, incluyendo sistemas de supervisión, control y adquisición de datos (SCADA); sistemas de soporte a la decisión (SSD); sistemas de información geográfica (GIS); y aplicaciones web y para teléfono móvil.

Por último en el Capítulo 7 se recogen las principales conclusiones de esta tesis, y se presenta la propuesta de futuras líneas de trabajo derivadas de la investigación realizada. 


\section{Capítulo 2}

\section{ANTECEDENTES Y ESTADO DEL ARTE}

En este Capítulo se realiza una síntesis del estado del conocimiento actual sobre: el regadío en la Región de Murcia, las comunidades de regantes (CCRRs), las técnicas de benchmarking, la relación entre el agua y la energía en el regadío, y la modernización de los regadíos.

\subsection{EL REGADÍO EN LA REGIÓN DE MURCIA}

\subsubsection{Antecedentes históricos}

El regadío y la cultura del agua en la Región de Murcia, tienen un arraigo inmemorial que se ha ido desarrollando y sigue tecnificándose hasta la actualidad. Comienza a tener una auténtica entidad con los árabes, no más alla del siglo $\mathrm{X}$. Anteriormente, su aprovechamiento por otras civilizaciones, como la romana, se limitó a tomas directas del río para el desvío de aguas a parcelas aisladas, o abastecimiento de poblaciones, pero carecía del complejo y laberíntico sistema que le confirieron los árabes (Vera, 2005). En el siglo XII la huerta regada por los árabes no sobrepasaría las cinco mil hectáreas de superficie, según los primeros libros de repartimientos a los colonizadores cristianos (García y Olivares, 1968).

Con la Reconquista se produjo una decadencia y abandono de la huerta en toda la Región. En el siglo XVI se produce una expansión agrícola con la introducción de los citricos y la morera, este crecimiento del regadío finalizó a finales del siglo XIX, dado que se agotaron las posibilidades de captar más recursos de las aguas superficiales a partir de azudes en el río.

A partir de la segunda mitad del siglo XX fue cuando se produjo la gran expansión del regadío, sobre todo, con el empleo de aguas subterráneas y con la llegada 
del Trasvase Tajo-Segura, lo que permitió consolidar y/o aumentar las áreas regadas (Morales et al., 2005). Los orígenes del Trasvase, aunque fue mencionado por primera vez en 1902, se remontan al año 1932, cuando el entonces Ministro de Obras Públicas D. Indalecio Prieto, encomendó al Ingeniero D. Manuel Lorenzo Pardo la realización de un plan nacional del aprovechamiento de las aguas. Un año después era presentado el "Plan Nacional de Obras Hidráulicas", que incluía el Trasvase Tajo-Segura, pero al final no se llevó a cabo por diversas causas. La realización del Trasvase se volvió a retomar en la O. M. de 30 de julio de 1966, donde se ordena la redacción del "Anteproyecto General del Aprovechamiento Conjunto de los Recursos Hidráulicos del Centro y Sureste de España, Complejo Tajo-Segura", del cual formaba parte integrante la construcción del Trasvase Tajo-Segura (San Martín, 2011; SCRATS, 2013). En 1979 llegaron las primeras aguas a la Cuenca del Segura procedentes del río Tajo.

El Trasvase Tajo-Segura siempre ha generado una gran polémica entre sus partidarios y detractores (San Martín, 2011), desde su puesta en marcha fue utilizado como una excusa para criticar al anterior régimen franquista, bajo el cual se habían iniciado las obras. Pero el Trasvase no puede ser considerado como una obra de un régimen político: se gestó durante la II República, las obras se iniciaron con la dictadura, y entró en funcionamiento durante la transición democrática española. En la actualidad sigue siendo muy criticado principalmente por motivaciones territoriales (Melgarejo et al., 2009) y medioambientales. Respecto a esta polémica Melgarejo et al. (2010) señalan: "treinta años después de iniciada la explotación del Acueducto TajoSegura, resulta díficil de entender que su funcionamiento todavía no se haya normalizado y que todavía se siga cuestionando el suministro de agua”.

La puesta en marcha definitiva, de las infraestructuras del Trasvase Tajo-Segura, posibilitó la expansión de la actual horticultura intensiva de la Región de Murcia, que la 
sitúa entre una de las mayores zonas de producción fuera de temporada de hortalizas al aire libre de Europa (Martínez-Carrasco y Martínez, 2011), convirtiendo a esta Región en la denominada "huerta de Europa" (Pérez-Sirvent et al., 2003). Todo ello ha provocado que la Región de Murcia sea un mosaico de paisajes agrarios, tradicionales y modernos, extensivos e intensivos, con un gran contraste entre el regadío y el secano (Gil, 2006).

\subsubsection{La agricultura de regadío}

La Región de Murcia se ubica en el sudeste de España con una superficie de $11.314 \mathrm{~km}^{2}$ (el 2,2\% de la superficie del país). El clima puede considerarse como Mediterráneo semiárido, las precipitaciones en general son escasas e irregulares, con una precipitación media de poco más de $320 \mathrm{~mm}$ anuales, las temperaturas son suaves, rondando los $17^{\circ} \mathrm{C}$ de media y con un alto nivel de insolación, cercano a 3.000 horas de sol de media anual (Martínez et al., 2006).

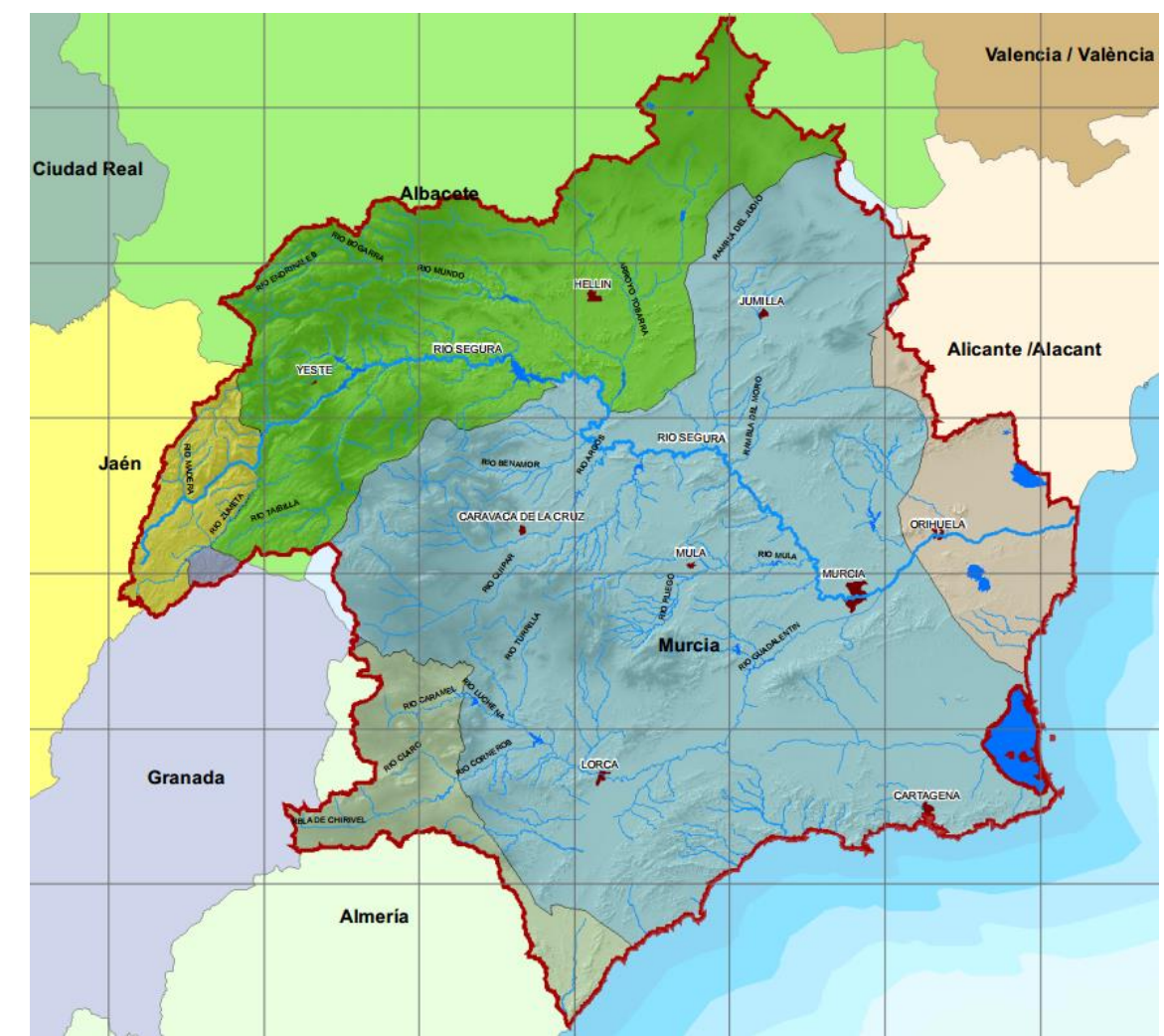

Figura 2.1. Distribución territorial de la Cuenca Hidrográfica del Segura (CHS, 2013). 
La Región de Murcia se encuentra, prácticamente en su totalidad (el 99\% de la superficie), en la Cuenca Hidrográfica del Segura (Fig. 2.1), representando un 59\% de la superficie total de la misma.

Por comarcas agrarias (Fig. 2.2) en el regadío podemos observar diferencias en los cultivos (Fig. 2.3) y en los sistemas de riego empleados (Fig. 2.4), siendo sus principales características las siguientes:

I. Altiplano. Históricamente ha tenido áreas de cultivo reducidas, muy antiguas, y siempre concentradas junto a los manantiales que las originaron. Con la construcción de pozos manuales y posteriormente, ya entrado en el siglo $\mathrm{XX}$, de sondeos de gran profundidad, estos riegos experimentaron un gran desarrollo. Los acuíferos que suministran agua a estos regadíos presentan una gran sobreexplotación (Molina et al., 2009). Los cultivos principales son la vid y los frutales no cítricos (Fig. 2.3). De esta comarca para su estudio se ha seleccionado la Comunidad de Regantes de Miraflores (CRM).

II. Noroeste. En torno a los ríos Quípar, Argos y Benamor se desarrollaron los regadíos del noroeste desde épocas remotas con las aguas que emanan de sus arroyos. A partir de los años 60 se realizaron numerosos sondeos para complementar los recursos disponibles en los meses de verano y años de sequía. Posteriormente se construyeron embalses de regulación en las tres cuencas. De esta comarca no se ha seleccionado CCRR para su estudio, debido a que esta zona no presenta una alta tecnificación en cuanto al regadío, con menos de un 50\% de riego localizado (Fig. 2.4).

III. Río Mula. Se trata de regadíos tradicionales de origen musulmán que toman sus aguas del Río Mula (Gómez et al., 2005), redotados con aguas subterráneas. Posteriormente con la llegada del Trasvase Tajo-Segura se crearon nuevos regadíos y se redotaron aquellos que sus dotaciones eran insuficientes (Del Amor et al., 1998). Más 
del $90 \%$ de la superficie de regadío se encuentra dedicada a cultivos leñosos (Fig. 2.3).

De esta comarca se ha seleccionado para su estudio la Comunidad de Regantes Pantano de la Cierva (CRPC).

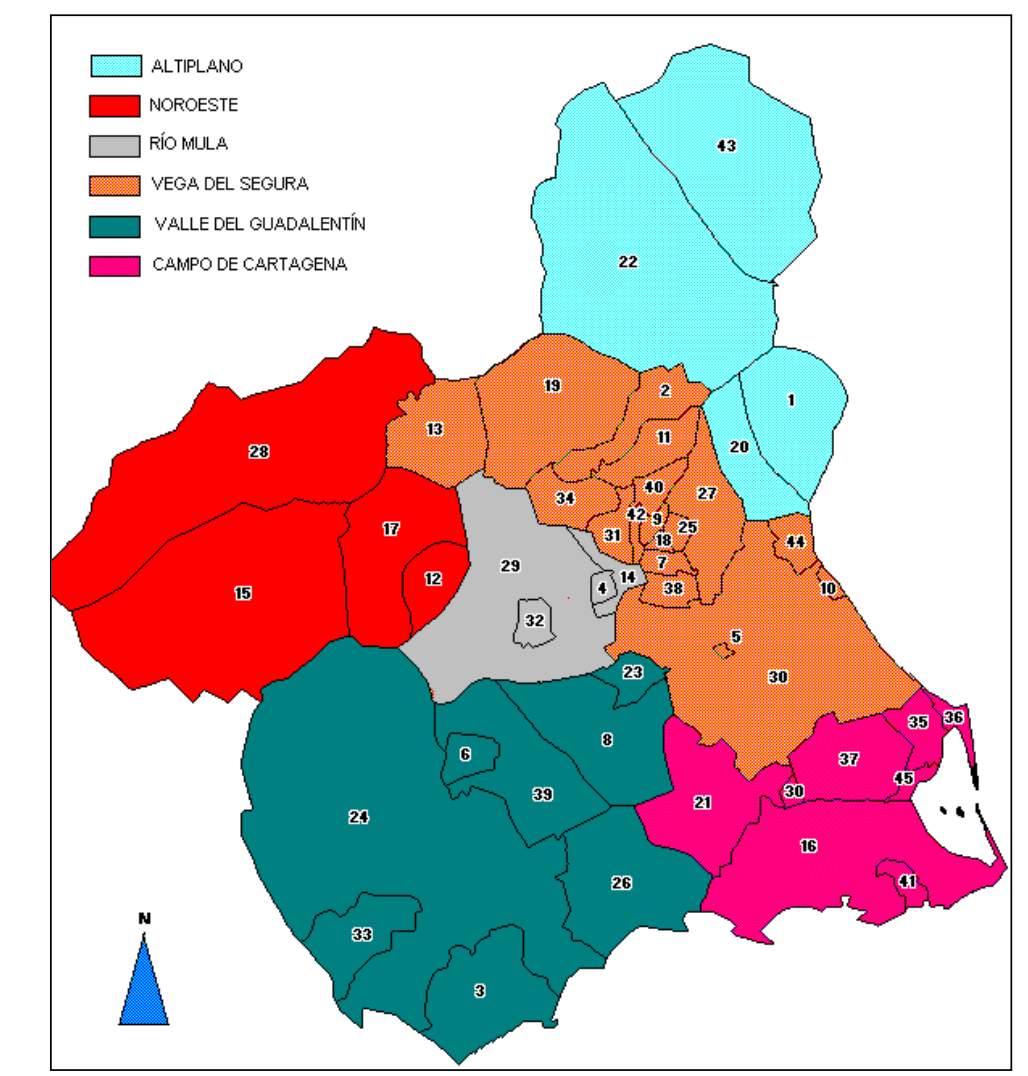

Figura 2.2. Comarcas agrarias y municipios de la Región de Murcia (CARM, 2013).

IV. Vega del Segura. Esta comarca presenta los regadíos tradicionales, con concesiones inmemoriales que se abastecen directamente del río Segura, y los nuevos regadíos creados en los años 60 y 70 por el Programa de Acción Especial de Riegos del antiguo Instituto Nacional de Colonización que impulsó la construcción de sondeos (Gómez et al., 2007). Con el Trasvase Tajo-Segura se crearon nuevos regadíos y se redotaron aquellos que eran insuficientes. Más del $80 \%$ de los cultivos de regadío son leñosos (Fig. 2.3). De esta comarca se ha seleccionado para su estudio la Comunidad de Regantes del Trasvase Tajo Segura Calasparra-Cieza (CRTCC). 
V. Valle del Guadalentín. Esta comarca tiene regadíos tradicionales que se abastecen por el pequeño aluvial del río Guadalentín y por los manantiales de las diferentes zonas. Estos exiguos caudales fueron reforzados con la construcción de la tercera presa de Puentes en 1884 y posteriormente con el embalse de Valdeinfierno. En los años 30, comenzaron los sondeos por todo el valle y en los 60 se crearon las zonas regables del Valle del Guadalentín, alimentadas por los acuíferos ubicados en este valle, y la zona regable de Fortuna y Abanilla regada con aguas procedentes del acuífero Ascoy-Sopalmo. Con la llegada del Trasvase Tajo-Segura se redotaron algunas zonas y se crearon nuevos regadíos (Martínez y Gómez, 2008). De esta comarca se ha seleccionado la Comunidad de Regantes de Lorca (CRLO) para su estudio.

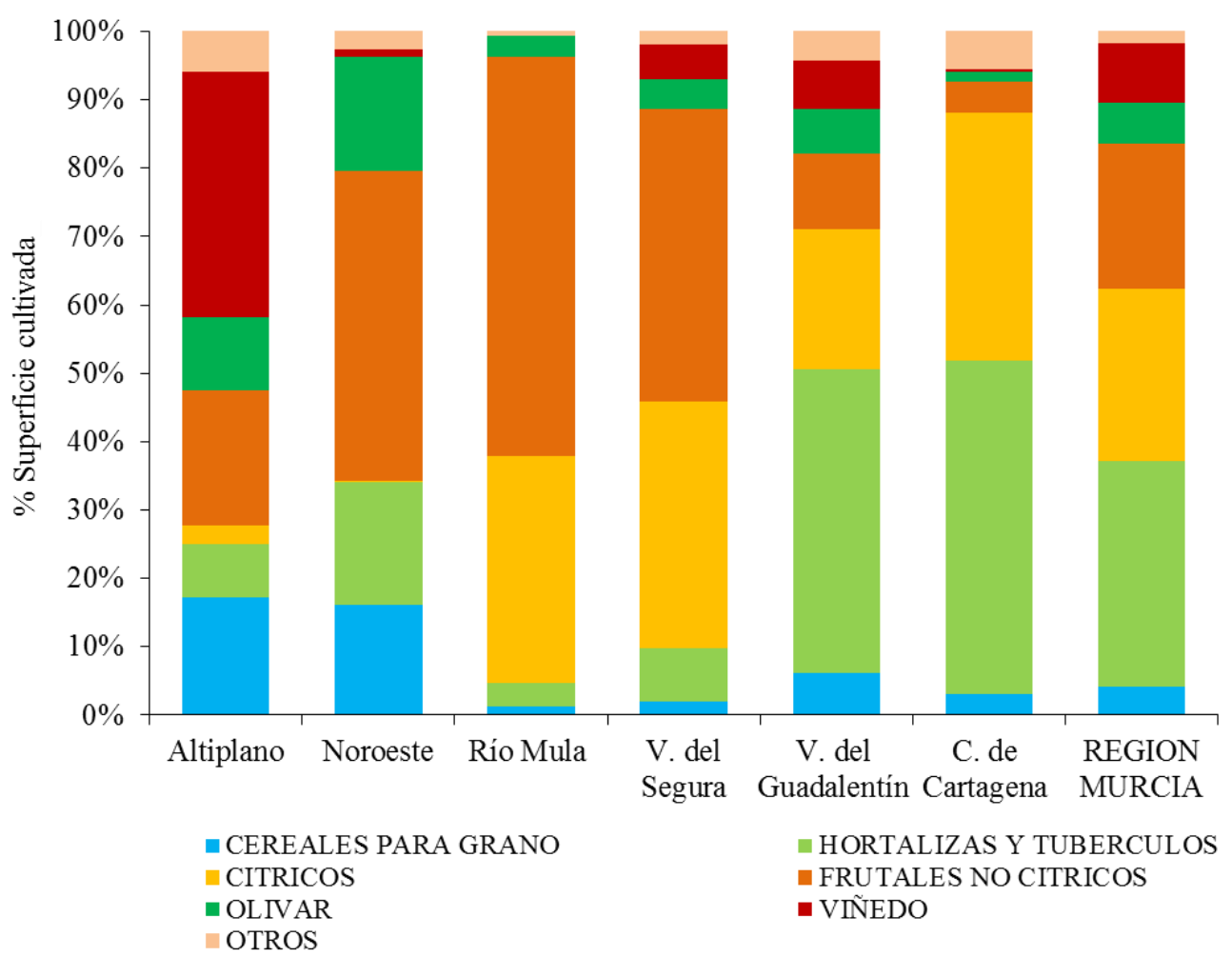

Figura 2.3. Grupos de cultivos por comarcas agrarias. Elaboración propia con datos propuesta PHCS y estadística regional (CARM, 2013; CHS, 2013). 
VI. Campo de Cartagena. Los regadíos tradicionales comenzaron con la extracción de aguas subterráneas impulsadas por molinos de viento. En los años 60 y 70 se intensificó la extracción de las aguas subterráneas con nuevos sondeos y ya en los 80 con el funcionamiento del Trasvase del Tajo-Segura, se redotaron y ampliaron los regadíos del Campo de Cartagena. De esta comarca para su estudio se ha seleccionado a la Comunidad de Regantes del Campo de Cartagena (CRCC).

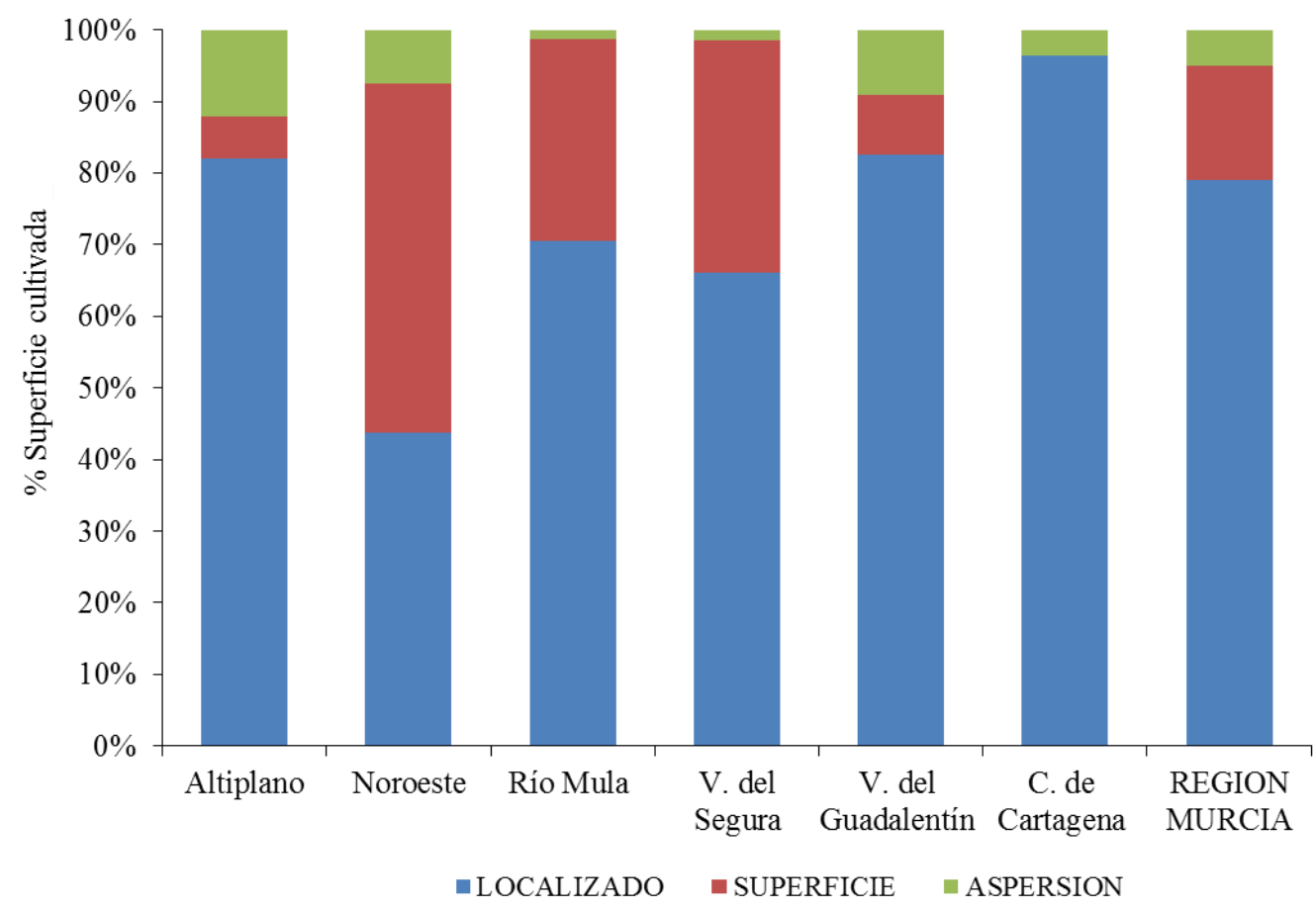

Figura 2.4. Sistemas de riego por comarcas agrarias. Elaboración propia con datos propuesta PHCS y estadística regional (CARM, 2013; CHS, 2013).

En el Epígrafe 2.4.5 del presente Capítulo se realiza una caracterización del regadío de la Región de Murcia mediante indicadores de gestión.

\subsubsection{Demanda hídrica}

Tal como se ha indicado en el Capítulo 1, el sector agrícola es el mayor demandante de agua, la gestión de su demanda se basa en la Unidad de Demanda Agrícola (UDA), que el Plan Hidrológico de la Cuenca del Segura (PHCS) identifica como "una unidad diferenciable de gestión, bien por su origen de recursos, por sus 
condiciones administrativas, por su tecnología de riego, por su similitud hidrológica, o por consideraciones estrictamente territoriales”. En la propuesta del Plan Hidrológico de Cuenca (CHS, 2013) se describen 75 UDAs, de las que 49 se encuentran ubicadas completamente o en parte en la Región de Murcia. En la Tabla 2.1 se muestran las UDAs agrupadas por las comarcas agrarias (CARM, 2013; CHS, 2013).

Tabla 2.1. Agrupación de UDAs por comarcas agrarias en la Región de Murcia. Elaboración propia (CARM, 2013; CHS, 2013).

\begin{tabular}{|c|c|c|c|c|}
\hline COMARCA & UDAs & $\begin{array}{l}\text { Superficie } \\
\text { bruta (ha) }\end{array}$ & $\begin{array}{r}\text { Superficie } \\
\text { neta (ha) } \\
\end{array}$ & Municipios \\
\hline I. Altiplano. & $1,2,5,6,7,55$ & 52.798 & 24.957 & Abanilla, Fortuna, Jumilla y Yecla. \\
\hline II. Noroeste & $\begin{array}{l}14,15,16,27 \\
28,30 \text { y } 31\end{array}$ & 22.707 & 11.941 & $\begin{array}{l}\text { Bullas, Caravaca de la Cruz, Cehegín y } \\
\text { Moratalla }\end{array}$ \\
\hline III. Río Mula & $\begin{array}{l}41,42,43,44 \\
73\end{array}$ & 10.573 & 4.649 & $\begin{array}{l}\text { Albudeite, Campos del Río, Mula y } \\
\text { Pliego. }\end{array}$ \\
\hline $\begin{array}{l}\text { IV. Vega del } \\
\text { Segura }\end{array}$ & $\begin{array}{l}3,4,17,18 \\
20,21,22,25 \\
26,29,32,34 \\
36,37,38,39 \\
40,45\end{array}$ & 87.345 & 47.804 & $\begin{array}{l}\text { Abarán, Alcantarrilla, Alguazas, } \\
\text { Archena, Blanca, Calasparra, Ceutí, } \\
\text { Cieza, Las Torres de Cotillas, Lorquí, } \\
\text { Molina de Segura, Murcia, Ojós, Ricote, } \\
\text { Santomera, Ulea y Villanueva del Río } \\
\text { Segura, }\end{array}$ \\
\hline $\begin{array}{l}\text { V. Valle del } \\
\text { Guadalentín }\end{array}$ & $\begin{array}{l}60,61,63,64, \\
65,66\end{array}$ & 108.356 & 55.945 & $\begin{array}{l}\text { Aledo, Águilas, Alhama de } \begin{array}{r}\text { Murcia, } \\
\text { Librilla, Lorca, Mazarrón, Puerto } \\
\text { Lumbreras y Totana. }\end{array} \\
\end{array}$ \\
\hline $\begin{array}{l}\text { VI. Campo de } \\
\text { Cartagena }\end{array}$ & $57,58,59,75$ & 88.990 & 34.001 & $\begin{array}{l}\text { Cartagena, Fuente Álamo, Los } \\
\text { Alcázares, Murcia, San Javier, San Pedro } \\
\text { del Pinatar, Torre-Pacheco y La Unión. }\end{array}$ \\
\hline TOTAL & & 370.769 & 179.297 & \\
\hline
\end{tabular}

El abastecimiento de las poblaciones está a cargo de la "Mancomunidad de los Canales del Taibilla". Esta organización estatal se creó en 1927 para resolver los graves problemas de abastecimiento de la población que se produjeron en la primera mitad del siglo XX, especialmente en Cartagena. La demanda urbana no se ha estabilizado, debido en gran parte al crecimiento de la actividad turística. La demanda industrial ha evolucionado de una manera similar a la demanda urbana. Una parte de las instalaciones industriales están conectadas a la red urbana, y otras son suministradas directamente por la Mancomunidad de los Canales del Taibilla (Grindlay et al., 2011).

Respecto a la demanda medioambiental, se ha fijado un caudal mínimo ecológico en base a la experiencia, estando pendiente de estudios específicos. Se han 
considerado unos caudales mínimos de $3 \mathrm{~m}^{3} \mathrm{~s}^{-1}$ desde Ojós hasta el Azud Mayor o Contraparada en Murcia, y de $4 \mathrm{~m}^{3} \mathrm{~s}^{-1}$ desde la Contraparada hasta la Presa de San Antonio en Guardamar (CHS, 2013). En general, el río Segura presenta unas buenas condiciones en sus tramos de cabecera, e incluso en el curso medio. La situación se agrava a partir de la localidad de Ojós, y, sobre todo, a partir de la Contraparada. En este punto se produce una importante reducción de los caudales circulantes como consecuencia de las captaciones de agua para el regadío, y se producen unos mayores vertidos al río, procedentes de las zonas industriales y urbanas de las poblaciones ribereñas de las vegas media y baja (Gallego-Elvira, 2011).

\subsubsection{Recursos hídricos}

Los recursos hídricos de la Región de Murcia están directamente relacionados con los disponibles en la Cuenca del Segura. Estos provienen, tal como se ha indicado en el Capítulo 1, de diferentes fuentes: superficiales, Trasvase Tajo-Segura, subterráneos, desalación y reutilización.

El organismo encargado de la gestión de los recursos de la Cuenca del río Segura es la Confederación Hidrográfica del Segura (CHS). La naturaleza de este organismo es pública, dependiente del Ministerio de Agricultura, Alimentación y Medio Ambiente (CHS, 2013). El PHCS fija un déficit estructural de agua sobre los $460 \mathrm{hm}^{3}$ año $^{-1}$, dado que los recursos de la misma no son suficientes para satisfacer la demanda estimada. En la Fig. 2.5 se presenta el balance general del PHCS.

El origen del agua utilizada para riego (ETI, 2008) es muy variable, en su mayoría procede de los recursos superficiales $(36,7 \%)$, subterráneos $(30,5 \%)$ y el agua procedente del Trasvase Tajo-Segura $(24,8 \%)$. En menor medida $(8,0 \%)$, se abastecen por agua procedente de las estaciones depuradoras de aguas residuales y desalación. 


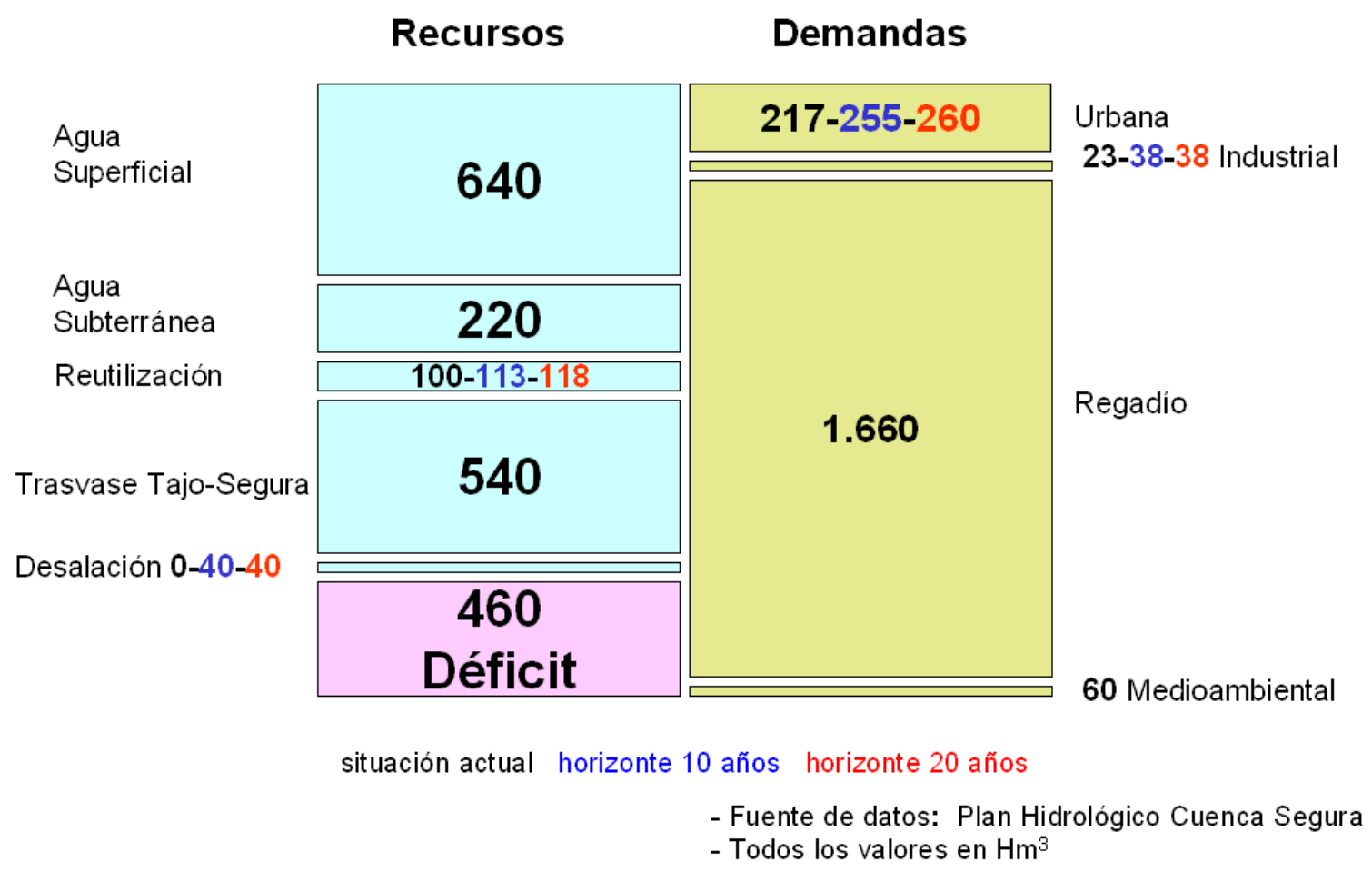

Figura 2.5. Balance de la Cuenca del Segura del PHCS (CHS, 2013).

\subsubsection{Agua superficial de la Cuenca}

La recursos superficiales estimados por el PHCS son $640 \mathrm{hm}^{3}$ año ${ }^{-1}$. Las fuentes principales de los recursos superficiales de la Cuenca por orden de importancia son (CHS, 2013): (i) la cabecera (ríos Segura y Mundo hasta su confluencia); (ii) los afluentes de la margen derecha (Moratalla, Argos, Quípar y Mula), sus cauces transportan caudales de forma permanente, que son consumidos localmente; (iii) los afluentes de la margen izquierda carecen de importancia, se trata principalmente de las ramblas del Judío, Moro, Tinajón, Salada y Abanilla; (iv) el río Guadalentín es un importante afluente de la margen derecha; y (v) las ramblas litorales no suponen aportes significativos a los recursos superficiales de la Cuenca.

La disponibilidad de estos recursos superficiales sufre gran variabilidad a lo largo del tiempo, tal como se ve en la Fig. 2.6, donde se muestran las aportaciones realizadas a la Cuenca desde el año hidrológico 1959-60 en color azul. 


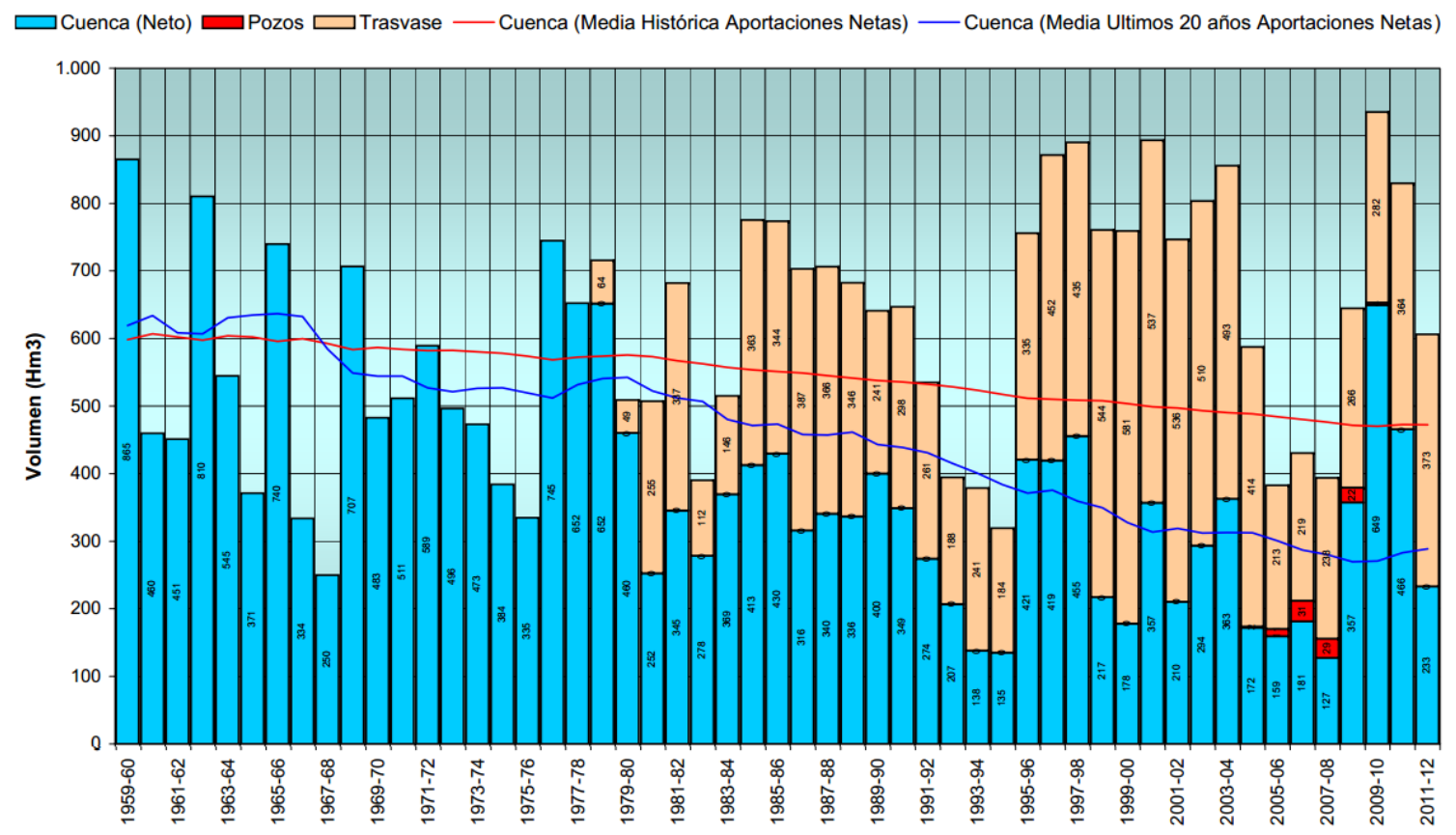

Figura 2.6. Aportación anual de la Cuenca y el Trasvase Tajo-Segura (CHS, 2013).

Las aguas superficiales de la Cuenca presentan una conductividad eléctrica (CE) media superior a $3 \mathrm{dS} \mathrm{m} \mathrm{m}^{-1}$, por tanto existe un riesgo grave de salinización al emplear estas aguas para el riego. La mejor calidad la presenta el agua de la zona de la Vega Alta con una CE de 1,51 dS m $\mathrm{m}^{-1}$ y la del Noroeste con una CE de 1,58 dS m $\mathrm{m}^{-1}$ (Alcón et al., 2012).

\subsubsection{Aguas subterráneas}

Actualmente las aguas subterráneas son muy importantes para el regadío en la Cuenca, según la información facilitada por la Fundación Instituto Euromediterráneo del Agua y el Instituto Geológico y Minero de España se estiman unas extracciones medias anuales para el periodo 1980-2009 de $570 \mathrm{hm}^{3}$, con un mínimo $424 \mathrm{hm}^{3}$ y un máximo de $753 \mathrm{hm}^{3}$. Estos valores son superiores a los $220 \mathrm{hm}^{3}$ indicados por el PHCS. Esto ha provocado una sobreexplotación de los acuíferos en la Cuenca (Grindlay et al. 2011; Molina et al., 2011), conocida desde finales de la década de los 80, que se agudiza en períodos de sequía, donde la disponibilidad de otros recursos (superficiales 
de la Cuenca y recursos del Trasvase Tajo-Segura) disminuyen notablemente, por lo que se ven aumentadas las extracciones de aguas subterráneas para satisfacer las demandas hídricas de los cultivos agrícolas.

Por todo ello la escasez de agua es la principal causa de la sobreexplotación de los acuíferos de la Cuenca, dado que los agricultores emplean las aguas subterráneas para compensar la carencia de otras fuentes de agua.

El valor medio de la CE de las aguas subterráneas es de 2,64 dS m ${ }^{-1}$. La mejor CE se da en la zona del Noroeste y en la Vega Alta con valores de 0,60 y 0,73 dS m ${ }^{-1}$ respectivamente, mientras la zona del litoral presenta unos valores medios muy altos, de 3,97 dS m (Alcón et al., 2012).

\subsubsection{Trasvase Tajo-Segura}

El Acueducto Tajo-Segura es la infraestructura que conecta el embalse de Bolarque (Tajo) con el embalse del Talave, que se encuentra en la Cuenca del Segura. Esta conducción tiene una longitud de $286 \mathrm{~km}$ y fue proyectada y ejecutada para transportar un caudal máximo de $33 \mathrm{~m}^{3} \mathrm{~s}^{-1}$ (Melgarejo, 2009). A partir del embalse del Talave se inician las infraestructuras del Postravase que distribuyen el agua a todas las zonas regables (Fig. 2.7).

El volumen asignado para riego agrícola del Trasvase Tajo-Segura es de 400 $\mathrm{hm}^{3}$, aproximadamente el $53 \%$ corresponden para nuevos regadíos y el resto para la redotación del regadío tradicional. En la Tabla 2.2 se indican las dotaciones para riego de la $1^{\text {a }}$ fase para el Postrasvase. Según la tramitación de concesiones de mediados del año 2009, las áreas regables del Postrasvase comprenden una superficie nominal de 132.724 ha; de las que 82.257 ha (62\%) se ubican en la Región de Murcia. (Gómez et al., 2011). 


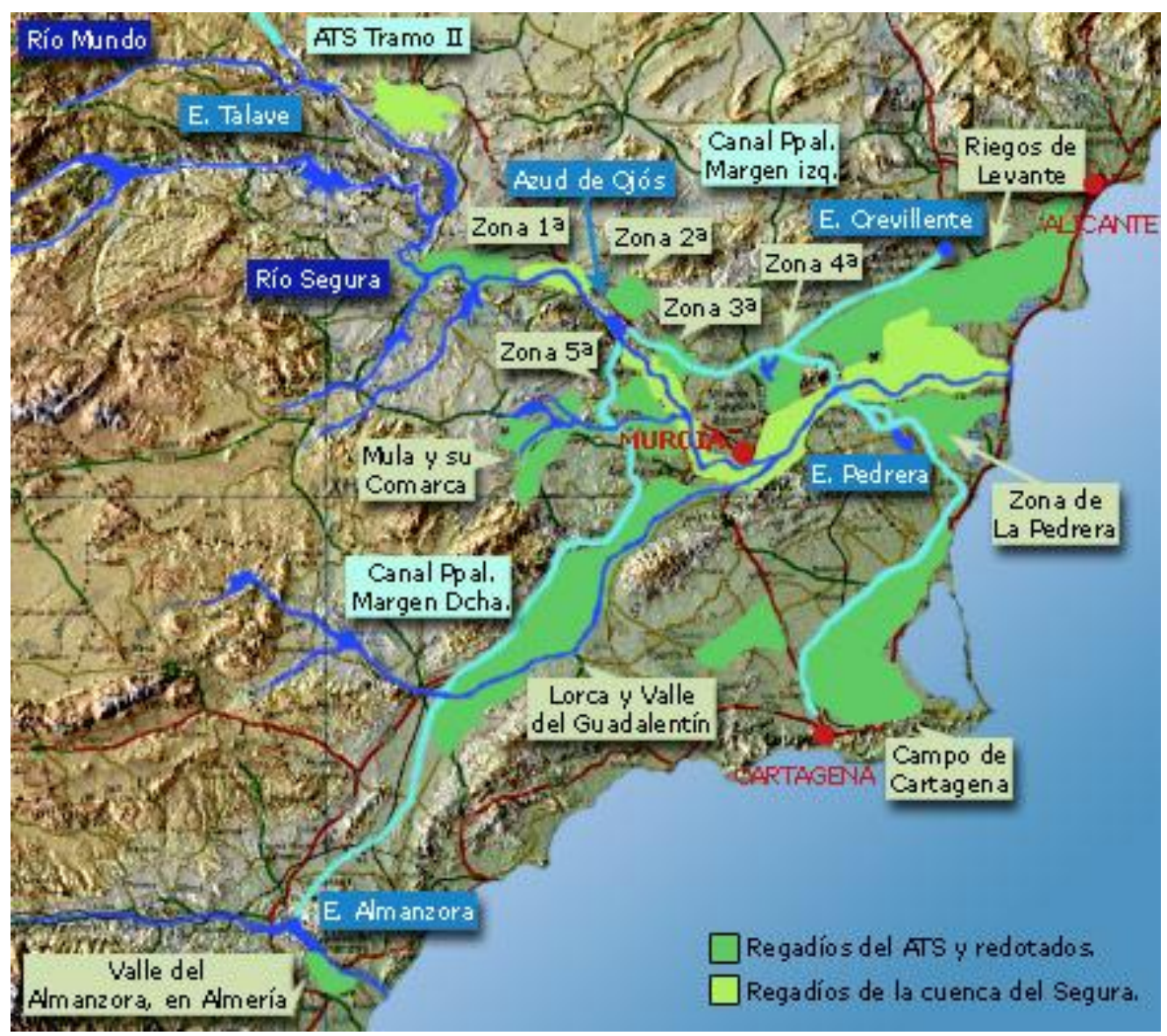

Figura 2.7. Zonas Regables de Postrasvase (SCRATS, 2013).

En la Fig. 2.8 se muestran los volúmenes trasvasados en origen a la Cuenca del Segura. Para riego el valor medio anual ha sido de $196 \mathrm{hm}^{3}$, casi la mitad del volumen asignado. Como se puede observar en la Fig. 2.8 los volúmenes trasvasados para abastecimiento no han sufrido grandes variaciones a lo largo del tiempo, al contrario de lo sucedido para el riego.

Tabla 2.2. Dotaciones para riego en la $1^{\mathrm{a}}$ fase del Postravase (Gómez et al., 2011).

\begin{tabular}{|c|c|c|c|c|}
\hline \multirow[b]{2}{*}{ ÁREA DE RIEGO } & \multicolumn{2}{|c|}{ Volumen $\left(\mathrm{hm}^{3}\right.$ año $\left.^{-1}\right)$} & \multicolumn{2}{|c|}{ Superficie de riego (ha) } \\
\hline & Trasvasados & Propios & Nueva & Redotada \\
\hline Vegas Alta y Media del Segura & 65 & 50 & 9.451 & 8.927 \\
\hline Regadíos de Mula y su Comarca & 8 & 9 & 1.500 & 1.050 \\
\hline Lorca y Valle del Guadalentín & 65 & 80 & 6.731 & 19.214 \\
\hline Campo de Cartagena & 122 & 31 & 23.000 & 9.800 \\
\hline Valle del Almanzora (Almería) & 15 & - & 3.000 & - \\
\hline $\begin{array}{l}\text { Riegos de Levante, Vega Baja del Segura } \\
\text { y Saladares de Alicante }\end{array}$ & 125 & 80 & 27.390 & 23.293 \\
\hline TOTAL & 400 & 250 & 71.072 & 62.284 \\
\hline
\end{tabular}




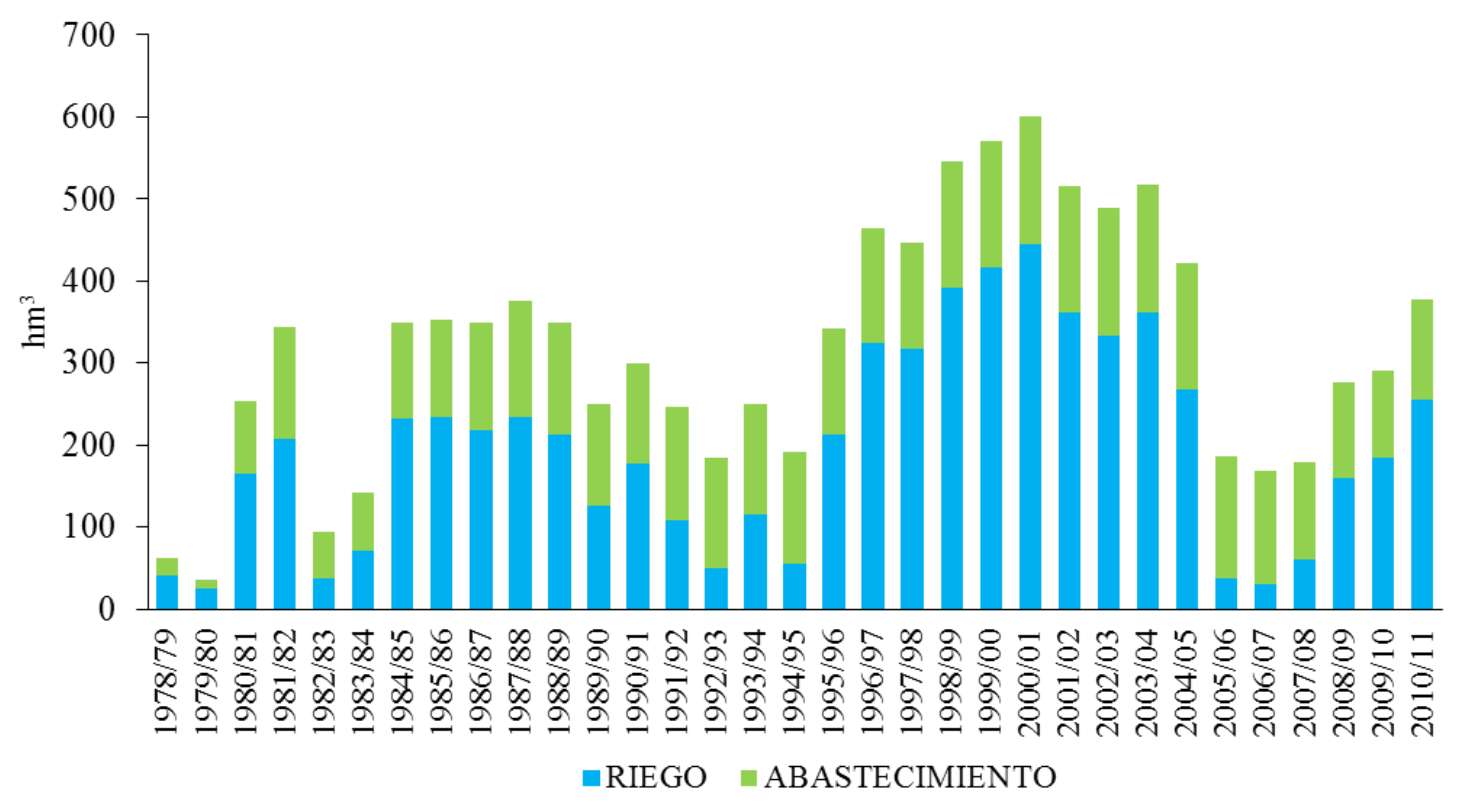

Figura 2.8. Trasvase Tajo-Segura. Volúmenes trasvasados. Elaboración propia (CHS, 2013).

\subsubsection{Desalinización}

En la última década han aumentado las plantas desalinizadoras como consecuencia de los períodos de sequía y por la necesidad de incrementar los recursos hídricos en la Cuenca. Estas infraestructuras han sido realizadas en su mayor parte por la Administración dentro del Programa AGUA, CCRRs y particulares. Entre las plantas de desalinización actualmente en funcionamiento para uso agrícola en la Región de Murcia destacan: Valdelentisco $\left(37 \mathrm{hm}^{3}\right)$, Águilas $\left(30 \mathrm{hm}^{3}\right)$, Virgen del Milagro (16

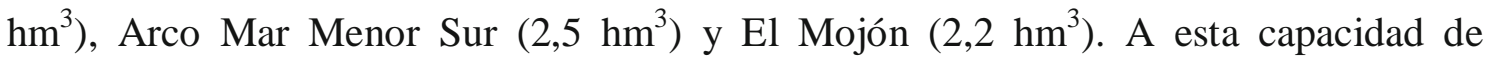
producción hay que añadir la proveniente de desalobradoras particulares existentes en explotaciones agrarias.

La Fundación Instituto Euromediterráneo del Agua y el Instituto Geológico y Minero de España estiman la producción total de agua desalada en la Cuenca para riego, en función del año, durante la última década entre 50 y $101 \mathrm{hm}^{3}$ año $^{-1}$. Actualmente muchas de estas desaladoras solo se ponen en marcha en el caso de no disponer agua de 
otros recursos, debido a su alto coste de producción motivado principalmente por su alto consumo energético.

\subsubsection{Reutilización}

La reutilización de las aguas residuales es un elemento esencial del ciclo natural del agua (Iglesias y Ortega, 2008), y de hecho, la Directiva Marco del Agua (2000/60/CEE) la contempla como medida para solucionar los problemas de la escasez de agua. La reutilización es muy valiosa para la agricultura, dado que garantiza el recurso de forma continua.

En diciembre de 2007 se promulgó el Real Decreto 1620/2007 (BOE, 2007), que ha sido un importante paso en la regulación de la reutilización del agua, ya que aclara tanto las responsabilidades de las Administraciones Públicas como las de los concesionarios y los usuarios finales, estableciendo los usos permitidos y criterios de calidad, la frecuencia mínima de muestreo, el punto de referencia para los métodos analíticos y los criterios de conformidad. También especifica los procedimientos relativos a la concesión, incluyendo una solicitud para obtener la concesión o autorización de reutilización de aguas (Iglesias et al., 2010).

El organismo encargado de la depuración de las aguas urbanas en la Región de Murcia es la Entidad Regional de Saneamiento y Depuración de Aguas Residuales (ESAMUR), se trata de una Empresa Pública Regional adscrita a la Consejería de Agricultura y Agua de la Comunidad Autónoma de la Región de Murcia. En la Fig. 2.9 se muestra la evolución de los volúmenes de agua depurados durante el periodo 2002 11, que han tenido un valor medio de $103 \mathrm{hm}^{3}$. 


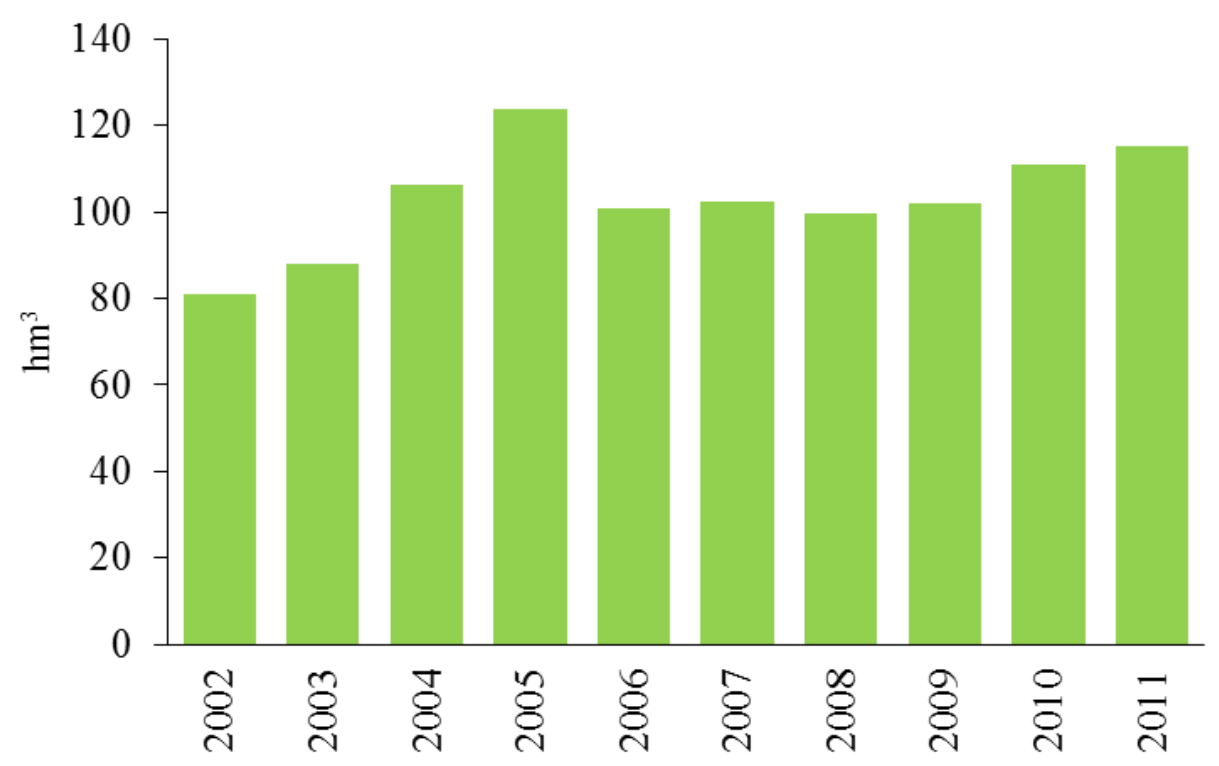

Figura 2.9. Volúmenes de agua depurados durante el periodo 2002-11 en la Región de Murcia. Elaboración propia (INE 2012; ESAMUR 2013).

\subsubsection{La escasez de agua}

La escasez de agua representa el grado en que la demanda supera los recursos hídricos disponibles. Concierne tanto a la cantidad y a la calidad, porque recursos hídricos degradados dejan de estar disponibles para usos más restrictivos. La escasez de agua puede ser debida a diferentes causas (Pereira et al., 2002): (a) la aridez, que es un proceso natural que se caracteriza por una baja precipitación, con alta variabilidad espacial y temporal; (b) la sequía, que también es un proceso natural, consecuencia de un desequilibrio temporal en la disponibilidad de agua; (c) la desertificación, inducida por el hombre, que es un desequilibrio permanente en la disponibilidad de agua, que se combina con la degradación del suelo, un uso del suelo inapropiado, extracción de aguas subterráneas, salinización, aumento de las inundaciones, pérdida de humedales y una reducción de la capacidad de carga de los ecosistemas; (d) el estrés hídrico, también inducido por el hombre, que es un desequilibrio temporal que incluye sobreexplotación de acuíferos, disminución de las reservas en los embalses, reducción y alteración del 
suelo, reducción de la capacidad de carga de los ecosistemas, y empeoramiento de la calidad del agua.

Si hubiese que buscar un rasgo geográfico característico para la Región de Murcia, éste podría ser el de la aridez, dado que es la región europea donde la escasez de lluvias se presenta con mayor severidad (Vera, 2005). Una de las mayores limitaciones de su agricultura es el agua, tanto en términos de cantidad y calidad, como de disponibilidad de la misma (Montaner, 1992; García, 2007). Existiendo un desequilibrio en relación entre la oferta de recursos y la demanda hídrica, y por ello, el déficit hídrico estructural pone de manifiesto la importancia que tiene una gestión eficiente del agua para la agricultura (Arcas y Alcón, 2007).

Aunque la agricultura en esta zona es de las más rentables y competitivas del país, generando una importante entrada de divisas vía exportaciones, el funcionamiento de estos regadíos queda comprometido, cuando disminuyen de forma acusada los recursos hídricos: (a) por fenómenos de índole natural, como las sequías con varios años de precipitaciones escasas; o (b) por decisiones de tipo político, como la disminución drástica de la transferencia de recursos hídricos externos, i.e. el Trasvase Tajo-Segura (Gómez et al., 2005). Por tanto, el agua es un factor limitante para el agricultor, al no disponer del agua necesaria para satisfacer las necesidades de sus cultivos. Otro factor relevante es la incertidumbre acerca de la cantidad de agua que finalmente va a disponer el agricultor en una campaña de riego (Tobarra y Castro, 2011). Esto ha provocado que los agricultores coincidan en manifestar que la escasez de agua es uno de los principales problemas a la hora del manejo del riego, ya que en muchas ocasiones el debate no está en cuánto y cómo regar sino cuándo dispondré de agua para regar (Erena et al., 2008). 
Alcalá y Sancho (2002) diferencian los efectos de la escasez de agua a corto plazo con respecto al largo plazo. Estos autores indican que un descenso de la disponibilidad del agua tiene inicialmente un efecto relativamente reducido sobre la producción, pero en la medida en que la escasez se mantenga más de un período, se inicia un proceso de reducción de la superficie regada que llega a extenderse hasta cuatro períodos después de que se detectase por primera vez la escasez de agua.

Como se muestra en la Fig. 2.10 existe poca correlación entre la precipitación y la superficie regada (Sr). Sin embargo, esta correlación sí se da con los volúmenes de agua trasvasados (Fig. 2.11) para riego a la Cuenca del Segura. Por lo tanto la evolución de la superficie regada va a depender más de los volúmenes trasvasados que de las precipitaciones.

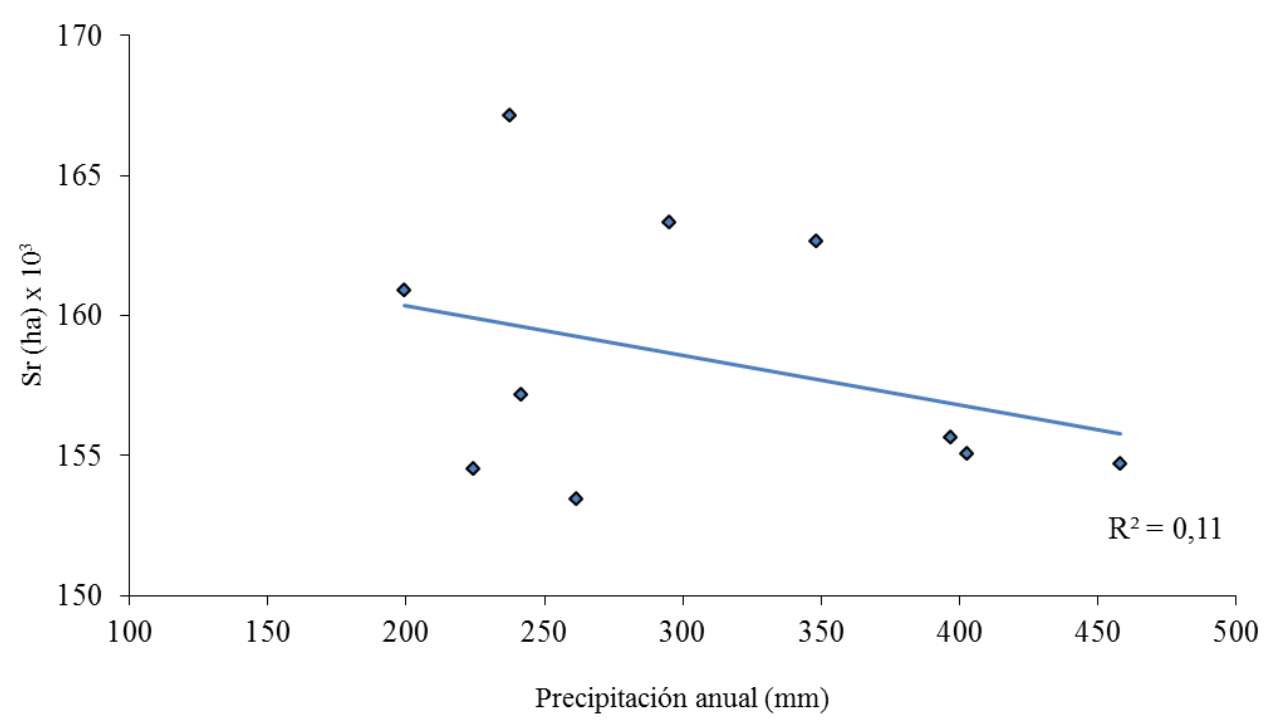

Figura 2.10. Relación entre la precipitación anual respecto a la superficie regada ( $\mathrm{Sr}$ ) en la Región de Murcia durante el periodo 2002-11. Elaboración propia (CARM, 2013; ECONET, 2013). 


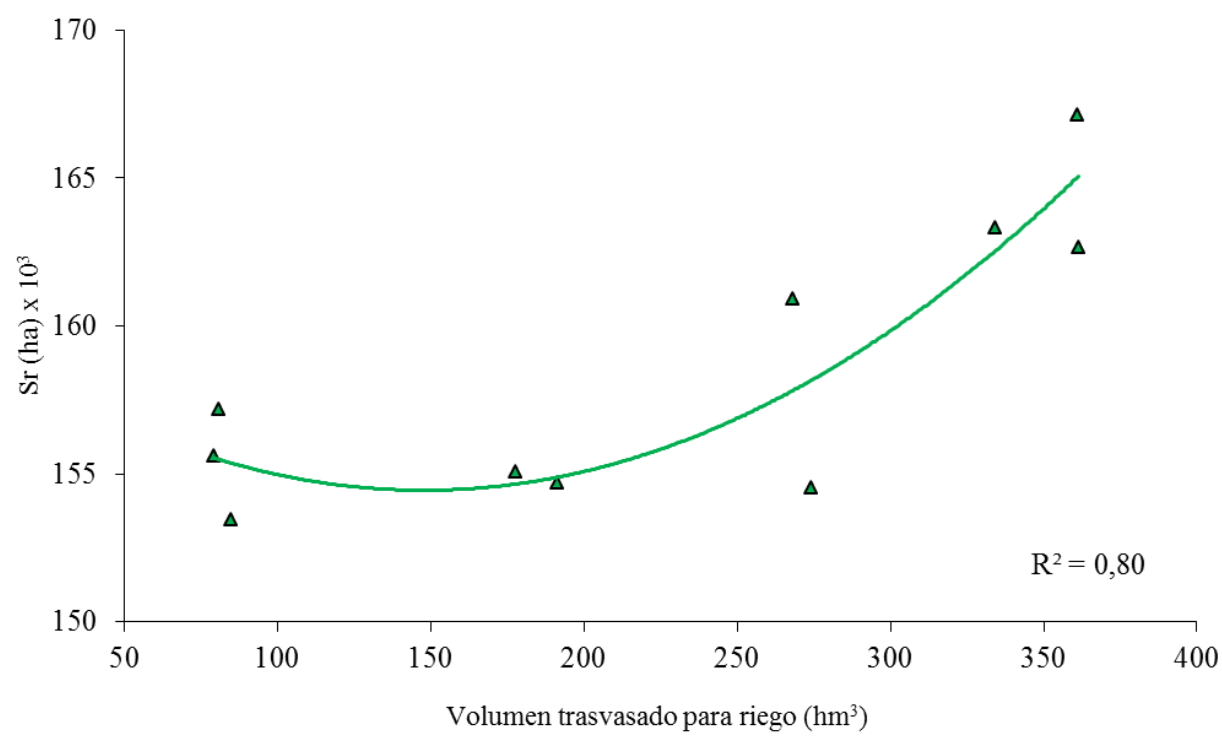

Figura 2.11. Relación entre el volumen anual trasvasado para riego respecto a la superficie regada ( $\mathrm{Sr}$ ) en la Región de Murcia durante el periodo 2002-11. Elaboración propia (CARM, 2013; CHS, 2013).

En las épocas de reducción de los recursos procedentes del Trasvase TajoSegura, éstos son sustituidos en parte por aguas subterráneas y procedentes de la desalación. Este desequilibrio entre los recursos disponibles y la demanda ha provocado grandes problemas de sobreexplotación de los acuíferos, agudizados en estos periodos donde los trasvases de agua para riego disminuyen (Fig. 2.12).

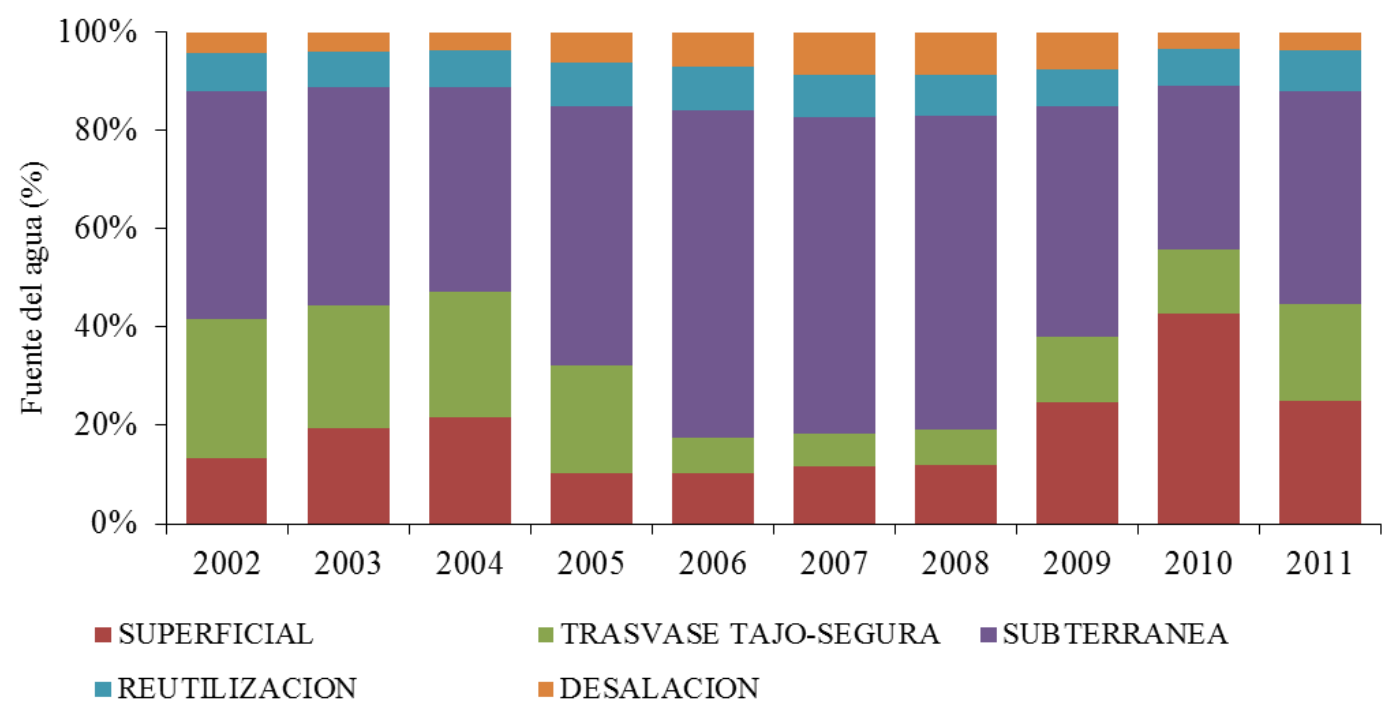

Figura 2.12. Evolución de las fuentes de agua para riego en la Cuenca del Segura. Elaboración propia (INE, 2012; CHS, 2013; ESAMUR, 2013; SCRATS, 2013). 
Una de las mejores estrategias para hacer frente a la escasez de agua es la implantación de sistemas de gestión, que utilicen modelos y herramientas para estimar la disponibilidad de los recursos hídricos en cada región y su variación con el tiempo. De esta forma se puede buscar un equilibrio entre la oferta y la demanda, favoreciendo la asignación los recursos de agua con criterios sociales, económicos y ambientales (Tarjuelo et al., 2010).

En el Capítulo 5 se analizan los efectos de la escasez de agua en la zona de estudio.

\subsubsection{Impacto medioambiental del regadío}

El regadío proporciona importantes beneficios a la sociedad: (a) asegura la producción alimentaria; y (b) juega un papel muy importante desde el punto de vista del paisaje, la biodiversidad y la vida rural (Castañón, 2009; De Stefano y Llamas, 2013).

Como contrapartida genera un impacto medioambiental, debido a que es una importante fuente de contaminación difusa de las aguas superficiales y subterráneas (Dechmi et al., 2012; Skhiri y Dechmi, 2012) como consecuencia del empleo de fertilizantes (nitrogenados, fosfatos, potásicos, etc.) y fitosanitarios (insecticidas, herbicidas, fungicidas). Otro de los principales contaminantes inducidos por el riego en zonas áridas y semiáridas es la alta concentración de sales disueltas en el agua aplicada. Las concentraciones excesivas de sales también se han demostrado ser perjudiciales para los cultivos, los suelos y la salud humana (Barros et al., 2012). La salinización de los suelos es uno de los mayores problemas que presentan las áreas bajo prácticas de agricultura intensiva en las zonas áridas y semiáridas.

Por otro lado para poder satisfacer las demandas agrícolas, muchos de los acuíferos han sido sobreexplotados, causando graves problemas como una reducción del nivel piezométrico, intrusión marina, salinización creciente y la degradación de la 
calidad del agua (Grindlay et al., 2011). Los principales problemas de sobreexplotación se encuentran en los acuíferos del Altiplano, Ascoy-Sopalmo y Valle del Guadalentín. Los acuíferos relacionados con los afluentes de la margen derecha (Argos, Quípar, Moratalla y Mula) también presentan problemas, donde se han secado manantiales y otros están viendo reducidas sus descargas notablemente. En total, de las 63 masas de aguas subterráneas actualmente definidas en la Cuenca del Segura, 40 de ellas han sido declaradas con riesgo. El problema de sobreexplotación es tan grave que los acuíferos del Altiplano son considerandos los segundos más sobreexplotados del mundo, después de los acuíferos de la Cuenca del río Hai en China (Werner et al., 2013).

Otros de los graves problemas es la acumulación excesiva de nitratos, por encima del límite máximo admisible establecido por la Unión Europea de $50 \mathrm{mg} \mathrm{l}^{-1}$. Los acuíferos de tres zonas han sido declarados como vulnerables (Fernández y Soria, 2011): Zona 1, acuíferos Cuaternario y Plioceno en el Campo de Cartagena; Zona 2, acuíferos de las Vegas Alta y Media de la Cuenca del Segura; y Zona 3, Valle del Guadalentín, correspondiente a los acuíferos del Alto Guadalentín, bajo Guadalentín y Puentes, en el término municipal de Lorca.

Por otro lado, la gran diferencia entre la productividad entre la agricultura de secano y de regadío provoca una gran tensión hacia la transformación del secano al regadío, con lo que se agravan los problemas medioambientales por la escasez de los recursos hídricos.

Por todo lo expuesto, es necesario seguir fomentando el cumplimiento de las buenas prácticas en la agricultura de regadío para garantizar su sostenibilidad. 


\subsection{COMUNIDADES DE REGANTES}

En muchos países del mundo se ha transferido la distribución del agua en las zonas regables a organizaciones no gubernamentales, Vermillion y Sagardoy (2001) las clasifican en seis tipos básicos: (i) asociaciones multipropósito de usuarios del agua, que son los grupos de usuarios del agua que combinan las funciones de gobierno y de gestión, tratándose generalmente de cooperativas de usuarios del agua; (ii) empresas públicas, que son normalmente autónomas desde el punto de vista financiero, y tienen objetivos fijados desde el gobierno para suministrar el agua a una zona asignada; (iii) gobiernos locales como las poblaciones o las municipalidades, que gestionan en ocasiones las redes de riego; (iv) distrito de riego, que es normalmente un tipo de organización local pública o semipública, y suele gozar de ciertos privilegios e inmunidades, que no están al alcance de otras organizaciones del sector privado; (v) compañías mutuas, que son generalmente sociedades de responsabilidad limitada, formadas a partir de acciones de la red de riego que pertenecen a los propietarios y regantes; y (vi) compañías privadas, que se dan en grandes plantaciones, en las que la red de riego suele estar operada por la compañía privada que gestiona la producción agrícola en la superficie regada.

En España el tipo de organización mayoritaria son las CCRRs, que siguiendo la clasificación anterior correspondería a los distritos de riego. Giménez et al. (2010) las definen "como una agrupación de todos los propietarios de una zona regable, que se unen obligatoriamente por Ley, para la administración autónoma y común de las aguas públicas, sin ánimo de lucro. A esa zona concreta de tierra regable se le otorga una concesión de agua para regar, es la superficie de tierra la beneficiaria de la concesión y no el comunero propietario de la misma”. Se encuentran reguladas por el Real Decreto Legislativo 1/2001 (BOE, 2001). 


\subsubsection{Antecedentes históricos y base legal}

Las CCRRs, no aparecen en nuestro derecho histórico claramente definidas, ya que se trataba de asociaciones regidas por sistemas y reglas propias de los romanos y árabes (como las hermandades, sindicatos, juntas, gremios, etc.) dotadas de una organización que permitía la administración y distribución del agua para el regadío de los cultivos. En los textos de derecho histórico de la Región de Murcia, incluso antes de la conquista árabe del siglo VIII, ya aparecían este tipo de organizaciones como asociaciones que, con diferentes denominaciones, poseían un sistema de organización mediante el cual administraban y distribuían el agua destinada al regadío de los cultivos (Alcón, 2007).

Por todo ello hay antecedentes históricos como para afirmar que la distribución del agua en común, y mediante acequias de riego, data de épocas muy anteriores a los musulmanes, pudiéndose originarse en época romana. Así pues, las CCRRs son instituciones de larga tradición histórica en la distribución de las aguas y en la organización propia del regadío, y se encuentran profundamente enraizadas en la conciencia popular.

Las normas de distribución del agua estaban basadas en la costumbre, que se transmitía por generaciones verbalmente y que contenían experiencias muy contrastadas por sus aplicaciones prácticas. Con el tiempo estas prácticas habituales se plasmaron en Ordenanzas escritas (Del Campo, 2008).

La primera Ley de Aguas fue la de 3 de agosto de 1866. La siguiente Ley de Aguas, del 13 de Junio de 1879, incorporó la figura de las CCRRs al ordenamiento jurídico español. Ya la siguiente Ley de Aguas se promulgó el 2 de Agosto de 1985, en la que se adopta el modelo de las CCRRs para todo tipo de organizaciones de usuarios de agua. Esta ley fue reformada el 13 de diciembre de 1999, fomentándose las CCRRs, 
además de potenciarse los aspectos medioambientales del uso del agua (Ruiz y Molina, 2010). Finalmente, como ya se ha indicado anteriormente, con el Real Decreto Legislativo 1/2001, de 20 de julio, se aprobó el texto refundido de la Ley de Aguas.

\subsubsection{Importancia y régimen de funcionamiento}

En España el $75 \%$ de los recursos hídricos consuntivos disponibles son consumidos por el sector agrícola (INE, 2012), dado que las CCRRs distribuyen el agua al 70\% de la superficie regable del país (Berbel et al., 2007), las mismas juegan un papel muy importante en la gestión del regadío. Según el Plan Nacional de Regadíos horizonte 2008, existían censadas 7.196 CCRRs en España en 2001, de las que 239 se encuentran en la Región de Murcia, según los datos proporcionados por la Consejería de Agricultura y Agua.

Las principales actividades que realizan las CCRRs son (Sagardoy et al., 1982): (a) adaptar la oferta a la demanda tanto como sea posible, (b) la distribución del agua para riego, (c) el mantenimiento de las infraestructuras, (d) la supervisión de los suministros, (e) el seguimiento de las actividades de mantenimiento y asistencia a los regantes. De todas estas actividades su función principal es la distribución de agua a las parcelas de su zona regable.

Alcón (2007) indica la importancia de las CCRRs en un estudio realizado sobre la adopción y difusión de tecnologías del riego en la Región de Murcia, donde llega a la siguiente conclusión: "la adopción de tecnología, por las CCRRs, como la gestión hídrica, que éstas realizan, mejoran la gestión de los recursos naturales de la Región de Murcia, contribuyendo al mantenimiento de la actividad agraria y la sostenibilidad medioambiental de la Región”. 
El régimen de funcionamiento y la organización de las CCRRs está regulado, con carácter general por el capítulo IV “de las comunidades de usuarios” del título IV “de la utilización del dominio público hidráulico” de la Ley de Aguas (BOE, 2001):

- Obligación de constituir CCRR (artículo 81) a los usuarios del agua de riego de una misma toma o concesión.

- Regulación de las CCRRs mediante estatutos u ordenanzas (artículo 81).

- Las CCRRs son corporaciones de derecho público (artículo 82) adscritas al Organismo de cuenca.

- Facultades de las CCRRs (artículo 83): (a) podrán ejecutar por sí mismas, los acuerdos incumplidos que impongan una obligación de hacer; (b) serán beneficiarias de la expropiación forzosa y de la imposición de las servidumbres; (c) vendrán obligadas a realizar las obras e instalaciones que la Administración les ordene, a fin de evitar el mal uso del agua; y (d) las deudas a la CCRR motivadas por la administración y distribución de las aguas, gravarán la finca en cuyo favor se realizaron.

- Órganos de las CCRRs (artículo 84): (a) la Junta o Asamblea General, constituida por todos los usuarios de la CCRR es el órgano soberano de la misma; (b) la Junta de Gobierno, elegida por la Junta General, es la encargada de la ejecución de las ordenanzas y de los acuerdos propios y de los adoptados por la Junta General; y (c) el Jurado de Riego al que le corresponde conocer las cuestiones de hecho que se susciten entre los usuarios de la CCRR en el ámbito de las ordenanzas e imponer a los infractores las sanciones reglamentarias.

Hay que significar que con la aplicación de la Directiva Marco del Agua (2000/60/CEE), cuyo objeto es establecer un marco para la protección de las aguas superficiales continentales, las aguas de transición, las aguas costeras y las aguas 
subterráneas, ha cambiado el papel de las CCRRs. Dado que las CCRRs pasan a ser responsables del cuidado de los ecosistemas asociados al agua, lo que conlleva como consecuencia una necesaria gestión de las demandas de agua en contraposición a la tradicional gestión de la oferta (Giménez et al., 2010).

\subsection{ZONA DE ESTUDIO}

Se han seleccionado cinco de las principales y más representativas CCRRs del regadío murciano (Fig. 2.13), siendo el periodo de estudio de 2002 a 2011. Las cinco CCRRs seleccionadas (CRCC, CRLO, CRPC, CRTCC, CRM) tienen una superficie de 71.954 ha, representado un 38,5 \% del total de la superficie regable de la Región de Murcia en 2011. Cada una de ellas es típica de los regadíos de las comarcas del Campo de Cartagena, del Valle del Guadalentín, de la Vega del Segura, de Río Mula y del Altiplano.

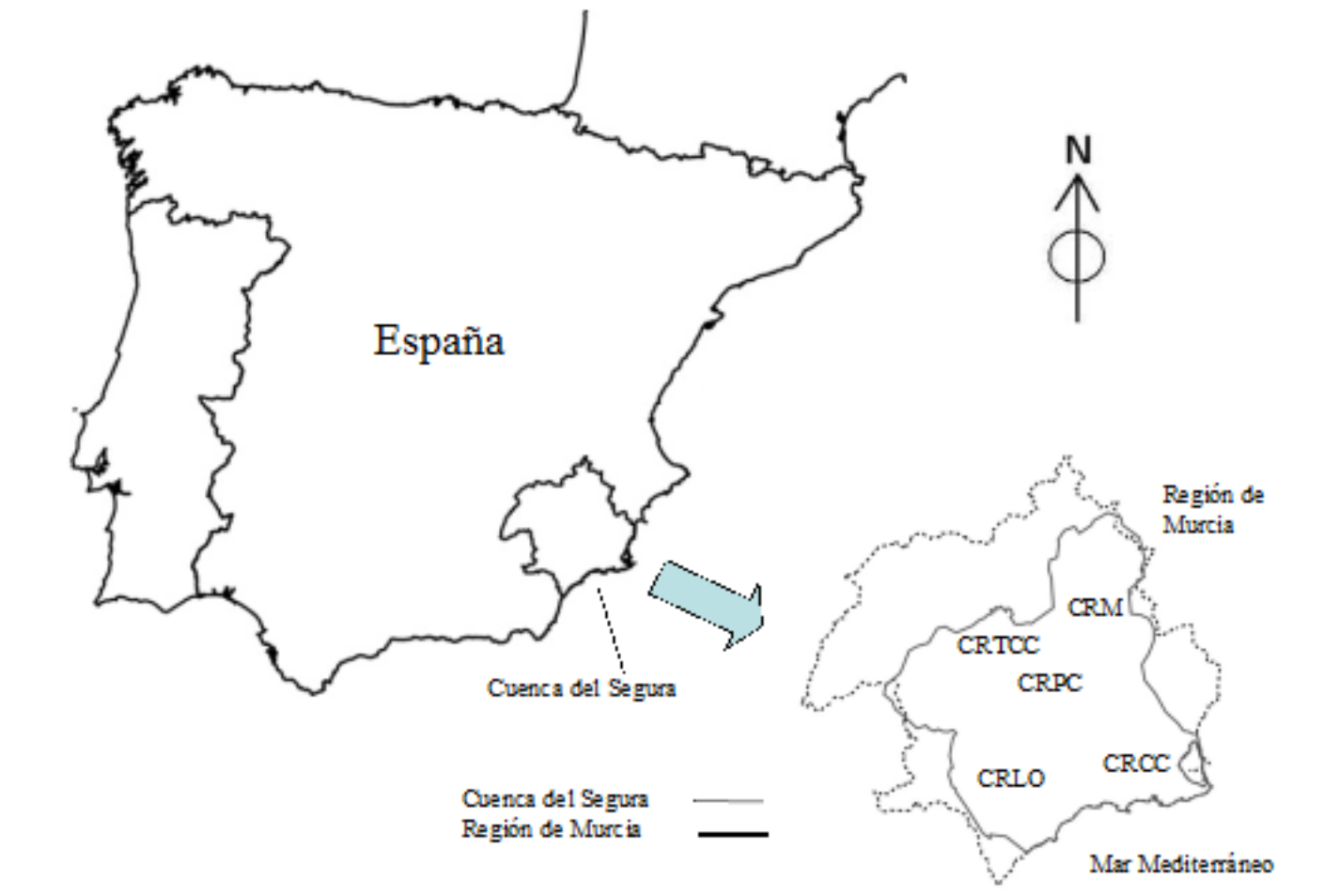

Figura 2.13. Localización de las CCRRs estudiadas en la Región de Murcia. 


\subsubsection{Comunidad de Regantes del Campo de Cartagena (CRCC)}

La CRCC se ubica en la Comarca del Campo de Cartagena, que tiene una de las agriculturas más rentables de la Región de Murcia y del país (Pérez-Blanco et al., 2011). El clima es mediterráneo con una precipitación media de 300 mm y una temperatura media anual de $18{ }^{\circ} \mathrm{C}$ (Jiménez-Martínez et al. 2009).

En el año 1952, se constituyó la CRCC, pero los primeros riegos los realizó en 1979 con la llegada de las aguas del Trasvase Tajo-Segura. Comprende una superficie regable de 41.065 ha con 9.506 comuneros, se extiende por los términos municipales de Cartagena, Fuente Álamo, Los Alcázares, Murcia, San Javier, San Pedro del Pinatar y Torre Pacheco en la provincia de Murcia, incluyendo también El Pilar de la Horadada en la provincia de Alicante (CRCC, 2013). Se trata de una de las CCRRs más grandes y tecnificadas de Europa (Alcón et al. 2006). En la Fig. 2.14 se muestra el mapa de la Zona Regable.

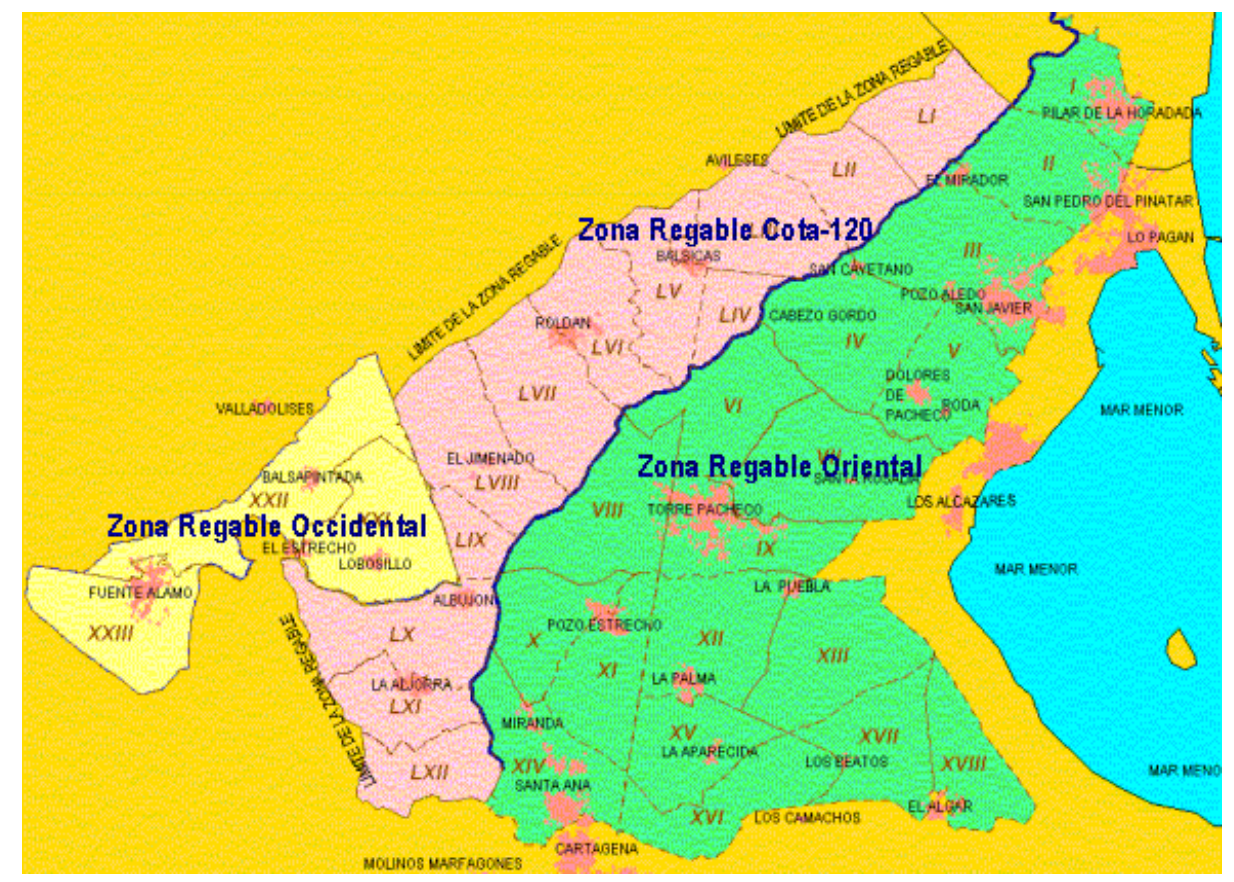

Figura 2.14. Mapa de la Zona Regable de la Comunidad de Regantes del Campo de Cartagena (CRCC, 2013). 
El área regada durante el periodo 2002-2011 ha variado entre 30.831 y 34.131 ha en función de la disponibilidad de agua. Los cultivos predominantes en la zona regable, por orden de importancia, son los hortícolas (lechuga, melón, alcachofa y bróculi), cítricos (limonero y naranjo) y cultivos de invernadero (pimiento). Los recursos hídricos máximos son de 141,6 $\mathrm{hm}^{3}$ año ${ }^{-1}$, procediendo en su mayor parte del Trasvase TajoSegura $\left(122 \mathrm{hm}^{3}\right)$, pero también se suministra de otras fuentes (superficial de la Cuenca $\left(4,2 \mathrm{hm}^{3}\right)$, desalinizada $\left(2,2 \mathrm{hm}^{3}\right)$ y reutilizada $\left(13,2 \mathrm{hm}^{3}\right)$. Esta CCRR está sometida a una gran irregularidad en la disponibilidad de sus dotaciones de agua, habiéndose alcanzado situaciones muy críticas, como por ejemplo en 1995, cuando solo pudo distribuir $18 \mathrm{hm}^{3}$.

Esta CCRR ha tenido un proceso de modernización en tres fases (Soto-García et al., 2007) desde 1996 a 2010, con una inversión económica de 34 M€. La primera fase comenzó en 1996 y finalizó en 2002, siendo automatizada el 17\% de la superficie, la segunda fase terminó en 2006 con un $57 \%$ y en 2010 se completó la tercera fase con el 26\% restante. La modernización ha consistido principalmente en: (a) la sustitución de elementos de control y de medida por otros preparados para el telecontrol; (b) la instalación de equipos de medida en balsas y tuberías principales; (c) la agrupación de las estaciones de bombeo; (d) el aumento de la capacidad de almacenamiento y de la red de distribución; (e) la incorporación de las tecnologías de la información y la comunicación a la gestión de la CCRR. Este proceso de modernización es continuado con el desarrollo continuo de aplicaciones Web y para teléfono móviles (Del Amor, 2006). La modernización ha permitido un control exhaustivo del agua utilizada por cada comunero, permitiendo a los regantes la gestión de sus riegos a través de Internet o de telefonía móvil (Arcas y Alcón, 2007). 
La infraestructura de distribución está constituida por el Canal Principal del Campo de Cartagena de $64 \mathrm{~km}$ de longitud que transporta y distribuye los recursos almacenados en el embalse de La Pedrera hasta las tuberías principales de cada sector de riego. La Zona Regable tiene 33 sectores de riego, 18 en la Zona Regable Oriental, 3 en la Occidental y 12 en la Cota 120 , con 1.033 km de tuberías, y 25 embalses con una capacidad total de $2,5 \mathrm{hm}^{3}$. Las tuberías principales tienen un diámetro comprendido entre 1.600 y $800 \mathrm{~mm}$, las primarias entre 700 y $300 \mathrm{~mm}$, y las secundarias entre 250 y $80 \mathrm{~mm}$, que son donde se ubican las 1.187 tomas de riego. La Impulsión de Fuente Álamo abastece la Zona Regable Occidental, con 6 bombas que son capaces de elevar a una altura manométrica de 93 mca un caudal de $4,64 \mathrm{~m}^{3} \mathrm{~s}^{-1}$. La Zona Regable Cota-120 es abastecida por la Impulsión de la Trinchera, con cuatro bombas, con un caudal máximo $1,040 \mathrm{~m}^{3} \mathrm{~s}^{-1}$ a una altura manométrica de 90 mca y la Impulsión del Embalse de Cola, con tres bombas, con un caudal máximo de $0,737 \mathrm{~m}^{3} \mathrm{~s}^{-1}$ a una altura manométrica de 101 mca.

\subsubsection{Comunidad de Regantes de Lorca (CRLO)}

La zona regable de la CRLO, se encuentra enclavada en el Valle del Guadalentín, se extiende en los términos municipales de Lorca y Puerto Lumbreras. Con una temperatura media anual de $18^{\circ} \mathrm{C}$, y una pluviometría sobre los $240 \mathrm{~mm}$, confieren a la zona condiciones de gran aridez, que aumenta de Norte a Sur, hasta la zona de Águilas, que es la que registra los valores más bajos de precipitación en toda la Región.

El regadío de Lorca existe desde la época de la ocupación musulmana en España, pero fue el Rey Alfonso X El Sabio quien dispuso la primera regulación en este sentido; así en el año 1268 estableció dos Reales Decretos: uno, sobre el reparto de las 
tierras, y otro, para dividir y repartir las aguas claras, las turbias y las de lluvias (CRLORCA, 2013).

La CRLO, con una superficie regable de 12.190 ha y 7.617 comuneros, se constituyó por la Orden Ministerial de Obras Públicas de 24 de noviembre de 1978. Está repartida en dos áreas, la primera de ellas ocupa gran parte del Valle que delimitan las sierras de Tercia y Almenara; y la segunda, se extiende desde la ciudad de Lorca en dirección Noroeste, curso arriba del Guadalentín, a ambos lados del mismo. Este ámbito territorial prácticamente coincide con el regadío tradicional de Lorca, conformado por los Heredamientos de Alcalá, Altritar, Serrata, Hornillo, Sutullena y Alberquilla, Real, Tercia y Albacete; y con la agregación de la zona de ampliación del Plan Coordinado en el sector de Torrecilla (Fig. 2.15). Se divide en 6 grandes sectores de riego que se corresponden aproximadamente con la divisoria de servicio de los canales principales de la red tradicional, los cuales se despliegan en forma radial a partir de la población de Lorca.

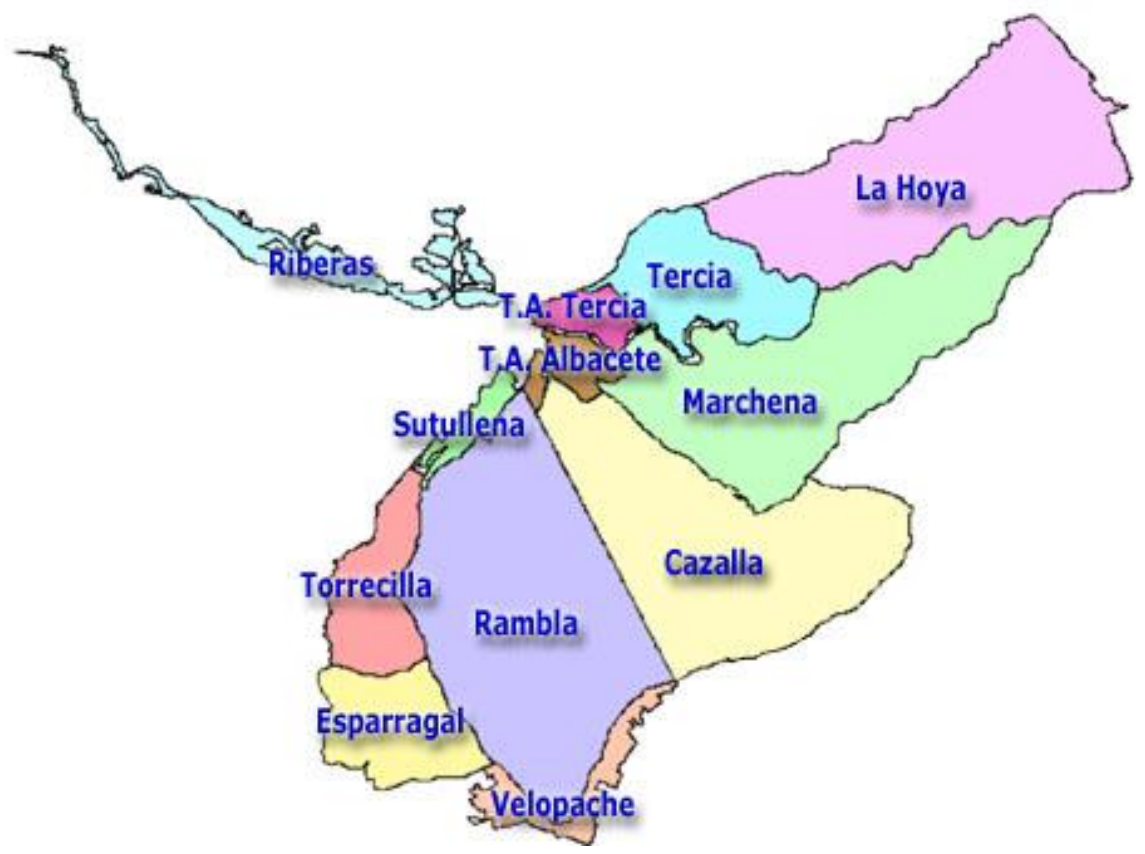

Figura 2.15. Mapa de la Zona Regable de la Comunidad de Regantes de Lorca (CRLORCA, 2013). 
La superficie regada durante el periodo 2002-2011 ha variado entre 16.237 y 11.933 ha en función de la disponibilidad de agua. Los cultivos predominantes en la zona regable son los hortícolas $(85,2 \%$ en 2.011$)$, por orden de importancia los principales son: bróculi, lechuga y alcachofa. Los recursos hídricos máximos disponibles son de 54,01 $\mathrm{hm}^{3}$ año $^{-1}$ (SCRATS, 2013), procediendo en su mayor parte del Trasvase Tajo-Segura $\left(29,06 \mathrm{hm}^{3}\right)$, pero también se suministra de otras fuentes: superficiales de la Cuenca $\left(4,2 \mathrm{hm}^{3}\right)$, superficiales propios $\left(6 \mathrm{hm}^{3}\right)$, subterráneas $(13$ $\mathrm{hm}^{3}$ ) y reutilizada $\left(1,75 \mathrm{hm}^{3}\right)$. A estos recursos hay que añadir la concesión otorgada por la CHS en septiembre de 2011, de $23 \mathrm{hm}^{3}$ procedentes de la desaladora de Águilas (CHS, 2013), con estos recursos se regularizaron 11.254 ha de regadío consolidado, que pasan a formar parte de la Comunidad de Regantes de Lorca. La planta desaladora de Águilas comenzó su funcionamiento en Junio de 2012.

Desde 1992 se han llevado a cabo un proceso de modernización. Con una inversión de unos $133 \mathrm{M} €$ en el periodo 1992-2007. Entre las principales infraestructuras destacan: las mejoras en la Casa Mata (lugar de bombeo y distribución de la mayoría de los recursos de la Comunidad de Regantes de Lorca), los embalses de regulación (A. Botia de $400.000 \mathrm{~m}^{3}$, Leonés de $400.000 \mathrm{~m}^{3}$, Torrecilla de $200.000 \mathrm{~m}^{3}$, La Hoya de $175.000 \mathrm{~m}^{3}$, Jeresa de $110.000 \mathrm{~m}^{3}$ ), la red de tuberías principales (entre 500 y 1.600 mm de diámetro), secundarias (entre 200 y 400 mm de diámetro), la instalación de hidrantes a nivel parcela, automatismos y la informatización del sistema (Martínez y Gómez, 2008). Está pendiente la modernización del Heredamiento de la Tercia y la finalización en el Heredamiento de las Riberas (Gómez et al., 2011). 


\subsubsection{Comunidad de Regantes del Trasvase Tajo Segura Calasparra-Cieza (CRTCC)}

La CRTCC se ubica en la Vega del Segura. Presenta una superficie regable de 3.983 ha, con 350 comuneros. Se extiende por los municipios de Cieza (65\%) y Calasparra (35\%). Se trata de nuevos regadíos creados con la llegada de las aguas procedentes del Trasvase Tajo-Segura.

El área regada durante el periodo 2002-2011 ha variado entre 3.131 y 2.865 ha, siendo los cultivos principales frutales de hueso (melocotonero, ciruelo y albaricoquero) que en 2011 representaban un 87\%. En la actualidad, el $100 \%$ de las parcelas de la zona regable disponen de riego localizado.

Los recursos hídricos máximos disponibles son de $13,49 \mathrm{hm}^{3}$ año ${ }^{-1}$ (SCRATS, 2013), procedentes del Trasvase Tajo-Segura. En los periodos de escasez, debidamente autorizados por la CHS, pueden tomar agua de los denominados pozos de sequía que captan los recursos del acuífero Sinclinal de Calasparra.

La zona regable se divide en dos sectores con independencia hidráulica (Fig. 2.16). La infraestructura principal que proporciona el agua de la zona es la del aprovechamiento del Trasvase Tajo-Segura, captándose las aguas en la margen izquierda del río Segura mediante una impulsión, a la altura de la población de Calasparra. Las redes primarias están dotadas de contadores volumétricos, con contadores a nivel parcela. El sistema está diseñado para funcionar a la demanda y sin restricciones (SCRATS, 2013).

Las infraestructuras, incluidas las obras de la modernización, de esta CCRR consisten principalmente en: (a) cinco embalses con capacidad de $45.000 \mathrm{~m}^{3}, 130.000$ $\mathrm{m}^{3}, 200.000 \mathrm{~m}^{3}, 600.000 \mathrm{~m}^{3}$ y $850.000 \mathrm{~m}^{3}$; (b) una estación de bombeo para un caudal de $1,58 \mathrm{~m}^{3} \mathrm{~s}^{-1}$; (c) la adecuación de la red general y de distribución; (d) edificio para sede social, oficinas y atención al regante de la CCRR; (e) la instalación de hidrantes a 
nivel parcela; y (f) el automatismo y telecontrol. Toda esta mejora y modernización del regadío ha supuesto una inversión hasta 2010 de 8.000.000 € (Gómez et al., 2011).

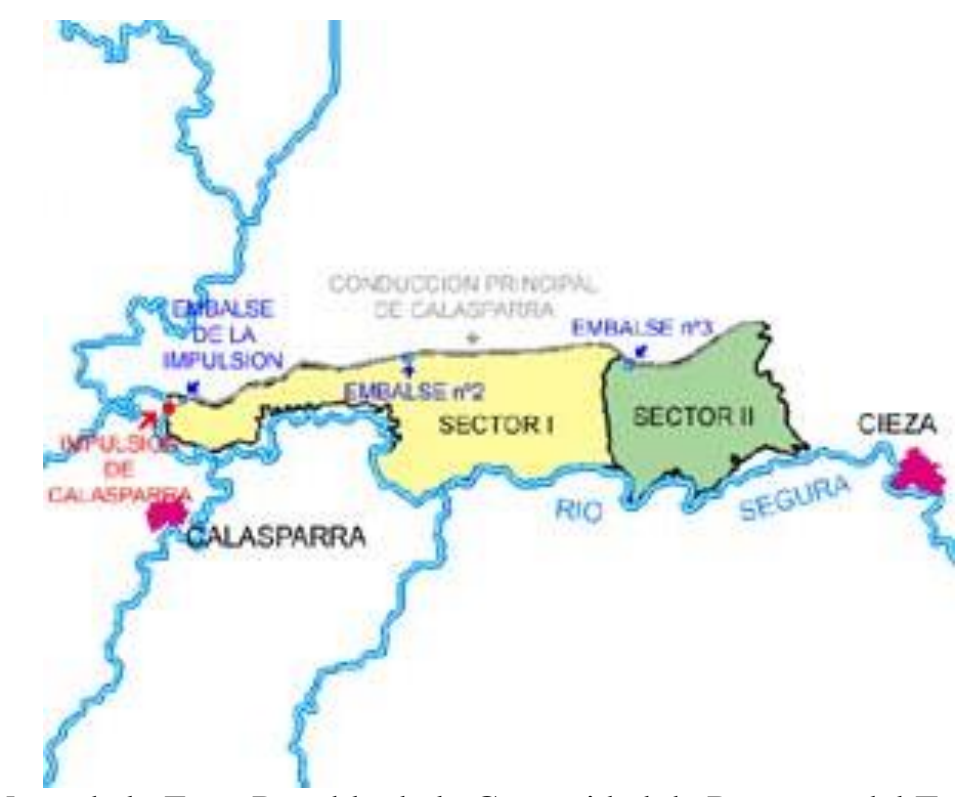

Figura 2.16. Mapa de la Zona Regable de la Comunidad de Regantes del Trasvase Tajo Segura Calasparra-Cieza (SCRATS, 2013).

\subsubsection{Comunidad de Regantes del Pantano de La Cierva (CRPC)}

A partir de 1935, se crea la Comunidad de Regantes del Pantano El Corcovado (hoy La Cierva), tutelada por CHS hasta 1966. Esta CCRR se ubica en el término municipal de Mula. El clima es semiárido, con precipitación media anual de unos 280 mm, y con una temperatura media entre 16 y $17^{\circ} \mathrm{C}$ (Del Amor et al., 1998). Se trata de regadíos tradicionales desde la época musulmana, que fueron redotados con el Trasvase Tajo-Segura.

Presenta una superficie de 1.947 ha, con 1.750 comuneros. El área regada durante el periodo 2002-2011 ha variado entre 1.935 ha y 1.797 ha, siendo los cultivos principales frutales de hueso (albaricoquero y melocotonero) y cítricos (naranjo, limonero y mandarino), estos cinco cultivos en 2011 representaban un 88,4\% de la superficie regada. En la actualidad, el 98,5 \% de las parcelas de la zona regable 
disponen de riego localizado. Esta CCRR fue pionera en la modernización de sus regadíos y en la sustitución del tradicional riego por superficie a riego localizado (Del Amor et al., 1998; Gómez et al.; 2011). A esta CCRR se le concedió el "Premio Iberdrola 1997 a la Innovación Tecnológica en la Gestión y el Uso del Agua”, a finales del siglo XX era un referente a nivel mundial en cuanto a la modernización de sus regadíos.

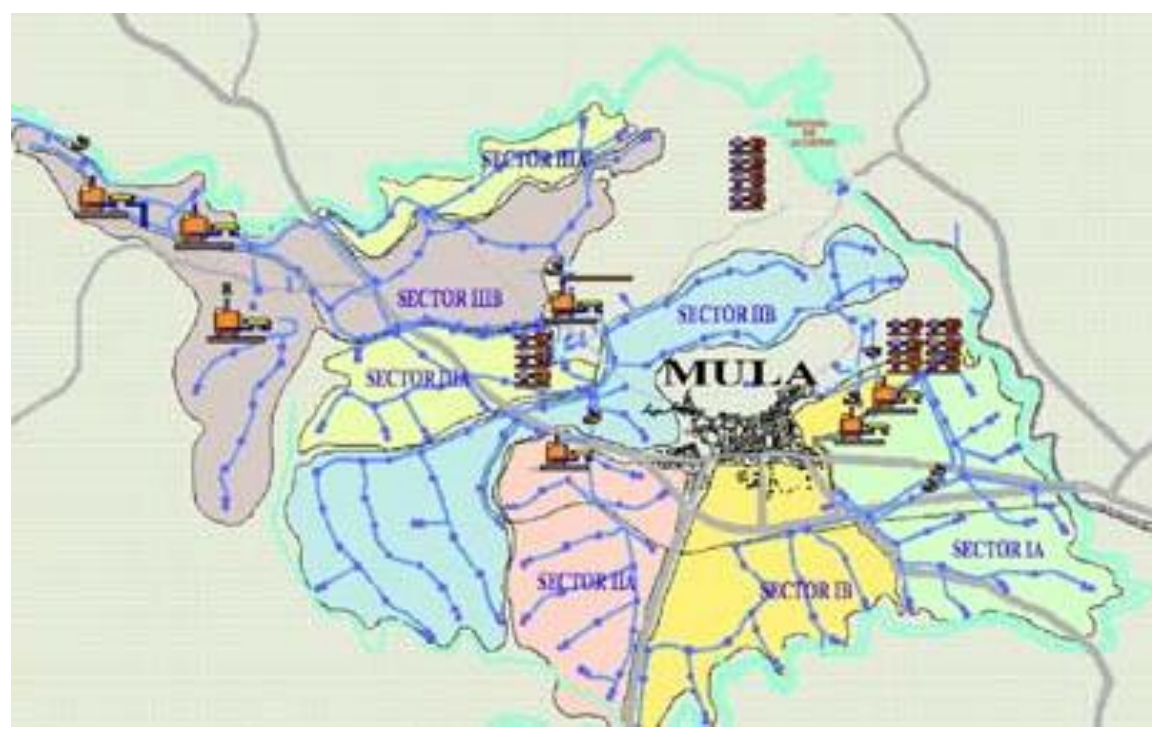

Figura 2.17. Mapa de la Zona Regable de la Comunidad de Regantes Pantano de la Cierva (SCRATS, 2013).

Los recursos máximos disponibles son $8,5 \mathrm{hm}^{3}: 0,6 \mathrm{hm}^{3}$ de recursos superficiales de la Cuenca, $4 \mathrm{hm}^{3}$ del Trasvase Tajo-Segura y 3,9 $\mathrm{hm}^{3}$ de aguas subterráneas procedentes de los pozos "Pradillo" y "Corral de Comba". La zona regable se encuentra dividida en 7 sectores de riego (Fig. 2.17), los caudales se regulan mediante 7 embalses de riego, con una capacidad total de $580.000 \mathrm{~m}^{3}$. A partir de cada embalse, comienza la red de riego correspondiente al sector. La longitud total de tuberías es de $83 \mathrm{~km}$, con diámetros entre 110 y $700 \mathrm{~mm}$. Existen tres estaciones de bombeo, en la cabeza de cada sector hay una estación de filtrado. Con hidrantes a nivel parcela, el sistema se encuentra totalmente automatizado (Del Amor et al., 1998). 


\subsubsection{Comunidad de Regantes Miraflores (CRM)}

La CRM, anteriormente S.A.T. n 3.176, se ubica en el término municipal de Jumilla, en la comarca del Altiplano. Este municipio está caracterizado por la ausencia de cursos de agua permanente y quedó excluido de las infraestructuras del Acueducto Tajo-Segura. La demanda hídrica de los cultivos es satisfecha por los recursos subterráneos, que se encuentran sobreexplotados (Molina et al., 2009). En la zona predomina el clima mediterráneo continental, con precipitaciones anuales medias entre 300-350 mm, y las temperaturas medias oscilan entre 13 y $18^{\circ} \mathrm{C}$ (Nicolás et al., 2012).

Esta zona fue declarada de interés nacional por el Decreto 1534/1963 de 4 de julio, aprobándose el Plan General de Colonización de la zona regable con aguas subterráneas por el Decreto 2440/1964 de 9 de julio. El antiguo Instituto Nacional de Colonización llevó a cabo las obras del Plan y realizó diversos sondeos profundos para aportar los recursos para la transformación en regadío de esta zona (Gómez, 1997).

La superficie regable de esta CCRR es de 1.515 ha, donde se distinguen dos subzonas (Fig. 2.18) definidas: subzona de Jumilla con 1.350 ha y subzona de La Alquería y Fuente del Pino con 165 ha (Nicolás et al., 2012). El área regada durante el periodo 2002-2011 ha variado entre 1.283 ha y 1.182 ha, siendo los cultivos principales: peral $(46,3 \%)$, melocotonero $(32,2 \%)$ y albaricoquero $(6,5 \%)$, que representaban en 2011 un $88,4 \%$ del total.

Los recursos máximos actuales disponibles son $3,85 \mathrm{hm}^{3}$ provenientes de 6 pozos: Grajas I, Alquería, Vereda, Puntillas, Escarabaja y Loma de Hellín. Estos recursos se han ampliado en $1,5 \mathrm{hm}^{3}$ en 2013 , con la reutilización de las aguas procedentes de la EDAR de Jumilla. 


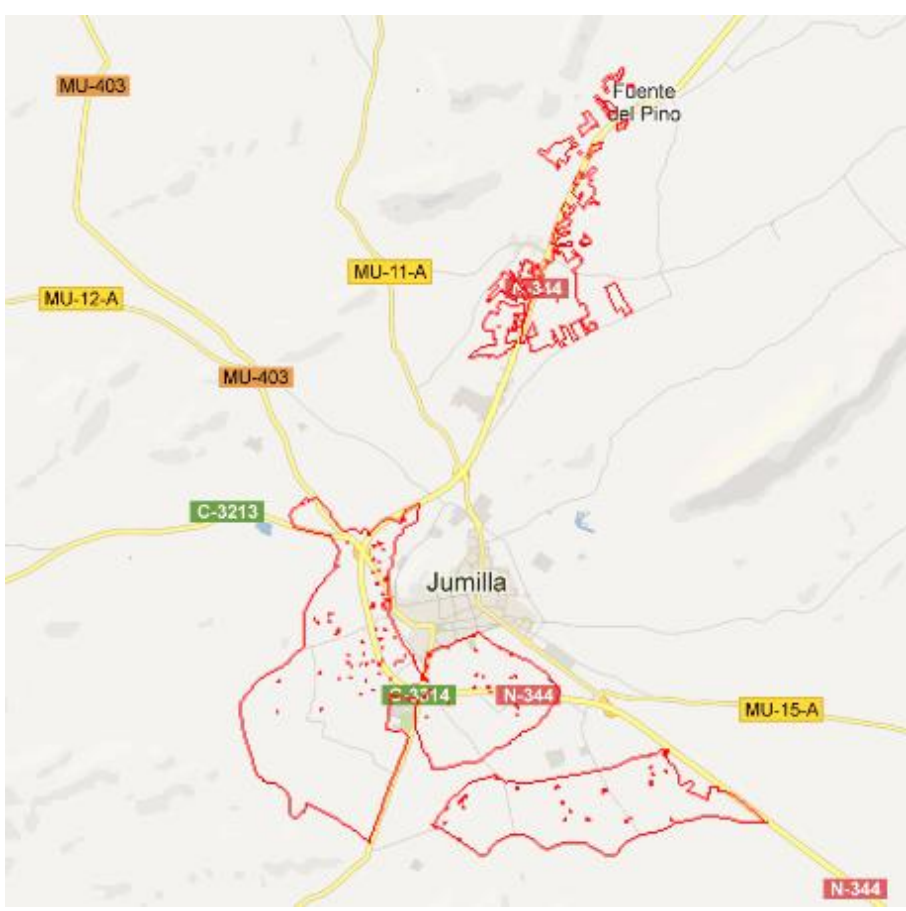

Figura 2.18. Mapa de la Zona Regable de la Comunidad de Regantes Miraflores.

Las infraestructuras actuales de la CRM constan fundamentalmente de: (a) 6 embalses reguladores con una capacidad de $715.000 \mathrm{~m}^{3}$; (b) cabezales de filtrado para cada sector de riego; (c) redes de tuberías generales y secundarias que distribuyen el agua por toda la zona regable; (d) hidrantes individualizados para cada regante que controlan la dotación de agua asignada; y (e) un sistema de telecontrol por cable y vía radio, que permite controlar, tanto las infraestructuras de la CCRR, como la dotación y el suministro de agua asignada a cada comunero. El riego es a la demanda, con una dotación única de $2,4 \mathrm{~m}^{3} \mathrm{~h}^{-1}$ por hectárea de forma continua para todos los regantes, la facturación se realiza mediante la lectura de los contadores. Se trata de la CCRR más tecnificada de su comarca.

La modernización, que comenzó en 1994 y finalizó en 1997, se ha realizado en tres fases: (i) la infraestructura principal (conducción general y embalses reguladores), (ii) las redes secundarias en tuberías presurizadas para los cinco sectores de riego en que se divide la zona regable (La Huerta, Salinas, El Molar, Santa Ana, Alquería-Fuente del 
Pino), (iii) la automatización y control informático de la red de riego. (Gómez, 1997).

Estos planes de modernización han supuesto una inversión total de 6,6 M€ (Gómez et al., 2007).

\subsection{INDICADORES DE GESTIÓN Y TÉCNICAS DE BENCHMARKING}

\subsubsection{Introducción}

El benchmarking, tal como se conoce actualmente, fue desarrollado en Estados Unidos durante los años setenta (Campalans, 2001), y tiene su origen en la actividad empresarial, como un medio para mejorar su gestión y de este modo el rendimiento de la organización. Su uso está muy extendido al sector público y privado.

Definir el benchmarking no es una tarea sencilla, más bien lo contrario, al tratarse de un fenómeno y concepto evolutivo por naturaleza, su revisión y clasificación representa un reto desde el punto de vista teórico y práctico (Gurutze y Ochoa, 2005). A continuación se indican tres definiciones de esta técnica: (i) el Centro de Calidad y Productividad Americano (APQC, 2006) lo define como "el proceso de identificar y aprender a partir de las mejores prácticas en cualquier parte del mundo, es una herramienta poderosa en la búsqueda de una mejora continua y de avances importantes"; (ii) Malano y Burton (2001) lo definen como "un proceso de aprendizaje de tu propio funcionamiento pasado y de la actuación de los demás en la búsqueda de la mejora continua"; y (iii) Rodríguez (2003) define esta técnica "como una estrategia para localizar las mejores prácticas de la industria, se encuentren donde se encuentren, y tratar de adaptarlas a la empresa interesada”.

Por todo ello el benchmarking implica que para mejorar hay que comparar, ya sea internamente con lo realizado anteriormente o con las metas futuras, o externamente con organizaciones que presentan las mejores prácticas. 
El objetivo principal del benchmarking es una mejora continua de la organización a lo largo del tiempo. Las técnicas de benchmarking se pueden dividir en cuatro categorías diferentes (Córcoles, 2009):

○ Benchmarking interno. Se produce en las grandes empresas que presentan múltiples divisiones, incluso internacionales. Los datos e información son de fácil acceso dado que son de la propia compañía y no existen problemas de confidencialidad, y se pueden disponer tan amplios como se deseen.

- Benchmarking competitivo. Consiste en compararse directamente con los competidores directos, de este modo conoceré mis ventajas y desventajas. La mayor dificultad consiste en la obtención de datos e información de la competencia.

- Benchmarking genérico. Consiste en buscar y encontrar las mejores prácticas y procedimientos que no estén implantados en la organización estudiada y que sí presenta la competencia.

- Benchmarking funcional. Se centra en la posibilidad de identificar competidores funcionales o líderes de la industria, que no son competidores directos, para utilizarlos en el benchmarking.

La aplicación de técnicas de benchmarking para mejorar el funcionamiento de las CCRRs es un fenómeno relativamente reciente (Malano y Burton, 2001; Rodríguez et al., 2008; Borgia et al., 2013).

\subsubsection{Fases en el proceso de benchmarking aplicado al regadío}

El proceso de aplicación de benchmarking en regadío (Malano y Burton, 2001; Malano et al., 2004) se muestra en la Fig. 2.19, presentando seis fases: (1) identificación 
y planificación, (2) toma de datos, (3) análisis, (4) integración, (5) acción, y (6) seguimiento y evaluación.

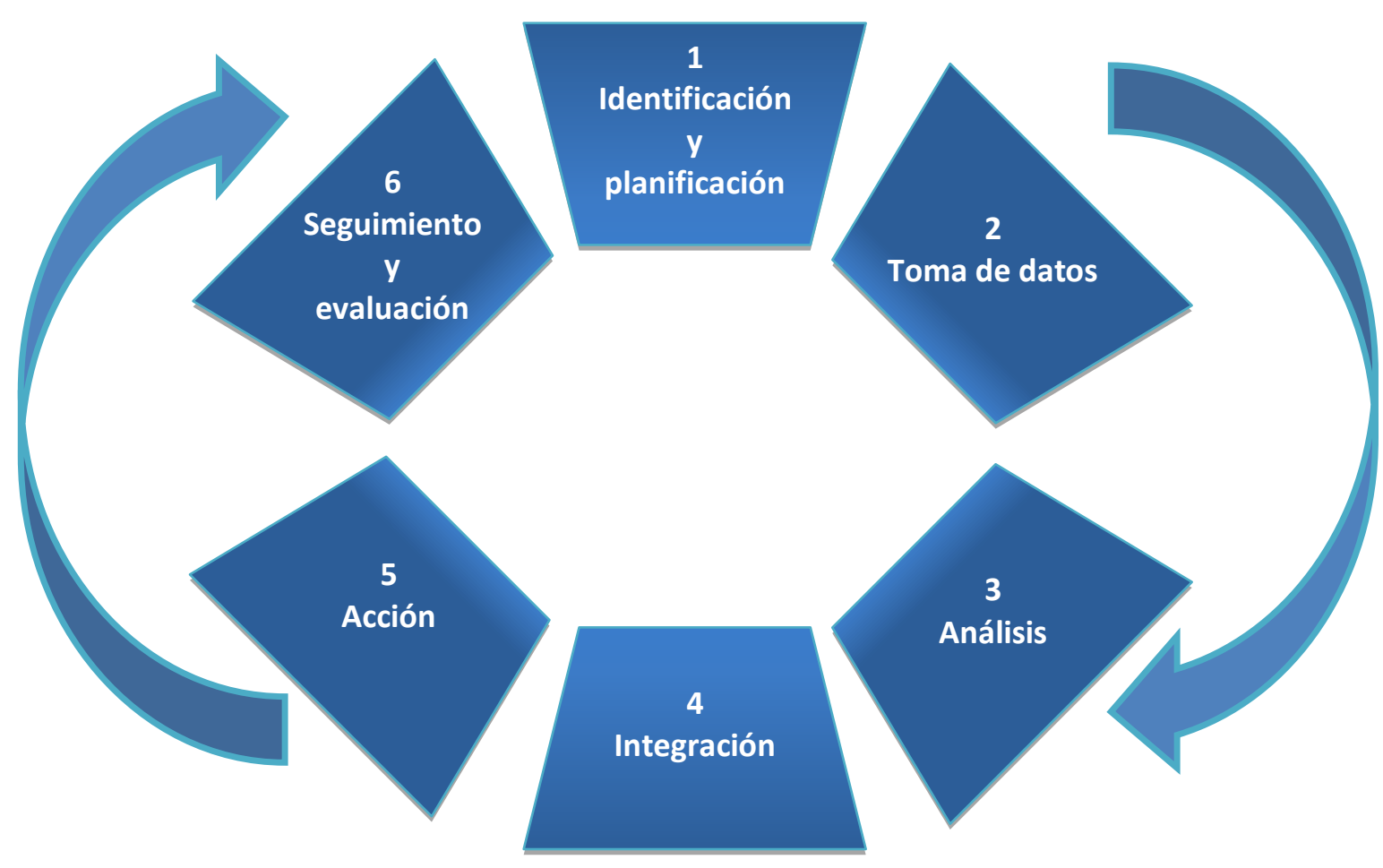

Figura 2.19. Fases en el proceso de benchmarking aplicado al regadío.

En la fase $n^{o} 1$, denominada identificación y planificación, (i) se define el propósito del estudio y qué resultados se pretenden obtener del proceso de benchmarking; (ii) se seleccionan las zonas regables donde se va aplicar esta técnica; (iii) se identifican los factores principales que influyen en la gestión; (iv) se identifican los procesos a analizar; (v) se seleccionan los indicadores de gestión; y (vi) se identifican los datos requeridos y como se va a recopilar y procesar esta información.

La fase $n^{o} 2$, denominada toma de datos, consiste en la recopilación de los datos que vamos a utilizar para calcular los indicadores de gestión. Estos datos tienen que ser consistentes y fácilmente comparables. Este es un aspecto importante que tiene que ser 
previsto, dado que los datos a recopilar van a estar en función de las variables de los indicadores de gestión seleccionados en la fase $\mathrm{n}^{\circ} 1$.

En la fase $n^{o} 3$, denominada análisis, se comparan los indicadores de las zonas regables seleccionadas, identificando los puntos débiles de cada organización, cuales son las causas que lo provocan y cómo se pueden solucionar. De esta manera el benchmarking aplicado al regadío no es solo una comparación entre zonas regables, sino que también se incorpora un diagnóstico y análisis de las CCRRs estudiadas. Una vez que se conocen las causas que provocan una disfunción, se pueden tomar las medidas oportunas para solucionarla. Esta etapa del proceso de benchmarking puede necesitar mucho tiempo y ser muy difícil de realizar.

En la fase $n^{o} 4$, denominada integración, la estrategia y plan de acción desarrollado a partir de la fase de análisis deben integrarse en los procesos y procedimientos operativos de la organización a fin de lograr el cambio deseado. Es crucial que los responsables del programa de benchmarking tengan la autoridad para realizar los cambios necesarios y que el proceso de cambio esté totalmente integrado dentro de los procesos y procedimientos de gestión de la organización.

En la fase $n^{o} 5$, denominada acción, se ponen en marcha los nuevos procesos y procedimientos para lograr los cambios deseados. En esta etapa se realiza también un seguimiento y evaluación de los nuevos procesos y procedimientos implementados para asegurar que se consiguen los objetivos previstos, y en caso de ser necesario se tomen las medidas correctivas oportunas.

La fase $n^{\circ}$ 6, denominada seguimiento y evaluación, consiste en el continuo seguimiento en la gestión de la CCRR, para comprobar que se han conseguido los objetivos previstos con las medidas propuestas. Hay que tener en cuenta que estos objetivos pueden variar con el tiempo. Este hecho pone de manifiesto las características 
de evaluación y aprendizaje continuo que suponen las técnicas de benchmarking (Córcoles, 2009).

\subsubsection{Indicadores de gestión}

Como ya se ha comentado en el Capítulo 1 esta técnica considera diferentes indicadores para describir las características principales de gestión de las zonas regables analizadas. Estos indicadores son útiles para caracterizar a la CCRR estudiada, y de este modo poder evaluar su gestión y compararla con otras. Los indicadores proporcionados por esta técnica y su estudio estadístico son fundamentales para entender donde los sistemas de riego funcionan correctamente y donde se pueden mejorar (Zwart et al., 2010).

Los indicadores empleados en el presente trabajo (Tabla 2.3) se basan en la propuesta del "International Program for Technology and Research on Irrigation and Drainage” IPTRID (Malano y Burton, 2001), considerando adicionalmente otros indicadores propuestos por distintos autores (Rodríguez, 2003; Córcoles, 2009; Abadía et al., 2010), se dividen en 5 grupos:

- Indicadores de Rendimiento: Relacionan la disponibilidad de agua con la superficie, necesidades de los cultivos y eficiencia de distribución.

○ Indicadores Financieros: Relacionan los diferentes costes con la superficie y el volumen de agua.

○ Indicadores de Eficiencia de Producción: Relacionan el valor de la producción agrícola con la superficie y el volumen de agua.

○ Indicadores Energéticos: Relacionan el consumo energético con la superficie y el volumen de agua. 
- Indicadores Ambientales: consideran la calidad del agua de riego y los impactos

ambientales.

Tabla 2.3. Descripción y método de cálculo de los indicadores de gestión empleados.

\begin{tabular}{|c|c|c|c|}
\hline $\begin{array}{l}\text { Nombre del indicador y } \\
\text { acrónimo }\end{array}$ & Unidad & Clasificación & Descripción y cálculo \\
\hline Superficie regable $(\mathrm{Sa})$ & ha & De rendimiento & $\begin{array}{l}\text { Superficie de todas las parcelas que se } \\
\text { riegan durante el año o que son susceptibles } \\
\text { de ser regadas por disponer de } \\
\text { equipamiento fijo para este fin; se incluyen } \\
\text { tanto las que se riegan de forma continua } \\
\text { como eventual. }\end{array}$ \\
\hline Superficie regada $(\mathrm{Sr})$ & ha & De rendimiento & $\begin{array}{l}\text { Es la superficie regada total, constituida por } \\
\text { la superficie regada de cada parcela. Es la } \\
\text { superficie de las parcelas que han recibido } \\
\text { aporte de agua de riego durante la campaña. } \\
\text { Está relacionada con la intensidad de } \\
\text { cultivos, pudiendo ser superior a la Sa, ya } \\
\text { que una misma parcela con dos cultivos } \\
\text { durante la campana supone una Sr del doble } \\
\text { de su superficie. }\end{array}$ \\
\hline Volumen derechos (Vr) & $\mathrm{m}^{3}$ & De rendimiento & $\begin{array}{l}\text { Volumen de agua sobre el que la CCRR } \\
\text { tiene derechos. }\end{array}$ \\
\hline $\begin{array}{l}\text { Volumen que entra al sistema } \\
\text { de la CCRR (VT) }\end{array}$ & $\mathrm{m}^{3}$ & De rendimiento & $\begin{array}{l}\text { Volumen de agua de riego que entra al } \\
\text { sistema de la CCRR. }\end{array}$ \\
\hline $\begin{array}{l}\text { Volumen total que entra a la } \\
\text { zona regable (VTT) }\end{array}$ & $\mathrm{m}^{3}$ & De rendimiento & $\begin{array}{l}\mathrm{VT}+\text { la precipitación efectiva }+ \text { agua de } \\
\text { otra procedencia distinta a la CCRR. }\end{array}$ \\
\hline Volumen suministrado (Vs) & $\mathrm{m}^{3}$ & De rendimiento & $\begin{array}{l}\text { Volumen de agua de riego suministrado a } \\
\text { las explotaciones agrícolas. Es el volumen } \\
\text { facturado a los regantes en base a las } \\
\text { lecturas de los contadores instalados. }\end{array}$ \\
\hline $\begin{array}{l}\text { Evapotranspiración de los } \\
\text { cultivos }(\mathrm{ETc})\end{array}$ & $\mathrm{m}^{3}$ & De rendimiento & $\begin{array}{l}\text { Es la evapotranspiración total anual de } \\
\text { todos los cultivos de la zona regable de la } \\
\text { CCRR. }\end{array}$ \\
\hline Precipitación efectiva $\left(\mathrm{P}_{\mathrm{ef}}\right)$ & $\mathrm{m}^{3}$ & De rendimiento & $\begin{array}{l}\text { Fracción de la precipitación total que es } \\
\text { aprovechada por los cultivos. }\end{array}$ \\
\hline Necesidades brutas $(\mathrm{Nb})$ & $\mathrm{m}^{3}$ & De rendimiento & $\begin{array}{l}\text { Son las necesidades brutas de todos los } \\
\text { cultivos de la zona regable de la CCRR. }\end{array}$ \\
\hline Garantía de suministro (Sg) & $\%$ & De rendimiento & $\begin{array}{l}\mathrm{VT} / \mathrm{Vr} \\
\text { Relación entre la cantidad de agua que entra } \\
\text { al sistema y el volumen sobre el que se } \\
\text { tiene derecho. }\end{array}$ \\
\hline Intensidad de cultivo ( $\mathrm{SrSa})$ & $\%$ & De rendimiento & $\begin{array}{l}\text { Representa en \% la superficie que se está } \\
\text { regando en la CCRR respecto a la } \\
\text { superficie regable. }\end{array}$ \\
\hline $\begin{array}{l}\text { Eficiencia de distribución } \\
\text { (ED) }\end{array}$ & $\%$ & De rendimiento & $\begin{array}{l}\text { Vs/VT } \\
\text { Representa las pérdidas de distribución de } \\
\text { agua de la CCRR. }\end{array}$ \\
\hline $\begin{array}{l}\text { Suministro de agua por } \\
\text { unidad de área regada ( } \mathrm{VsSr})\end{array}$ & $\mathrm{m}^{3} \mathrm{ha}^{-1}$ & De rendimiento & $\mathrm{Vs} / \mathrm{Sr}$ \\
\hline $\begin{array}{l}\text { Aporte relativo de agua } \\
\text { suministrada(ARWS) }\end{array}$ & - & De rendimiento & $\left(\mathrm{Vs}+\mathrm{P}_{\mathrm{ef}}\right) / \mathrm{ETc}$ \\
\hline $\begin{array}{l}\text { Aporte relativo de agua de } \\
\text { riego (ARIS) }\end{array}$ & - & De rendimiento & $\mathrm{Vs} /\left(\mathrm{ETc}-\mathrm{P}_{\mathrm{ef}}\right)$ \\
\hline
\end{tabular}




\begin{tabular}{lll}
\hline Costes de manejo del sistema & $€$ & Financieros \\
(CMS) & & \\
& & \\
& & \\
Gastos generales del sistema & $€$ & Financieros \\
(GG) & & \\
Costes energéticos (CEN) & & \\
Costes personal (CP) & & \\
Costes mantenimiento (CM) & & \\
& & Financieros
\end{tabular}

Ingresos (Ing)

Retornos brutos $(\mathrm{Rb})$

Inversiones (Inv)

Número de trabajadores (NP) Precio del agua (PA)

Superficie regada por trabajador (SrNP)

Recuperación de costes (RC)

Costes de manejo del sistema por unidad de agua de riego suministrada (CMSVs)

Costes de manejo del sistema por unidad de área regada (CMSSr)

Gastos generales del sistema por unidad de agua de riego suministrada (GGVs)

Gastos generales del sistema por unidad de área regada (GGSr)

Costes personal por unidad de agua de riego suministrada (CPVs)

Costes personal por unidad de área regada (CPSr)

Costes mantenimiento por unidad de agua de riego suministrada (CMVs)

Costes mantenimiento por unidad de área regada (CMSr)
Costes de manejo del sistema. Los CMS se refieren a los gastos que se originan como consecuencia de los servicios prestados con el riego. Los CMS incluyen: coste de personal relacionado con el riego (CP), coste de mantenimiento (CM), coste energético (CEN), costes de gestión de la sociedad (CGS), costes de la Junta Central de Regantes (CJC) y otros costes diversos (OC). CMS se expresa como un valor anual al final de cada campaña.

Gastos generales. Este grupo está relacionado con los gastos necesarios para el funcionamiento de la sociedad, constituido por los CP (costes de personal), CM (costes de mantenimiento), CGS (costes de gestión de la sociedad) y OC (otros costes diversos), calculado como un valor anual al final de la campaña: $\mathrm{GG}=\mathrm{CP}$ $+\mathrm{CM}+\mathrm{CGS}+\mathrm{OC}$

Son los costes de personal.

Son los costes de mantenimiento de la infraestructura de la CCRR.

Incluyen el coste de energía (facturada) empleada para el bombeo del agua, y para dar presión a la red de riego. En las CCRRs de estudio, corresponden a los costes de la energía utilizada para la captación y bombeo del agua, incluyendo los derivados de las captaciones, así como el rebombeo, desde los embalses de almacenamiento.

Ingresos totales anuales de la CCRR

Son los pagos que hacen los regantes a la CCRR. Se incluye el pago por el agua suministrada como otras cuotas.

Son las inversiones realizadas en los últimos 10 años

Número de trabajadores totales de la CCRR Precio del agua (valor medio ponderado pagado por el agricultor)

$\mathrm{Sr} / \mathrm{NP}$

\section{$100 \cdot \mathrm{Rb} / \mathrm{CMS}$}

Proporción de recuperación de los costes de la explotación.

$€ \mathrm{~m}-3 \quad$ Financieros

CMS/Vs

$€$ ha-1 Financieros $\quad$ CMS/Sr

$€ \mathrm{~m}^{-3} \quad$ Financieros $\quad$ GG/Vs

$€$ ha $^{-1} \quad$ Financieros $\quad$ GG/Sr

$€ \mathrm{~m}^{-3} \quad$ Financieros $\quad$ CP/Vs

$€$ ha $^{-1} \quad$ Financieros $\quad \mathrm{CP} / \mathrm{Sr}$

$€ \mathrm{~m}^{-3} \quad$ Financieros $\quad \mathrm{CM} / \mathrm{Vs}$

$€$ ha $^{-1} \quad$ Financieros $\quad \mathrm{CM} / \mathrm{Sr}$ 


\begin{tabular}{|c|c|c|c|}
\hline $\begin{array}{l}\text { Coste energético por unidad } \\
\text { de agua de riego suministrada } \\
\text { (CENVs) } \\
\text { Coste energético por unidad } \\
\text { de área regada (CENSr) }\end{array}$ & $€$ ha $^{-1}$ & Financieros & CEN/Vs \\
\hline $\begin{array}{l}\text { Valor producción agrícola } \\
\text { (VP) }\end{array}$ & $€$ & $\begin{array}{l}\text { De eficiencia de } \\
\text { producción }\end{array}$ & $\begin{array}{l}\text { Valor total de la producción agrícola. } \\
\text { Cantidad total que reciben los agricultores } \\
\text { por la venta de la producción de las } \\
\text { cosechas, dependiendo de los precios de } \\
\text { mercado de cada cultivo. }\end{array}$ \\
\hline Margen bruto (MB) & $€$ & $\begin{array}{l}\text { De eficiencia de } \\
\text { producción }\end{array}$ & $\begin{array}{l}\text { Valor de la producción bruta agrícola (VP) } \\
\text { del que se deducen determinados costes } \\
\text { globales generados por la producción } \\
\text { agrícola. }\end{array}$ \\
\hline $\begin{array}{l}\text { Valor producción agrícola por } \\
\text { unidad de agua demandada } \\
\text { por los cultivos (VPETc) }\end{array}$ & $€ \mathrm{~m}^{-3}$ & $\begin{array}{l}\text { De eficiencia de } \\
\text { producción }\end{array}$ & $\mathrm{VP} / \mathrm{ETc}$ \\
\hline $\begin{array}{l}\text { Valor producción agrícola por } \\
\text { unidad de agua de riego } \\
\text { suministrada (VPVs) }\end{array}$ & $€ \mathrm{~m}^{-3}$ & $\begin{array}{l}\text { De eficiencia de } \\
\text { producción }\end{array}$ & $\mathrm{VP} / \mathrm{Vs}$ \\
\hline $\begin{array}{l}\text { Valor producción agrícola por } \\
\text { unidad de superficie regada } \\
\text { (VPSr) }\end{array}$ & $€$ ha $^{-1}$ & $\begin{array}{l}\text { De eficiencia de } \\
\text { producción }\end{array}$ & $\mathrm{VP} / \mathrm{Sr}$ \\
\hline $\begin{array}{l}\text { Margen bruto por unidad de } \\
\text { agua demandada por los } \\
\text { cultivos (MBETc) }\end{array}$ & $€ \mathrm{~m}^{-3}$ & $\begin{array}{l}\text { De eficiencia de } \\
\text { producción }\end{array}$ & $\mathrm{MB} / \mathrm{ETc}$ \\
\hline $\begin{array}{l}\text { Margen bruto por unidad de } \\
\text { agua de riego suministrada } \\
\text { (MBVs) }\end{array}$ & $€ \mathrm{~m}^{-3}$ & $\begin{array}{l}\text { De eficiencia de } \\
\text { producción }\end{array}$ & $\mathrm{MB} / \mathrm{Vs}$ \\
\hline $\begin{array}{l}\text { Margen bruto por unidad de } \\
\text { superficie regada (MBSr) }\end{array}$ & $€$ ha $^{-1}$ & $\begin{array}{l}\text { De eficiencia de } \\
\text { producción }\end{array}$ & $\mathrm{MB} / \mathrm{Sr}$ \\
\hline Potencia Contratada (Nc) & $\mathrm{kW}$ & Energéticos & $\begin{array}{l}\text { Es la potencia total contratada por la } \\
\text { CCRR. }\end{array}$ \\
\hline $\begin{array}{l}\text { Energía activa consumida } \\
\text { (Eac) }\end{array}$ & $\mathrm{kWh}$ & Energéticos & $\begin{array}{l}\text { Es la energía activa (facturada) consumida } \\
\text { para la distribución del riego. }\end{array}$ \\
\hline $\begin{array}{l}\text { Energía reactiva consumida } \\
\text { (Ear) }\end{array}$ & VAr & Energéticos & $\begin{array}{l}\text { Es la energía reactiva (facturada) } \\
\text { consumida para la distribución del riego. }\end{array}$ \\
\hline $\begin{array}{l}\text { Potencia Contratada por } \\
\text { unidad de área regada (NcSr) }\end{array}$ & $\mathrm{kW} \mathrm{ha}^{-1}$ & Energéticos & $\mathrm{Nc} / \mathrm{Sr}$ \\
\hline Energía específica (EacVs) & $\mathrm{kWh} \mathrm{m}^{-3}$ & Energéticos & $\mathrm{Eac} / \mathrm{Vs}$ \\
\hline $\begin{array}{l}\text { Energía activa consumida por } \\
\text { unidad de superficie regada } \\
\text { (EacSr) }\end{array}$ & $\mathrm{kWh} \mathrm{ha}^{-1}$ & Energéticos & $\mathrm{Eac} / \mathrm{Sr}$ \\
\hline $\begin{array}{l}\text { Energía reactiva consumida } \\
\text { por unidad de volumen } \\
\text { suministrado (EarVs) }\end{array}$ & VAr $\mathrm{m}^{-3}$ & Energéticos & Ear/Vs \\
\hline $\begin{array}{l}\text { Energía reactiva consumida } \\
\text { por unidad de superficie } \\
\text { regada (EarSr) }\end{array}$ & VAr ha ${ }^{-1}$ & Energéticos & $\mathrm{Ear} / \mathrm{Sr}$ \\
\hline $\begin{array}{l}\text { Unidad de fertilizante de } \\
\text { nitrógeno (UFN) }\end{array}$ & UF & Medioambientales & $\begin{array}{l}\text { Unidades de fertilizante de nitrógeno } \\
\text { consumidas en la zona regable }\end{array}$ \\
\hline Conductividad Eléctrica (CE) & $\mathrm{dS} \mathrm{m} \mathrm{m}^{-1}$ & Medioambientales & Conductividad eléctrica del agua de riego \\
\hline $\begin{array}{l}\text { Relación de adsorción del } \\
\text { sodio (RAS) }\end{array}$ & $\mathrm{mmol} \mathrm{l}^{-1}$ & Medioambientales & Relación de adsorción del sodio \\
\hline $\begin{array}{l}\text { Unidad de fertilizante de } \\
\text { nitrógeno por unidad de agua } \\
\text { suministrada (UFNVs) }\end{array}$ & $\mathrm{UF}^{-3}$ & Medioambientales & UFN/Vs \\
\hline $\begin{array}{l}\text { Unidad de fertilizante de } \\
\text { nitrógeno por unidad de } \\
\text { superficie regada (UFNSr) }\end{array}$ & $\mathrm{UF} \mathrm{ha}^{-1}$ & Medioambientales & $\mathrm{UFN} / \mathrm{Sr}$ \\
\hline
\end{tabular}




\subsubsection{Aplicaciones del benchmarking en los regadíos}

En este apartado se relacionan algunos programas y estudios del regadío realizados mediante la técnica de benchmarking.

A nivel mundial destacan las siguientes aplicaciones:

- Australian National Committee on Irrigation and Drainage (ANCID) fue pionera en empleo del benchmarking, su primer informe fue para la campaña de riego 1997-98. El objetivo pretendido con esta metodología era el manejo de los recursos de manera sostenible a tres niveles (ambiental, económico y social), a través del empleo de las mejores prácticas. Los indicadores desarrollados por esta iniciativa se centraron en los suministradores de agua de riego a zonas regables (Malano et al., 2004; Córcoles, 2009).

- El Proceso De Evaluación Rápido (RAP) es empleado para el diagnóstico de proyectos internacionales (Burt, 2001). Esta herramienta ha sido desarrollada por Food and Agricultural Organisation (FAO) y Irrigation Training and Research Center (ITRC) of California Polytechnic State University. Se define como un proceso de recolección y análisis de datos, que dura entre 12 semanas, incluidos los trabajos de oficina y campo. Provee un examen sistemático de las infraestructuras y procesos usados para el transporte y distribución del agua a todos los niveles dentro del proyecto (desde la fuente hasta las parcelas). Se desarrollan una serie de indicadores para tener: (i) una línea base de información para ser comparada contra los resultados futuros después de la modernización, (ii) el Patrón de Referencia para la comparación entre proyectos de riego, y (iii) una base para realizar recomendaciones específicas para la modernización y la mejora del servicio de distribución del agua. 
- Benchmarking de sistemas de riego y drenaje es una iniciativa internacional conjunta entre el Banco Mundial, International Program for Technology and Research in Irrigation and Drainage (IPTRID), International Commission on Irrigation and Drainage (ICID), International Water Management Institute (IWMI), y por la FAO. A partir de esta iniciativa surgió la guía realizada por Malano y Burton (2001), que es utilizada como referencia para la aplicación de las técnicas de benchmarking en el regadío.

- Cropcheck: Modelo participativo de agricultores de benchmarking para mejorar la productividad (Lacy, 2011). Este programa de benchmarking, que se está aplicando en Australia, identifica las mejores prácticas de las explotaciones agrícolas relacionadas con los altos rendimientos de los cultivos agrícolas, consiguiendo un aumento de la rentabilidad agrícola.

- Mapa global de benchmark de la productividad del agua para el trigo (Zwart et al, 2010). El modelo de productividad de agua para trigo realizado mediante teledetección empezó a aplicarse a principios de este siglo, y en él se pretende una comprensión completa de los patrones espaciales por país o Cuenca hidrográfica, como sistema de apoyo a la decisión y de qué medidas tomar para hacer más productiva el agua en la agricultura.

En España destacan las siguientes aplicaciones de esta técnica en el estudio de CCRRs:

- Rodríguez (2003) realizó un estudio de la gestión del agua de riego y aplicación de las técnicas de benchmarking a las zonas regables de Andalucía, donde se abarca a 9 CCRRs durante los años 1996-2002. Para realizar este estudio empleó la aplicación IGRA (Aplicación de los Indicadores de Gestión en las zonas Regables), esta aplicación es una 
sencilla herramienta para poder aplicar el benchmarking a las CCRR (Rodríguez et al., 2005).

- Córcoles (2009) estudió la gestión del agua y la energía en el regadio mediante técnicas de benchmarking, donde analizó 7 CCRRs de Castilla-La Mancha durante el periodo 2006-2008 (Córcoles et al., 2010).

○ Melián-Navarro et al. (2010) aplicaron los indicadores de benchmarking para comparar dos CCRRs de Sudeste español con dos CCRR de la zona de Beira Interior en Portugal.

- El estudio comparativo sobre las medidas de ahorro energético y económico en CCRRs (Abadía et al., 2010), en el mismo se analizaron desde un punto de vista energético a 22 CCRRs, 15 de Castilla-La Mancha, 2 de la Región de Murcia y 5 al sur de la Comunidad Valenciana.

\subsubsection{Indicadores de gestión del regadío de la Región de Murcia}

En este subapartado se caracteriza el regadío de la Región de Murcia (Tabla 2.4) mediante indicadores de gestión. Los mismos se describen en el Epígrafe 2.4.3. Los valores económicos incluidos en su definición han sido actualizados a 2011 mediante el IPC para su análisis comparativo.

En el año 2011 la superficie regable (Sa) fue de 187.064 ha, lo que representó respecto a 2002 una reducción del 3,5\%, de esta superficie el 50,9\% estaba dedicada a cultivos leñosos, el 27,8\% a cultivos herbáceos y 21,3\% restante se encontraba en barbecho o no se cultivaba (ECONET, 2013). 
Tabla 2.4. Principales indicadores de gestión del regadío de la Región de Murcia durante el periodo 2002-11. Elaboración propia (ESYRCE, 2011; INE, 2012; CARM, 2013).

\begin{tabular}{|c|c|c|c|c|}
\hline Indicador de gestión & Medio & Máximo & Mínimo & $\begin{array}{l}\text { Desviación } \\
\text { Estándar }(\sigma)\end{array}$ \\
\hline Superficie regable $(\mathrm{Sa} ; \mathrm{ha})$ & 189.965 & 193.907 & 187.064 & 2.902 \\
\hline Superficie regada (Sr; ha) & 158.453 & 167.128 & 153.456 & 4.692 \\
\hline Intensidad de cultivo ( $\mathrm{SrSa}, \%$ ) & 83,4 & 86,2 & 81,4 & 1,33 \\
\hline Volumen suministrado $\left(\mathrm{Vs} ; \mathrm{hm}^{3}\right)^{\mathrm{a}}$ & 554,835 & 619,518 & 507,840 & 39,955 \\
\hline $\begin{array}{l}\text { Suministro de agua por unidad de área regada ( } \mathrm{VsSr} \\
\left.\mathrm{m}^{3} \mathrm{ha}^{-1}\right)^{\mathrm{a}}\end{array}$ & 3.490 & 3.809 & 3.283 & 182 \\
\hline Valor producción agrícola (VP; M€) & 1.590 & 2.134 & 1.211 & 276 \\
\hline $\begin{array}{l}\text { Valor producción agrícola por unidad de superficie } \\
\text { regada (VPSr; } € \mathrm{ha}^{-1} \text { ) }\end{array}$ & 10.008 & 13.067 & 7.838 & 1.533 \\
\hline $\begin{array}{l}\text { Valor producción agrícola por unidad de agua de riego } \\
\left.\text { suministrada (VPVs; } € \mathrm{~m}^{-3}\right)^{\mathrm{a}}\end{array}$ & 2,93 & 3,48 & 2,18 & 0,31 \\
\hline
\end{tabular}

La superficie regada (Sr) era en 2011 de 154.541 ha, teniendo una reducción del $7,5 \%$ respecto a 2002 , pero se puede considerar la actividad agrícola estable en la zona tal como muestran las pequeñas variaciones en la intensidad de cultivo (SrSa). En 2011 los 10 cultivos principales de regadío, que representaban un $74,4 \%$ de la superficie regada, fueron: limonero $(14,8 \%)$, melocotonero $(8,9 \%)$, lechuga $(8,8 \%)$, viñedo $(8,7 \%)$, brócoli $(6,9 \%)$, naranjo $(6,4 \%)$, olivar $(6,1 \%)$, albaricoquero $(5,5 \%)$, alcachofa (4,3\%) y almendro (4,1\%) (CARM, 2013). En la Fig. 2.20 se muestra la evolución de la superficie regada para el periodo 2002-11 por grupos de cultivos.

En año 2010 el volumen suministrado (Vs) a las explotaciones agrícolas fue de $507,840 \mathrm{hm}^{3}$, lo que representó un 3,2 \% del volumen suministrado en España. Respecto al 2002 se ha producido una reducción del 10,2 \% (INE, 2012). 


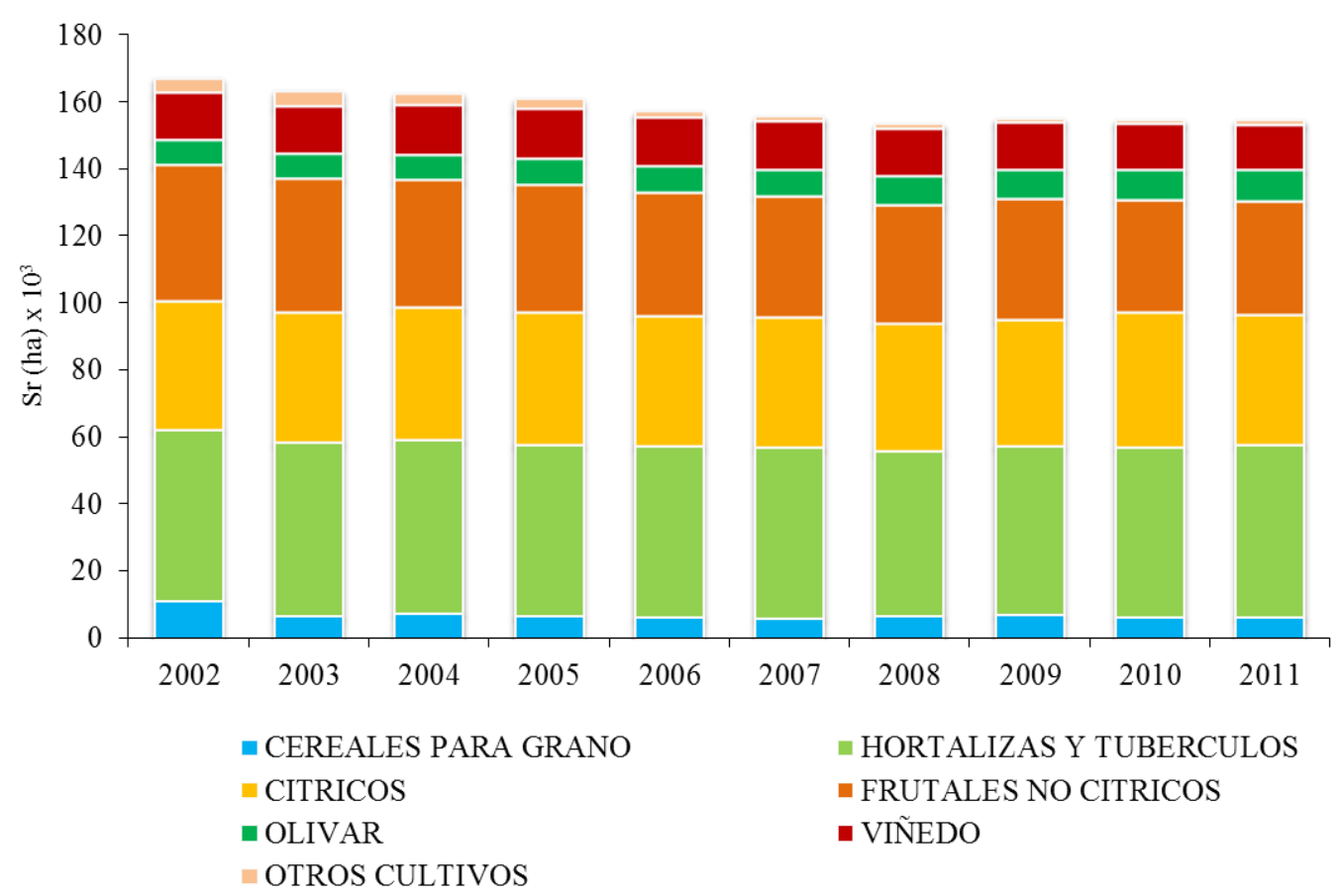

Figura 2.20. Evolución de la superficie regada ( $\mathrm{Sr}$ ) en la Región de Murcia por grupos de cultivos. Elaboración propia (CARM, 2013).

El indicador suministro de agua por unidad de área regada (VsSr) tuvo un valor medio para el periodo $2002-10$ de $3.490 \mathrm{~m}^{3} \mathrm{ha}^{-1}$, siendo un $29,4 \%$ inferior a la media española para ese mismo periodo que fue de $4.943 \mathrm{~m}^{3} \mathrm{ha}^{-1}$. En la Fig. 2.21 se puede ver una comparativa de la evolución de este indicador para la Región de Murcia con la media española (ESYRCE, 2011; INE, 2012; CARM, 2013).

El valor de la producción agrícola (VP) en 2011 fue de 1.211 M€, con un valor medio en el periodo 2002-11 de 1.590 M€ (CARM, 2013). El valor de la producción agrícola sufre gran variación anual debido a la variabilidad de los precios agrícolas. Por importancia destacan las hortalizas y tubérculos, que en el periodo 2002-11 supusieron un 55,7 \% del total de la producción vegetal de la Región de Murcia, seguido de las frutas con un $38,6 \%$. 


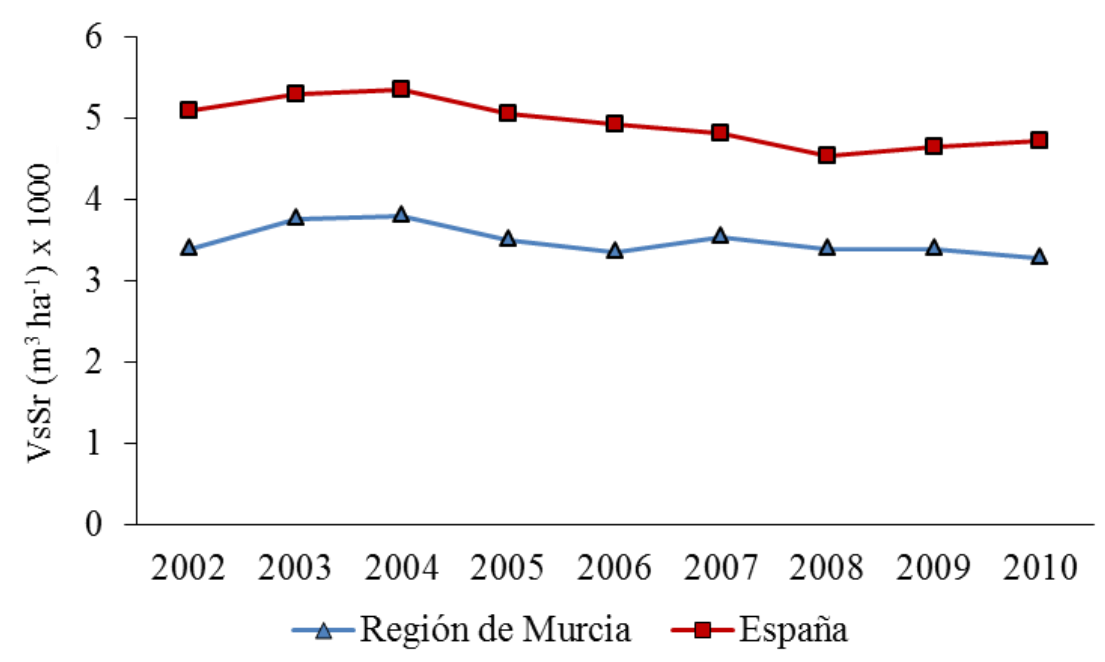

Figura 2.21. Evolución suministro de agua por unidad de área regada (VsSr) en la Región de Murcia y España. Elaboración propia (ESYRCE, 2011; INE, 2012; CARM, 2013).

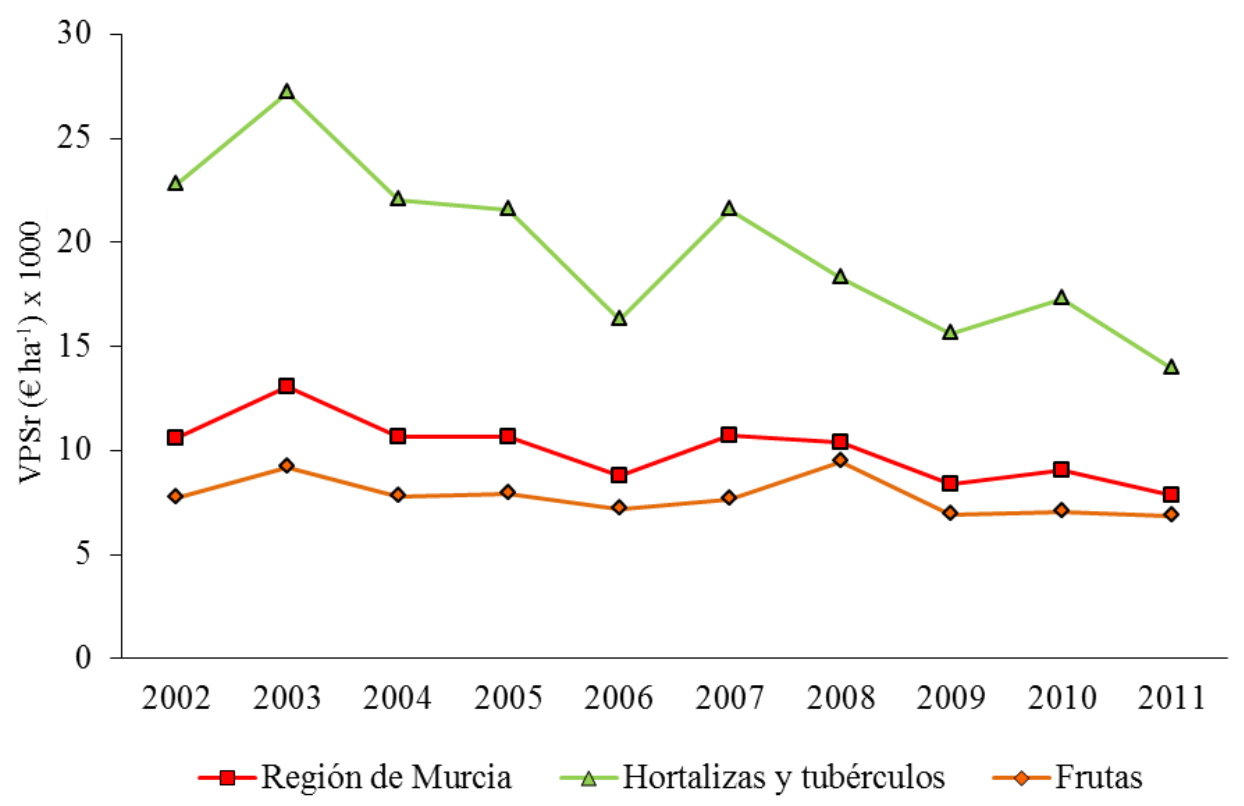

Figura 2.22. Evolución del valor de la producción agrícola por unidad de superficie regada (VPSr) en la Región de Murcia por grupos de cultivos. Elaboración propia (CARM, 2013).

El valor medio de la producción agrícola por unidad de superficie regada (VPSr), en el periodo 2002-2011 fue de $10.008 €$ ha $^{-1}$. Entre el 2002 y el 2011 se produjo una reducción del VPSr del 25,9\%. En la Fig. 2.22 se observa la evolución de VPSr anual medio para la Región de Murcia y los grupos de cultivos más importantes. Los cultivos hortícolas, que incluyen los de invernadero, son los que mayor VPSr 
presentan, con un valor promedio para este periodo de $19.647 € \mathrm{ha}^{-1}$, seguido de las frutas con $7.777 € \mathrm{ha}^{-1}$.

\subsection{ANÁLISIS DE LA RELACIÓN ENTRE EL AGUA Y LA ENERGÍA EN EL REGADÍO}

\subsubsection{Nexo agua-energía}

Tanto el agua como la energía son inputs necesarios para el desarrollo social y económico de cualquier nación, un aumento de las actividades agrícolas e industriales lleva asociado un aumento de la demanda de agua y energía (Jebaraj e Iniyan, 2006). En los últimos años ha aumentado la competencia por el uso del agua, y esta escasez de recursos no solo se está agravando en las regiones áridas y semiáridas, sino también en regiones con abundantes lluvias (Pereira, 2004). Por otro lado la demanda mundial de energía se incrementará en un 55\% hasta el 2030 (IEA, 2007).

Existe una fuerte interrelación entre el agua y la energía. La energía es consumida en muchos procesos relacionados con el uso del agua: (a) en la captación (aguas superficiales y subterráneas); (b) en el transporte y distribución (uso urbano, industrial y agrícola); y (c) en el tratamiento (potabilización, depuración, y desalinización). Por otro lado son muchos los procesos para producir energía que consumen agua. Además de la producción directa de energía en las centrales hidroeléctricas, también se emplea para la refrigeración de las centrales nucleares, de gas, carbón o fuel, y de las plantas termosolares. Esta interrelación se suele denominar como el "nexo agua-energía", y cada vez es más considerada durante los procesos de planificación (Siddiqi y Diaz, 2011; Hardy et al., 2012). Esta constatación de que ambos sectores deben planificarse de manera conjunta y coordinada es muy reciente (Hardy y Garrido, 2010). 
La racionalización conjunta del agua y de la energía está ligada al cambio climático, el ahorro de agua implica ahorro de energía y, por tanto, minimiza la emisión de gases de efecto invernadero (Cabrera, 2011). Además a causa del encarecimiento, la escasez y la contaminación relacionada con la energía, todos los sectores económicos han intensificado sus esfuerzos para mejorar la eficiencia del uso energético.

Dado que la agricultura consume a nivel mundial el $70 \%$ del agua dulce, el uso sostenible de los recursos hídricos y energéticos en el sector agrícola debe ser prioritario, con una gestión eficiente de los sistemas de riego, consiguiendo de esta manera minimizar los problemas ambientales (Kim y Evans, 2009; Kizilaslan, 2009; WWAP, 2012).

En España en 2007 el 7 \% del consumo eléctrico estaba relacionado con el uso del agua (Hardy y Garrido, 2010), siendo el regadío uno de los sectores que ha experimentado un aumento considerable del consumo energético en los últimos años (Carrillo-Cobo et al, 2010; Rodríguez et al., 2011b; Abadía et al., 2012). Hardy y Garrido (2010) estiman que el riego en España tiene un consumo de energía que varía entre $0,28 \mathrm{kWh} \mathrm{m}^{-3}$, cuando solo se considera el gasto de energía en la captación y distribución, y 0,34 $\mathrm{kWh} \mathrm{m}^{-3}$ cuando se tienen en cuenta el tratamiento y transporte. Las variaciones de consumo energético son amplias: un sistema de riego por gravedad y con agua superficial tendrá un consumo energético del orden de $0,02 \mathrm{kWh} \mathrm{m}^{-3}$, mientras que localizado y con aguas subterráneas tendrá un consumo energético del orden de 0,68 $\mathrm{kWh} \mathrm{m}^{-3}$.

Muchas políticas gubernamentales apuestan por la conversión del riego por gravedad al riego presurizado para la reducción del consumo de agua. Sin embargo, esta mejora puede provocar un aumento del consumo energético en los cultivos de regadío (Jackson et al. 2010). La modernización de los regadíos, en la mayoría de CCRRs, ha 
supuesto un aumento del consumo energético, siendo por tanto necesario manejar los recursos agua y energía de una manera más eficiente (Rodríguez et al., 2011a). En España Corominas (2009) indicó que mientras el consumo de agua por hectárea se ha reducido de $8.250 \mathrm{~m}^{3} \mathrm{ha}^{-1}$ a $6500 \mathrm{~m}^{3} \mathrm{ha}^{-1}(21 \%)$ entre 1950 y 2007 , la demanda de energía ha aumentado de $206 \mathrm{kWh} \mathrm{ha}^{-1}$ a $1.560 \mathrm{kWh} \mathrm{ha}^{-1}(657 \%)$.

Debido a este aumento del consumo de energía en las redes colectivas de riego, se está realizando un gran esfuerzo en España por parte de la Administración, centros de investigación, universidades y desde las asociaciones de CCRRs con el objetivo de reducir el consumo energético en el regadío:

- El Plan de Acción 2008-2012 de la Estrategia de Ahorro y Eficiencia Energética propone las auditorías energéticas en las CCRRs. El objetivo general de una auditoria energética es evaluar el consumo energético en la CCRR y proponer medidas que le supongan un incremento de la eficiencia energética, y por tanto, un ahorro energético y económico. Desde la publicación por parte del Instituto para Diversificación y Ahorro de la Energía (IDAE) del Protocolo de Auditorías Energéticas en Comunidades de Regantes (Abadía et al., 2008a), se han realizado numerosas auditorías en distintas zonas regables de España (Abadía et al, 2010; Moreno et al. 2010a). En complemento con las auditorías energéticas, se está llevando a cabo un proceso de formación e información dirigido a técnicos y agricultores, destacando las guías: Ahorro y Eficiencia Energética en Agricultura de Regadío (IDAE, 2005) y Ahorro y Eficiencia Energética en Comunidades de Regantes (Rocamora et al., 2008).

- Los centros de investigación y universidades han publicado numerosos estudios y metodologías, que con su aplicación se pueden alcanzar ahorros 
superiores al 20\%: (a) cálculo de la eficiencia global energética del sistema, considerando el funcionamiento de los grupos de bombeo y la distribución espacial de la red de distribución (Abadía et al., 2008b; Abadía et al., 2012); (b) empleo de Epanet 2.0 (Rossman, 2000) en el análisis de los requerimientos de energía de una red de riego presurizada a la demanda (Rodríguez et al., 2009); (c) agrupamiento de tomas de riego en redes presurizadas reguladas por grupos de bombeo (Jiménez-Bello et al., 2010; Jiménez-Bello et al., 2011); y (d) programación y sectorización de sistemas de distribución por turnos (Carrillo-Cobo et al. 2011).

- Desde la Federación Nacional de Comunidades de Regantes de España se está potenciado el ahorro y la eficiencia energética en el regadío. Destaca el curso de gestor energético en CCRRs, realizado en colaboración con el IDAE, la Universidad Miguel Hernández y una empresa de ingeniería.

En el Capítulo 4 se analiza la relación agua-energía en la zona de estudio.

\subsubsection{Coste de energía}

Uno de los mayores problemas de la agricultura de regadío es el coste energético. Entre 2008 y 2010 las tarifas de energía para el riego en España se han incrementado en un 120\% (Rodríguez et al., 2011a). Debido a la liberalización del mercado eléctrico español en 2008, cuando las tarifas especiales para riego desaparecieron, el regadío pasó a utilizar las mismas tarifas que el resto de sectores. Este hecho le ha perjudicado considerablemente, dado que durante los meses de junio y julio, cuando la demanda de riego es mayor, la mayoría de las horas de funcionamiento se incluyen en el período tarifario más caro (Carrillo-Cobo et al., 2010). Otro factor que le perjudica es que tiene que contratar la máxima potencia que necesita en los meses de 
máxima demanda para todo el año, cuando en muchas CCRRs hay periodos de varios meses donde no riegan. Provocando el incremento de los costes fijos (término de potencia) de la factura eléctrica. Ederra y Murugarren (2010) indican que se ha producido un incremento medio del 82\% en el coste energético entre 2005 y 2009 en CCRRs modernizadas en Navarra.

Moreno et al. (2010a) concluyen, después de analizar las medidas de ahorro de energía para 15 CCRRs, que el ahorro económico estimado puede ser mayor que el ahorro de energía debido principalmente a la contratación óptima de las tarifas eléctricas. Bescós et al. (2008) indican que el hecho de diseñar las redes de riego a la demanda utilizando las horas punta con el objeto de reducir la potencia instalada y por tanto el coste del término de potencia, no compensa la penalización del $70 \%$ en el término de energía que supone el utilizar las horas más caras en cuanto al término de energía. Por otro lado Pulido et al., (2006) llegan a la conclusión que la presencia de un depósito de regulación en un sistema de impulsión permite independizar los caudales bombeados de la variabilidad del uso del agua en la red de distribución. De este modo el depósito permite la reducción de los costes energéticos, al poder adaptar el funcionamiento de los grupos de bombeo al tipo de discriminación horaria de las tarifas eléctricas, y al poder conseguir un funcionamiento más regular de las estaciones de bombeo en comparación con la impulsión directa a la red de distribución, aunque esta última opción sea más eficiente desde un punto de vista energético.

Un seguimiento de las instalaciones también es importante para conseguir una disminución de los costes energéticos, dado que una desviación de las condiciones óptimas de manejo, puede producir un aumento del consumo de energía. Este incremento en el consumo rara vez se estima debido a la falta de control en muchas 
CCRRs (Luc et al., 2006). También se aumenta el ahorro con un mantenimiento apropiado y el uso de variadores de frecuencia (Lamaddalena y Khila 2012).

Por lo tanto el coste energético de las CCRRs va a depender del tipo de tarifa contratada, el diseño, el manejo y estado de las infraestructuras para la distribución del agua. De ahí la importancia de realizar auditorías energéticas en las CCRRs y llevar un seguimiento permanente de las instalaciones mediante indicadores energéticos.

\subsection{LA MODERNIZACIÓN DE LOS REGADÍOS}

La FAO (1997) define la modernización de los regadíos como "un proceso de mejora técnica y de gestión (en oposición a la mera rehabilitación) de los sistemas de riego con el objetivo de mejorar la utilización de los recursos (mano de obra, agua, economía, medio ambiente) y el suministro del agua a las explotaciones agrícolas".

\subsubsection{Plan Nacional de Regadíos}

Con la Directiva 2000/60/CE del Parlamento Europeo y del Consejo, de 23 de octubre, conocida como Directiva Marco del Agua, se incluyen criterios medioambientales en la gestión y regulación de los recursos hídricos, la protección de los mismos ante la contaminación, así como la conservación del medioambiente y de la biodiversidad. La Directiva Marco del Agua establece un marco comunitario de protección y gestión de las masas de agua y fija el año 2015 como fecha para alcanzar el objetivo de conseguir un buen estado ecológico de las mismas. La política española en el ámbito del regadío se adecuó a estas normas y le dio un nuevo enfoque al Plan Nacional de Regadíos (PNR), más en consonancia con las nuevas sensibilidades sociales y ambientales. 
Por lo expuesto, a principios del siglo XXI se impulsa una nueva orientación en la gestión del agua, basado en la garantía de su disponibilidad y calidad, en su gestión eficiente y sostenible, en la potenciación de la regeneración y reutilización, en la obtención de nuevos recursos, en la modernización de regadíos, y en el fomento de la investigación y la incorporación de las nuevas tecnologías. Para aplicar estas nuevas políticas, la Administración del Estado ha llevado a cabo las siguientes acciones de planificación en la última década:

○ El PNR Horizonte 2008 (MAGRAMA, 2013) cuyo objetivo principal es: "racionalizar el uso del agua en todas las zonas regables españolas, nuevas o antiguas, armonizando los objetivos de la política del agua con la mejora en las condiciones de vida de los regantes, el desarrollo rural y el aumento de su competitividad en los mercados agrarios”.

- Plan de Choque (PCH) de Modernización de Regadíos 2006-2008 (MAGRAMA, 2013) destinado a: "garantizar una mejor gestión de los recursos hídricos y a paliar los daños producidos por la sequía padecida en los años 2004 y 2005. Este Plan, refuerzo del PNR, consiguió la mejora y consolidación de una superficie de 866.898 hectáreas y supuso un ahorro anual de $1.162 \mathrm{hm}^{3}$ en el consumo de agua”.

○ La Estrategia Nacional para la Modernización Sostenible de los Regadíos Horizonte 2015 (MAGRAMA, 2013) cuyos objetivos son: "el ahorro de agua, la transferencia de tecnología, el fomento de la utilización de recursos hídricos alternativos, la eficiencia energética, la mejora de la renta agraria, la creación de puestos de trabajo adicionales y, en general, el fomento de la sostenibilidad del regadio español”. 
La mejora y consolidación de los regadíos afectados por estas actuaciones, en el ámbito del PNR y del PCH representa casi el $90 \%$ de la superficie total contemplada en la planificación, y una inversión de más del 80 \% del total, reflejados en la Tabla 2.5.

Tabla 2.5. Actuaciones en el ámbito del PNR y PCH (MAGRAMA, 2013).

\begin{tabular}{lrrrrr} 
& \multicolumn{4}{c}{ Ejecución PNR y PCH: Periodo 2000-2008 } \\
\cline { 2 - 6 } & \multicolumn{3}{c}{ Superficie ejecutada } & \multicolumn{2}{c}{ Inversión comprometida } \\
& \multicolumn{1}{c}{ (ha) } & \multicolumn{1}{c}{$(\%)$} & \multicolumn{1}{c}{$(€)$} & $(\%)$ \\
\hline Mejora y consolidación & 895.097 & 88,8 & 2.463 .652 .691 & 84,1 \\
Regadíos en ejecución & 103.836 & 10,3 & 355.495 .755 & 12,1 \\
Regadíos sociales & 3.429 & 0,3 & 19.957 .404 & 0,7 \\
Regadíos privados & 6.196 & 0,6 & 22.996 .998 & 0,8 \\
Programas de apoyo & - & - & 67.394 .720 & 2,3 \\
\hline Total & $\mathbf{1 . 0 0 8 . 5 5 8}$ & 100 & $\mathbf{2 . 9 2 9 . 4 9 7 . 5 6 8}$ & 100 \\
\hline
\end{tabular}

Estas actuaciones distribuidas por todo el territorio nacional han consistido principalmente en la modernización de infraestructuras de transporte y distribución del agua de riego, así como en los sistemas de aplicación de agua en parcela. De esta forma los esfuerzos de la planificación se han destinado principalmente a la sustitución de las redes de conducciones abiertas por tuberías a presión, con el fin de disminuir las pérdidas en los sistemas de distribución y conseguir un ahorro de agua. También se han implantado las tecnologías de la información y la comunicación (TICs) al medio rural y a la gestión del regadío (MAGRAMA, 2013).

Unos pocos estudios han analizado la situación antes y después de los procesos de modernización. Por ejemplo, los efectos de la modernización son evaluados por Rodríguez et al. (2011a) en una CCRR típica de Andalucía, llegando a las siguientes conclusiones: (a) la cantidad de agua destinada para el riego de las parcelas se redujo; (b) los costes de operación y mantenimiento del sistema aumentaron considerablemente; y (c) la energía requerida para bombear el agua a la red de presión es muy superior en comparación con la situación anterior. 
2.6.2. Aplicación de las TICs en la gestión de las comunidades de regantes

La aplicación de las TICs ofrece muchas oportunidades a los gestores de las CCRRs, dado que pueden contar con diferentes herramientas para optimizar la distribución de agua, prestando un mejor servicio a sus regantes: sistemas de supervisión y adquisición de datos (SCADA), sistemas de soporte a la decisión (SSD), sistemas de información geográfica (GIS), y aplicaciones Web y para telefonía móvil.

El SCADA realiza el telecontrol y monitorización de la red de riego. El sistema permite llevar la información hacia y desde los elementos de operación hasta el centro de control, realizando el análisis y control necesarios sobre los diferentes elementos, y transmitiendo las acciones requeridas para el control de procesos (Bailey y Wright, 2003; Burt y Anderson, 2005). Los sistemas de telecontrol mediante comunicación vía radio han proporcionado oportunidades para implementar la comunicación inalámbrica de datos en la agricultura (Lee et al., 2002; Oksanen et al., 2004; Zhang, 2004). Las ventajas principales de utilizar sensores inalámbricos es la reducción de los costes de cableado y la facilidad de su instalación y mantenimiento (Dursun y Ozden, 2012).

Los SSD son herramientas potentes para la ayuda a la gestión. Integran datos, modelos matemáticos y el conocimiento del usuario, por lo que permite la simulación de un gran número de soluciones alternativas al considerar el efecto de los factores más relevantes introducidos al sistema (Zazueta et al., 2006; Richards et al., 2008). La aplicación de los SSD en la gestión de riego se inició a principios de los años 90, siendo de gran utilidad, ya que permite la consideración conjunta del riego, de la hidráulica y de los criterios económicos (Gonçalves y Pereira, 2009; Xu et al., 2011).

Particularmente relevante para la gestión de las CCRRs son los GIS, debido a la gran cantidad de datos espaciales georreferenciados que manejan. Un GIS integra hardware, software y los datos disponibles en el sistema; manejando, analizando y 
mostrando toda la información espacial (Pavan et al., 2011). El WebGIS permite a los usuarios no especializados la rápida generación de mapas temáticos y consultas gráficas (Serrano et al., 2008). Estas aplicaciones presentan un gran potencial para compartir datos, proporcionando un fácil acceso a los usuarios con conocimientos limitados de los GIS; y recopilando datos e información personalizada por temas específicos, apoyando la toma de decisiones (Nelson, 2002; Mathiyalagan et al., 2005; Orellana et al., 2011).

La disponibilidad del uso de Internet en diferentes dispositivos electrónicos (PC, Tablet, Smartphone, y Smart TV) y el sencillo manejo de las diferentes aplicaciones Web está permitiendo establecer nuevos canales de comunicación para el uso de los servicios de las CCRRs, tanto para el personal de la misma como para los agricultores.

\subsubsection{Modernización de regadíos en la Región de Murcia}

Desde que en 1985 la Comunidad Autónoma de la Región de Murcia asumió las competencias en materia de reforma y desarrollo agrario, se centraron sus acciones en las mejoras de las infraestructuras del regadío. En 1992 la Consejería de Agricultura y Agua realizó un breve estudio para determinar las deficiencias de las infraestructuras agrarias en la Región de Murcia. Como resultado se estableció como una tarea preferente la modernización del regadío, con el fin de conseguir su consolidación dada la carencia de agua existente.

De esta manera se impulsa, promueve y financia la modernización del regadío, basada en: (a) la mejora de infraestructuras; (b) la instalación de sistemas de telecontrol; (c) la innovación y desarrollo a través de los centros de investigación y universidades; y (d) la formación y asesoramiento al agricultor. La participación de la Administración ha sido muy importante en las políticas de mejora, consolidación y modernización del 
regadío en la Región, tanto a nivel CCRR como a nivel parcela, mediante la firma de convenios entre los regantes y las administraciones, y la concesión de ayudas:

- Convenios realizados en el marco del PNR. La mayor parte de todas estas actuaciones se ha realizado bajo la forma jurídica de un convenio firmado entre las administraciones y las CCRRs. El acuerdo de financiación ha sido de la siguiente manera: del $100 \%$ de la inversión prevista, la Consejería de Agricultura y Agua realiza un 25\%; del $75 \%$ restante, el $29 \%$ los asumen las CCRRs y el resto lo financia y lo ejecuta una sociedad de infraestructuras agrarias (SEIASA) a la que los regantes devolverán la inversión en veinticinco años. De esta última parte no hay que devolver la totalidad cuando exista una aportación de fondos europeos FEOGA (Gómez et al, 2011).

- Concesión de las ayudas para la mejora, modernización y consolidación de los regadíos. Este tipo de ayudas suele ser anual y su procedimiento de concesión se tramita en régimen de concurrencia competitiva, estando destinada a las CCRRs. La ayuda puede llegar hasta el 50\% de la inversión realizada, fomentando: (a) la instalación de dispositivos para medir y registrar el volumen distribuido, (b) la automatización de la red de riego, (c) la informatización de la gestión. Incluso puede llegar al $60 \%$ cuando se cubren las balsas de riego para evitar la evaporación del agua.

- Concesión de ayudas para el aprovechamiento en regadío de las aguas residuales regeneradas procedentes de las Estaciones Depuradoras. Este tipo de ayudas suele ser anual y el procedimiento de concesión de las ayudas se tramita en régimen de concurrencia competitiva, estando destinada a las CCRRs. La ayuda puede llegar hasta el 70\% de la inversión realizada. La finalidad es la 
consolidación de los regadíos de la Región de Murcia mediante la incorporación de nuevos recursos procedentes de las EDARs de dicho ámbito territorial.

- Ayudas a la modernización de explotaciones agrarias. Estas ayudas van dirigidas directamente a los agricultores. En lo referente al riego, potencian la instalación de sistemas de riego que permitan un uso más eficiente del agua y la energía, de manera que, además, permitan utilizar aguas de riego de mediana calidad. La ayuda corresponderá al $40 \%$ de la inversión, aumentando a un 50\% si se efectúan en zonas desfavorecidas, y se incrementan un $10 \%$ cuando se trate de un joven agricultor.

Para mejorar la aplicación del agua a nivel parcela el Instituto Murciano de Investigación y Desarrollo Agrario y Alimentario (IMIDA) ofrece el servicio de asesoramiento de riego a través de su página Web (SIAM, 2013).

Todas estas medidas han convertido a la Región en un laboratorio de experiencias de modernización de regadíos (Gil, 2010), donde se encuentran involucrados la Administración del Estado, la Administración Regional, los centros de investigación, las universidades, las CCRRs y los agricultores. Esta colaboración ha conseguido que la Región de Murcia sea un referente en cuanto a la gestión del agua; y que la técnica de riego más empleada sea el localizado con un 79\%, la Región de Murcia es la comunidad autónoma con una mayor superficie que emplea este tipo de riego, seguida de Andalucía con un 74,7\%, siendo la media nacional de un $47,7 \%$ (ESYRCE, 2011). Como ejemplo de esta colaboración se puede citar la participación de la CRCC en diferentes proyectos europeos, siendo su última implicación como socio en el proyecto europeo "Rural Water Management Demonstrators at Smart Regions", donde participan 25 organizaciones de 11 países. 
En el Capítulo 6 se analizan los efectos de la modernización en la zona de estudio. 



\section{Capítulo 3}

\section{CARACTERIZACIÓN DE LAS COMUNIDADES DE REGANTES DE LA REGIÓN DE MURCIA}

En el presente Capítulo se caracterizan los regadíos de la Región de Murcia mediante la comparación de los indicadores de gestión y el análisis de su evolución en las comunidades de regantes seleccionadas.

Se pretende definir los valores característicos de los indicadores de gestión en la zona de estudio, para que sirvan de referencia a los gestores en otras zonas regables en futuros trabajos que apliquen estas técnicas. Este Capítulo representa un complemento a los estudios previos realizados por varios autores en otras regiones españolas, pretendiendo aportar la información correspondiente de los regadíos de la Región de Murcia a la visión general de la situación del regadío en España, que se está obteniendo mediante la aplicación de técnicas de benchmarking.

\subsection{INTRODUCCIÓN}

Muchos países en todo el mundo tienen transferidas la distribución del agua a organizaciones de usuarios, en España se encargan las comunidades de regantes (CCRRs), tal como se ha descrito en el Capítulo 2. En la Región de Murcia la gestión eficiente de los recursos hídricos, por parte de estos organismos, se considera fundamental para amortiguar los efectos desestabilizadores que sobre la renta y el empleo agrario provoca la escasez estructural de agua (Arcas y Alcón, 2007).

Para conseguir mejoras en la gestión y la eficiencia del uso del agua en las CCRRs es importante el desarrollo de herramientas que evalúen el funcionamiento de las mismas, siendo el benchmarking una herramienta adecuada para este fin (Malano y Burton, 2001; Malano et al., 2004; Rodríguez et al., 2008; Córcoles et al., 2010). 
En España destacan los estudios previos realizados, mediante esta técnica, por Rodríguez (2003) y Córcoles (2009). Rodríguez (2003) aplicó las técnicas de benchmarking para analizar la gestión del agua en 9 CCRRs de Andalucía durante los años 1996-2002. Mientras que Córcoles (2009) aplicó estas técnicas en el estudio de la gestión del agua y la energía en el regadío de 7 CCRRs de Castilla-La Mancha durante el periodo 2006-2008. También cabe destacar el estudio comparativo sobre las medidas de ahorro energético y económico en CCRRs (Abadía et al., 2010), en el mismo se analizaron desde un punto de vista energético 22 CCRRs: 15 de Castilla-La Mancha, 2 de la Región de Murcia y 5 al sur de la Comunidad Valenciana.

Con el análisis de los indicadores de gestión, mediante su comparación a lo largo del tiempo, se puede mejorar el conocimiento sobre el efecto de los procesos o circunstancias específicas que le suceden a las CCRRs, así como detectar los puntos donde pueden mejorar su gestión.

\subsection{METODOLOGÍA}

La metodología para llevar a cabo este estudio se ha estructurado en varias fases. En primer lugar se seleccionaron un conjunto adecuado de indicadores de gestión para poder caracterizar las CCRRs seleccionadas: Comunidad de Regantes del Campo de Cartagena (CRCC), Comunidad de Regantes de Lorca (CRLO), Comunidad de Regantes del Trasvase Tajo Segura Calasparra-Cieza (CRTCC), Comunidad de Regantes Pantano de la Cierva (CRPC) y Comunidad de Regantes de Miraflores (CRM).

A continuación, el valor de estos indicadores fue calculado para el período de los 10 años analizado (2002-2011). Para ello fue necesario obtener datos de los gestores y de las bases de datos de las CCRRs seleccionadas. 
Para poder comparar los resultados de los indicadores seleccionados, se realizó una revisión bibliográfica de los estudios publicados sobre CCRRs españolas con red de distribución presurizada.

\subsubsection{Indicadores de gestión aplicados}

Los indicadores de gestión describen una gran variedad de procesos del riego a través de las variables relacionadas, de tal manera que una gran cantidad de información se reduce a un solo índice. Los indicadores seleccionados deben ser: (i) fáciles de obtener a partir de datos recogidos de manera sistemática en la CCRR, (ii) en su mayoría orientados hacia los aspectos relacionados con la gestión de la CCRR, y (iii) adecuados para el propósito de cada estudio específico.

Numerosos trabajos han propuesto y aplicado indicadores de gestión en numerosas partes del mundo (Fernández et al., 2007; Kazbekov et al., 2009; Zwart et al., 2010; Awan et al., 2011; Montoro et al., 2011; Pereira et al., 2012; Borgia et al., 2013) en la medida de la eficacia y sostenibilidad de la agricultura de regadío, pero muy pocos los han aplicado a periodos tan prolongados como es nuestro caso.

Los indicadores de gestión de benchmarking empleados en el presente estudio, tal como se ha indicado en el Capítulo 2, se basan en la propuesta del "International Program for Technology and Research on Irrigation and Drainage” IPTRID (Malano y Burton, 2001), considerando otros indicadores adicionales propuestos por autores que han aplicado previamente técnicas de benchmarking en España (Rodríguez, 2003; Córcoles, 2009; Abadía et al., 2010).

En la Tabla 2.3 del Capítulo 2 se relacionan todos los indicadores empleados, a excepción de los indicadores ambientales. Los indicadores ambientales quedaron excluidos del estudio, debido a que no se suele realizar ningún tipo de medida de ellos 
en las CCRRs, y no fue posible conseguir de otras fuentes datos fiables para poder calcularlos durante el periodo de estudio; por lo general este tipo de indicadores presentan una alta incertidumbre (Córcoles, 2010). Por otro lado, los indicadores energéticos son analizados en el Capítulo 4.

\subsubsection{Comunidades de regantes seleccionadas}

Las cinco CCRRs (CRCC, CRLO, CRTCC, CRPC y CRM) seleccionadas (Tabla 3.1), descritas en el Capítulo 2, representaban en 2011 el 38,5\% del total de la superficie regable de la Región de Murcia.

Tabla 3.1. Principales características de las CCRRs analizadas en el periodo 2002-11.

\begin{tabular}{|c|c|c|c|c|c|}
\hline & \multicolumn{5}{|c|}{ Comunidades de regantes } \\
\hline & CRCC & CRLO & CRTCC & CRPC & CRM \\
\hline $\begin{array}{l}\text { Superfície regada } \\
(\mathrm{Sr} ; \mathrm{ha})^{\mathrm{a}}\end{array}$ & $30.831-34.131$ & $11.933-16.237$ & $2.882-3.131$ & $1.797-1.935$ & $1.182-1.283$ \\
\hline $\begin{array}{l}\text { Volumen suministrado } \\
\left(\mathrm{Vs} ; \mathrm{hm}^{3}\right)^{\mathrm{ab}}\end{array}$ & $17,88-104,50$ & $28,00-55,04$ & $6,84-12,06$ & $3,51-6,35$ & $3,38-4,86$ \\
\hline Comuneros (n.) & 9.506 & 7.617 & 350 & 1.750 & 972 \\
\hline \multicolumn{6}{|l|}{ Recursos $(\%)^{\mathrm{ab}}$} \\
\hline Superficiales & $1-10$ & $8-20$ & - & $1-7$ & - \\
\hline Subterráneos & $0-20$ & $27-64$ & $0-82$ & $47-97$ & 100 \\
\hline Trasvase Tajo-Segura & $70-97$ & $12-51$ & $18-100$ & $2-53$ & - \\
\hline Desalinización & $1-7$ & - & - & - & - \\
\hline Reutilización & $0-2$ & $4-6$ & - & - & - \\
\hline Sistema de distribución & Turnos & Demanda & Demanda & Turnos & Demanda \\
\hline \multicolumn{6}{|l|}{ Cultivos principales $^{\mathrm{a}}$} \\
\hline & Lechuga $(15 \%)$ & Brócoli (28\%) & $\begin{array}{l}\text { Melocotonero } \\
\quad(61 \%)\end{array}$ & $\begin{array}{c}\text { Albaricoquero } \\
(26 \%)\end{array}$ & Peral (46\%) \\
\hline & $\begin{array}{c}\text { Limonero } \\
(14 \%)\end{array}$ & Lechuga (24\%) & Ciruelo (17\%) & Naranjo $(25 \%)$ & $\begin{array}{l}\text { Melocotonero } \\
\quad(32 \%)\end{array}$ \\
\hline & Melón (11\%) & Alcachofa (17\%) & $\begin{array}{c}\text { Albaricoquero } \\
(13 \%)\end{array}$ & $\begin{array}{l}\text { Limonero } \\
(18 \%)\end{array}$ & $\begin{array}{c}\text { Albaricoquero } \\
(7 \%)\end{array}$ \\
\hline Método riego & $\begin{array}{l}\text { Localizado } \\
\quad(96 \%)\end{array}$ & Localizado (84\%) & $\begin{array}{l}\text { Localizado } \\
(100 \%)\end{array}$ & $\begin{array}{l}\text { Localizado } \\
\quad(98 \%)\end{array}$ & $\begin{array}{l}\text { Localizado } \\
(100 \%)\end{array}$ \\
\hline
\end{tabular}

${ }^{\text {a }}$ rango en el periodo 2002-11

${ }^{b}$ para CRLO y CRPC rango entre 2002-10

Se han seleccionado CCRRs muy representativas, de diferentes comarcas agrarias (Campo de Cartagena, Valle del Guadalentín, Vega del Segura, Comarca del 
Río Mula y el Altiplano), y con grandes diferencias entre superficies, cultivos y procedencia de los recursos hídricos.

Durante el periodo de estudio tres CCRRs han tenido procesos de modernización: CRCC, CRLO y CRTCC. La CRPC y la CRM ya estaban modernizadas con anterioridad a 2002.

\subsubsection{Adquisición de datos}

Para llevar a cabo este estudio fue necesario obtener gran cantidad de información descriptiva y cuantitativa de las zonas regables, para ello se tomaron datos referidos tanto a nivel de parcela, como de la CCRR, además de la información agroclimática requerida para la estimación de las necesidades hídricas de los cultivos. Los datos fueron facilitados por los gestores de las CCRRs, procedentes de los registros de sus bases de datos y sus memorias anuales. Gracias al conjunto de datos manejados se pudo realizar el cálculo de los indicadores de gestión.

Para la gestión y análisis de toda esta información se han utilizado bases de datos (Access), hojas de cálculo (Excel), sistemas de información geográfica (GeoMedia y AutoCAD Map) y programas de tratamiento estadístico (StatGraphics).

La superficie de los cultivos considerados se ha obtenido a partir de los parcelarios de las CCRRs y de la Estadística Agraria Regional de Murcia (CARM, 2013).

De las estaciones agrometeorológicas automáticas, ubicadas en las zonas regables de las CCRRs analizadas, se obtuvieron los datos climáticos necesarios para el cálculo mensual de la evapotranspiración de referencia $\left(\mathrm{ET}_{\mathrm{o}}\right)$ mediante PenmanMonteith y la precipitación diaria durante el periodo de estudio. La ETc y la precipitación efectiva (Pef) se calcularon siguiendo las directrices indicadas en la 
metodología FAO (Brouwer y Heibloem, 1986; Allen et al., 1998), los coeficientes de cultivos se han ajustado a las condiciones locales según los valores proporcionados por el Servicio Agrícola Regional (http://siam.imida.es).

El volumen de agua que entra al sistema (VT) se ha tomado de las lecturas de los contadores existentes en los puntos de aportación de agua a las CCRRs. El volumen suministrado (Vs) se ha obtenido de la suma anual del volumen facturado a los regantes, en base a la lectura de todos los contadores instalados en la red de distribución de cada una de las CCRRs analizadas y que se encuentra registrado en las bases de datos de las mismas.

Los indicadores financieros se han tomado de las cuentas anuales de las CCRRs. Los indicadores energéticos anuales se han considerado a partir de las facturas eléctricas mensuales.

Los rendimientos de los cultivos, precios medios y los costes de producción de los mismos se han elaborado a partir de datos de la estadística regional (CARM, 2013), de la estadística nacional (MAGRAMA, 2013), de la AMOPA (Asociación Murciana de Organizaciones de Productores Agrarios), de las OCAs (Oficinas Comarcales Agrarias) y de encuestas realizadas a los agricultores de la zona.

Los indicadores se han calculado mediante la combinación de una o varias variables medidas. Siendo contrastado su valor con la bibliografía existente.

Para poder analizar la evolución de los indicadores financieros $\mathrm{y}$ de productividad en el periodo de estudio, se han actualizado los mismos mediante el IPC nacional, tomando como base el año 2011 (INE, 2012). 


\subsubsection{Fiabilidad de los datos e Índice General de Fiabilidad (IGF)}

Unos de los mayores problemas a la hora de calcular los indicadores de gestión de una CCRR es la fiabilidad de los datos considerados, un cierto error o incertidumbre es inherente a cualquier proceso de medición o estimación (Burt, 2001). Sería prácticamente imposible obtener un error inferior al 5-10\% en el estudio de las zonas regables (Burt et al., 1997). En nuestro caso los datos obtenidos de las CCRRs tienen la incertidumbre de la precisión de los equipos de medida empleados (agua y energía), que va a estar por debajo del 5\%; y la de los datos procedentes de la estadística nacional (Ley 12/1989, de 9 de mayo, de la Función Estadística Pública) y regional (Ley 6/2002, de 25 de junio, de estadística de la Región de Murcia).

Para calcular la incertidumbre de los datos obtenidos se ha seguido la metodología indicada por Rodríguez (2003), y que se basa en el cálculo del Índice General de Fiabilidad (IGF). En la Tabla 3.2 se muestra el valor de cada variable considerada para la obtención del IGF.

La suma de todos los valores de cada apartado daría el valor definitivo de IGF, aplicando la siguiente ecuación:

$$
\mathrm{IGF}=1,8 \mathrm{VC}+2 \mathrm{MC}+0,5 \mathrm{IR}+1,5 \mathrm{DC}+2 \mathrm{EP}+0,7 \mathrm{CS}+1,5 \mathrm{VF}
$$

La interpretación de IGF se realiza teniendo en cuenta los siguientes valores: muy mala $<3$, pobre 3-5, aceptable 5-7, buena 7-9 y muy buena $>9$ 
Tabla 3.2. Índice General de Fiabilidad (Rodríguez, 2003).

\begin{tabular}{lr}
\hline Tipo de variables & Valor \\
\hline Valores Climáticos (VC) & $\mathbf{1 , 8}$ \\
Estación meteorológica en la zona regable & 1 \\
Valores de organismos regionales o nacionales & 0,8 \\
Extrapolación de zonas próximas & 0,5 \\
Interpolación entre años & 0,1 \\
\hline Medición de Caudales (MC) & $\mathbf{2}$ \\
Existencia de datos de contadores & 1 \\
Aforadores en puntos intermedios & 0,5 \\
Estimación del personal de la CCRR & 0,2 \\
\hline Infraestructura de la Red (IR) & $\mathbf{0 , 5}$ \\
Datos del proyecto & 1 \\
Estimación del personal de la CCRR & 0,2 \\
\hline Datos de Cultivos (DC) & $\mathbf{1 , 5}$ \\
Datos propios de la Comunidad de Regantes & 1 \\
Datos de organismos regionales o nacionales & 0,8 \\
Datos obtenidos de forma indirecta & 0,3 \\
\hline Estimación de Perdidas (EP) & $\mathbf{2}$ \\
Diferencia en medidores de caudal (entre ${ }^{\circ}$ y $3^{\circ}$ nivel) & 1 \\
Diferencia en medidores de caudal intermedios & 0,6 \\
Estimación del personal de la CCRR & 0,1 \\
\hline Capacidad de Suministro (CS) & $\mathbf{0 , 7}$ \\
Proyecto & 1 \\
Estimación del personal de la CCRR & 0,4 \\
\hline Variables Financieras (VF) & $\mathbf{1 , 5}$ \\
Presupuestos detallados & 1 \\
Datos suministrados por el personal & 0,7 \\
Estimación del personal de la CCRR & 0,3 \\
\hline & 0,1 \\
\hline
\end{tabular}

\subsubsection{Indicadores de gestión de otros estudios previos}

En este apartado se muestran los indicadores de gestión obtenidos de otros estudios previos realizados en CCRRs españolas, destacando principalmente los de Rodríguez (2003) en Andalucía y Córcoles (2009) en Castilla La Mancha (Tabla 3.3), tal como se ha comentado anteriormente. En la Tabla 3.3 se muestran los indicadores de estos estudios junto a los realizados por Melián-Navarro et al. (2010) y Rodríguez et al. (2011b). Todos los datos de índole económica se han actualizado mediante el IPC (INE, 2012), tomando como base el año 2011.

En un estudio comparativo sobre el consumo de energía en CCRRs, Abadía et al. (2010) analizaron a 15 CCRRs de Castilla-La Mancha durante el año 2007 obteniéndose 
el valor medio \pm desviación estándar $(\sigma)$ de los siguientes indicadores: $\operatorname{VsSr}(3.120 \pm 2.429$ $\left.\mathrm{m}^{3} \mathrm{ha}^{-1}\right), \operatorname{CENSr}\left(200 \pm 141 € \mathrm{ha}^{-1}\right)$ y CENVs $\left(0,12 \pm 0,11 € \mathrm{~m}^{-3}\right)$

Tabla 3.3. Valores de indicadores de gestión de otros estudios previos.

\begin{tabular}{|c|c|c|c|c|}
\hline \multirow[b]{6}{*}{ ED $(\%)$} & Andalucía & C. La Mancha & Andalucía & Alicante \\
\hline & $1997-2002$ & 2006-08 & 2006-2007 & 2009 \\
\hline & 5 CCRRs & 7 CCRRs & 10 CCRRs & 2 CCRRs \\
\hline & Rodríguez (2003) & Córcoles (2009) & Rodríguez et al. & Melián-Navarro \\
\hline & & & (2011b) & et al. (2010) \\
\hline & $91 \pm 5$ & $87 \pm 9$ & & 97 \\
\hline $\operatorname{VsSr}\left(\mathrm{m}^{3} \mathrm{ha}^{-1}\right)$ & $4.334 \pm 1.968$ & $3.458 \pm 2.301$ & $2.589 \pm 1.138$ & 2.203 \\
\hline ARIS & $1,20 \pm 0,56$ & $1,09 \pm 0,26$ & $0,93 \pm 1,00$ & \\
\hline CMSSr $\left(€\right.$ ha $\left.^{-1}\right)$ & $452 \pm 200$ & $370 \pm 192$ & & 474 \\
\hline CMSVs $\left(€ \mathrm{~m}^{-3}\right)$ & $0,13 \pm 0,06$ & $0,13 \pm 0,05$ & $0,12 \pm 0,05$ & 0,23 \\
\hline $\operatorname{GGSr}\left(€\right.$ ha $\left.^{-1}\right)$ & $105 \pm 46$ & $127 \pm 44$ & & \\
\hline $\operatorname{GGVs}\left(€ \mathbf{m}^{-3}\right)$ & $0,03 \pm 0,01$ & $0,06 \pm 0,04$ & & \\
\hline $\operatorname{CPSr}\left(€ \mathrm{ha}^{-1}\right)$ & $49 \pm 12$ & $72 \pm 28$ & & \\
\hline CPVs $\left(€ \mathrm{~m}^{-3}\right)$ & $0,01 \pm 0,01$ & $0,03 \pm 0,03$ & & \\
\hline $\operatorname{CMSr}\left(€ \mathrm{ha}^{-1}\right)$ & $21 \pm 13$ & $26 \pm 24$ & & 69 \\
\hline $\operatorname{CMVs}\left(€ \mathrm{~m}^{-3}\right)$ & $0,01 \pm 0,00$ & $0,02 \pm 0,02$ & & 0,03 \\
\hline $\operatorname{CENSr}\left(€\right.$ ha $\left.^{-1}\right)$ & $227 \pm 164$ & $241 \pm 164$ & & 146 \\
\hline CENVs $\left(€ \mathrm{~m}^{-3}\right)$ & $0,06 \pm 0,04$ & $0,07 \pm 0,02$ & $0,04 \pm 0,024$ & 0,07 \\
\hline $\mathrm{RC}(\%)$ & $98 \pm 10$ & $106 \pm 10$ & & \\
\hline $\operatorname{VPSr}\left(€ \mathrm{ha}^{-1}\right)$ & $5.526 \pm 4.250$ & $3.857 \pm 1.457$ & & \\
\hline VPVs $\left(€ \mathrm{~m}^{-3}\right)$ & $1,51 \pm 0,97$ & $1,67 \pm 1,04$ & $2,84 \pm 2,70$ & \\
\hline $\operatorname{MBSr}\left(€ \mathbf{h a}^{-1}\right)$ & & $1.607 \pm 841$ & & \\
\hline $\operatorname{MBVs}\left(€ \mathrm{ha}^{-1}\right)$ & & $0,63 \pm 0,43$ & & \\
\hline
\end{tabular}

Valor medio \pm desviación estándar

En el estudio indicado en el párrafo anterior también se analizaron a 5 CCRRs de la Comunidad Valenciana durante el 2007, el valor de los indicadores fue el siguiente: VsSr $\left(1.736 \pm 832 \mathrm{~m}^{3} \mathrm{ha}^{-1}\right), \operatorname{CENSr}\left(245 \pm 184 € \mathrm{ha}^{-1}\right)$ y CENVs $(0,08 \pm 0,02 €$ $\mathrm{m}^{-3}$ ). Jiménez-Bello et al. (2011), en un estudio para minimizar el consumo energético, también analizaron una CCRR de la Comunidad Valenciana durante el periodo 2006-10, en el mismo se indicó que el volumen suministrado de agua por unidad de área regada 
(VsSr) estuvo comprendido entre 3.257 y $4.154 \mathrm{~m}^{3} \mathrm{ha}^{-1}$, y la eficiencia de distribución (ED) entre el 98 y el $99 \%$.

\subsection{RESULTADOS}

\subsubsection{Análisis de la fiabilidad de los datos}

En la Tabla 3.4 se muestra el valor del IGF para cada una de las CCRRs analizadas.

Tabla 3.4. Valores del Índice General de Fiabilidad para las CCRRs objeto del estudio.

\begin{tabular}{lr}
\hline Comunidades de regantes & IGF \\
\hline Comunidad de Regantes del Campo de Cartagena (CRCC) & 9,64 \\
Comunidad de Regantes de Lorca (CRLO) & 8,89 \\
Comunidad de Regantes Trasvase Tajo Segura Calasparra-Cieza (CRTCC) & 7,53 \\
Comunidad de Regantes Pantano de la Cierva (CRPC) & 7,23 \\
Comunidad de Regantes de Miraflores (CRM) & 8,35 \\
\hline
\end{tabular}

A partir de los valores obtenidos se puede considerar que la fiabilidad de los datos manejados es muy buena para la CRCC y buena para el resto de las CCRRs.

\subsubsection{Indicadores de rendimiento}

Los indicadores de rendimiento están relacionados con la idoneidad con la que opera la CCRR en la distribución del agua para satisfacer las necesidades requeridas por los agricultores, en la Tabla 3.5 se exponen los resultados obtenidos.

El promedio de intensidad de cultivo ( $\mathrm{SrSa}$ ) fue del 80,6\%, ligeramente inferior a la media regional de $83,4 \%$ (Tabla 2.4) para ese mismo periodo. Cuando el ratio $\mathrm{SrSa}$ es menor al $100 \%$ se considera bajo (Uysal y Atis, 2010), tal como ocurre para todas las CCRRs analizadas durante el periodo de estudio. La CRPC y la CRM son las CCRRs que tienen un valor más alto de SrSa. La mayor variabilidad de SrSa (Fig. 3.1a) la 
presenta la CRCC y la CRLO, dado que tienen una mayor proporción de cultivos hortícolas, y la superficie de estos cultivos sufre gran variación en función de los recursos disponibles, según se analiza en el Capítulo 5.

Tabla 3.5. Indicadores de rendimiento más significativos en el periodo 2002-11.

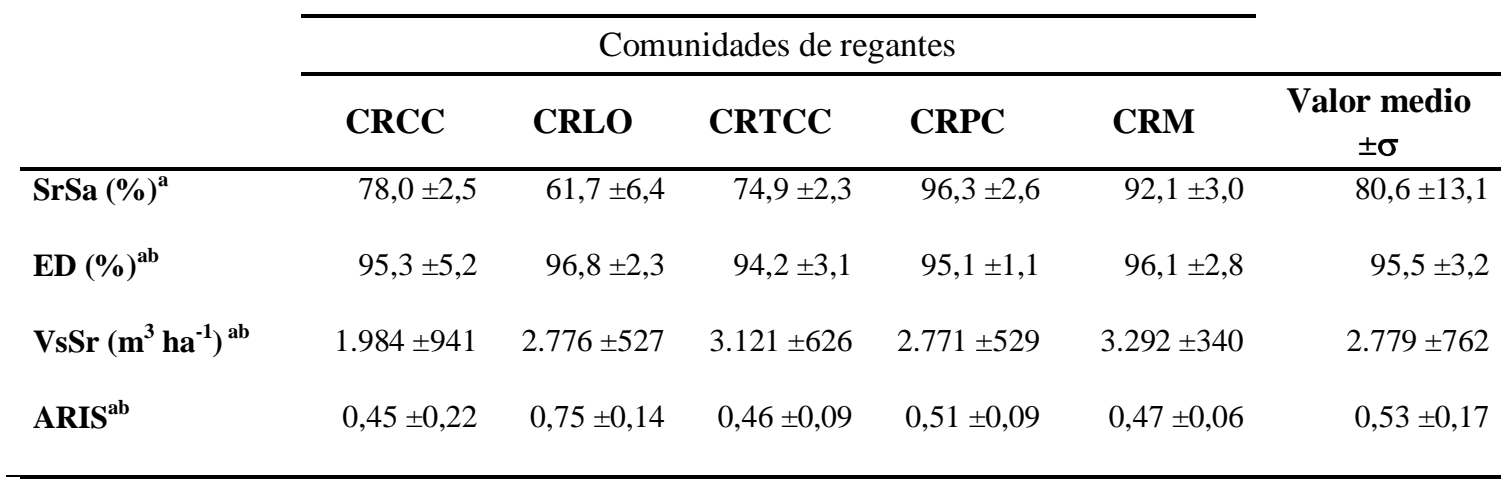

a valor medio \pm desviación estándar en el periodo 2002-2011

${ }^{\mathrm{b}}$ para CRLO y CRPC periodo 2002-10

La eficiencia de distribución (ED) es muy alta en todas las CCRRs analizadas, con un valor medio superior al 95\%. Como se muestra en la Fig. 3.1b, solo hay dos años en los que en alguna de las CCRRs analizadas esté por debajo del 90\%. Hay que observar para el caso de la CRCC que la ED alcanzó valores cercanos al 99\% en los años normales, y fue menor del $90 \%$ en los años donde se produjo una mayor restricción de recursos. Para el resto de CCRRs analizadas la ED media estuvo comprendida entre el $94 \%$ y el $97 \%$. Estos valores representan un funcionamiento excelente del sistema de distribución para todas las CCRRs analizadas.

El volumen suministrado por unidad de área regada (VsSr) prueba la gran irregularidad existente en la disponibilidad de agua (Fig. 3.1c), presenta un máximo de $4.093 \mathrm{~m}^{3} \mathrm{ha}^{-1}$ en el año 2002 para la CRTCC y un mínimo en la CRCC en el año 2006 de $558 \mathrm{~m}^{3} \mathrm{ha}^{-1}$. La CRCC es la que más variación sufre en el periodo de estudio, causado por su gran dependencia con el Trasvase Tajo-Segura, mientras que la CRM la que menos, por ser todos sus recursos procedentes de las aguas subterráneas. Como se 
puede observar en la Tabla 3.5 la CRM es la que ha podido distribuir un mayor volumen de agua a sus agricultores. El valor medio obtenido de VsSr fue de $2.779 \mathrm{~m}^{3} \mathrm{ha}^{-1}$, inferior a la media regional para ese mismo periodo, que fue de $3.490 \mathrm{~m}^{3} \mathrm{ha}^{-1}$ (Tabla 2.4).

a)

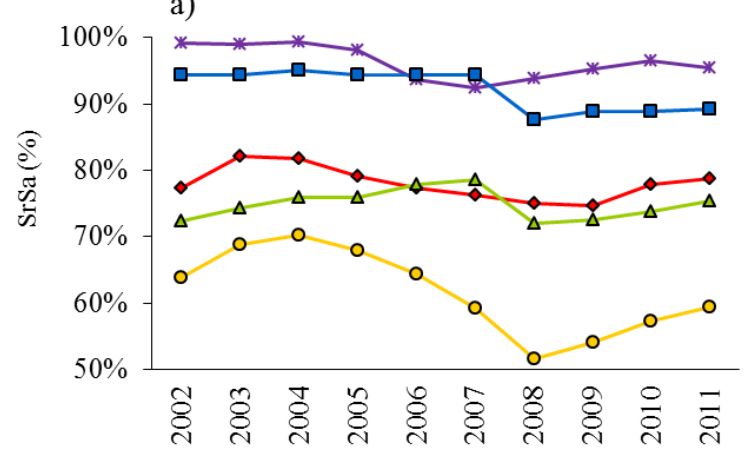

b)

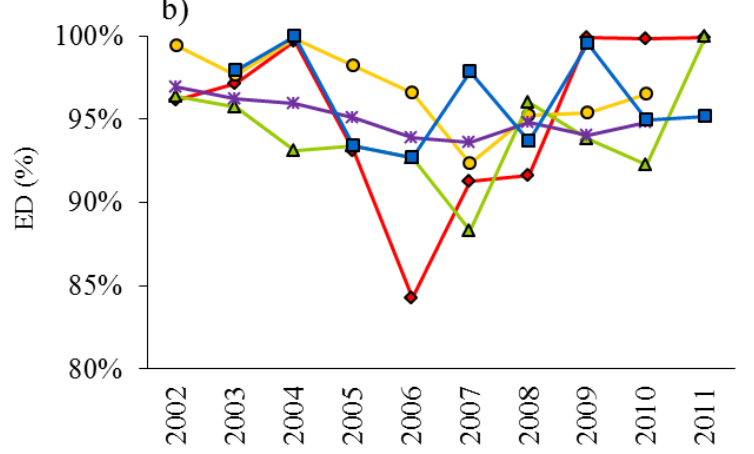

c)

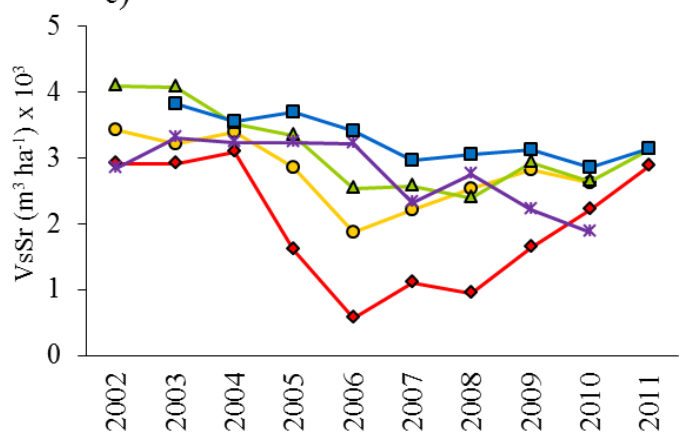

d)

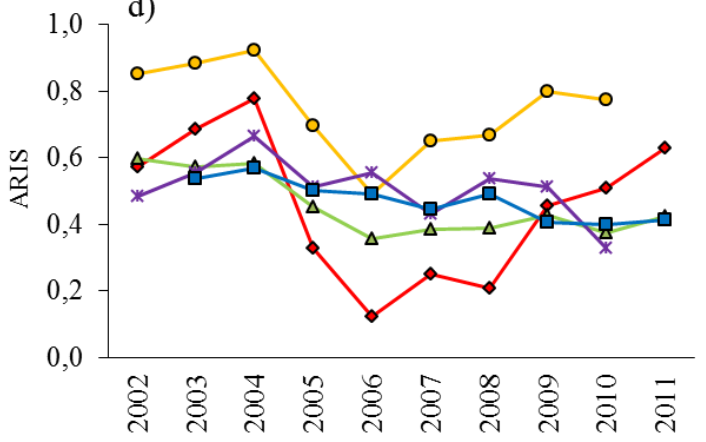

$\neg \mathrm{CRCC} \multimap \mathrm{C}$ CRLO $\triangle \mathrm{CRTCC} \rightarrow$ - CRPC $\rightarrow-\mathrm{CRM}$

Figura 3.1. Evolución de los indicadores de rendimiento: a) SrSa, b) ED, c) VsSr y d) ARIS.

El aporte relativo de agua de riego (ARIS) mostró valores muy variables en cada una de las CCRRs (Fig. 3.1d). Los valores más altos se dieron en la CRLO y en la CRCC por tener una mayor proporción de cultivos hortícolas. El ARIS presenta valores inferiores a 1 en todas las CCRRs, lo que indica que el VsSr no cubría las necesidades hídricas de los cultivos (diferencia entre la ETc y la precipitación efectiva), produciéndose por tanto un riego deficitario. 


\subsubsection{Indicadores financieros}

Los indicadores financieros miden la eficacia con la que la CCRR utiliza los recursos económicos para prestar sus servicios. La importancia de la gestión económica para el manejo de los recursos hídricos, en este estudio surge del hecho de que el agua es el factor más limitante para la producción agrícola en el sureste de España (Berbel et al., 2011). En la Tabla 3.6 se muestran los valores obtenidos de los indicadores financieros de las CCRRs estudiadas.

Tabla 3.6. Indicadores financieros más significativos en el periodo 2002-11.

\begin{tabular}{|c|c|c|c|c|c|c|}
\hline & \multicolumn{5}{|c|}{ Comunidades de regantes } & \multirow[b]{2}{*}{$\begin{array}{c}\text { Valor } \\
\text { medio } \pm \sigma\end{array}$} \\
\hline & CRCC & CRLO & CRTCC & CRPC & CRM & \\
\hline$\overline{P A}\left(€ \mathrm{~m}^{-3}\right)^{\mathrm{ab}}$ & $0,19 \pm 0,04$ & $0,22 \pm 0,04$ & $0,16 \pm 0,03$ & $0,21 \pm 0,02$ & $0,16 \pm 0,04$ & $0,19 \pm 0,04$ \\
\hline $\begin{array}{l}\text { SrNP (ha } \\
\left.\text { empleado }^{-1}\right)^{\mathrm{a}}\end{array}$ & $1.033 \pm 37$ & $312 \pm 25$ & $1.192 \pm 255$ & $268 \pm 7$ & $310 \pm 12$ & $623 \pm 422$ \\
\hline $\operatorname{CMSSr}\left(€ \mathrm{ha}^{-1}\right)^{\mathrm{ab}}$ & $362 \pm 148$ & $582 \pm 61$ & $893 \pm 325$ & $408 \pm 48$ & $1.037 \pm 110$ & $650 \pm 315$ \\
\hline CMSVs $\left(€ \mathrm{~m}^{-3}\right)^{\mathrm{ab}}$ & $0,20 \pm 0,06$ & $0,21 \pm 0,03$ & $0,31 \pm 0,16$ & $0,15 \pm 0,03$ & $0,32 \pm 0,06$ & $0,24 \pm 0,10$ \\
\hline $\operatorname{GGSr}\left(€ \mathrm{ha}^{-1}\right)^{\mathrm{ab}}$ & $91 \pm 23$ & $163 \pm 20$ & $115 \pm 23$ & $199 \pm 44$ & $219 \pm 47$ & $157 \pm 59$ \\
\hline GGVs $\left(€ \mathrm{~m}^{-3}\right)^{\mathrm{ab}}$ & $0,06 \pm 0,04$ & $0,06 \pm 0,01$ & $0,04 \pm 0,01$ & $0,07 \pm 0,03$ & $0,07 \pm 0,01$ & $0,06 \pm 0,03$ \\
\hline $\operatorname{CPSr}\left(€ \mathrm{ha}^{-1}\right)^{\mathrm{ab}}$ & $47 \pm 4$ & $116 \pm 14$ & $30 \pm 6$ & $98 \pm 10$ & $88 \pm 15$ & $76 \pm 34$ \\
\hline CPVs $\left(€ \mathrm{~m}^{-3}\right)^{\mathrm{ab}}$ & $0,03 \pm 0,02$ & $0,04 \pm 0,01$ & $0,01 \pm 0,00$ & $0,04 \pm 0,01$ & $0,03 \pm 0,01$ & $0,03 \pm 0,02$ \\
\hline $\operatorname{CMSr}\left(€ \mathbf{h a}^{-1}\right)^{\mathrm{ab}}$ & $16 \pm 5$ & $46 \pm 19$ & $85 \pm 21$ & $100 \pm 42$ & $131 \pm 38$ & $75 \pm 50$ \\
\hline $\operatorname{CMVs}\left(€ \mathrm{~m}^{-3}\right)^{\mathrm{ab}}$ & $0,01 \pm 0,01$ & $0,02 \pm 0,01$ & $0,03 \pm 0,01$ & $0,04 \pm 0,02$ & $0,04 \pm 0,01$ & $0,03 \pm 0,02$ \\
\hline CENSr $\left(€ \mathrm{ha}^{-1}\right)^{\mathrm{ac}}$ & $27 \pm 6$ & $72 \pm 13$ & $134 \pm 79$ & $110 \pm 53$ & $299 \pm 63$ & $126 \pm 105$ \\
\hline CENVs $\left(€ \mathrm{~m}^{-3}\right)^{\text {ac }}$ & $0,02 \pm 0,01$ & $0,03 \pm 0,01$ & $0,05 \pm 0,03$ & $0,04 \pm 0,02$ & $0,09 \pm 0,02$ & $0,04 \pm 0,03$ \\
\hline $\mathrm{RC}(\%)^{\mathrm{ab}}$ & $95,7 \pm 16,7$ & $107,4 \pm 10,1$ & $79,5 \pm 22,9$ & $115,9 \pm 23,8$ & $84,1 \pm 5,8$ & $96,5 \pm 21,5$ \\
\hline
\end{tabular}

\footnotetext{
${ }^{a}$ valor medio \pm desviación estándar en el periodo 2002-2011

${ }^{\mathrm{b}}$ para CRLO, CRTCC y CRPC periodo 2002-10

c para CRLO y CRPC periodo 2002-10
}

El precio del agua (PA) pagado por los regantes ha variado entre 0,11 y $0,27 € \mathrm{~m}^{-}$ ${ }^{3}$, siendo el valor medio de $0,19 € \mathrm{~m}^{-3}$. En todas las CCRRs analizadas la tarifa está en 
función del consumo de agua efectuado, aunque también se producen derramas en función de la superficie, como es el caso sobre todo de la CRM. Este sistema tarifario, variable en función del consumo de cada regante, se encuentra extendido a la mayoría de las CCRRs de la Región de Murcia, debido al alto precio, a la baja disponibilidad y la escasa garantía del agua (Arcas y Alcón, 2007). Que el agricultor pague el agua en función de la cantidad consumida, en lugar de por superficie regable, influye en un uso más eficiente del agua de riego (Rodríguez, 2003). Además hay que tener en cuenta que estas tarifas, para las CCRRs que toman recursos procedentes del Trasvase Tajo-Segura o de la Cuenca, están influenciadas en todo momento por las tarifas vigentes de estos recursos, establecidas por el Estado.

En la Tabla 3.7 se pueden ver las tarifas vigentes del Trasvase Tajo-Segura y de la Cuenca del Segura durante el periodo de estudio, indicando la fecha de su entrada en vigor. Estas tarifas afectan a todas las CCRRs analizadas, a excepción de CRM, ya que todos sus recursos son subterráneos.

Tabla 3.7. Tarifas Trasvase Tajo-Segura y de peaje de la Cuenca (SCRATS, 2013).

\begin{tabular}{lccccc}
\cline { 2 - 6 } & $\mathbf{2 2 / 0 2 / 2 0 0 1}$ & $\mathbf{1 2 / 1 0 / 2 0 0 2}$ & $\mathbf{0 7 / 0 3 / 2 0 0 4}$ & $\mathbf{0 1 / 0 2 / 2 0 0 5}$ & $\mathbf{1 / 1 0 / 2 0 0 9}$ \\
\hline Trasvase Tajo-Segura & 0,0833 & 0,0872 & 0,0866 & 0,0996 & 0,1741 \\
Peaje Cuenca & 0,0326 & 0,0248 & 0,0123 & 0,0170 & 0,0551 \\
\hline
\end{tabular}

Los costes de manejo del sistema por unidad de área regada (CMSSr) es el indicador financiero más representativo por englobar todos los costes a los que la CCRR debe hacer frente para su funcionamiento (Rodríguez, 2003). Este indicador presenta un valor medio de $650 € \mathrm{ha}^{-1}$, con una variación considerable en función del año. Como se puede observar en la Fig. 3.2a, en todas las CCRRs, salvo la CRPC (por una reducción del $\mathrm{VsSr}$ ), este indicador tiende a incrementarse a lo largo de los años, si comparamos los primeros años del estudio y los últimos. Esto se debe a la subida de la tarifa del 
Trasvase Tajo-Segura y al peaje de la Cuenca (Tabla 3.7), al incremento de los costes energéticos y a los efectos de la modernización. Como se puede advertir en la Fig. 3.2a la CRM es la que presenta mayores CMSSr, debido sobre todo a los costes energéticos para la captación de las aguas subterráneas. Igual sucede en la CRTCC, los años que ponen en marcha sus sondeos para paliar en parte la falta de los recursos procedentes del Trasvase Tajo-Segura.

Los costes de manejo del sistema por unidad de agua de riego suministrada (CMSVs) tiene un valor medio de $0,24 € \mathrm{~m}^{-3}$, presentado las mismas características que CMSSr. Con una tendencia clara en todos los casos a incrementarse (Fig. 3.2b), por el incremento de los costes energéticos, pero con grandes variaciones dada su vinculación con el VsSr. Los valores más bajos de este indicador los presenta la CRPC y la CRCC, las mayores fluctuaciones para este indicador en la CRCC son causadas por las variaciones en cuanto a sus recursos disponibles (Fig. 3.1c).

Los gastos generales por unidad de área regada (GGSr) varía entre 67 y $293 €$ $\mathrm{ha}^{-1}$, con una tendencia clara al alza durante el periodo de estudio (Fig. 3.2c). El valor medio es de $157 € \mathrm{ha}^{-1}$. Siendo la CRM la que mayor GGSr presenta, y la CRCC la que menos, ya que su gran tamaño hace que los gastos generales se dividan en una gran cantidad de hectáreas. No se observa el mismo comportamiento para CRLO, dado el gran número de personas empleadas, una por cada 312 ha regadas (Tabla 3.6).

Los gastos generales por unidad de agua de riego suministrada (GGVs) tiene un valor medio de $0,06 € \mathrm{~m}^{-3}$, con una tendencia clara alcista, como sucede para GGSr y CMSVs.

Los costes de personal por unidad de área regada (CPSr) varía entre 22 y $137 €$ $\mathrm{ha}^{-1}$, con un valor medio de $76 € \mathrm{ha}^{-1}$. La CRTCC y la CRCC son las que tienen un valor menor (Fig. 3.2e), mientras que la CRLO es la que presenta mayores costes de este tipo, 
por disponer de un mayor número de empleados. En todas las CCRRs se ha producido un incremento a lo largo del periodo de estudio de este indicador.
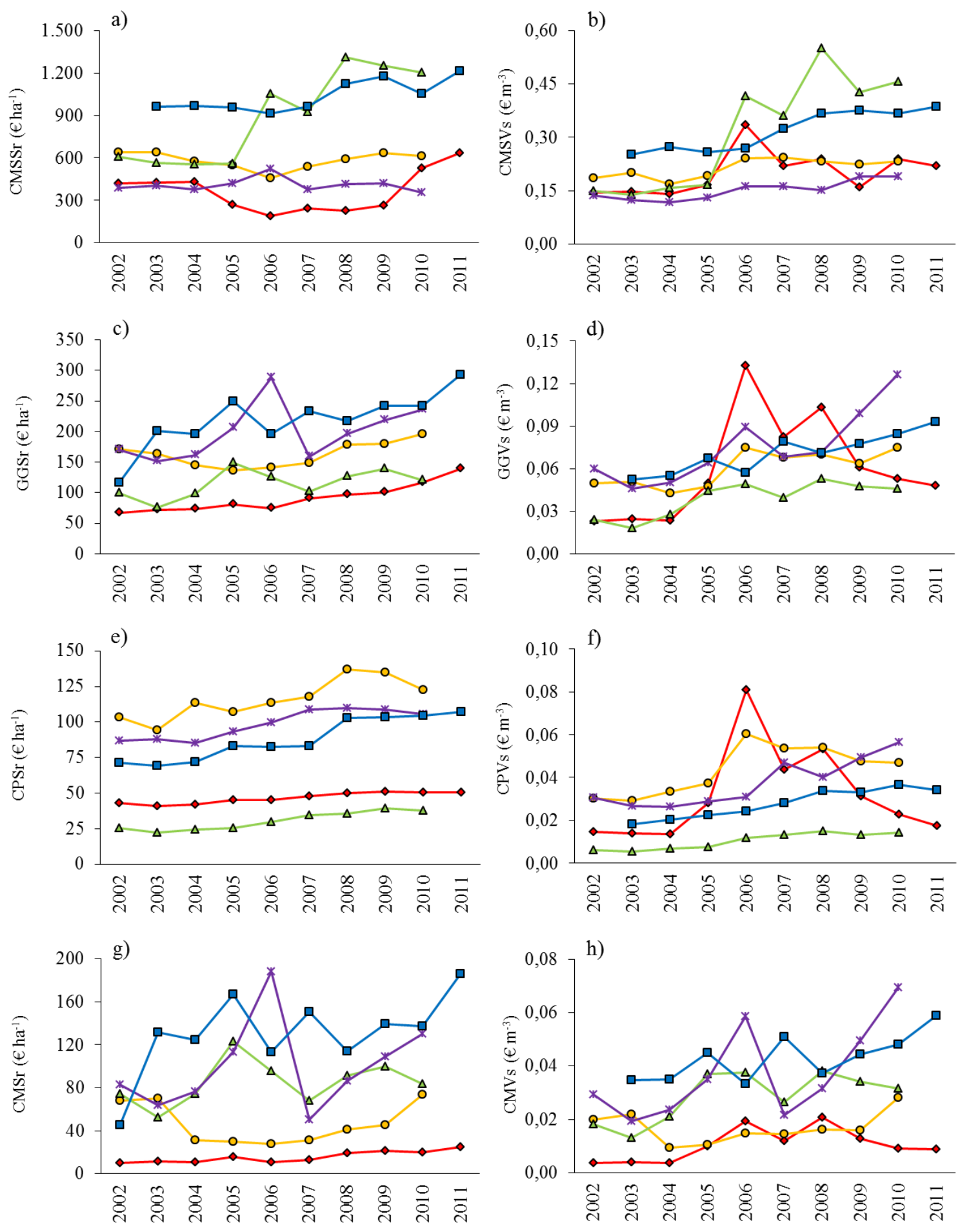

$\rightarrow \mathrm{CRCC} \rightarrow \mathrm{O}$ CRLO $\triangle \mathrm{CRTCC} \rightarrow$ * $\mathrm{CRPC} \rightarrow \mathrm{CRM}$

Figura 3.2. Evolución de los indicadores financieros: a) CMSSr, b) CMSVs, c) GGSr, d) GGVs, e) CPSr, f) CPVs, g) CMSr y h) CMVs. 
Los costes de personal por unidad de agua de riego suministrada (CPVs) sigue la misma tendencia que CPSr, pero con mayores fluctuaciones (Fig. 3.2f) dada su relación con $\mathrm{VsSr}$. El valor medio obtenido para este indicador ha sido de $0,03 € \mathrm{~m}^{-3}$ (Tabla 3.6).

Los costes de mantenimiento por unidad de área regada (CMSr) tiene un valor medio de $75 € \mathrm{ha}^{-1}$, pero en función del año y de la CCRR seleccionada varía entre un mínimo de $10 € \mathrm{ha}^{-1}$ para la CRCC en 2002 y un máximo de $188 € \mathrm{ha}^{-1}$ para la CRPC en 2006. La CRCC y la CRLO son las que presentan un valor menor, mientras que la CRM tiene los mayores CMSr (Fig. 3.2g). Estos costes sufren gran variación a lo largo del tiempo, porque también dependen de las averías que se produzcan en la infraestructura de la CCRR. En todas las CCRRs se ha producido un incremento de estos costes a lo largo del tiempo.

Los costes de mantenimiento por unidad de agua de riego suministrada (CMVs) tienen un valor medio de $0,03 € \mathrm{~m}^{-3}$, y siguen la tendencia de CMSr, pero con mayores fluctuaciones dada su relación con $\mathrm{VsSr}$ (Fig. 3.2h).

El coste energético por unidad de área regada (CENSr) fue de $126 € \mathrm{ha}^{-1}$ (Tabla 3.6), pero este valor cambia considerablemente en función de la CCRR y del año, entre $15 € \mathrm{ha}^{-1}$ para la CRCC en el año 2006 y $430 € \mathrm{ha}^{-1}$ para la CRM en 2009. Como se puede ver en la Fig. 3.3a, el valor más alto lo presenta la CRM, a causa que sus recursos son $100 \%$ aguas subterráneas y la captación la realiza directamente. La Fig. 3.3a también muestra cómo se produce un aumento considerable en los CENSr en la CRTCC, CRPC y CRLO en el periodo de sequía 2006-2009, esto se debe a que estas CCRRs disponen de aguas subterráneas (Tabla 3.1), aumentando el consumo de los mismas, con el coste energético que lleva asociado su captación, para paliar la falta de recursos procedentes del Trasvase Tajo-Segura. De igual modo hay que significar el 
gran incremento de CENSr en 2009 para la CRM, que se produjo por la liberalización del mercado eléctrico español en 2008, cuando las tarifas especiales para riego desaparecieron, lo que perjudicó la contratación eléctrica para el regadío, tal como se expuso en el Capítulo 2.
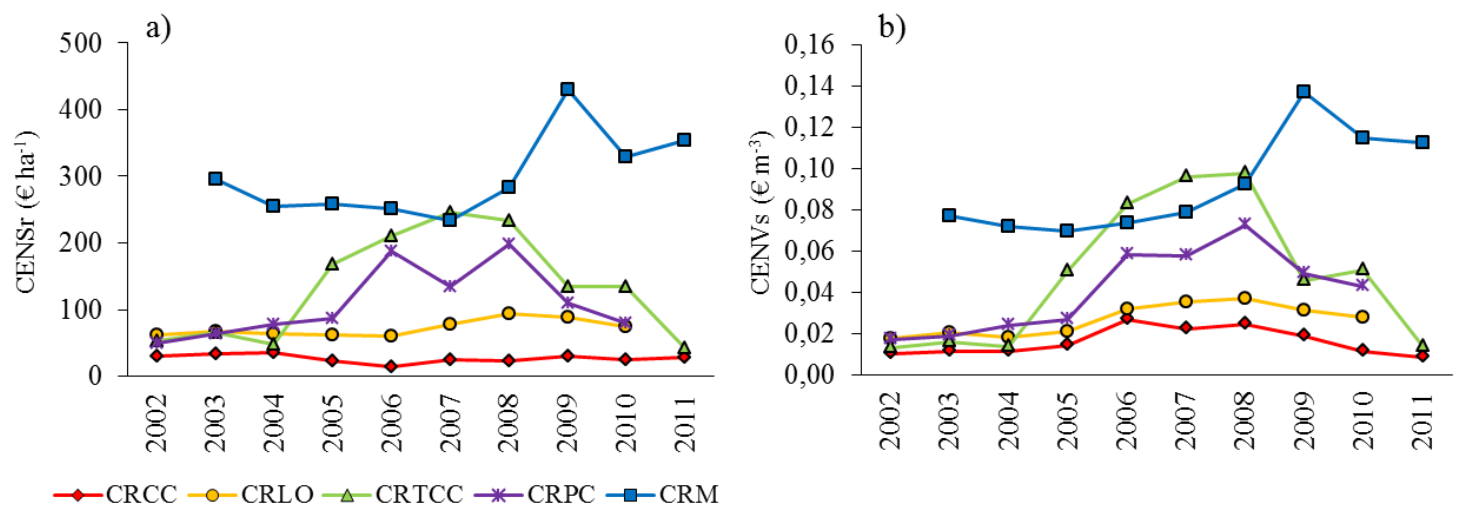

Figura 3.3. Evolución de los indicadores financieros energéticos: a) CENSr y b) CENVs.

El coste energético por unidad de agua de riego suministrada (CENVs) tiene un valor medio de $0,04 € \mathrm{~m}^{-3}$ (Tabla 3.6), pero como ocurre con CENSr presenta grandes variaciones a lo largo del tiempo. Además de lo comentado en el párrafo anterior para CRM, CRLO, CRTCC y CRPC, se puede observar para la CRCC en la Fig. 3.3b en el periodo 2006-2008 un considerable incremento de CENVs (Fig. 3.3b), causado principalmente por tratarse de un periodo de sequía (Fig. 3.1c), donde el porcentaje de agua desalada fue mayor, con un gran incremento en el consumo energético, tal como se analiza en el Capítulo 4.

La recuperación de costes (RC) es muy alta, superior al 96\% la media, por el tipo de tarifa en las CRCCs. La tarifa predominante es por metro cúbico, por lo que el uso de derramas es muy reducido, salvo en la CRM. 


\subsubsection{Indicadores de eficiencia de producción}

Los indicadores de eficiencia de producción miden la eficacia con la que los agricultores utilizan el agua en la producción de sus cultivos y el valor económico obtenido por los mismos. En la Tabla 3.8 se muestran los valores obtenidos de los indicadores de eficiencia de producción para las CCRRs estudiadas.

Tabla 3.8. Indicadores de eficiencia de producción más significativos en el periodo 2002-11.

\begin{tabular}{lrrrrrr}
\cline { 2 - 5 } & \multicolumn{5}{c}{ Comunidades de regantes } & \\
\cline { 2 - 6 } & \multicolumn{1}{c}{ CRCC } & CRLO & CRTCC & CRPC & CRM & Valor medio $\pm \boldsymbol{\sigma}$ \\
\hline $\operatorname{VPSr}\left(\boldsymbol{\epsilon} \mathbf{~ h a}^{-1}\right)^{\mathbf{a}}$ & $12.536 \pm 2.455$ & $9.423 \pm 1.494$ & $13.032 \pm 2.335$ & $7.217 \pm 1.397$ & $12.907 \pm 2.106$ & $11.023 \pm 3.031$ \\
$\operatorname{VPVs}\left(\boldsymbol{\epsilon} \mathbf{~ m}^{-\mathbf{3}}\right)^{\mathbf{a b}}$ & $8,25 \pm 5,23$ & $3,59 \pm 0,56$ & $4,32 \pm 1,18$ & $2,64 \pm 0,43$ & $4,02 \pm 0,85$ & $4,64 \pm 3,12$ \\
$\operatorname{MBSr}\left(\boldsymbol{(} \mathbf{~ h a}^{-\mathbf{1}}\right)^{\mathbf{a b}}$ & $4.016 \pm 2.446$ & $2.960 \pm 1.408$ & $4.814 \pm 2.349$ & $1.454 \pm 1.377$ & $2.929 \pm 2.120$ & $3.235 \pm 2.228$ \\
$\operatorname{MBVs}\left(\boldsymbol{(} \mathbf{~ m}^{-\mathbf{3}}\right)^{\mathbf{a b}}$ & $2,44 \pm 1,59$ & $1,17 \pm 0,29$ & $1,59 \pm 0,89$ & $0,48 \pm 0,48$ & $0,96 \pm 0,70$ & $1,36 \pm 1,12$
\end{tabular}

${ }^{\text {a }}$ valor medio \pm desviación estándar en el periodo 2002-2011

${ }^{\mathrm{b}}$ para CRLO y CRPC periodo 2002-10

El valor de la producción agrícola por unidad de superficie regada (VPSr) presenta valores muy altos, con un valor medio de $11.023 € \mathrm{ha}^{-1}$, en comparación con otras regiones españolas (Salvador et al, 2011; Córcoles et al, 2010; Rodríguez-Díaz et al, 2008). El valor medio de este indicador fue superior a la media regional para ese mismo periodo $10.008 € \mathrm{ha}^{-1}$ (Tabla 2.4). Este indicador ha tenido grandes fluctuaciones a lo largo de periodo de estudio (Fig. 3.4a), por su dependencia de los precios agrícolas. En la Fig. 3.3a se puede ver cómo los valores más altos se producen en la CRTCC, la CRCC y la CRM, y los más bajos en la CRPC. Este valor de la producción agrícola tan bajo en la CRPC, en comparación con el resto de CCRRs analizadas se debe al gran minifundio existente en esta CCRR y a que sus cultivos no son de los más productivos (López, 2006). 
a)

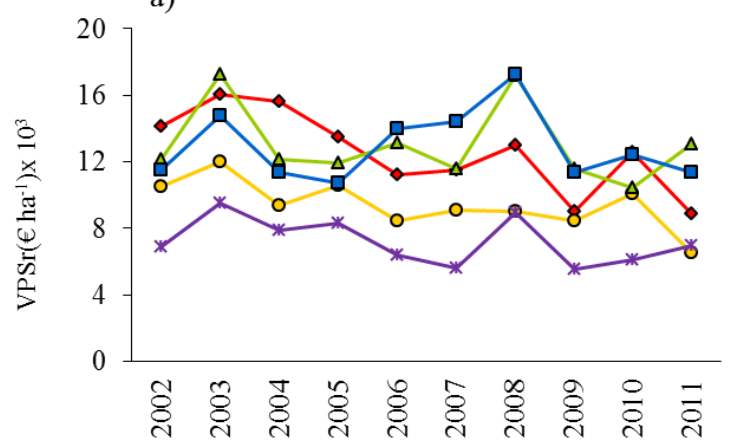

c)

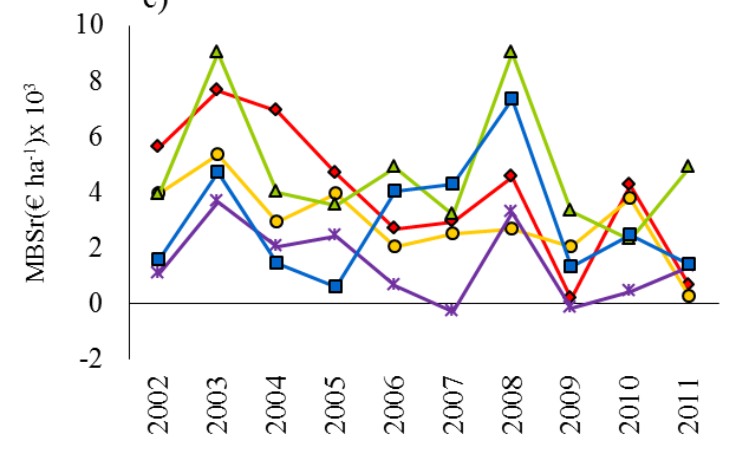

b)

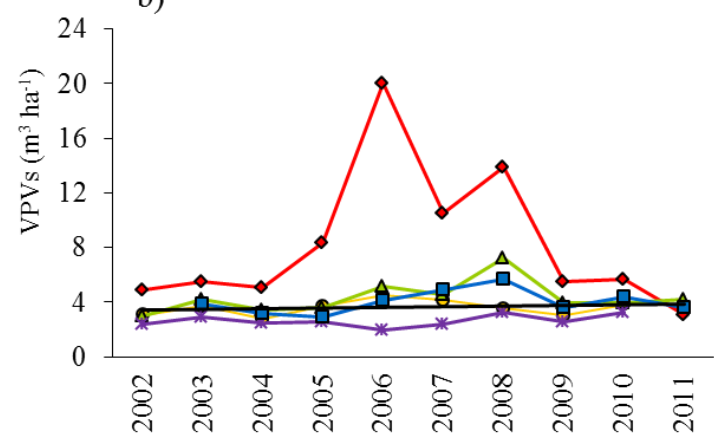

d)

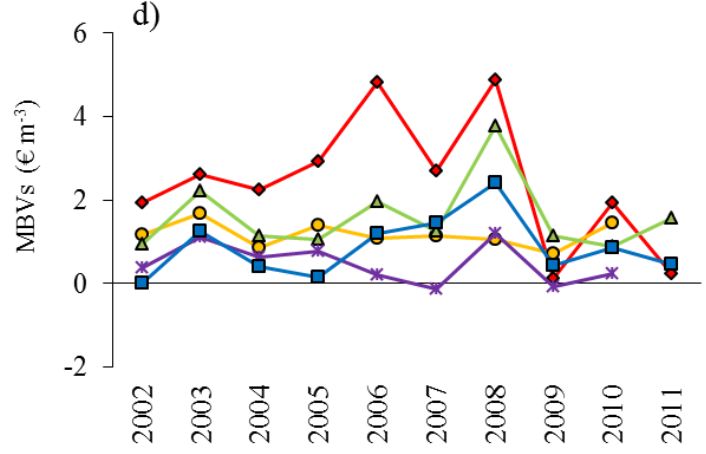

Figura 3.4. Evolución de los indicadores de eficiencia de la producción: a) VPSr, b) VPVs, c) MBSr y d) MBVs.

El valor de la producción agrícola por unidad de agua de riego suministrada (VPVs) presenta valores muy altos en comparación con otras regiones españolas, como sucede con VPSr, teniendo un valor medio de 4,64 $€ \mathrm{~m}^{-3}$ (Tabla 3.8). VPVs presenta una variación mayor que VPSr (Fig. 3.4b y 3.4a) por su vinculación con VsSr, además de depender de las fluctuaciones de los precios agrícolas. Los mayores valores de este indicador, como era de esperar, se producen en los periodos de escasez de agua (Fig. 3.4b y Fig. 3.1c) causado por su relación con VsSr, según se analiza en el Capítulo 5.

Los demás indicadores de eficiencia de producción (margen bruto por unidad de agua de riego suministrada, MBVs, y el margen bruto por unidad de superficie regada, MBSr) siguieron una evolución paralela a VPVs y VPSr respectivamente (Fig. 3.4), pero con mayores fluctuaciones a lo largo del tiempo, ya que además de la variación de los precios de los cultivos también influye el precio de los input agrícolas, como por 
ejemplo el PA (Tabla 3.6). El valor medio de MBSr y MBVs fue de $3.235 €$ ha $^{-1}$ y 1,36 $€ \mathrm{~m}^{-3}$ respectivamente (Tabla 3.8$)$.

\subsection{DISCUSIÓN}

El empleo de los indicadores de gestión es una herramienta eficaz para la caracterización de las CCRRs, así como para identificar las deficiencias en la gestión de las mismas y determinar qué medidas se deben tomar para mejorarlas. Los valores de estos indicadores están determinados por una compleja combinación de factores técnicos, económicos y socio-culturales.

A lo largo de los 10 años estudiados los indicadores han presentado importantes variaciones en las CCRRs analizadas. Por lo tanto, el enfoque tradicional que maneja indicadores de gestión como valores constantes o fijos específicos es inadecuado en zonas con estrés hídrico, ya que la disponibilidad de agua provoca una gran variación en su valor, por lo que los indicadores se deben considerar a lo largo del tiempo. Por lo tanto, de acuerdo con García-Vila et al. (2008), se llega a la conclusión de que la mejora de la gestión del riego mediante la evaluación comparativa en áreas sujetas a períodos de escasez de agua requiere un buen conocimiento del funcionamiento del sistema durante periodos de tiempo prolongados.

Del análisis de los indicadores de rendimiento en su conjunto se desprende que: (a) la actividad agrícola en las cinco CCRRs estudiadas es estable, tal como la intensidad de cultivo ( $\mathrm{SrSa}$ ) pone de manifiesto, ya que se basa en cultivos muy rentables; (b) la eficiencia de distribución (ED) es tan alta, que prácticamente ya no tiene mejora; (c) el volumen suministrado por superficie regada (VsSr) es muy variable a lo largo del tiempo y parece indicar una ligera tendencia a la baja; y (d) los volúmenes suministrados por las CCRRs no satisfacen las necesidades hídricas de los cultivos de 
sus zonas regables, dado que el aporte relativo de agua de riego (ARIS) en todos los casos es menor que 1 .

Del estudio de los indicadores financieros se deduce que: (a) por lo general la tendencia de los mismos es al alza; (b) el tamaño influye en los costes unitarios, pudiéndose reducir éstos cuanto mayor es la CCRR; y (c) los costes se incrementan cuando la falta de recursos hace que éstos se sustituyan por aguas subterráneas o procedentes de la desalación, sobre todo por el incremento de los costes energéticos.

El valor de los indicadores de la eficiencia de la producción es muy alto, con grandes fluctuaciones, debido, sobre todo a la gran variación de los precios agrícolas y a los efectos de las restricciones de agua respecto al descenso en el rendimiento de los cultivos.

El estudio de estos indicadores también evidencia donde las CCRRs analizadas pueden mejorar:

- La CRCC presenta las mayores fluctuaciones en el VsSr, dado que la gran mayoría de sus recursos proceden del Trasvase Tajo-Segura, el cual es muy irregular. Por lo tanto, sus esfuerzos deben continuar en la defensa del mismo y en la búsqueda de recursos alternativos, tal como está llevando a cabo en los últimos años con la incorporación de recursos procedentes de la reutilización y la desalación de agua salobre.

- La CRLO tiene los mayores costes laborales por unidad de superficie regada, aunque por tamaño es la segunda después de la CRCC. Por tanto se recomienda un ajuste en la plantilla. Aunque ya se ha realizado una reducción del $20 \%$ del personal durante el periodo de estudio, este ajuste todavía es insuficiente dado que tiene los mayores costes de personal por unidad de superficie regada de las 5 CCRRs analizadas. 
- La CRTCC presenta un incremento considerable de los costes de manejo del sistema durante los periodos de escasez de recursos procedentes del Trasvase Tajo-Segura, porque éstos son sustituidos en parte por recursos subterráneos, provocando que durante estos periodos los costes de manejo del sistema se dupliquen, por el incremento de los costes energéticos. Se recomienda la búsqueda de recursos alternativos con un menor consumo energético que los de las aguas subterráneas, ver Capítulo 4.

- La CRPC podría mejorar respecto a los costes laborales. Por tanto se recomienda, lo mismo que lo indicado a la CRLO. Por otro lado el valor de la producción agraria es el menor de las cinco CCRRs analizadas, y por ello sus esfuerzos deberían ir encaminados a una reducción del minifundio y proponer a sus agricultores la sustitución de los cultivos actuales por otros con una mayor cuota de mercado.

- La CRM es la que presenta unos mayores costes de manejo del sistema, debido básicamente a los costes energéticos por la captación de los recursos subterráneos, que representan el $100 \%$ de los recursos disponibles. Una manera de reducir estos costes es emplear recursos alternativos, tal como se ha comenzado en 2013, con la incorporación de recursos procedentes de la reutilización. También sus esfuerzos deben ir encaminados en la reducción de sus gastos generales.

Finalmente en la Tabla 3.9 se expone la comparación de los indicadores obtenidos en nuestro estudio con los resultados obtenidos por Rodríguez (2003) en Andalucía, Córcoles (2009) en Castilla la Mancha y Melián-Navarro et al. (2010) en Alicante para CCRRs con redes presurizadas. De esta comparación se puede concluir para las CCRRs analizadas en el presente trabajo: (a) que la ED es de las más altas, (b) 
el $\mathrm{VsSr}$ es inferior junto a las de Alicante al de otras regiones, (c) no se cubren las necesidades hídricas de los cultivos, (d) los costes de manejo del sistema son superiores, y (e) el valor de la producción agrícola es muy alto. Mostrando además esta comparación que disponer de una alta ED lleva asociado unos mayores costes de manejo de sistema y que las CCRRs con sistemas de redes presurizadas deben tener como objetivo conseguir una ED superior al 95\%, tal como sucede en muchas de las CCRRs analizadas (Rodríguez, 2003; Córcoles, 2009; Jiménez-Bello et al., 2011).

Tabla 3.9. Comparativa de los resultados obtenidos en esta tesis con otros estudios previos.

\begin{tabular}{|c|c|c|c|c|}
\hline & R. Murcia & Andalucía & C. La Mancha & Alicante \\
\hline & $2002-11$ & $1997-2002$ & 2006-08 & 2009 \\
\hline & 5 CCRRs & 5 CCRRs & 7 CCRRs & 2 CCRRs \\
\hline & & Rodríguez (2003) & Córcoles (2009) & $\begin{array}{l}\text { Melián-Navarro et } \\
\text { al. (2010) }\end{array}$ \\
\hline ED $(\%)$ & $96 \pm 3$ & $91 \pm 5$ & $87 \pm 9$ & 97 \\
\hline $\operatorname{VsSr}\left(\mathrm{m}^{3} \mathrm{ha}^{-1}\right)$ & $2.779 \pm 762$ & $4.334 \pm 1.968$ & $3.458 \pm 2.301$ & 2.203 \\
\hline ARIS & $0,53 \pm 0,17$ & $1,20 \pm 0,56$ & $1,09 \pm 0,26$ & \\
\hline $\operatorname{CMSSr}\left(€\right.$ ha $\left.^{-1}\right)$ & $650 \pm 315$ & $452 \pm 200$ & $370 \pm 192$ & 474 \\
\hline CMSVs $\left(€ \mathbf{m}^{-3}\right)$ & $0,24 \pm 0,10$ & $0,13 \pm 0,06$ & $0,13 \pm 0,05$ & 0,23 \\
\hline $\operatorname{GGSr}\left(€ \mathrm{ha}^{-1}\right)$ & $157 \pm 59$ & $105 \pm 46$ & $127 \pm 44$ & \\
\hline GGVs $\left(€ \mathrm{~m}^{-3}\right)$ & $0,06 \pm 0,03$ & $0,03 \pm 0,01$ & $0,06 \pm 0,04$ & \\
\hline $\operatorname{CPSr}\left(€ \mathbf{h a}^{-1}\right)$ & $76 \pm 34$ & $49 \pm 12$ & $72 \pm 28$ & \\
\hline $\operatorname{CPVs}\left(€ \mathrm{~m}^{-3}\right)$ & $0,03 \pm 0,02$ & $0,01 \pm 0,01$ & $0,03 \pm 0,03$ & \\
\hline $\operatorname{CMSr}\left(€ \mathrm{ha}^{-1}\right)$ & $75 \pm 50$ & $21 \pm 13$ & $26 \pm 24$ & 69 \\
\hline CMVs $\left(€ \mathbf{m}^{-3}\right)$ & $0,03 \pm 0,02$ & $0,01 \pm 0,00$ & $0,02 \pm 0,02$ & 0,03 \\
\hline $\operatorname{CENSr}\left(€\right.$ ha $\left.^{-1}\right)$ & $126 \pm 105$ & $227 \pm 164$ & $241 \pm 164$ & 146 \\
\hline CENVs $\left(€ \mathrm{~m}-{ }^{3}\right)$ & $0,04 \pm 0,03$ & $0,06 \pm 0,04$ & $0,07 \pm 0,02$ & 0,07 \\
\hline $\mathrm{RC}(\%)$ & $96,5 \pm 21,5$ & $98 \pm 10$ & $106 \pm 10$ & \\
\hline $\operatorname{VPSr}\left(€ \mathrm{ha}^{-1}\right)$ & $11.023 \pm 3.031$ & $5.526 \pm 4.250$ & $3.857 \pm 1.457$ & \\
\hline $\operatorname{VPVs}\left(€ \mathrm{~m}^{-3}\right)$ & $4,64 \pm 3,12$ & $1,51 \pm 0,97$ & $1,67 \pm 1,04$ & \\
\hline $\operatorname{MBSr}\left(€ \mathbf{h a}^{-1}\right)$ & $3.235 \pm 2.228$ & & $1.607 \pm 841$ & \\
\hline $\operatorname{MBVs}\left(€ \mathbf{h a}^{-1}\right)$ & $1,36 \pm 1,12$ & & $0,63 \pm 0,43$ & \\
\hline
\end{tabular}

El orden de magnitud de los indicadores financieros en los 4 estudios realizados (Tabla 3.9) es muy similar, con lo que estos valores pueden servir de referencia a la hora 
de cuantificar los costes del sistema cuando se produce la transformación de una CCRR con riego tradicional por canales abiertos a redes presurizadas. 



\section{Capítulo 4}

\section{RELACIÓN AGUA Y ENERGÍA EN EL REGADÍO}

Este Capítulo analiza el vínculo del agua y la energía en el regadío de la Región de Murcia. Durante un periodo de diez años se evalúa el consumo de energía para el riego, particularizando para los diferentes niveles de gestión del regadío (cuenca, comunidad de regantes y parcela) y las diferentes comunidades de regantes (CCRRs) estudiadas. Los resultados de la cuantificación del consumo de agua y energía pueden ser útiles para la formulación de recomendaciones que permitan racionalizar el uso del agua y la energía en la agricultura de regadío.

\subsection{INTRODUCCIÓN}

El agua y la energía se encuentran íntimamente interrelacionadas, muchos procesos de aprovechamiento, extracción y producción de energía emplean el agua; así como se requiere el consumo de energía durante los procesos de captación, tratamiento, distribución y uso del agua (USAID, 2001; Dubreuil et al., 2013). Por ello el agua y la energía han de considerarse de manera conjunta (Carrillo-Cobo et al., 2011). Esta interdependencia, denominada frecuentemente como el "nexo agua-energía", está siendo cada vez más considerada por los organismos gubernamentales para formular recomendaciones en los procesos de evaluación y planificación (Siddiqi y Díaz, 2011).

En el ámbito del sector hídrico, la energía eléctrica empleada para la distribución y el suministro del agua es la principal fuente de gases de efecto invernadero, promotores del cambio climático (Stokes y Horvath, 2009). Además en las regiones áridas y propensas a las sequías, la escasez de agua está provocando la incorporación de recursos no convencionales con altos requerimientos energéticos. Lo que está induciendo que el consumo de energía y los impactos ambientales asociados con la 
obtención, tratamiento y suministro de estos recursos estén aumentando a su vez la escasez de agua (Mo et al., 2011; WWAP, 2012).

En España cada sector que maneja agua tiene un nivel específico de consumo de energía por unidad de agua empleada. Aunque el rango es amplio, el consumo ha sido estimado en (Hardy y Garrido, 2010): 0,21 $\mathrm{kWh} \mathrm{m}^{-3}$ para uso urbano, 0,56 $\mathrm{kWh} \mathrm{m}^{-3}$ para depuración y 0,34 kWh $\mathrm{m}^{-3}$ para el regadío.

Por otro lado el regadío emplea el $75 \%$ del agua total consumida en España (INE, 2012), y el uso sostenible del agua en la agricultura es prioritario y requerido por la Directiva Marco del Agua (Directiva 2000/60/CE). Para cumplir con este propósito, como ya se ha comentado en el Capítulo 2, el regadío español ha experimentado profundas transformaciones en las últimas décadas, incluyendo la modernización con el objetivo principal de mejorar la eficiencia del uso del agua. Esto ha provocado que mientras el consumo de agua por hectárea se ha reducido un $21 \%$ entre 1950 y 2008 , la demanda de energía paradójicamente se ha incrementado un 657\% (Corominas, 2009). Por lo tanto se ha producido un aumento considerable del consumo energético en este sector, provocado principalmente por la sustitución de los sistemas tradicionales de riego por gravedad, por sistemas presurizados (Abadía et al., 2008b; Rodríguez et al., 2009; Carrillo-Cobo et al., 2011). Por ello es necesario gestionar los recursos hídricos y energéticos de manera más eficiente, para poder controlar el aumento de la demanda de energía del regadío (Jackson et al., 2010; Rodríguez et al., 2011a; Abadía et al., 2012).

\subsection{METODOLOGÍA}

La metodología empleada en este Capítulo se ha estructurado en varios pasos. En primer lugar se seleccionaron los indicadores de gestión adecuados para caracterizar la relación entre el agua y la energía en el regadío. A continuación, se calculó el valor de 
estos indicadores para el período de estudio (2002-2011) en las tres Comunidades de Regantes seleccionadas: Comunidad de Regantes del Campo de Cartagena (CRCC), Comunidad de Regantes Trasvase Tajo Segura Calasparra-Cieza (CRTCC) y Comunidad de Regantes de Miraflores (CRM). Las principales características de estas CCRRs se han descrito en el Capítulo 2. No se ha analizado la relación agua y energía para la Comunidad de Regantes de Lorca y para la Comunidad de Regantes Pantano de la Cierva por no disponer de los registros energéticos necesarios del periodo de estudio.

El análisis de los indicadores tuvo como objetivo evaluar: (a) los consumos de agua y energía en cada uno de los niveles de la gestión del regadío considerados, (b) las relaciones entre los requerimientos de energía y el uso de agua, y (c) el efecto de la modernización de las CCRRs analizadas en los indicadores energéticos.

En este análisis se han diferenciado tres niveles de gestión del regadío (SotoGarcía et al., 2013b): cuenca, CCRR y parcela. En el nivel de cuenca se considera la obtención, tratamiento y transporte del agua desde las fuentes hasta el punto de suministro de cada CCRR. Las CCRRs seleccionadas emplearon cinco tipos de recursos: aguas superficiales, aguas subterráneas, Trasvase Tajo-Segura, aguas procedentes de la reutilización y aguas salobres desalinizadas. El nivel de CCRR se refiere a la distribución del agua desde el punto donde la CCRR capta el recurso hasta la toma de riego del regante, realizado por las infraestructuras (grupos de bombeo, redes de distribución y balsas de riego) de la propia CCRR. Por último, a nivel de parcela se consideran las instalaciones en las explotaciones agrícolas para la aplicación de agua a los cultivos, que consisten en los elementos del sistema de riego localizado: cabezal (con o sin unidad de bombeo), tuberías, laterales, emisores y elementos hidráulicos de control y protección. 


\subsubsection{Indicadores aplicados}

Los indicadores hídricos y energéticos en el estudio de las CCRRs han sido considerados previamente en la literatura (Malano y Burton, 2001; Abadía et al., 2010; Moreno et al., 2010b).

La Tabla 4.1 describe el conjunto de los indicadores seleccionados en este Capítulo para abordar el análisis en los diferentes niveles de gestión. Los mismos están agrupados en dos grupos: de rendimiento y energéticos.

Tabla 4.1. Descripción y método de cálculo de los indicadores de gestión empleados.

\begin{tabular}{lcll}
\hline $\begin{array}{l}\text { Nombre del indicador y } \\
\text { acrónimo }\end{array}$ & Unidad & Clasificación & Descripción y cálculo \\
\hline Eficiencia de distribución (ED) & $\%$ & De rendimiento & $\begin{array}{l}100 \cdot \mathrm{Vs} / \mathrm{VT} \quad \begin{array}{l}\text { Representa las pérdidas de } \\
\text { distribución de agua. }\end{array} \\
\mathrm{Vs} / \mathrm{Sr}\end{array}$ \\
$\begin{array}{l}\text { Suministro de agua por unidad de } \\
\text { área regada (VsSr) }\end{array}$ & $\mathrm{m}^{3} \mathrm{ha}^{-1}$ & De rendimiento & $\mathrm{Eac} / \mathrm{Vs}$ \\
$\begin{array}{l}\text { Energía específica (EacVs) } \\
\begin{array}{l}\text { Energía activa consumida por } \\
\text { unidad de superficie regada (EacSr) }\end{array}\end{array}$ & $\mathrm{kWh} \mathrm{m}^{-3}$ & Energéticos & $\mathrm{Eac} / \mathrm{Sr}$ \\
\hline
\end{tabular}

Los indicadores de rendimiento están relacionados con la capacidad de los gestores de las CCRRs para satisfacer la demanda de los usuarios y optimizar el uso del agua. La eficiencia de distribución (ED) es la relación entre el agua suministrada y el agua que entra en el sistema de distribución, por lo que representa las pérdidas de agua producidas por las fugas en las conducciones y las pérdidas por evaporación en las balsas de riego colectivas (Martínez-Álvarez et al., 2009; Martínez-Granados et al., 2011). El suministro de agua por unidad de área regada (VsSr) analiza la cantidad de agua suministrada a los usuarios por unidad de superficie regada. Por lo general se aplica al análisis comparativo entre CCRRs (Malano y Burton, 2001; Moreno et al., 2010a). 
Los indicadores energéticos miden la energía requerida en cada nivel de gestión para la captación, tratamiento, distribución y uso del agua. El indicador energético más representativo es la energía específica (EacVs) según Abadía et al. (2010), que muestra la relación entre el consumo de energía y el volumen de agua suministrado; mientras que la energía activa consumida por unidad de superficie regada (EacSr) se emplea para determinar el consumo de energía por superficie.

\subsubsection{Nivel de cuenca}

El nivel de cuenca considera principalmente la captación, tratamiento y transporte del agua desde la fuente hasta el punto de suministro a las CCRRs. Cinco fuentes de agua diferentes se han considerado en este nivel: (1) superficial, (2) subterráneas, (3) Trasvase, (4) desalinizada, y (5) reciclada.

\subsubsection{Agua superficial}

La disponibilidad de este recurso ha sido muy variable a lo largo de los años analizados en la Región de Murcia, por la variabilidad en las precipitaciones, característico del clima mediterráneo semiárido. La captación de agua superficial tiene un reducido consumo de energía, ya que sólo requiere un pequeño bombeo para el suministro a las CCRRs. De las CCRRs analizadas en este Capítulo, sólo la CRCC empleó agua superficial. Los datos del consumo de agua y energía fueron obtenidos de la Confederación Hidrográfica del Segura (CHS).

\subsubsection{Aguas subterráneas}

La energía necesaria para impulsar las aguas subterráneas depende de numerosos factores, como la altura manométrica total (basada en la altura geométrica, rugosidad de 
la conducción y la presión requerida por el sistema), la velocidad de transporte y el rendimiento del grupo de bombeo (Lal, 2004). Los datos sobre la captación de aguas subterráneas y el consumo de energía fueron proporcionados por los gestores de los sondeos implicados.

\subsubsection{Trasvase Tajo-Segura}

Como se ha comentado en el Capítulo 2, en 1979 se inició el Trasvase de agua desde la cuenca del Tajo a la Cuenca del Segura para resolver los problemas sistemáticos de escasez de agua de la cuenca receptora. Un canal de 286 kilómetros de largo, denominado Acueducto Tajo-Segura, fue construido para el Trasvase, en una primera fase, de una cantidad anual de agua de $600 \mathrm{hm}^{3}$. En la práctica, la cantidad anual trasvasada es variable y depende de las reservas en cabecera, con un máximo de $400 \mathrm{hm}^{3}$ anuales para regadío. Durante el periodo de estudio los volúmenes medios trasvasados han sido de $221 \mathrm{hm}^{3}$ año ${ }^{-1}$ (CHS, 2013).

Los datos sobre el consumo de energía necesaria para el suministro a la CRCC y a la CRTCC con el agua trasvasada desde el Acueducto Tajo-Segura fueron obtenidos de la CHS y del Sindicato Central de Regantes del Acueducto Tajo-Segura (SCRATS).

\subsubsection{Desalinización}

La desalinización es considerada una fuente de agua viable en las regiones áridas y costeras, tales como California, Florida, el Mediterráneo y Oriente Medio. Sin embargo, el empleo de esta tecnología para la obtención de nuevos recursos hídricos no está exenta de críticas (Dickie, 2007), ya que el crecimiento de la desalinización se está produciendo a un coste considerable de energía y por su consecuente impacto ambiental. 
El coste de desalinizar el agua aumenta con la salinidad de la misma. El agua de mayor salinidad (por ejemplo, agua de mar) consume más energía y por lo tanto es más costosa su desalinización. La principal diferencia entre el coste de la desalinización de agua salobre y agua de mar es el consumo energético, lo que representa el $11 \%$ y el $44 \%$ de los costes totales, respectivamente (Younos, 2005). La desalinización por ósmosis inversa es la técnica más empleada en España, porque es la tecnología de desalación con menor consumo energético (Melgarejo y Montaño, 2009).

El volumen de agua utilizada y los datos de consumo de energía de este estudio se han tomado de la planta desalobradora "El Mojón", ubicada en San Pedro del Pinatar. Esta planta abastece de agua salobre desalada a la CRCC, que es la encargada de su gestión. La planta comenzó a utilizarse en 2002, emplea la tecnología de ósmosis inversa y tiene una producción de $2,2 \mathrm{hm}^{3}$ año ${ }^{-1}$.

\subsubsection{Reutilización}

Aunque el empleo de aguas residuales depuradas para riego de cultivos destinados al consumo humano suscita mucha preocupación a los consumidores y a las autoridades sanitarias, la reutilización se considera una solución para la escasez de agua y para mejorar el reciclaje de nutrientes (Styczen et al., 2010). En la Región de Murcia $115 \mathrm{hm}^{3}$ de aguas residuales fueron tratados en 2011 (ESAMUR, 2013).

El consumo de energía en el proceso de depuración del agua depende del tamaño de la planta, de la cantidad de materia orgánica eliminada, el tipo del reactor biológico empleado, y si se produce tratamiento terciario (Hernández-Sancho et al., 2010). En la Región de Murcia el consumo medio de energía específica en las estaciones depuradoras, entre 2006 y 2009, se incrementó de $0,56 \mathrm{kWh} \mathrm{m}^{-3}$ a $0,65 \mathrm{kWh} \mathrm{m}^{-3}$, debido 
al aumento del número de depuradoras que realizan el tratamiento terciario (ESAMUR, 2013).

Los datos utilizados en este estudio fueron proporcionados por la Entidad de Saneamiento y Depuración de Aguas Residuales de la Región de Murcia (ESAMUR). El volumen de agua tratada y el consumo de energía se obtuvieron de las cuatro estaciones de depuración de aguas residuales, con tratamiento terciario (Torre Pacheco, Balsicas-Roldán, Fuente Álamo y La Aljorra) que proveían de agua reutilizada a la CRCC durante el periodo analizado.

\subsubsection{Niveles de comunidad de regantes y de parcela}

Las CCRRs en España son asociaciones colectivas que organizan, distribuyen y suministran el agua, obtenida de diferentes fuentes, a las explotaciones agrícolas de su zona regable; como ya se expuso en el Capítulo 2. Las principales características de las CCRRs analizadas en este estudio se muestran en la Tabla 4.2.

Tabla 4.2. Principales características de las CCRRs analizadas en el periodo 2002-2011.

\begin{tabular}{|c|c|c|c|}
\hline & \multicolumn{3}{|c|}{ Comunidades de regantes } \\
\hline & CRCC & CRTCC & CRM \\
\hline Superficie regada $(\mathrm{Sr} ; \mathrm{ha})^{\mathrm{a}}$ & $30.831-34.131$ & $2.882-3.131$ & $1.182-1.283$ \\
\hline Volumen anual suministrado $\left(\mathrm{Vs} ; \mathbf{h m}^{\mathbf{3}}\right)^{\mathrm{a}}$ & $17,88-104,50$ & $6,84-12,06$ & $3,38-4,86$ \\
\hline Regantes $\left(n^{0}\right)$ & 2.962 & 350 & 972 \\
\hline \multicolumn{4}{|l|}{ Fuentes de agua $(\%)^{\mathrm{a}}$} \\
\hline Superficial & $1-10$ & - & - \\
\hline Subterráneas & $0-20$ & $0-82$ & 100 \\
\hline Trasvase Tajo-Segura & $70-97$ & $18-100$ & - \\
\hline Desalada & $1-7$ & - & - \\
\hline Reciclada & $0-2$ & - & - \\
\hline Método de distribución & Por turnos & A la demanda & A la demanda \\
\hline Principal sistema de riego & Localizado (96\%) & Localizado (100\%) & Localizado (100\%) \\
\hline
\end{tabular}

${ }^{a}$ máximo y mínimo valor en el periodo 2002-2011. 
Los datos, para poder analizar el consumo hídrico y energético de estas CCRRs, fueron proporcionados por los gestores de las mismas, procedentes de sus bases de datos.

El manejo del sistema de riego a nivel parcela está condicionado por el sistema de distribución de la CCRR. Las dos alternativas más comunes son:

- Parcelas con su propio sistema de bombeo. En la CRCC la distribución del agua se organiza por turnos. Los agricultores captan el agua de las tomas de riego de la red colectiva y la almacenan en sus balsas particulares. En estas condiciones, cada agricultor tiene un sistema de bombeo propio para suministrar el agua con la presión necesaria para el correcto funcionamiento de su sistema de riego, por estas causas se produce un consumo extra de energía a nivel parcela.

- Parcelas sin sistema de bombeo propio. En la CRTCC y la CRM se suministra el agua a sus comuneros a la demanda y con presión. Gracias a este sistema de distribución, los agricultores tienen conectados sus sistemas de riego directamente a la toma de la de la red colectiva, con lo que aprovechan la presión disponible en la misma, por ello no necesitan un consumo adicional de energía para el riego en sus explotaciones.

El consumo total de energía por el riego se obtuvo como la suma del consumo en los diferentes niveles de gestión del agua: cuenca, CCRR y parcela (Fig. 4.1).

Los datos necesarios para calcular los indicadores en parcela fueron obtenidos a través de encuestas realizadas a los agricultores. Estas encuestas se realizaron en el invierno de 2012 con el fin de caracterizar la actividad de los agricultores en el año 2011. Se obtuvieron datos referentes a sus explotaciones agrícolas, sobre las 
características de los cultivos y de los sistemas de riego, inputs agrícolas, aplicación de agua, consumo de energía y el rendimiento de los cultivos.

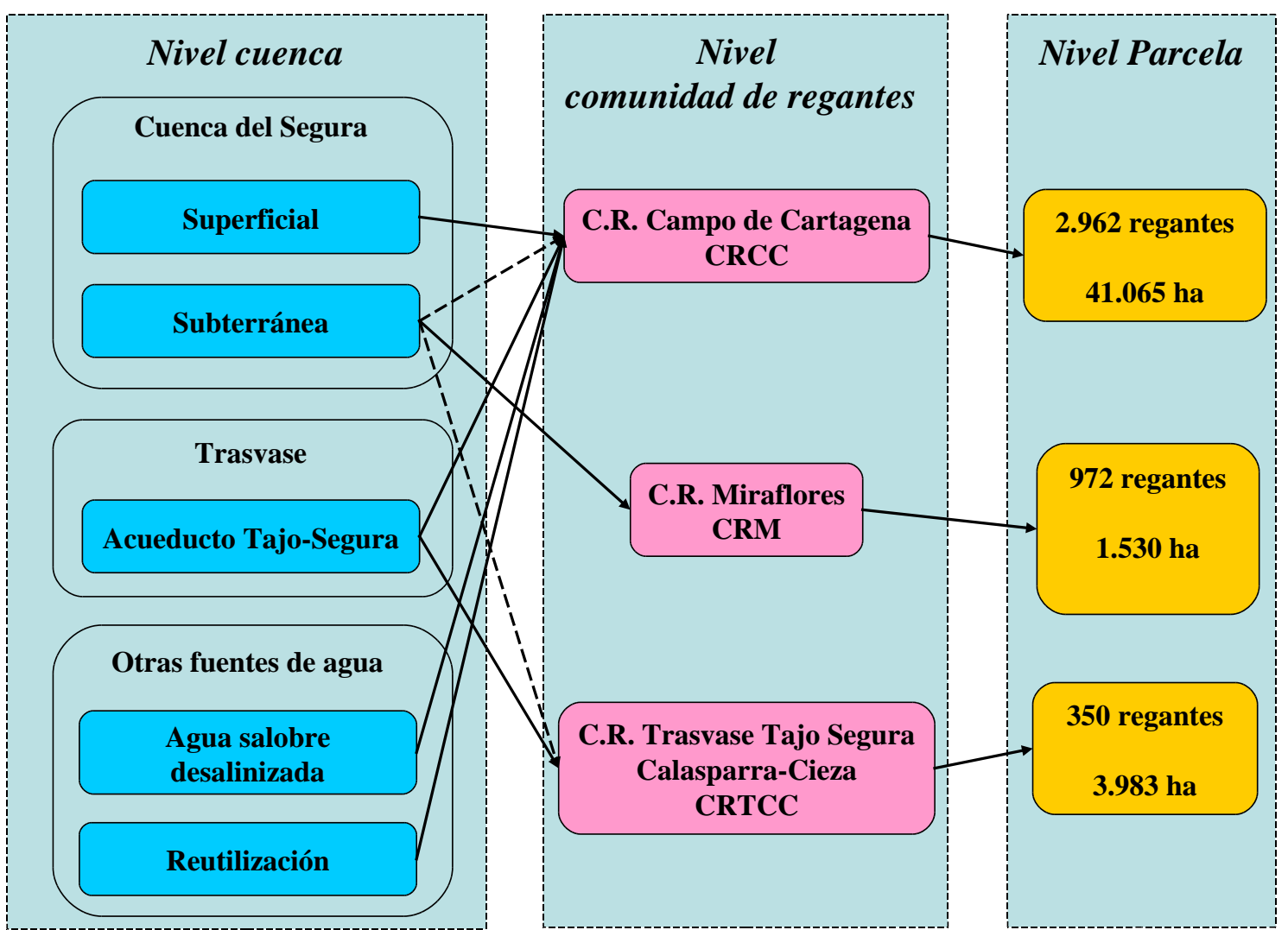

Figura 4.1. Resumen de los niveles de gestión para obtener el consumo de energía global para el riego en la Región de Murcia.

\subsection{RESULTADOS}

\subsubsection{Consumo agua y energía}

La Tabla 4.3 presenta el valor medio y el rango de variación para el periodo de estudio de la energía específica (EacVs) consumida en cada nivel de gestión por CCRR. La EacVs en el nivel de la cuenca se obtuvo mediante la ponderación del consumo de energía en función del porcentaje de agua suministrada de cada fuente. 
Tabla 4.3. Energía específica (EacVs) por CCRR. Valor medio y rango en el período 20022011.

\begin{tabular}{|c|c|c|c|c|c|c|}
\hline \multirow[t]{3}{*}{ Niveles de gestión } & \multicolumn{6}{|c|}{ Comunidades de regantes } \\
\hline & \multicolumn{2}{|c|}{ CRCC } & \multicolumn{2}{|c|}{ CRTCC } & \multicolumn{2}{|c|}{ CRM } \\
\hline & $\begin{array}{c}\text { medio } \\
\left(\mathrm{kWh} \mathrm{m}^{-3}\right) \\
\end{array}$ & 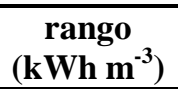 & 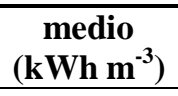 & 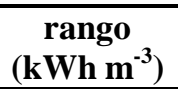 & 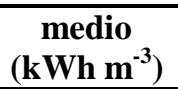 & $\begin{array}{c}\text { rango } \\
\left(\mathrm{kWh} \mathrm{m}^{-3}\right) \\
\end{array}$ \\
\hline \multicolumn{7}{|l|}{ Nivel cuenca } \\
\hline Superficial & 0,06 & $0,04-0,10$ & - & - & - & - \\
\hline Subterránea & 0,95 & $0,94-0,96$ & 0,90 & $0,89-0,91$ & 0,81 & $0,80-0,82$ \\
\hline Trasvase & 0,98 & $0,94-1,01$ & 0,98 & $0,94-1,01$ & - & - \\
\hline Desalinizada & 1,40 & $0,83-1,69$ & - & - & - & - \\
\hline Reutilizada & 0,78 & $0,72-0,86$ & - & - & - & - \\
\hline Total nivel cuenca $(1)^{a}$ & 0,95 & $0,87-1,02$ & 0,95 & $0,91-1,01$ & 0,81 & $0,80-0.82$ \\
\hline Nivel CCRR (2) & 0,16 & $0,14-0,20$ & 0,18 & $0,16-0,20$ & 0,15 & $0,15-0,16$ \\
\hline Nivel parcela (3) & 0,17 & $0,16-0,19$ & - & - & - & - \\
\hline $\begin{array}{l}\text { Total energía específica } \\
(1+2+3)\end{array}$ & $\mathbf{1 , 3 3}$ & $1,20-1,55$ & 1,18 & $1,10-1,25$ & 0,99 & $0,95-1,02$ \\
\hline
\end{tabular}

\subsubsection{Nivel de cuenca}

El agua superficial se empleó sólo en la CRCC, siendo el valor medio de la

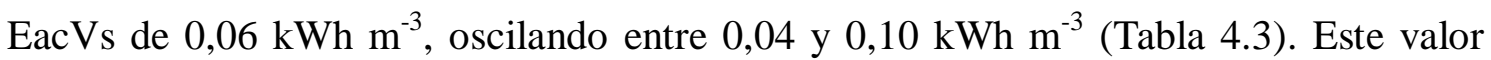
medio es similar al indicado en EEUU para esta fuente de agua (WWAP, 2012). El agua superficial utilizada en la CRCC varió de 1 al 10\% del agua total suministrada (Tabla 4.2), por lo que su impacto relativo en el consumo total de energía fue el más bajo. El uso de una mayor cantidad de agua superficial sería lo aconsejado desde un punto de vista energético, debido a que su EacVs es la más baja, sin embargo por lo general suele ser la fuente más sensible a la sequía, por lo que su disponibilidad es muy irregular en la Región de Murcia.

Las aguas subterráneas fueron empleadas en todas las CCRRs. Los valores medios de EacVs fueron de $0,95 \mathrm{kWh} \mathrm{m}^{-3}$ para CRCC, 0,90 $\mathrm{kWh} \mathrm{m}^{-3}$ para CRTCC y 0,81 $\mathrm{kWh} \mathrm{m}^{-3}$ para CRM. La variación del consumo de energía por la extracción de las aguas subterráneas fue debido a la diferencia de las características de los diferentes sondeos y a la modificación de los niveles piezométricos durante el periodo de estudio. 
Los valores de EacVs obtenidos fueron superiores a los indicados en California $(0,14-$ 0,69 $\mathrm{kWh} \mathrm{m}^{-3}$ ) por Plappally y Lienhard (2012).

El Trasvase Tajo-Segura fue la fuente principal de agua en la CRCC y la CRTCC. Concretamente este aporte representó entre el 70 y el 97\% del volumen total distribuido por la CRCC y el 100\% en la CRTCC, excepto en los años de sequía, donde se produjo una reducción del porcentaje de este recurso en un $82 \%$ (Tabla 4.2). El valor de EacVs obtenido para el agua trasvasada es la misma para CRCC y CRTCC $(0,98$ $\mathrm{kWh} \mathrm{m}^{-3}$ ), ya que ambas CCRRs captan el agua en el mismo tramo del Acueducto TajoSegura. Este consumo fue ligeramente menor que el consumo de energía medio del Trasvase Tajo-Segura (1,21 kWh m $\left.{ }^{-3}\right)$ (Melgarejo y Montaño, 2009).

El agua salobre desalinizada sólo se empleó en la CRCC, que es la más cercana a la costa. Esta fuente presenta los más altos valores de EacVs $\left(1,4 \mathrm{kWh} \mathrm{m}^{-3}\right)$, de acuerdo con el rango de EacVs de agua desalada salobre (1-1,5 $\left.\mathrm{kWh} \mathrm{m}^{-3}\right)$ indicado por Melgarejo y Montaño (2009). El porcentaje de agua salobre desalada en relación con el agua distribuida por la CRCC fue bastante pequeño (1-7\%, Tabla 4.2) y, en consecuencia, casi no influyó en el consumo total de energía. El consumo de energía para la desalinización de agua de mar por ósmosis inversa es muy superior al resultado obtenido para la desalinización del agua salobre en la CRCC, estando comprendidos para la ósmosis inversa en un rango entre 3,5 y $5 \mathrm{kWh} \mathrm{m}^{-3}$ (Melgarejo y Montaño, 2009).

La reutilización sólo se empleó en la CRCC. La CRCC comenzó a utilizar el agua reutilizada en el año 2008 debido a la disminución considerable de los recursos procedentes del Trasvase y a la construcción de nuevas plantas depuradoras en su comarca con tratamiento terciario. El volumen de agua reutilizada ha aumentado año tras año desde entonces, aunque el volumen máximo suministrado por la CRCC sólo ha 
representado el $2 \%$ de agua de esta procedencia (Tabla 4.2). Algunos autores han atribuido el bajo uso de este tipo de agua en las CCRRs a la estricta legislación vigente que impone unos requisitos mínimos de su calidad en función de la aplicación de la reutilización (García y Casañas, 2010). La EacVs del agua reutilizada fue de 0,78 kWh $\mathrm{m}^{-3}$ (Tabla 4.3), un valor parecido a los obtenidos en California, donde la horquilla está entre $0,30-0,50 \mathrm{kWh} \mathrm{m}^{-3}$ y el tratamiento terciario supone $0,25 \mathrm{kWh} \mathrm{m}^{-3}$ adicional (Cabrera, 2011). El uso de la reutilización ofrece importantes ventajas medioambientales, ya que reduce la presión sobre los recursos hídricos convencionales, y al mismo tiempo reduce la contaminación de los ríos, lagos y playas. De esta forma, los efectos negativos sobre las aguas superficiales y subterráneas se reducen (Plappally et al., 2012).

Por tanto, en relación con el consumo de energía específica obtenido, lo aconsejable sería el empleo de las fuentes de agua por este orden: superficial, reutilización, subterránea, Trasvase y agua salobre desalada. Las medidas para el ahorro de energía a nivel de cuenca son las más interesantes, ya que en este nivel se produce el mayor consumo de energía, suponiendo el $71 \%$ del total de EacVs en la CRCC, y el $82 \%$ en CRTCC y CRM.

\subsubsection{Niveles de comunidad de regantes y de parcela}

Como ya se ha indicado, el método de distribución del agua en la CRCC es por turnos, siendo el sistema de riego localizado el mayoritario en su zona regable. Por ello, los agricultores deben almacenar el agua proporcionada por la CRCC en sus balsas de riego particulares, para poder regar diariamente sus parcelas, debido a este hecho la presión disponible en las tomas de riego de la red colectiva no es aprovechada. Con lo 
que se produce un consumo adicional de energía a nivel parcela, necesario para el funcionamiento de los sistemas de riego particulares instalados.

En la CRTCC y la CRM el método de distribución del agua es a la demanda. Los agricultores de estas CCRRs tienen conectados sus sistemas de riego a las tomas de riego de las redes colectivas, con lo que aprovechan la presión disponible en las tomas de riego para el funcionamiento de sus equipos de riego. De esta manera se evita un consumo de energía adicional en parcela.

La EacVs a nivel de comunidad de regantes y parcela para la CRCC fue de 0,16 $\mathrm{kWh} \mathrm{m}^{-3}$ y $0,17 \mathrm{kWh} \mathrm{m}^{-3}$, respectivamente (Tabla 4.3), siendo por tanto el total de ambos niveles 0,33 $\mathrm{kWh} \mathrm{m}^{-3}$. La EacVs a nivel de comunidad de regantes para CRTCC y CRM fue de 0,18 y $0,15 \mathrm{kWh} \mathrm{m}^{-3}$ respectivamente, no teniendo un consumo de energía adicional para riego a nivel parcela, tal como se ha comentado.

El disponer de un sistema de distribución a la demanda y que los sistemas de riego de los agricultores estén conectados a las tomas de la CCRR, aprovechando la presión disponible, ha propiciado un ahorro de energía en la CRTCC y en la CRM del 47 y el 54\% de la EacVs requerida a nivel comunidad de regantes y parcela, en comparación con el manejo que se realiza en la CRCC.

Estudios previos a nivel parcela (Corominas, 2009) indicaron que el consumo medio de energía para el riego localizado en España fue de $0,18 \mathrm{kWh} \mathrm{m}^{-3}$. Este valor es similar al obtenido en la CRCC $\left(0,17 \mathrm{kWh} \mathrm{m}^{-3}\right)$. Valores más altos fueron obtenidos en Australia, donde el empleo del método de riego localizado presenta un consumo de energía de 0,22 $\mathrm{kWh} \mathrm{m}^{-3}$ (Ahmad y Khan, 2009). 


\subsubsection{Consumo global de energía}

La Fig. 4.2 muestra el porcentaje de cada fuente de agua y los valores totales de EacVs en cada CCRR para el período de estudio.

a)

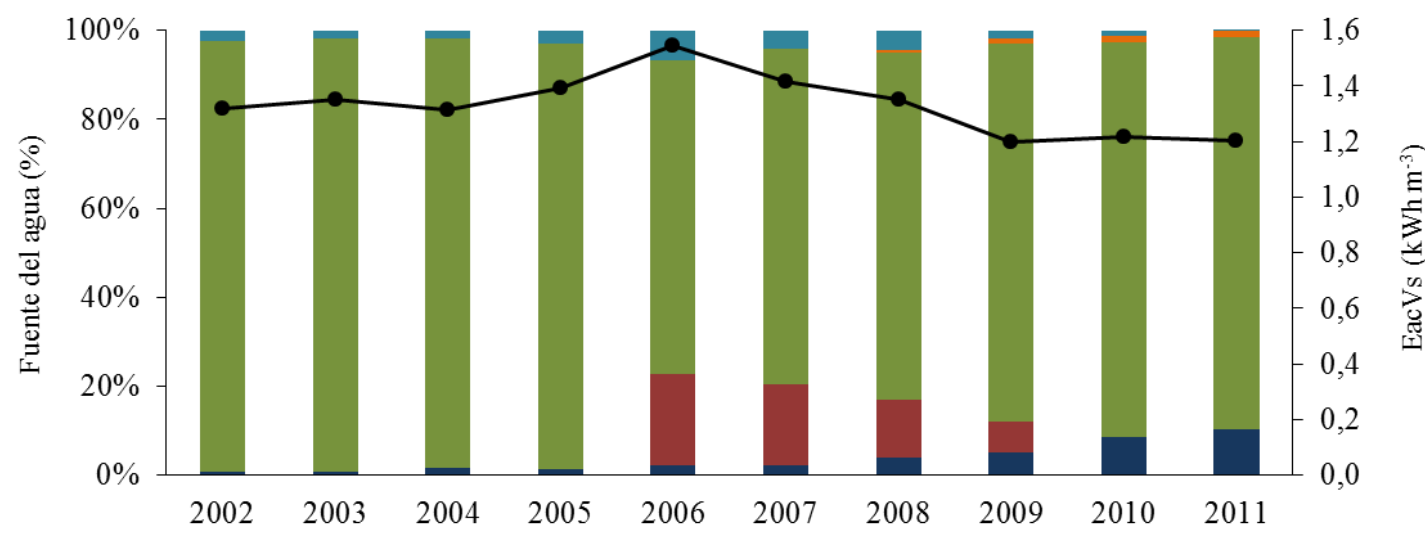

b)

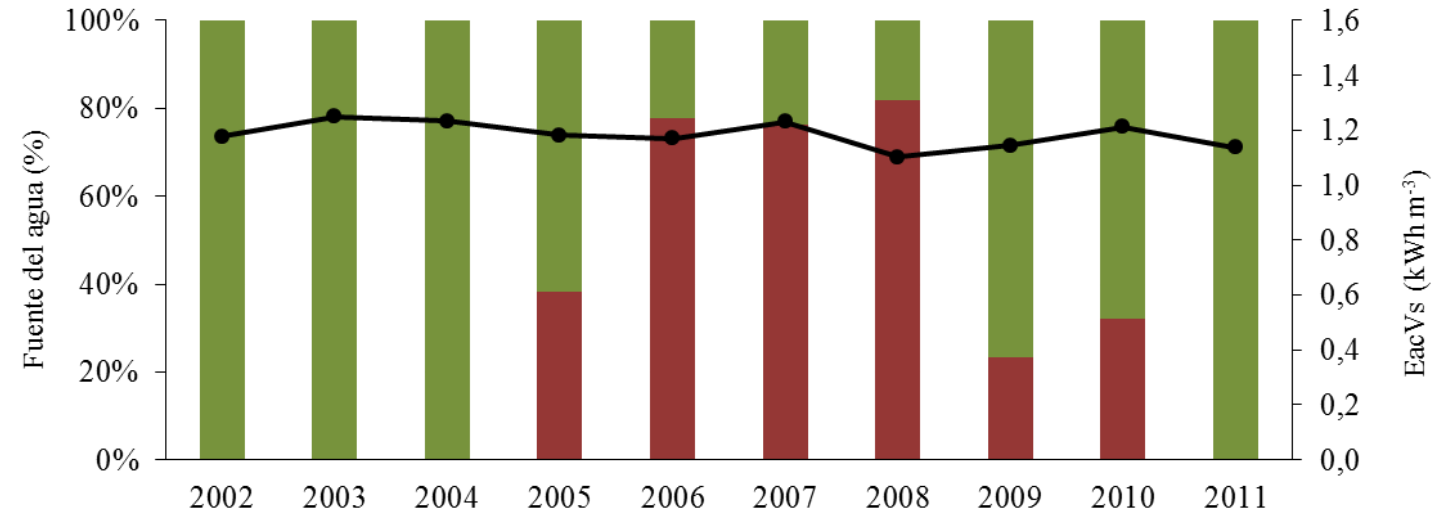

c)

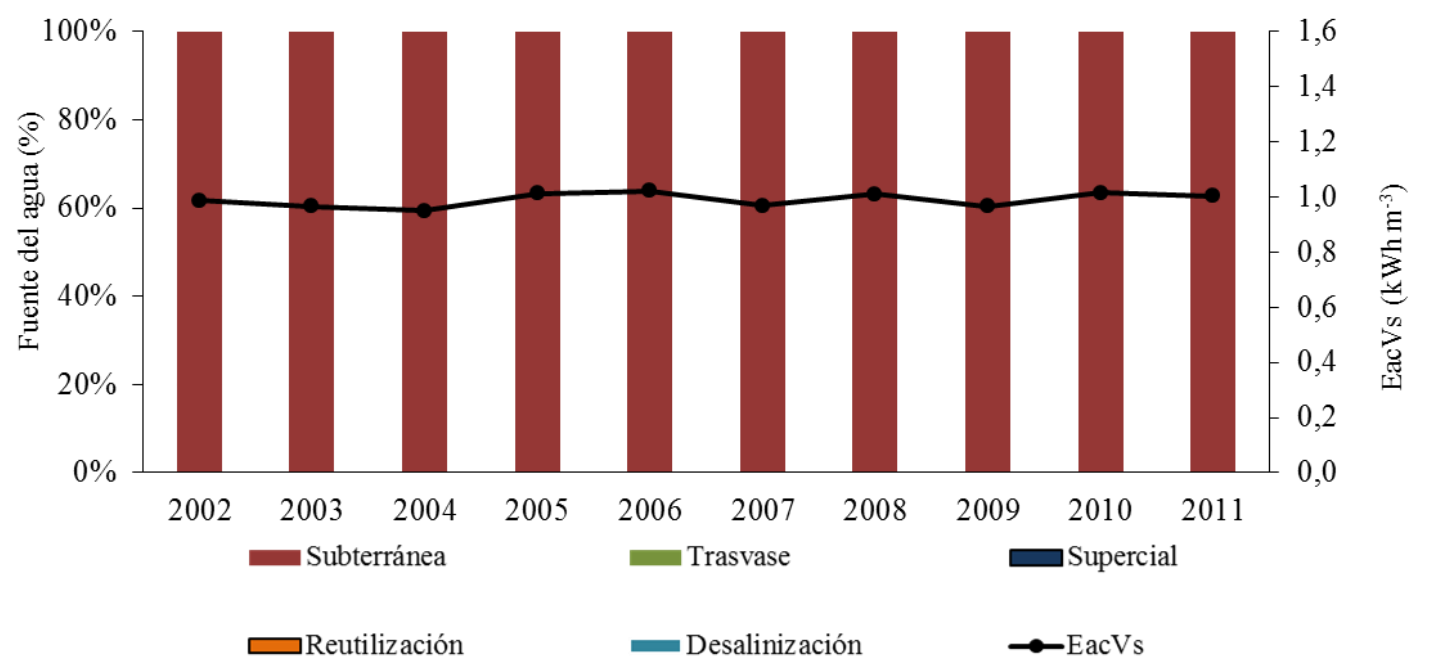

Figura 4.2. Evolución de las fuentes de agua y la energía específica (EacVs) por CCRRs en el periodo estudiado. a) CRCC; b) CRTCC; c) CRM. 
En la CRCC el Trasvase proporcionó entre el 88 y el 97\% del total de agua suministrada en los años considerados como normales (2002, 2003, 2004 y 2011), el volumen restante $12-3 \%$ fue agua desalada, superficial y procedente de la reutilización (Fig. 4.2a). La EacVs en este período estuvo comprendida entre 1,20 y $1,32 \mathrm{kWh} \mathrm{m}^{-3}$. Del año 2006 al 2009 hubo una sequía intensa y prolongada, lo que provocó la autorización de la CHS para la utilización de las aguas subterráneas proporcionadas por el SCRATS, así como comenzó el empleo de la reutilización y un mayor uso del agua desalada. Como consecuencia de ello, EacVs aumentó en este período, llegando a ser de hasta $1,55 \mathrm{kWh} \mathrm{m}^{-3}$ en 2006.

En la CRTCC los recursos procedieron del Trasvase Tajo-Segura, aunque durante los años 2005 a 2010, la CHS autorizó la captación de las aguas subterráneas para mitigar los efectos de la sequía, lo que significó un porcentaje del total de agua suministrada que osciló entre el 23 y el $82 \%$ (Fig. 4.2b). La EacVs en la CRTCC se mantuvo bastante constante durante el periodo de estudio ya que el valor de EacVs para ambos recursos fue similar, $0,98 \mathrm{kWh} \mathrm{m}^{-3}$ para el agua procedente del Trasvase y 0,95 $\mathrm{kWh} \mathrm{m}^{-3}$ para las aguas subterráneas.

En la CRM el valor de EacVs fue bastante uniforme, variando entre 0,95 y 1,02 $\mathrm{kWh} \mathrm{m}^{-3}$, con un valor medio de $0,99 \mathrm{kWh} \mathrm{m}^{-3}$ (Fig. 4.2c). El uso de una única fuente de agua (aguas subterráneas) justifica el valor uniforme de este indicador.

Resumiendo, el valor medio de EacVs para las CCRRs analizadas fue de 1,17 $\mathrm{kWh} \mathrm{m}^{-3}$, que varió entre 0,95 y 1,55 $\mathrm{kWh} \mathrm{m}^{-3}$ (Tabla 4.3). Este valor es muy superior a la EacVs media para los sistemas de riego localizado en España, que es 0,53 $\mathrm{kWh} \mathrm{m}^{-3}$ (Corominas, 2009). La principal razón que justifica esta gran diferencia es que el 79\% del agua empleada para riego en España es agua superficial (INE, 2012), siendo el recurso que necesita una menor energía específica, mientras que en nuestro estudio, solo 
la CRCC ha empleado este tipo de agua, representando un 6\% de los recursos consumidos.

\subsubsection{Relación entre el consumo de energía y agua}

En la Fig. 4.3 se representa la evolución del suministro de agua por unidad de área regada $(\mathrm{VsSr})$ y la energía activa consumida por unidad de superficie regada (EacSr) durante el periodo de estudio en la CRCC (Fig. 4.3a), la CRTCC (Fig. 4.3c ) y la CRM (Fig. 4.3e). La Fig. 4.3 también evalúa la sensibilidad de la energía específica (EacVs) a la variación de VsSr mediante regresión potencial entre estas variables en la CRCC (Fig. 4.3b), la CRTCC (Fig. 4.3d) y la CRM (Fig. 4.3f).

Se observa una gran sensibilidad a la sequía en la CRCC, ya que VsSr disminuye un $70 \%$ entre el periodo con normal disponibilidad de recursos (2002, 2003, 2004 y 2011) y el periodo de sequía (2006-2009). Esta gran sensibilidad se debe a que la principal fuente de agua en la CRCC es el Trasvase Tajo-Segura, que está vinculado a los recursos existentes en los embalses de Entrepeñas y Buendía (cabecera del Tajo) y a las decisiones sobre la autorización de estos trasvases. Se observa cierto paralelismo entre EacSr y VsSr (Fig. 4.3a), aunque el análisis de regresión entre EacVs y VsSr (Fig. 4.3b) pone de manifiesto que para valores menores de $\mathrm{VsSr}$ aumenta EacVs, lo que representa una disminución de la eficiencia energética del sistema durante los periodos de escasez de agua. Este resultado se debe a tres motivos: (a) durante la sequía se produce una disminución de los recursos procedentes del Trasvase, aumentando el porcentaje del consumo de otros recursos alternativos (aguas subterráneas, reutilización y agua salobre desalada); (b) la eficiencia de distribución del sistema (ED) disminuyó en los periodos de sequía, pasando del $98 \%$ en el periodo normal de suministro al $89 \%$ en los años más secos, aunque las pérdidas de agua por fugas y evaporación se 
mantuvieron bastante estables, representaban un porcentaje más alto del volumen distribuido a medida que aumenta la escasez de recursos disponibles para su suministro; y (c) el rendimiento hidráulico de los grupos de bombeo disminuye cuando se manejan caudales inferiores a los que se consideraron en su diseño, afectando por tanto a su rendimiento energético.
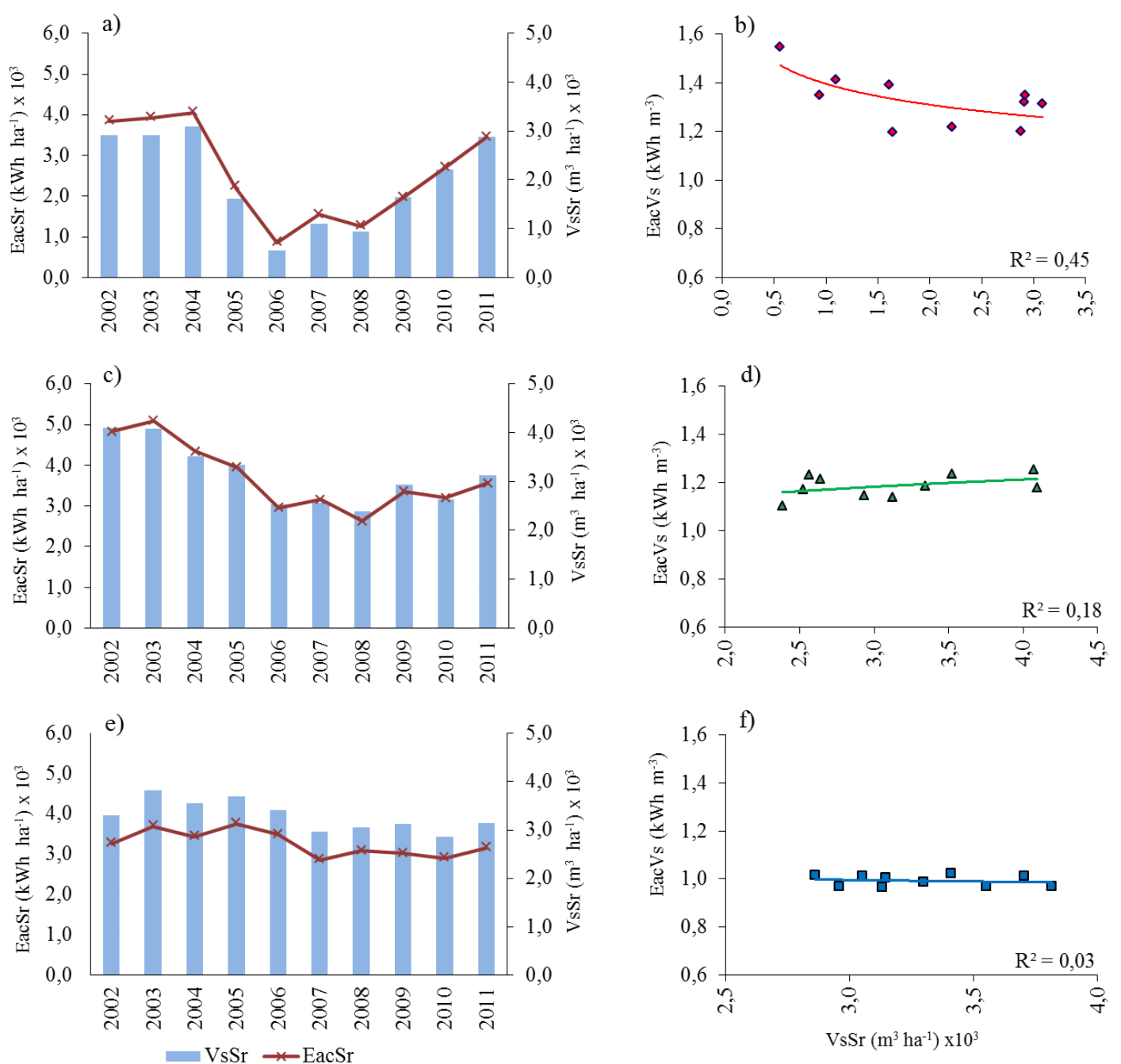

Figura 4.3. Evolución del suministro de agua por unidad de área regada (VsSr) y la energía activa consumida por unidad de superficie regada (EacSr) del 2002 al 2011 en la CRCC (a), la CRTCC (c) y la CRM (e). Relación entre el volumen suministrado de agua por unidad de área regada (VsSr) y la energía específica (EacVs) en la CRCC (b), la CRTCC (d) y la CRM (f).

La CRTCC muestra una sensibilidad a la sequía intermedia, con una disminución del 33\% en VsSr durante el periodo seco (Fig. 4.3c). El comportamiento de 
la CRTCC debería ser similar a la CRCC, ya que en condiciones normales se abastece exclusivamente del agua del Trasvase Tajo-Segura. Sin embargo, la CHS le autoriza el uso de agua subterránea en periodo de sequía, lo que le permite paliar parcialmente sus efectos, dado que dispone de pozos propios. Este menor descenso en VsSr hace que el efecto de la sequía en la ED también sea menor que en la CRCC, disminuyendo solamente del 96 al 92\%. La Fig. 4.3d muestra un ligero descenso de la energía específica con la sequía, resultado que está justificado por un mayor porcentaje de agua subterránea, con una menor energía específica que el agua trasvasada.

El comportamiento de la CRM es completamente distinto al observado en la CRCC. Apenas se observa sensibilidad a la sequía ya que VsSr sólo disminuyó un 9\% durante el periodo seco (Fig. 4.3e). Las escasas variaciones en VsSr explican el valor casi constante de la ED, que tan sólo oscila entre el $97 \%$ del periodo normal de suministro y el $95 \%$ en los años de mayor sequía. Este comportamiento independiente de los ciclos de sequía se debe a que la CRM se abastece exclusivamente de agua subterránea, recurso en menor medida afectado por los ciclos hidrológicos, como puede ser el agua superficial. Aun así la Fig. 4.3f muestra una ligera tendencia a aumentar en EacVs frente a valores de decrecientes de $\mathrm{VsSr}$, circunstancia que puede estar justificada por descensos en los niveles piezométricos habituales durante los ciclos de sequía, con el consecuente aumento de la energía específica requerida para la extracción del agua por los grupos de bombeo.

La Fig. 4.4 muestra la relación entre EacSr y $\mathrm{VsSr}$, que presentan una clara relación lineal para cada CCRR $\left(\mathrm{R}^{2}=0,98,0,97\right.$ y 0,92 para la CRCC, CRTCC y CRM, respectivamente, $\mathrm{p}<0,05$ para todas ellas). La pendiente de la regresión linear (forzada al origen) representa la energía anual consumida dividida por el volumen de agua suministrada, es decir, los EacVs total promedio para cada CCRR. Por cada $\mathrm{m}^{3}$ de agua 
aplicada el mayor consumo de energía se produjo en la CRCC y el menor en la CRM; presentando la CRTCC un valor intermedio. Estos valores ratifican los valores obtenidos en la Tabla 4.3. La reducción de VsSr en los periodos secos supuso una mayor reducción de EacSr en aquellas CCRRs con mayor pendiente (Fig. 4.4).

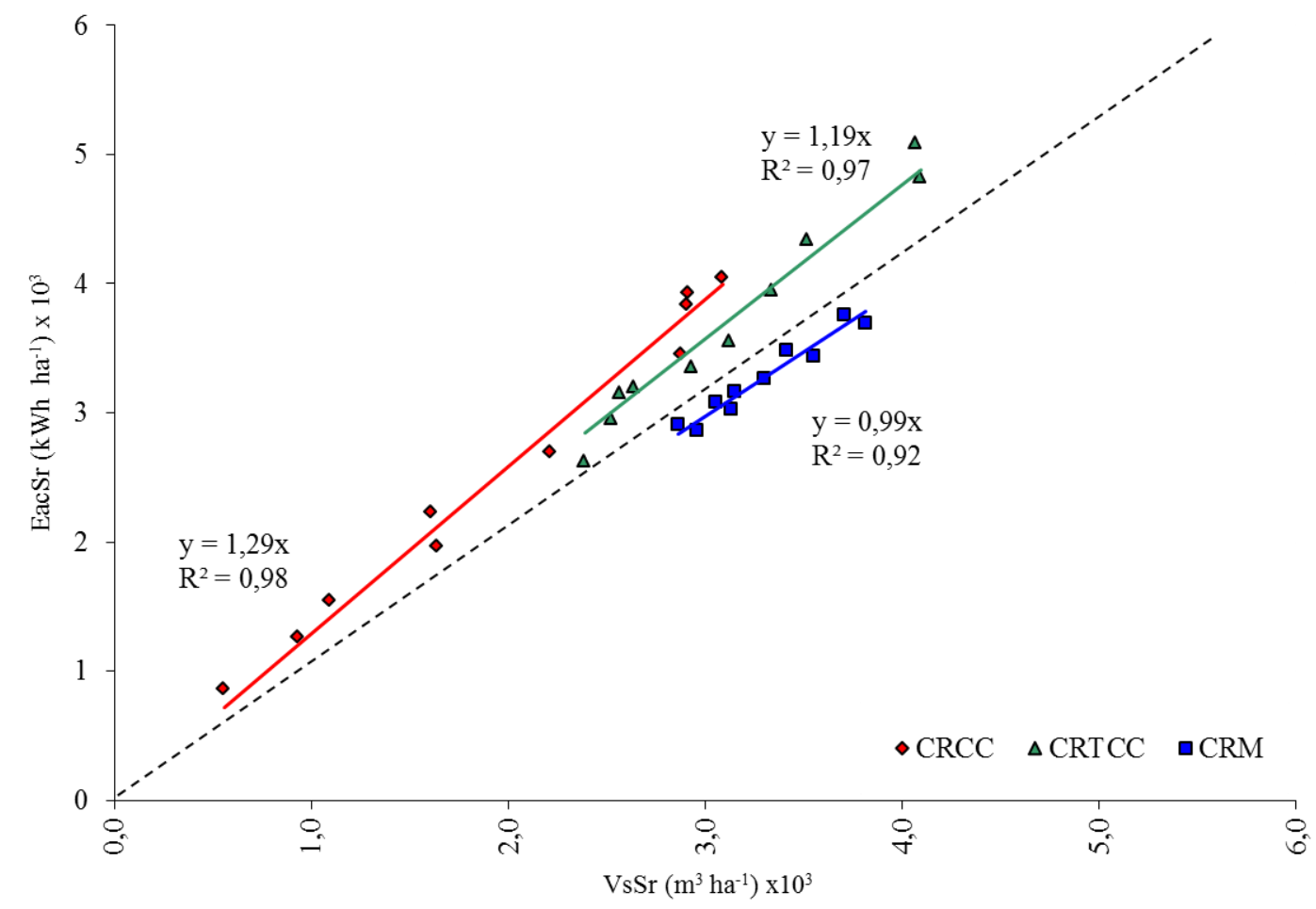

Figura 4.4. Relación entre la energía activa consumida por unidad de superficie regada (EacSr) y el suministro de agua por unidad de área regada (VsSr) por CCRR.

El consumo anual de la EacSr correspondiente a cada nivel de gestión y la EacSr total en cada CCRR se muestra en la Fig. 4.5. La EacSr media total varió entre 2.586 kWh ha ${ }^{-1}$ en la CRCC a $3.707 \mathrm{kWh} \mathrm{ha}^{-1}$ en CRTCC. En España, con la aplicación de unos $5.000 \mathrm{~m}^{3} \mathrm{ha}^{-1}$ por los sistemas de riego localizado, se estima que la energía requerida es aproximadamente de $2.640 \mathrm{kWh} \mathrm{ha}^{-1}$ (Corominas, 2009).

A nivel cuenca el rango medio de EacSr estuvo comprendido entre $1.891 \mathrm{kWh}$ $\mathrm{ha}^{-1}$ para la CRCC y $2.997 \mathrm{kWh} \mathrm{ha}^{-1}$ en la CRTCC; a nivel comunidad de regantes EacSr estuvo comprendido entre $314 \mathrm{kWh} \mathrm{ha}^{-1}$ en la CRCC y $544 \mathrm{kWh} \mathrm{ha}^{-1}$ en la 
CRTCC; y a nivel parcela fue $0 \mathrm{kWh} \mathrm{ha}^{-1}$ para la CRTCC y CRM, mientras que para la CRCC tuvo un valor medio de $327 \mathrm{kWh} \mathrm{ha}^{-1}$.
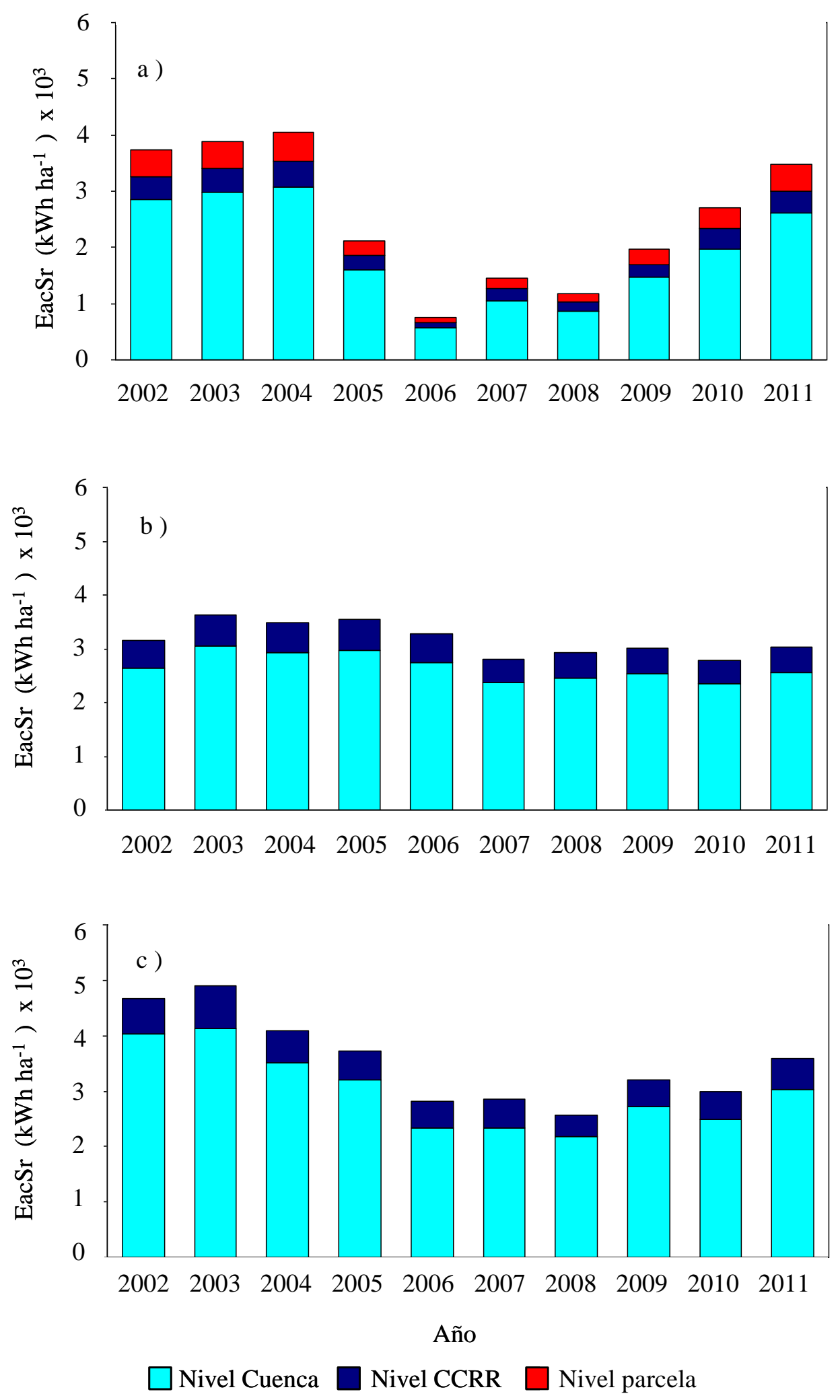

Figura 4.5. Evolución de la energía activa consumida por unidad de superficie regada (EacSr) por niveles de gestión desde el 2002 al 2011 en la CRCC (a), la CRM (b), y la CRTCC (c). 


\subsubsection{Efectos de la modernización en los indicadores energéticos}

El efecto de la modernización se evaluó comparando el valor de los indicadores energéticos empleados antes y después de este proceso, considerando períodos con similar VsSr. Bajo esta condición, el efecto de la escasez de agua en los indicadores puede dejarse de lado y la variación en los mismos puede atribuirse principalmente al proceso de modernización.

Los años comparados en la CRCC fueron 2002 (antes de la modernización) y 2011 (después de la modernización). Cabe señalar que VsSr fue prácticamente el mismo en esos años (-1,1\% de variación) y también hubo sólo una pequeña variación en la fuente de los recursos empleados. EacVs tuvo a una disminución del 9\% que puede atribuirse: (a) al aumento de la ED del $96 \%$ al 99\% debido al proceso de modernización, (b) a una mejor gestión y control de los grupos de bombeo debido a la asimilación de control remoto y tecnologías automáticas en el proceso de modernización, y (c) al aumento del porcentaje de agua superficial en el conjunto de las fuentes de agua disponibles, que pasó de 1 a 10\% entre 2002 y 2011. Como consecuencia de la reducción de EacVs, EacSr experimentó una disminución casi proporcional del 10\%.

Los años seleccionados para la CRTCC fueron 2005 (antes de la modernización) y 2011 (después de la modernización). En este caso hubo un 5,7\% de disminución en VsSr y no fue posible encontrar una combinación de años antes y después de la modernización con una variación de VsSr menor. Cabe señalar que en 2005 el 37\% de los recursos empleados fueron procedentes de agua subterránea, mientras que en el 2011 fueron todos procedentes del Trasvase Tajo-Segura. Aunque el agua subterránea tuvo una energía específica más baja que el agua procedente del Trasvase para CRTCC (Tabla 3), se observó una reducción del 4\% en EacVs entre 2005 y 2011, dejando claro que se produjo una mejora en la eficiencia energética del sistema. Esta mejora puede 
atribuirse principalmente al incremento de la ED de $93 \%$ a $99 \%$ y la asimilación de las nuevas tecnologías, ambas causas son consecuencia del proceso de la modernización. EacSr experimentó una disminución del 10\% entre 2005 y 2010, casi el doble que VsSr, evidenciando así de nuevo una mejora en la eficiencia del sistema.

Como se indicó anteriormente, la modernización de la CRM había finalizado en 2002, por lo que el efecto de la modernización en los indicadores energéticos no puede ser analizado para esta CCRR.

\subsection{DISCUSIÓN}

Tres niveles de gestión del agua están implicados en el suministro para el riego de los cultivos agrícolas: cuenca, comunidad de regantes y parcela. El análisis correcto del consumo de energía en cada nivel de gestión es necesario para conocer el valor global de los indicadores energéticos en la producción agrícola, así como para poder realizar un análisis comparativo local o regional (benchmarking).

Del presente estudio se desprende que el mayor consumo de energía por metro cúbico del agua suministrada o energía específica (EacVs) se produjo a nivel de cuenca, representando entre un 71 y un $82 \%$ del total. En este nivel el factor que más influyó en el consumo de energía fue el origen del agua, siendo el agua superficial la que presentó menor EacVs, y el agua salobre desalada la de mayor (Fig. 4.6). La EacVs consumida en el nivel de comunidad de regantes representó entre el 12 y el $15 \%$ del total, con consumos muy similares entre las tres comunidades de regantes consideradas en este estudio. A nivel parcela, la disponibilidad de la presión en las redes colectivas de riego eliminó el consumo de energía adicional para el sistema de riego cuando el método de distribución fue a la demanda, mientras que implicaba la re-presurización del sistema de 
riego cuando el método de distribución era por turnos. En este último caso, EacVs a nivel parcela representó el 13\% del total.

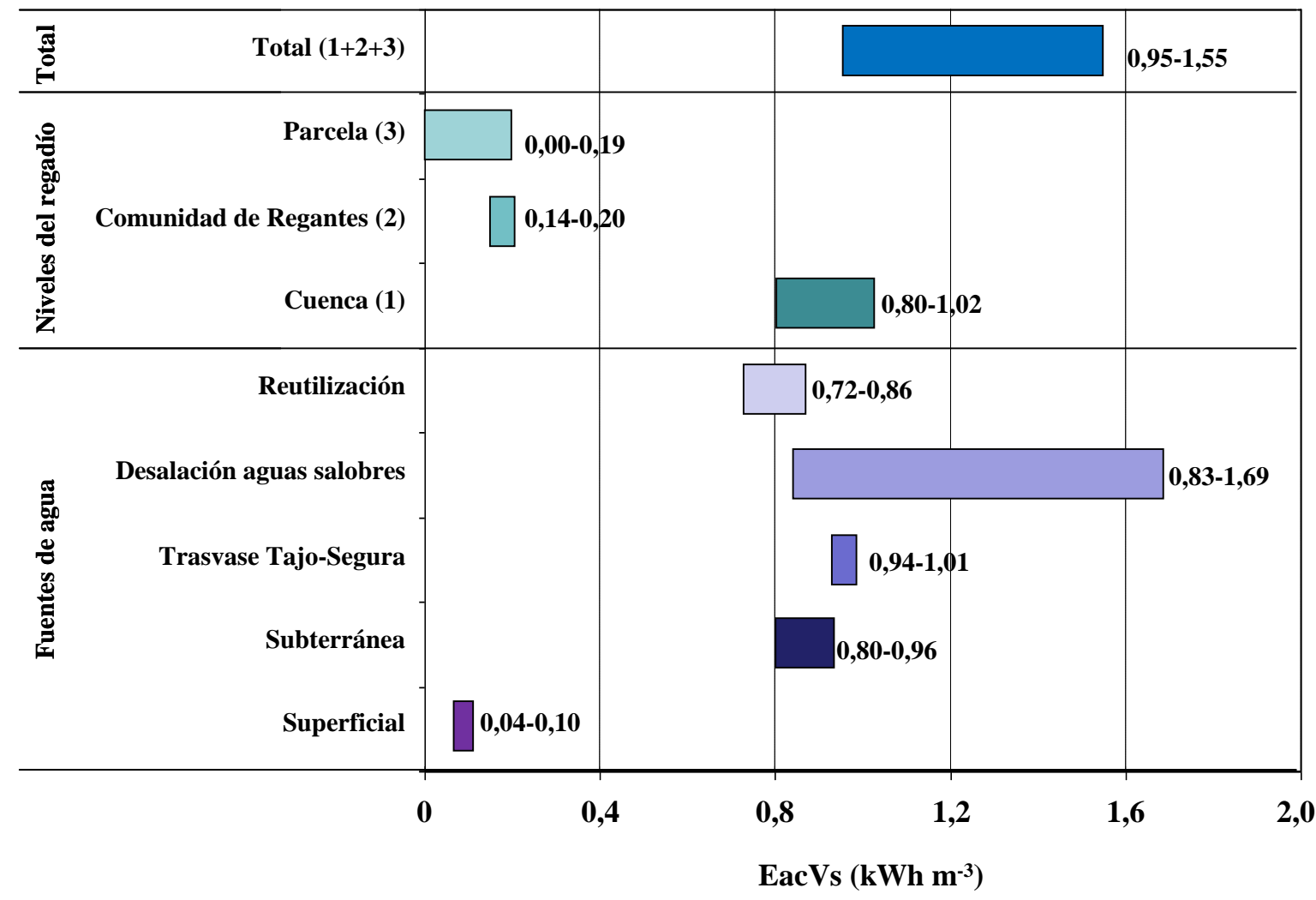

Figura 4.6. Consumo de energía específica (EacVs) en los diferentes niveles de gestión del agua para riego en la Región de Murcia.

El valor medio de EacVs para las CCRRs seleccionadas fue de $1,17 \mathrm{kWh} \mathrm{m}^{-3}$, lo que significa más de dos veces la EacVs media para los sistemas de riego localizado en España. Esta gran diferencia es inherente a la escasez habitual de las aguas superficiales en zonas semiáridas, donde otros recursos de agua con altos requerimientos de energía son aprovechados para riego (agua procedente de la reutilización, agua subterránea o el agua salobre desalada), o se produce el trasvase de otras cuencas (Acueducto TajoSegura).

El análisis del efecto de la escasez de agua durante los periodos de sequía sobre los indicadores energéticos pone de manifiesto una respuesta muy distinta de las CCRRs 
en función de sus recursos. Así, la CRCC que se abastece principalmente de Trasvase Tajo-Segura, presentó durante el periodo de sequía una disminución del $70 \%$ en el volumen de agua suministrada por área regada (VsSr). Por otro lado, la CRM apenas mostró sensibilidad a la sequía, ya que se abasteció exclusivamente de aguas subterráneas. El consumo de energía por superficie regada (EacSr) mostró en todas las CCRRs una variación paralela a la del $\mathrm{VsSr}$ a lo largo del periodo de estudio. Sin embargo, EacVs mantuvo valores muy constantes para distintos niveles de VsSr, destacando únicamente una ligera tendencia a incrementarse para valores bajos de $\mathrm{VsSr}$ como consecuencia principalmente de la disminución de la eficiencia de distribución (ED) durante el periodo de sequía.

Respecto a los indicadores energéticos, los procesos de modernización analizados sólo produjeron pequeñas mejoras en el uso de energía (EacSr) y en la eficiencia del uso de energía (EacVs). Este resultado contrasta con los indicados por otros autores para el caso de CCRRs que la modernización ha implicado la presurización de redes de distribución, sustituyendo a los canales abiertos existentes, donde por lo general se produce un aumento muy importante de los costes de gestión como resultado del aumento de la energía consumida.

En resumen, a nivel de cuenca, la Administración debe optimizar la gestión de los recursos hídricos disponibles con el fin de priorizar el uso de aquéllos con menor consumo de energía. A nivel de CCRR se propone utilizar técnicas de manejo que permitan agrupar la demanda en función de los requerimientos de presión (agrupando las tomas de riego en los sectores) y aprovechar la capacidad de control y gestión que ofrecen las nuevas tecnologías, así como la realización de auditorías energéticas. A nivel parcela, se recomienda el riego a la demanda, porque permite aprovechar la presión disponible en la red colectiva de riego y eliminar así el consumo de energía a este nivel. 
Para poder conseguir un regadío sostenible la Administración debe seguir promoviendo las buenas prácticas en la agricultura de regadío para mejorar la eficiencia en el uso del agua y la energía. 


\section{Capítulo 5}

\section{EFECTOS DE LA ESCASEZ DE AGUA}

Este Capítulo estudia, a nivel de comunidad de regantes, la sensibilidad de los indicadores de gestión a la escasez de agua. A nivel parcela también se analizan las estrategias seguidas por los agricultores (riego deficitario, desalinización de aguas salobres, cambios en el patrón de cultivo, etc.) durante los periodos de sequía, con el fin de interpretar correctamente los efectos obtenidos en la comunidad de regantes.

Las relaciones entre la intensidad en la escasez de agua y los cambios observados en los indicadores de gestión durante los periodos de sequía resultan de notable interés para los gestores de las comunidades de regantes.

\subsection{INTRODUCCIÓN}

En las últimas décadas se ha producido un aumento considerable en la demanda de agua en los países mediterráneos debido: (a) al aumento de la población; (b) al desarrollo urbanístico; (c) al desarrollo económico y social; (d) y en especial al regadío. Como resultado de este incremento de la demanda, las necesidades superan a los recursos renovables disponibles en muchas regiones. Esta circunstancia está provocando una fuerte competencia por el uso del agua disponible entre los distintos sectores implicados, incluido el medioambiente, que está desembocando en conflictos entre los diferentes usuarios (Iglesias et al., 2007; MedWSD, 2007). En el futuro se espera un agravamiento de esta situación, debido a la reducción prevista de los recursos hídricos disponibles en estas regiones a causa del cambio climático, especialmente en las zonas bajo clima mediterráneo semiárido (Pereira, 2004; Barros et al., 2011; García-Ruiz et al., 2011; Koutroulis et al., 2013), como es el caso de la Región de Murcia. 
Teniendo en cuenta la importancia del regadío en los países mediterráneos, dado que consumen el $64 \%$ del agua en la región, llegando incluso al $90 \%$ en muchos acuíferos y cuencas, reducir su demanda es actualmente una gran prioridad (Berbel et al., 2011). Este objetivo se podría alcanzar mediante la mejora del manejo del agua a nivel comunidad de regantes (CCRR) y a nivel parcela (Playán y Mateos, 2006; Hsiao et al., 2007).

A nivel de CCRR, como ya se ha comentado en capítulos anteriores, el benchmarking es una herramienta adecuada para mejorar la gestión y la eficiencia del uso del agua. El análisis de los indicadores de gestión puede ser especialmente útil para analizar los efectos de la escasez de agua en la agricultura de regadío. De esta forma la interpretación de estos indicadores se está convirtiendo en un instrumento cada vez más aplicado en la gestión de las CCRRs, dado que permiten explicar los factores que afectan al cambio y tendencia de su funcionamiento (Droogers y Kite, 1999; Lorite et al., 2004;. Playán y Mateos, 2006; Uysal y Atis, 2010).

A nivel de parcela, el riego localizado ha adquirido una importante relevancia en el sureste de España, dada su capacidad para reducir y mejorar la eficiencia en la aplicación del agua de riego (Alcón et al., 2011, Rodríguez et al., 2011a). También se están produciendo cambios en los patrones de cultivos hacia alternativas con menor demanda hídrica (García-Vila et al., 2008; Moreno-Pérez y Roldán-Cañas, 2013). Finalmente, en la última década se está promoviendo el uso de tecnologías de ahorro de agua en parcela como el riego deficitario controlado y la instalación de cubiertas para las balsas de riego (Geerts y Raes, 2009; Martínez-Álvarez et al., 2009).

En este Capítulo se ha trabajado a dos niveles diferentes de gestión del regadío. A nivel CCRR la metodología aplicada consistió en el análisis de la dinámica de los 
indicadores de gestión durante un período de 10 años, en las cinco CCRRs estudiadas, y en relación con el volumen suministrado de agua por unidad de área regada (VsSr).

A nivel parcela se ha caracterizado el comportamiento seguido por los agricultores de la Comunidad de Regantes del Campo de Cartagena (CRCC) en los periodos de grandes restricciones de disponibilidad de agua, a través de encuestas realizadas para los grupos de cultivos más importantes implantados en la zona. Este tipo de análisis es recomendado por diversos autores (Tanaka y Sato, 2005; García-Vila et al., 2008; Salvador et al., 2011) para la correcta interpretación de las tendencias de los indicadores de gestión a nivel CCRR.

\subsection{METODOLOGÍA}

La metodología para llevar a cabo este estudio se ha estructurado en varias fases. En primer lugar se seleccionaron un conjunto adecuado de indicadores de gestión para poder caracterizar los efectos de la escasez de agua sobre las CCRRs.

La sensibilidad a la escasez de agua se analizó mediante regresión entre cada uno de los indicadores de gestión y VsSr para cada una de las CCRRs seleccionadas: Comunidad de Regantes del Campo de Cartagena (CRCC), Comunidad de Regantes de Lorca (CRLO), Comunidad de Regantes del Trasvase Tajo Segura Calasparra-Cieza (CRTCC), Comunidad de Regantes Pantano de la Cierva (CRPC) y Comunidad de Regantes de Miraflores (CRM). Las principales características de estas CCRRs se han descrito en el Capítulo 2.

Para poder analizar el comportamiento y las estrategias de los agricultores a nivel parcela durante los periodos de escasez de agua se llevó a cabo una encuesta a los agricultores de la CRCC en el invierno de 2012. Las estrategias de los agricultores también se analizaron para los grupos de cultivos más importantes. 


\subsubsection{Indicadores seleccionados}

En la Tabla 5.1 se describe el conjunto de indicadores seleccionados y cómo fueron calculados para ser aplicados en este Capítulo.

Tabla 5.1. Descripción y método de cálculo de los indicadores de gestión empleados.

\begin{tabular}{|c|c|c|c|}
\hline $\begin{array}{l}\text { Nombre del indicador y } \\
\text { acrónimo }\end{array}$ & Unidad & Clasificación & Descripción y cálculo \\
\hline $\begin{array}{l}\text { Suministro de agua por } \\
\text { unidad de área regada (VsSr) }\end{array}$ & $\mathrm{m}^{3} \mathrm{ha}^{-1}$ & De rendimiento & $\begin{array}{l}\mathrm{Vs} / \mathrm{Sr} \\
\text { donde } \mathrm{Vs} \text { es el volumen total anual } \\
\text { suministrado a los usuarios y } \mathrm{Sr} \text { es la } \\
\text { superficie total regada. }\end{array}$ \\
\hline Intensidad de cultivo ( $\mathrm{SrSa}$ ) & $\%$ & De rendimiento & $\begin{array}{l}100 \cdot \mathrm{Sr} / \mathrm{Sa} \\
\text { donde } \mathrm{Sr} \text { es la superficie total regada y } \mathrm{Sa} \text { es } \\
\text { la superficie regable. }\end{array}$ \\
\hline $\begin{array}{l}\text { Eficiencia de distribución } \\
\text { (ED) }\end{array}$ & $\%$ & De rendimiento & $\begin{array}{l}100 \cdot \mathrm{Vs} / \mathrm{VT} \\
\text { donde Vs es el volumen total anual } \\
\text { suministrado a los usuarios y VT el volumen } \\
\text { anual que entra al sistema de la CCRR }\end{array}$ \\
\hline $\begin{array}{l}\text { Aporte relativo de agua } \\
\text { suministrada(ARWS) }\end{array}$ & - & De rendimiento & $\begin{array}{l}(\mathrm{Vs}+\mathrm{Pef}) / \mathrm{ETc} \\
\text { donde Vs es el volumen total anual } \\
\text { suministrado a los usuarios, } \mathrm{P}_{\text {ef }} \text { representa la } \\
\text { precipitación efectiva anual y ET } \mathrm{ET}_{\mathrm{c}} \text { es la } \\
\text { evapotranspiración total anual de los cultivos. }\end{array}$ \\
\hline $\begin{array}{l}\text { Aporte relativo de agua de } \\
\text { riego (ARIS) }\end{array}$ & - & De rendimiento & $\begin{array}{l}\mathrm{Vs} /(\mathrm{ETc}-\mathrm{Pef}) \\
\text { donde las variables son las mismas que en } \\
\text { ARWS. }\end{array}$ \\
\hline $\begin{array}{l}\text { Costes de manejo del sistema } \\
\text { por unidad de agua de riego } \\
\text { suministrada (CMSVs) }\end{array}$ & $€ \mathrm{~m}^{-3}$ & Financieros & $\begin{array}{l}\text { CMS/Vs } \\
\text { donde CMS son los costes anuales que se } \\
\text { originan a consecuencia de los servicios } \\
\text { prestados con el riego y Vs es el volumen } \\
\text { total anual suministrado a los usuarios. }\end{array}$ \\
\hline $\begin{array}{l}\text { Costes de manejo del sistema } \\
\text { por unidad de área regada } \\
\text { (CMSSr) }\end{array}$ & $€$ ha & Financieros & $\begin{array}{l}\mathrm{CMS} / \mathrm{Sr} \\
\text { donde CMS son los costes anuales que se } \\
\text { originan a consecuencia de los servicios } \\
\text { prestados con el riego y } \mathrm{Sr} \text { es la superficie } \\
\text { total regada. }\end{array}$ \\
\hline $\begin{array}{l}\text { Coste energético por unidad } \\
\text { de agua de riego suministrada } \\
\text { (CENVs) }\end{array}$ & $€ \mathrm{~m}^{-3}$ & Financieros & $\begin{array}{l}\text { CEN/Vs } \\
\text { donde CEN son los costes energéticos anuales } \\
\text { facturados y Vs es el volumen total anual } \\
\text { suministrado a los usuarios. }\end{array}$ \\
\hline $\begin{array}{l}\text { Coste energético por unidad } \\
\text { de área regada (CENSr) }\end{array}$ & $€ \mathrm{ha}^{-1}$ & Financieros & $\begin{array}{l}\text { CEN/Sr } \\
\text { donde CEN son los costes energéticos anuales } \\
\text { facturados y Sr es la superficie total regada. }\end{array}$ \\
\hline $\begin{array}{l}\text { Valor producción agrícola por } \\
\text { unidad de agua de riego } \\
\text { suministrada(VPVs) }\end{array}$ & $€ \mathrm{~m}^{-3}$ & $\begin{array}{l}\text { De eficiencia de } \\
\text { producción }\end{array}$ & $\begin{array}{l}\mathrm{VP} / \mathrm{Vs} \\
\text { donde VP es el valor total de la producción } \\
\text { agrícola y Vs es el volumen total anual } \\
\text { suministrado a los usuarios. }\end{array}$ \\
\hline $\begin{array}{l}\text { Valor producción agrícola por } \\
\text { unidad de superficie regada } \\
\text { (VPSr) }\end{array}$ & $€ \mathrm{ha}^{-1}$ & $\begin{array}{l}\text { De eficiencia de } \\
\text { producción }\end{array}$ & $\begin{array}{l}\mathrm{VP} / \mathrm{Sr} \\
\text { donde VP es el valor total de la producción } \\
\text { agrícola y Sr es la superficie total regada. }\end{array}$ \\
\hline $\begin{array}{l}\text { Margen bruto por unidad de } \\
\text { agua de riego suministrada } \\
\text { (MBVs) }\end{array}$ & $€ \mathrm{~m}^{-3}$ & $\begin{array}{l}\text { De eficiencia de } \\
\text { producción }\end{array}$ & $\begin{array}{l}\text { MB/Vs } \\
\text { donde MB es el margen bruto de la } \\
\text { producción agrícola y Vs es el volumen total } \\
\text { anual suministrado a los usuarios. }\end{array}$ \\
\hline $\begin{array}{l}\text { Margen bruto por unidad de } \\
\text { superficie regada (MBSr) }\end{array}$ & $€$ ha $^{-1}$ & $\begin{array}{l}\text { De eficiencia de } \\
\text { producción }\end{array}$ & $\begin{array}{l}\mathrm{MB} / \mathrm{Sr} \\
\text { donde MB es el margen bruto de la } \\
\text { producción agrícola y Sr es la superficie total } \\
\text { regada. }\end{array}$ \\
\hline
\end{tabular}


El ARIS es la relación entre el volumen de agua de riego anual suministrada a las parcelas agrícolas (Vs) y las necesidades netas de los cultivos. Mide la idoneidad del volumen de agua suministrado por la CCRR a las explotaciones agrícolas. Para la interpretación de ARIS en el caso de la CRCC, se debe tener en cuenta que las aguas subterráneas se mezclaron con el Vs a nivel de parcela. La mezcla es variable de acuerdo al Vs, el aumento del porcentaje de uso de las aguas subterráneas es proporcional a la escasez de agua.

Todos los valores monetarios relacionados con los indicadores financieros y de eficiencia de la producción se han actualizado a 2011 mediante el IPC para evitar los efectos de la inflación.

\subsubsection{Zona de estudio a nivel parcela}

A nivel parcela se ha analizado el comportamiento de los agricultores durante los periodos de escasez de agua en la CRCC, esta CCRR (Fig. 5.1.) se encuentra dividida en tres zonas regables (Oriental, Occidental y Cota-120), comprende una superficie de 41.065 ha, distribuidas en 23.498 parcelas, con 9.506 comuneros. Los principales cultivos se pueden clasificar en cinco grupos: cultivos hortícolas de invierno (lechuga, brócoli, apio, coliflor y patata), hortícolas anuales (alcachofa), hortícolas de verano (melón y sandía), cítricos (naranjo, limonero y mandarino) y otros cultivos leñosos (olivo y almendro).

La cantidad teórica anual del volumen suministrado por superficie regada en la CRCC, en ausencia de restricciones, es de $3.500 \mathrm{~m}^{3} \mathrm{ha}^{-1}$. Sin embargo, ningún año se pudo distribuir esta cantidad durante el período de estudio, produciéndose una escasez de agua en diferentes intensidades. Un análisis cluster (por el método de conglomeración de Ward) en función del volumen anual suministrado de agua por 
unidad de área regada (VsSr) de los años analizados dio lugar a tres grupos diferentes que fueron denominados: "años normales" (2002, 2003, 2004 y 2011), "años secos" (2005, 2009 y 2010) y "años muy secos" (2006, 2007 y 2008). El valor medio de VsSr

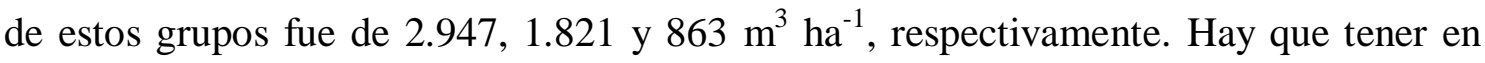
cuenta que, aunque estas cantidades de agua parecen muy escasas para la producción agrícola en regiones semiáridas, la alta calidad del agua suministrada por la CRCC (conductividad eléctrica $\approx 0,9 \mathrm{dS} \mathrm{m}^{-1}$ ) y la salinidad moderada del acuífero costero subyacente $\left(4,0 \mathrm{dS} \mathrm{m}^{-1}\right)$ permite que los agricultores mezclen estas dos fuentes de agua. Las encuestas a los agricultores confirmaron esta circunstancia, e indicaron que el agua empleada para riego presenta una conductividad eléctrica media alrededor de $2,0 \mathrm{dS} \mathrm{m}^{-}$

${ }^{1}$, lo que significa un incremento medio del $55 \%$ en el agua disponible a nivel parcela en relación con el agua suministrada por la CRCC. La necesidad de combinar diferentes fuentes de agua y la irregularidad en el suministro realizado justifica la alta densidad de balsas de riego existentes, que ocupan casi el 5\% de la superficie regable de la CRCC (Martínez-Álvarez et al., 2008).

\subsubsection{Adquisición de datos y encuestas}

Los datos para calcular los indicadores de gestión considerados, tal como se ha indicado en el Capítulo 3, se obtuvieron principalmente de los gestores de las CCRRs a partir de los registros de sus bases de datos.

La ETc se calculó siguiendo las directrices indicadas en la guía FAO-56 (Allen et al., 1998). Las necesidades brutas de agua de riego (Nb) de la CRCC se estimaron siguiendo la metodología de guía FAO-24 (Doorenbos y Pruitt, 1977).

Para poder analizar las estrategias de los agricultores a nivel parcela frente a los periodos de escasez de agua, entre diciembre de 2011 y febrero de 2012 se realizó una 
encuesta a los regantes de la CRCC. La encuesta se estructuró en cuatro grandes bloques de preguntas para caracterizar la actividad de los agricultores durante la campaña 2011: (a) datos agrícolas por cultivo (sistemas de cultivo y de riego, inputs y producción), (b) el agua de riego aplicada por cultivo, (c) manejo del agua de riego en las explotaciones (se preguntó específicamente sobre el volumen de las aguas subterráneas empleadas para los cultivos), y (d) cómo eran las prácticas culturales durante los periodos de escasez de agua. La encuesta consistió en entrevistas personales semi-estructuradas, ya que este método permite guiar la entrevista e interactuar con los agricultores, pudiendo realizar preguntas adicionales en función de las respuestas de los mismos. Para reducir el error de la muestra se siguió un procedimiento de muestreo aleatorio. La población total de parcelas (23.498) se dividió en tres zonas, coincidiendo con las zonas regables de la CRCC (Fig. 5.1). Dentro de cada zona se tomó una muestra aleatoria simple, con la única condición que fuera representativa de todos los grupos de cultivos. En la Fig. 5.1 se muestran las parcelas encuestadas y un histograma de frecuencias con el número de parcelas estudiadas por grupo de cultivos. El tamaño de la muestra total fue de 1.190 parcelas, con una superficie de 2.467 hectáreas, lo que representó un 7,62\% de la superficie regada en 2011. 


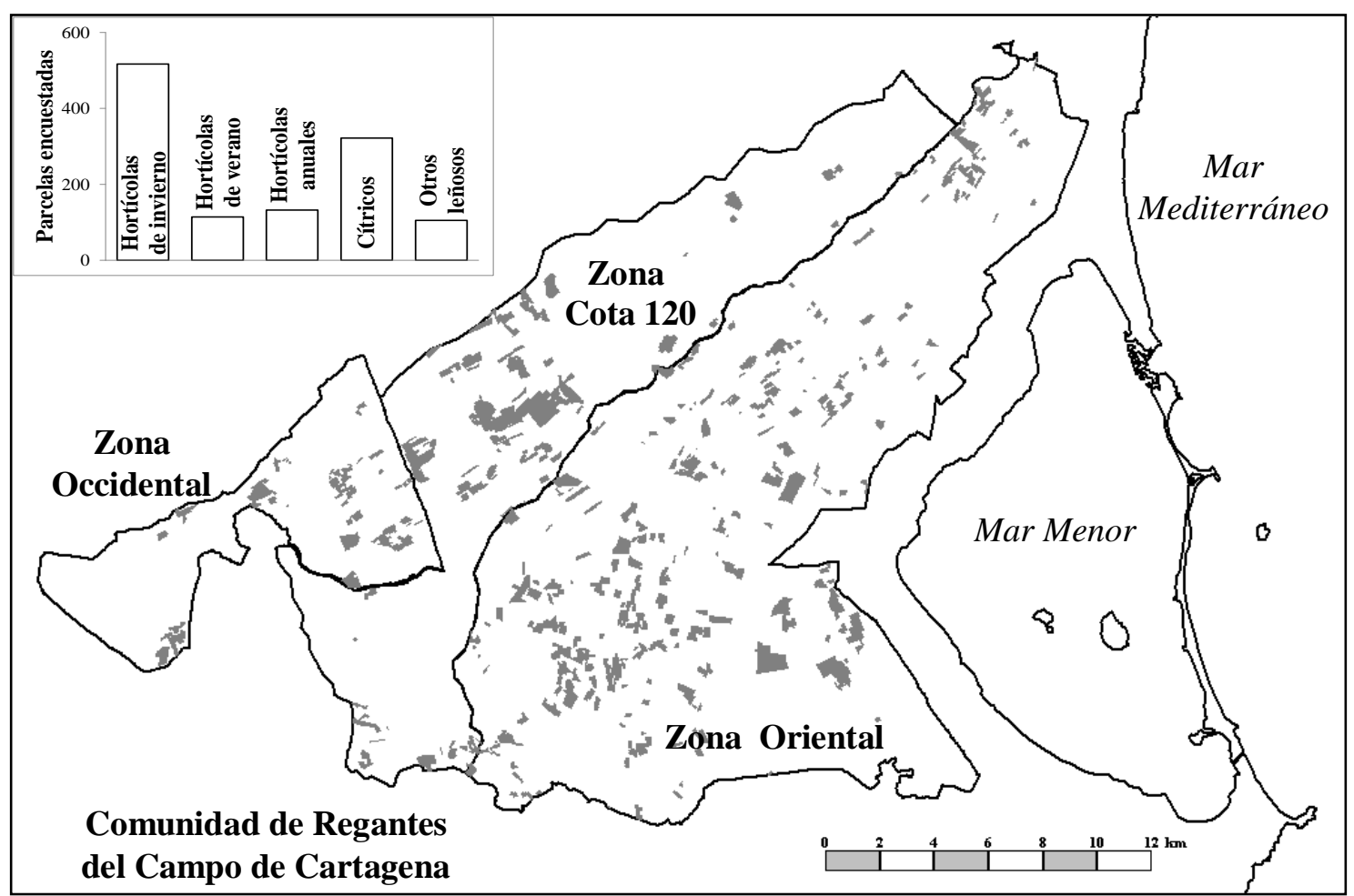

Figura 5.1. Mapa de las Zonas Regables de la CRCC y de las parcelas que fueron encuestadas. El histograma de frecuencia muestra el número de parcelas estudiadas por grupo de cultivos.

\subsection{RESULTADOS}

\subsubsection{Sensibilidad de los indicadores de gestión a la escasez de agua}

Con el fin de evaluar la sensibilidad de los indicadores de gestión por la escasez de agua, se relacionaron con VsSr, realizándose un análisis mediante regresión.

La Fig. 5.2 muestra la relación entre la intensidad de cultivo ( $\mathrm{SrSa}$ ) y VsSr. Este análisis muestra que cuanto mayor es el VsSr, mayor es la $\mathrm{SrSa}$ para la CRCC, la CRLO, la CRPC y la CRM (Fig. 5.2). La relación presenta cierta histéresis para el caso de la CRCC (línea de trazos en la Fig. 5.2a), ya que la recuperación de SrSa empezó un año después del último año seco. El análisis mediante regresión lineal indica una correlación moderada para la CRCC $\left(\mathrm{R}^{2}=0,44, \mathrm{p}<0,05\right)$ y la $\mathrm{CRM}\left(\mathrm{R}^{2}=0,47, \mathrm{p}<\right.$ $0,05)$, siendo escasa para el caso de CRLO $\left(R^{2}=0,18, p>0,1\right)$ y CRPC $\left(R^{2}=0,18, p>\right.$ $0,1)$, y prácticamente inexistente para CRTCC $\left(\mathrm{R}^{2}=0,06, \mathrm{p}>0,1\right)$. 

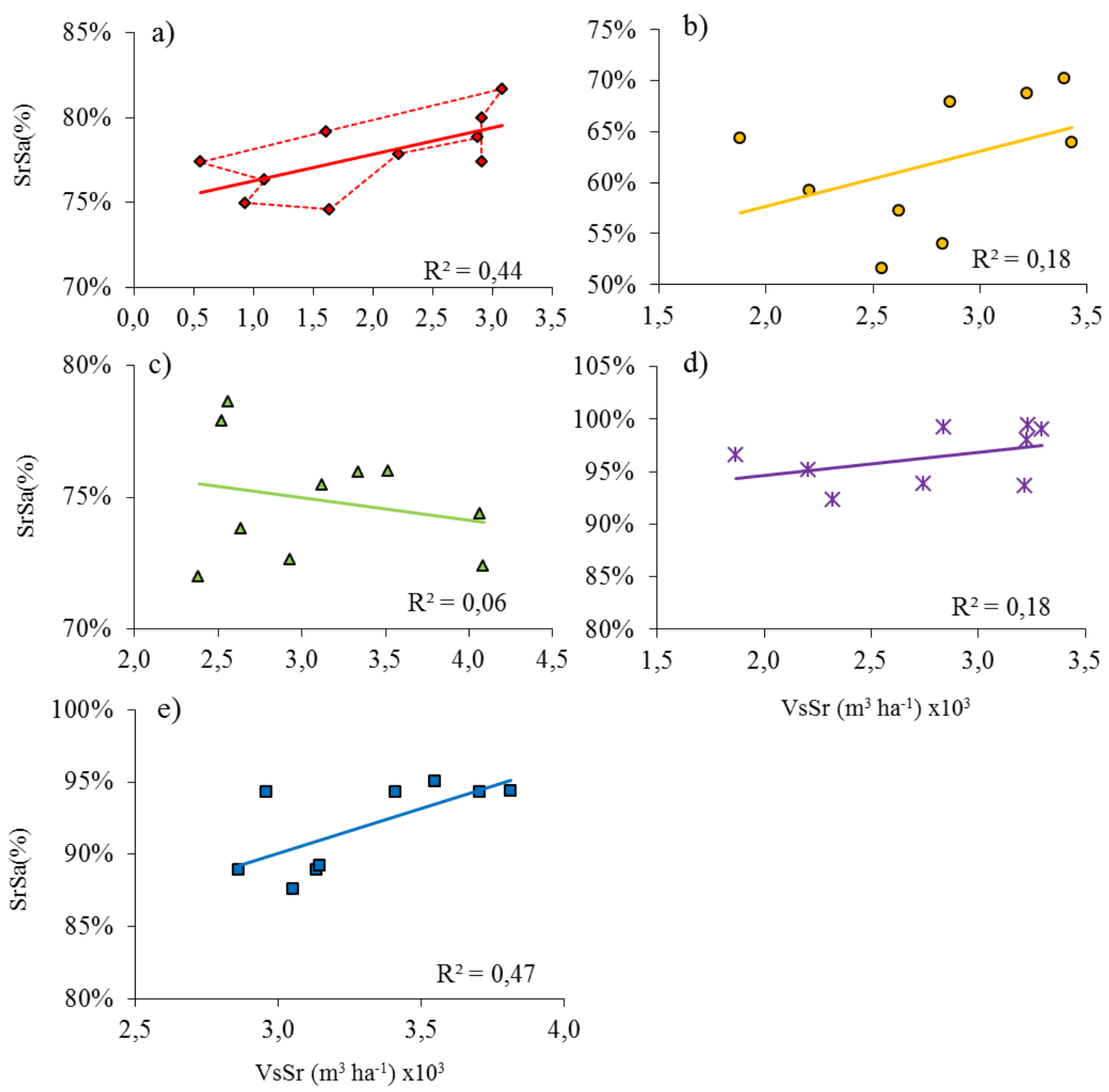

Figura 5.2. Análisis de regresión lineal entre los indicadores SrSa y VsSr. a) CRCC, b) CRLO, c) CRTCC, d) CRPC, y e) CRM.

La eficiencia de distribución (ED) mostró una tendencia a aumentar con el incremento de $\mathrm{VsSr}$ (Fig. 5.3). Esta relación se ajustó bien con una función potencial, que muestra una correlación muy significativa para la CRCC $\left(\mathrm{R}^{2}=0,77, \mathrm{p}<0,01\right)$, moderada para CRLO $\left(\mathrm{R}^{2}=0,47, \mathrm{p}<0,05\right)$, siendo esta correlación escasa para CRPC $\left(\mathrm{R}^{2}=0,19, \mathrm{p}>0,10\right)$ y CRTCC $\left(\mathrm{R}^{2}=0,16, \mathrm{p}>0,10\right)$, e inexistente para CRM. Este comportamiento de la ED se relaciona con la cantidad constante de las pérdidas de agua en el sistema de distribución, debido a (1) las fugas en la red de distribución y (2) las pérdidas por evaporación en las balsas (Martínez-Álvarez et al., 2009). Estas pérdidas se 
mantuvieron estables a pesar del valor $\mathrm{VsSr}$, por lo que representan un porcentaje mayor de $\mathrm{VsSr}$ a medida que aumenta la escasez de agua.
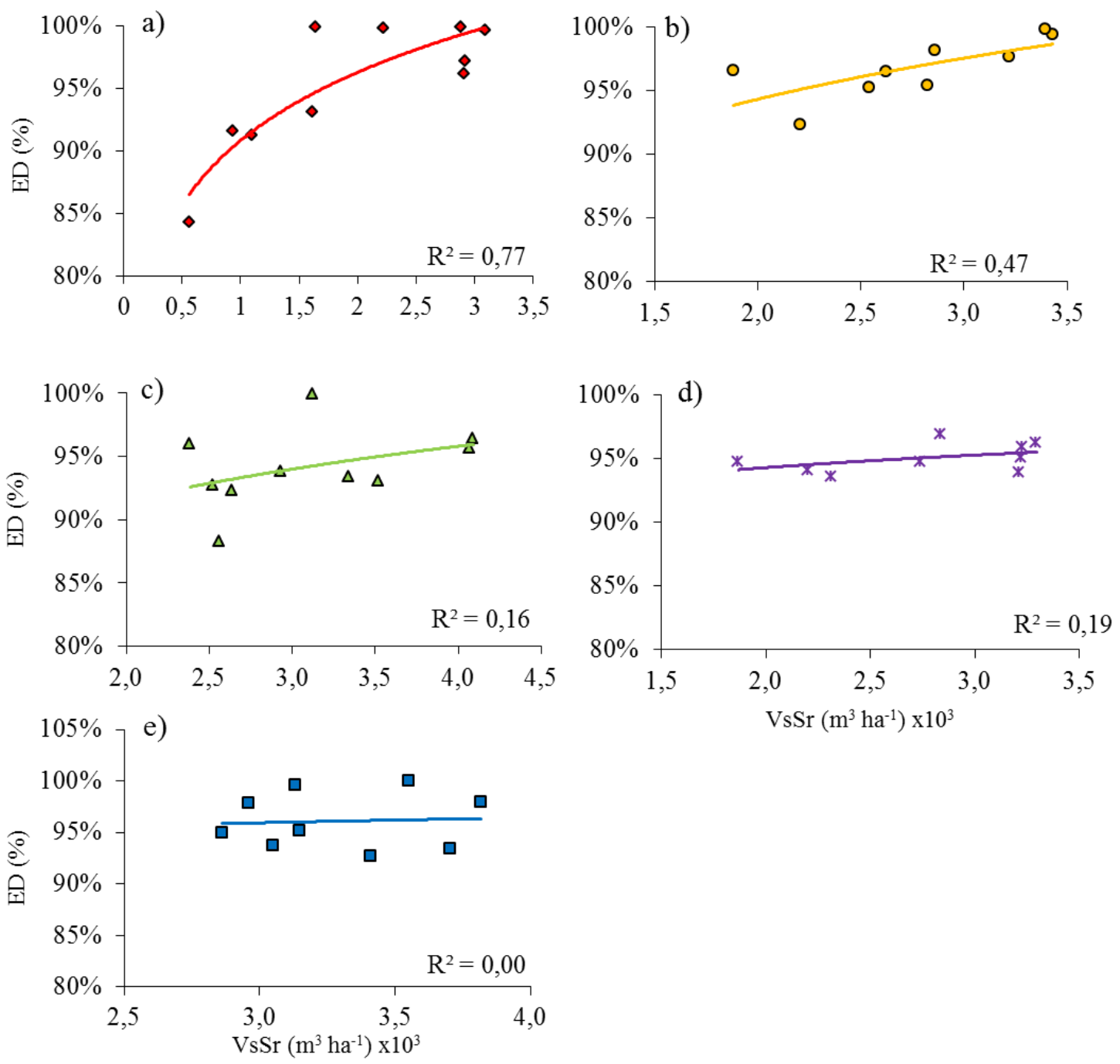

Figura 5.3. Análisis de regresión potencial entre los indicadores ED y VsSr. a) CRCC, b) CRLO, c) CRTCC, d) CRPC, y e) CRM.

La relación del aporte relativo de agua de riego (ARIS) con $\mathrm{VsSr}$ es claramente lineal para todas las CCRRs (Fig. 5.4), tal como era de esperar, ya que Vs interviene en el cálculo de ambos indicadores: CRCC $\left(\mathrm{R}^{2}=0,95\right), \operatorname{CRLO}\left(\mathrm{R}^{2}=0,87\right), \operatorname{CRTCC}\left(\mathrm{R}^{2}=\right.$ $0,88)$, CRPC $\left(R^{2}=0,64\right)$ y CRM $\left(R^{2}=0,61\right)$, con $p<0,01$ para todos los casos. El ARIS presentó valores decrecientes a medida que aumentaba la escasez de agua, los valores mínimos se dieron en la CRCC, alcanzando valores sobre 0,21 (de 0,17 a 0,27). 
Teniendo en cuenta que valores menores de 1 indican riego deficitario, es evidente que durante todo el periodo de estudio y en todas las CCRRs los agricultores hicieron riego deficitario, mientras que los valores más bajos durante los años muy secos eran más propios de riegos de socorro.
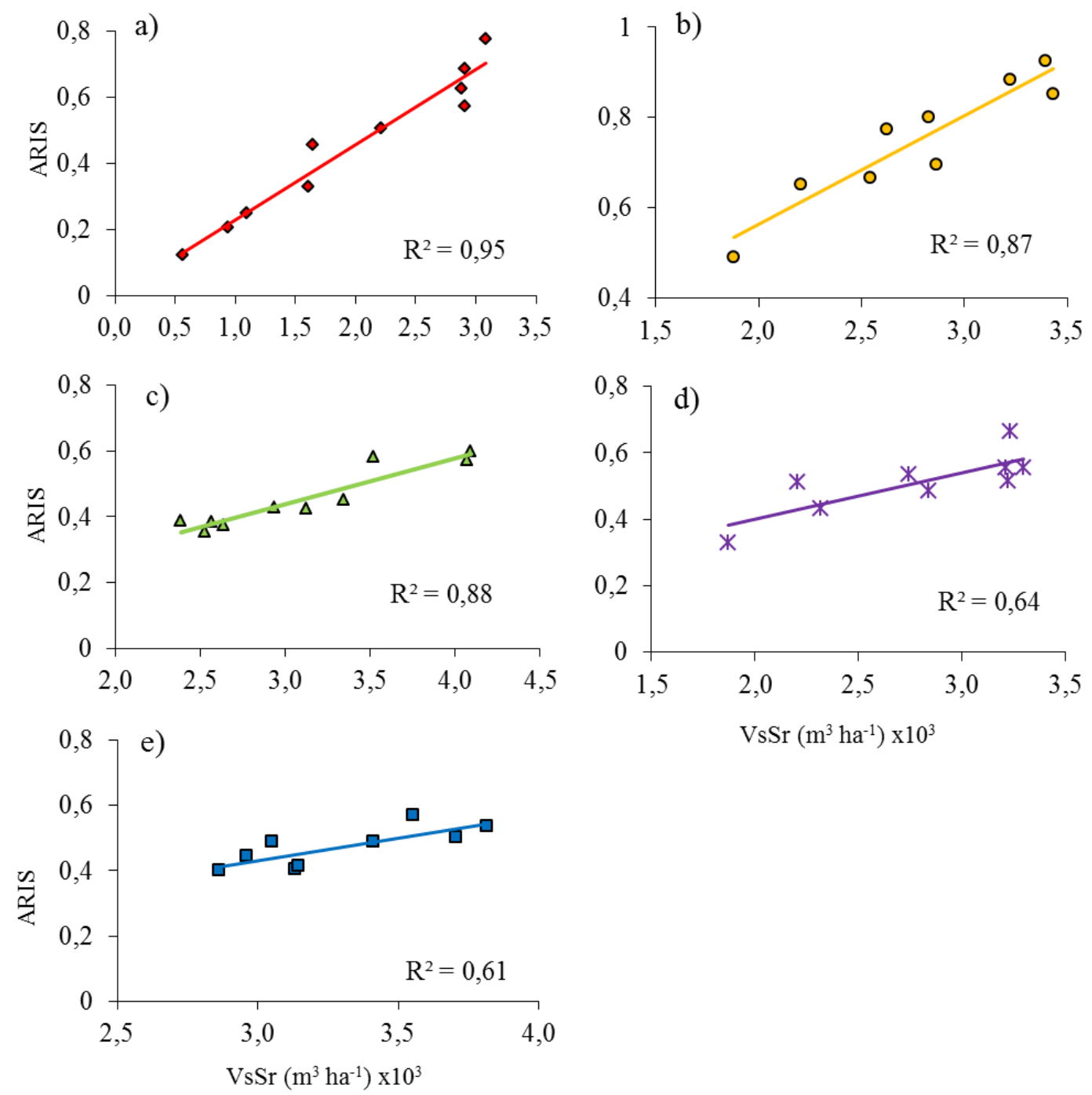

$\operatorname{VsSr}\left(\mathrm{m}^{3} \mathrm{ha}^{-1}\right) \times 10^{3}$

Figura 5.4. Análisis de regresión lineal entre los indicadores ARIS y VsSr. a) CRCC, b) CRLO, c) CRTCC, d) CRPC, y e) CRM.

Los costes de manejo del sistema por unidad de agua de riego suministrada (CMSVs) mostró una correlación muy buena con una función potencial negativa para todas las CCRRs (Fig. 5.5): CRCC $\left(\mathrm{R}^{2}=0,83\right), \mathrm{CRLO}\left(\mathrm{R}^{2}=0,74\right), \operatorname{CRTCC}\left(\mathrm{R}^{2}=0,88\right)$, CRPC $\left(\mathrm{R}^{2}=0,71\right)$ y CRM $\left(\mathrm{R}^{2}=0,76\right)$, con $\mathrm{p}<0,01$ para todas ellas; lo que indica que 
CMSVs decrece con el incremento de VsSr, pero con una estabilización de la pendiente.

Este comportamiento se debe a la estructura de los costes de manejo del sistema, que constan de costes fijos y variables, siendo el impacto de los costes fijos relativamente bajo cuando aumenta el volumen suministrado. En el caso de CRTCC (Fig. 5.5c) el incremento tan pronunciado de CMSVs por la escasez de agua se debe al aumento del consumo de aguas subterráneas, lo que provoca un incremento de los costes energéticos y los costes relacionados con el funcionamiento de estos sondeos. Como era de esperar, los costes de manejo del sistema por unidad de área regada (CMSSr) aumentaron con el aumento de $\mathrm{VsSr}$ (datos no mostrados).
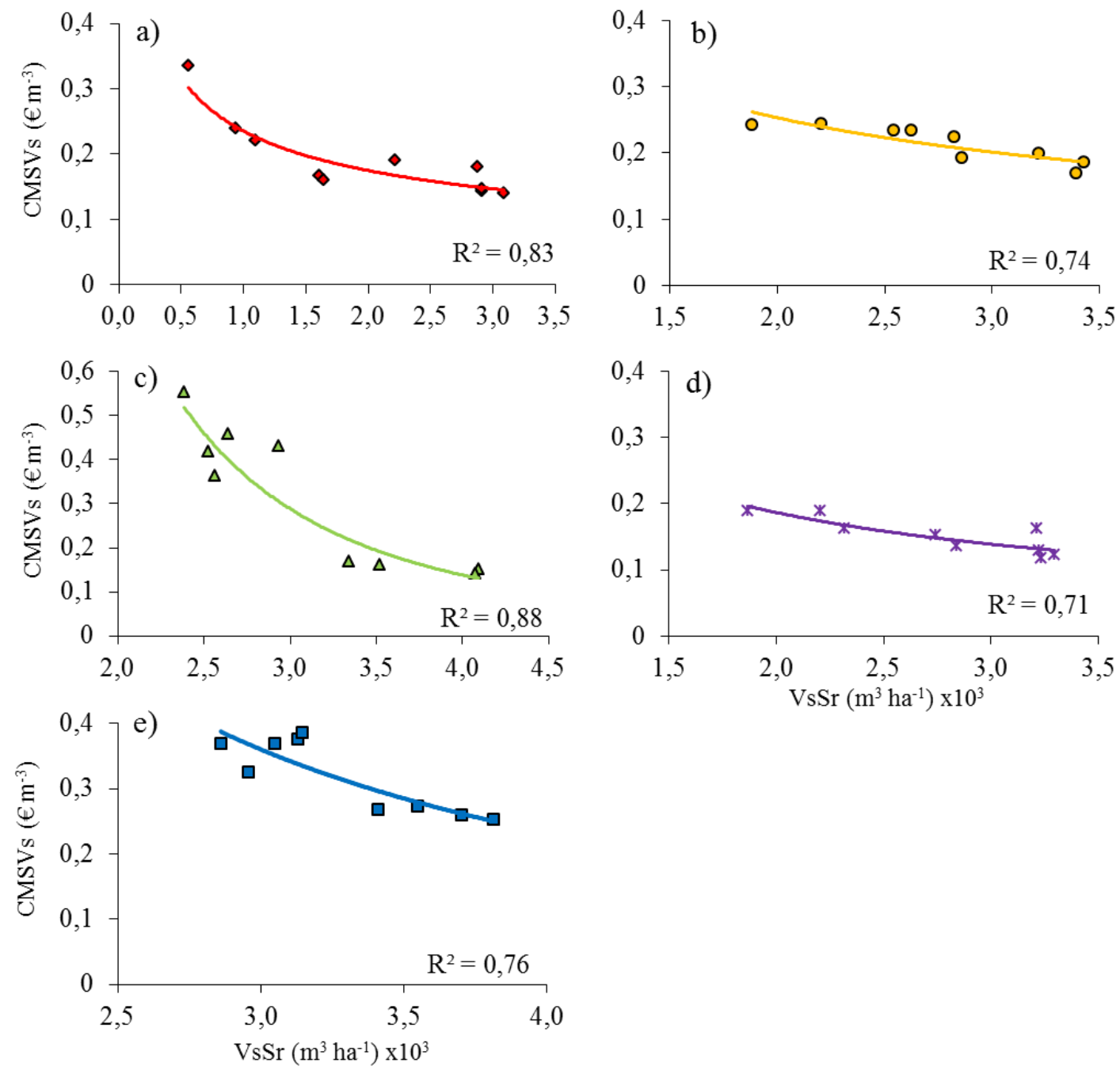

Figura 5.5. Análisis de regresión potencial entre los indicadores CMSVs y VsSr. a) CRCC, b) CRLO, c) CRTCC, d) CRPC, y e) CRM. 

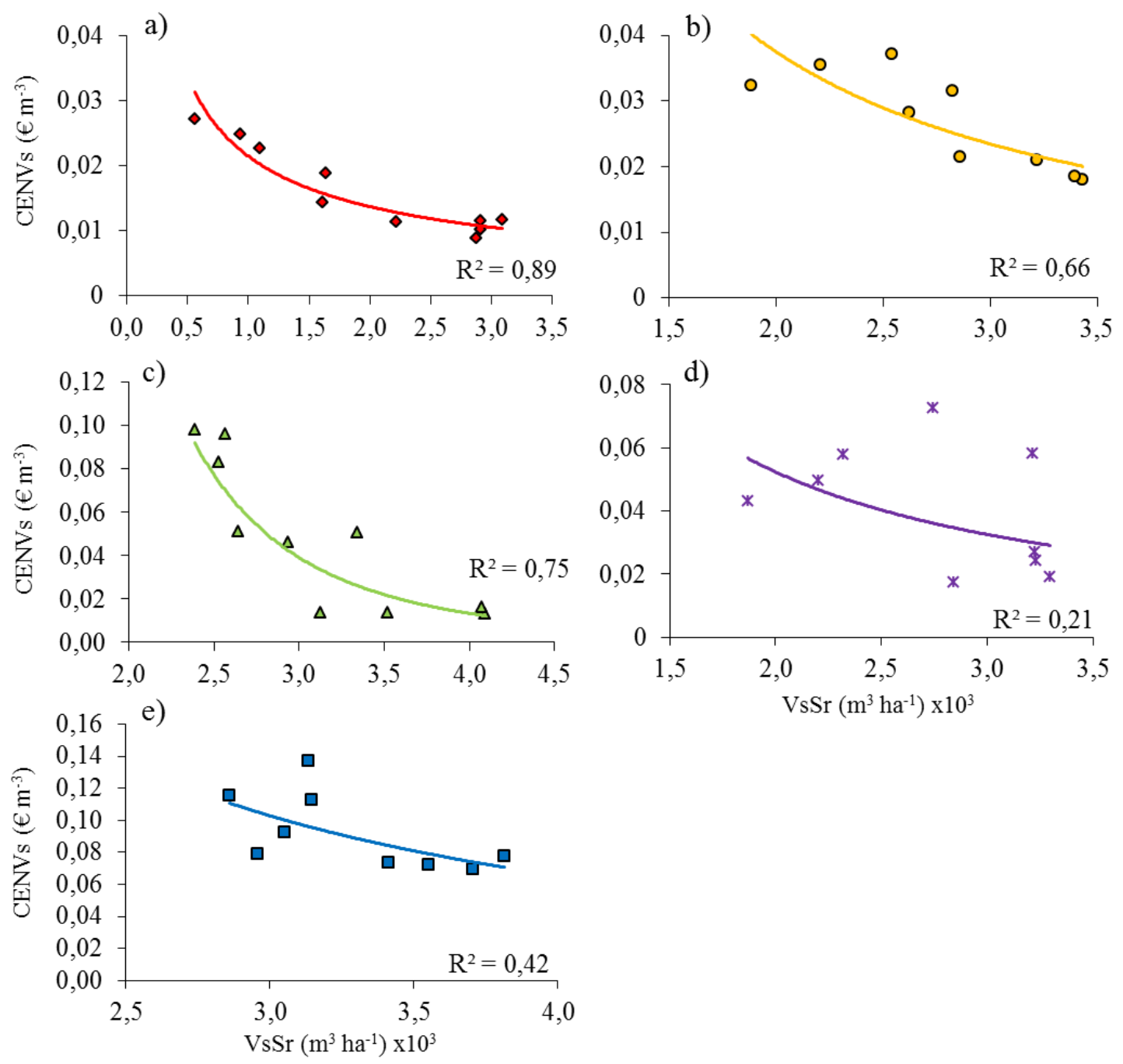

Figura 5.6. Análisis de regresión potencial entre los indicadores CENVs y VsSr. a) CRCC, b) CRLO, c) CRTCC, d) CRPC, y e) CRM.

La Fig. 5.6 muestra la relación, con una función potencial negativa para todas las CCRRs, entre el coste energético por unidad de agua de riego suministrada (CENVs) y VsSr. En todas las CCRRs la disminución de VsSr supone un incremento de CENVs, esto se debe principalmente a que los costes energéticos presentan una estructura de costes fijos (término de potencia) y variables (término de energía), con un impacto mayor de los costes fijos cuando disminuye VsSr. CENVs muestra un lento descenso con el incremento anual del agua suministrada para la CRCC (Fig. 5.6a) y CRLO (Fig. 5.6b), con $p<0,05$ para ambas. En el caso de la CRTCC (Fig. 5.6c) se produce un gran incremento de CENVs con la reducción de VsSr debido, tal como se ha comentado, a 
que en los periodos de sequía esta CCRR emplea las aguas subterráneas, con lo que aumentan los costes energéticos por la captación de las mismas.
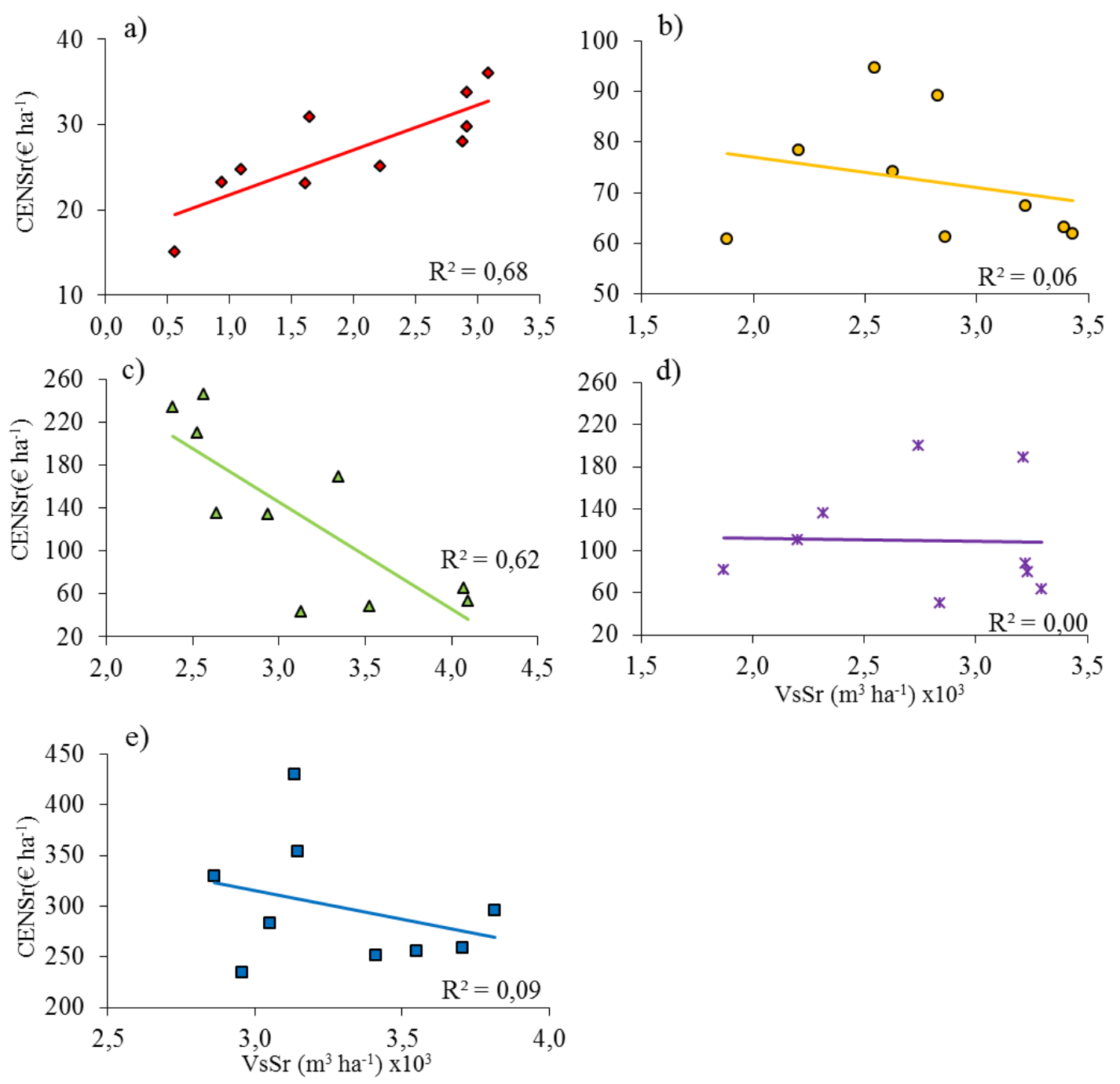

Figura 5.7. Análisis de regresión lineal entre los indicadores CENSr y VsSr. a) CRCC, b) CRLO, c) CRTCC, d) CRPC, y e) CRM.

Hay que destacar que la sensibilidad del coste energético por unidad de área regada (CENSr) respecto a la disminución del VsSr presentan una clara relación lineal (Fig. 5.7a y 5.7c) para el caso de la CRCC $\left(\mathrm{R}^{2}=0,68, \mathrm{p}<0,01\right)$ y la $\mathrm{CRTCC}\left(\mathrm{R}^{2}=0,62\right.$, $\mathrm{p}<0,01$ ), siendo prácticamente nula para las otras tres CCRRs (Fig. 5.7b, 5.7d y 5.7e). Para el caso de la CRCC está relación es lineal positiva (Fig. 5.7a), tal como era de esperar. Pero ocurre todo lo contrario para la CRTCC (Fig. 5.7c), debido que la falta de 
los recursos procedentes del Trasvase Tajo Segura en los periodos de sequía son sustituidos en parte con las aguas subterráneas.

La relación entre el valor de la producción agrícola por unidad de agua de riego suministrada (VPVs) y VsSr (Fig. 5.8) se ajustó perfectamente con una función potencial negativa $\left(\mathrm{R}^{2}=0,89, \mathrm{p}<0,01\right)$ para el caso de la CRCC (Fig. 5.8a), que es la que presenta una mayor variación en VsSr. Para el resto de CCRRs analizadas la correlación es moderada con $\mathrm{p}<0,1$, a excepción de CRPC (Fig. 5.8d) que fue escasa.
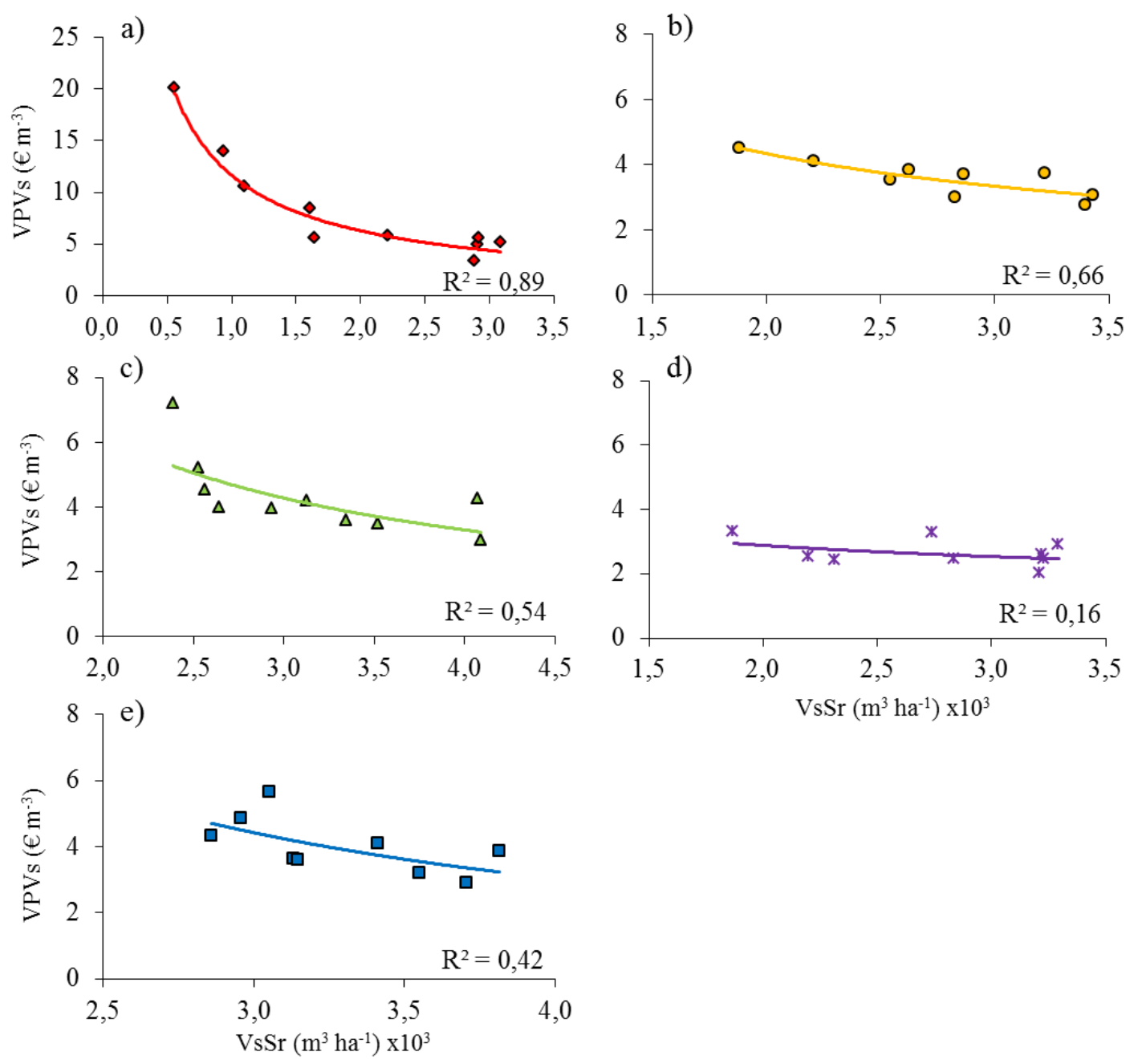

$\operatorname{VsSr}\left(\mathrm{m}^{3} \mathrm{ha}^{-1}\right) \times 10^{3}$

Figura 5.8. Análisis de regresión potencial entre los indicadores VPVs y VsSr. a) CRCC, b) CRLO, c) CRTCC, d) CRPC, y e) CRM. 
El valor de la producción agrícola por unidad de superficie regada (VPSr) muestra una moderada relación lineal positiva con VsSr en CRLO (Fig. 5.9b) y CRPC (Fig. 5.9d), con $\mathrm{p}<0,1$ en ambos casos, siendo esta relación lineal escasa para la CRCC y prácticamente inexistente para CRTCC y CRM. Esta escasa correlación deja claro que el valor económico de la producción depende en gran medida de otras variables diferentes al rendimiento de los cultivos, como son los precios de los cultivos principalmente. Como se advierte en la Fig. 5.9 la escasez de agua provoca una reducción del valor de la VPSr en la mayor parte de las CCRR estudiadas.
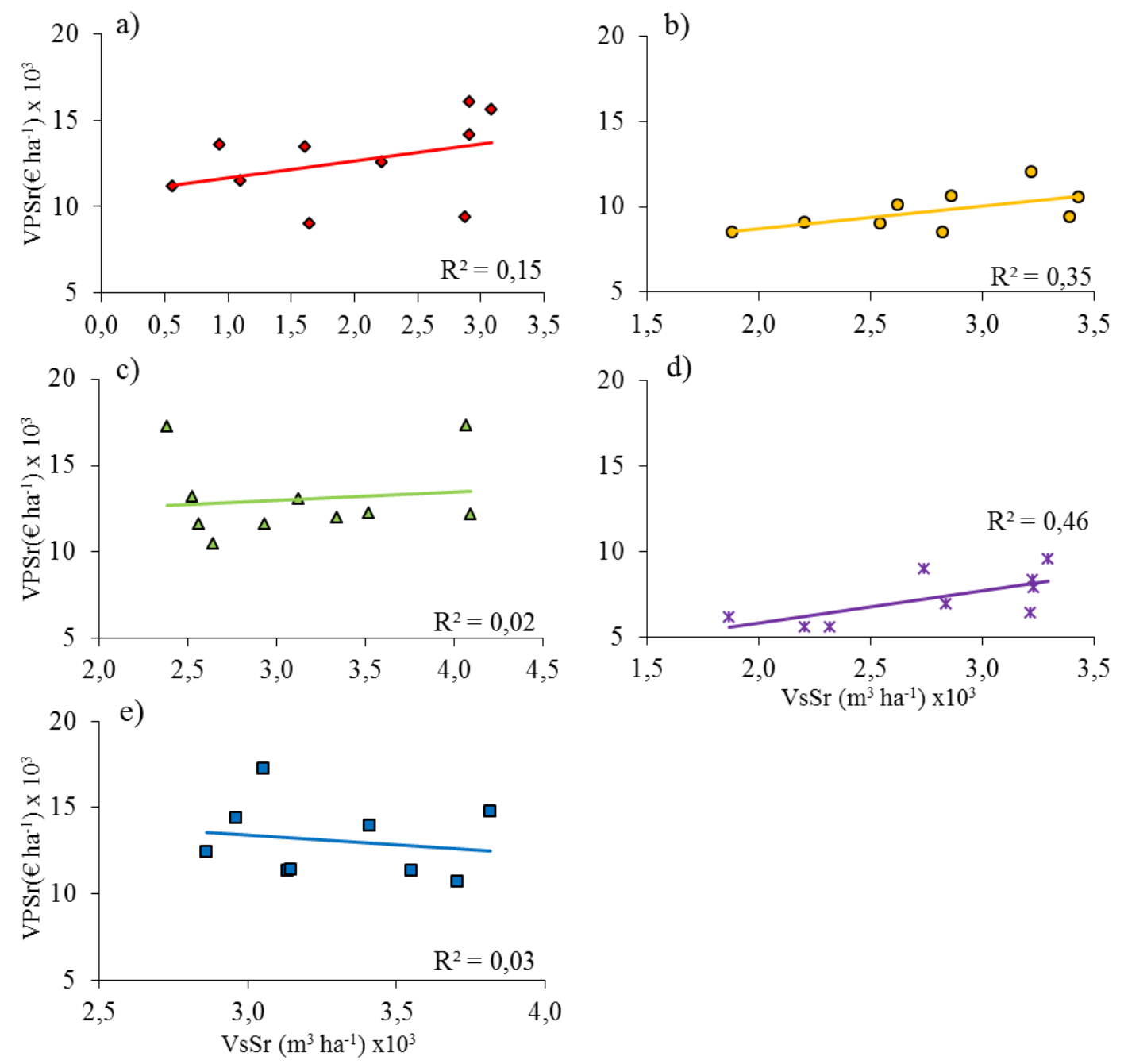

Figura 5.9. Análisis de regresión lineal entre indicadores VPSr y VsSr. a) CRCC, b) CRLO, c) CRTCC, d) CRPC, y e) CRM. 
Los demás indicadores de eficiencia de producción (margen bruto por unidad de agua de riego suministrada, MBVs, y el margen bruto por unidad de superficie regada, MBSr) siguieron una evolución paralela a VPVs y VPSr respectivamente. Sin embargo, su correlación con VsSr fue bastante peor para ambos indicadores, lo que indica que los precios de otros inputs agrícolas y los precios de los cultivos tienen un papel más importante que VsSr en las variaciones de valor de margen bruto. Pero al igual que sucede con VPSr, la reducción en el volumen suministrado induce a una reducción en el margen bruto.

En resumen, todos los indicadores definidos como un ratio con el volumen suministrado (CMSVs, CENVs, VPVs y MBVs) varían de forma inversamente proporcional a VsSr, relación que en la mayoría de los casos se explica bien con funciones potenciales negativas. Sus valores en los años secos generalmente triplican a los que corresponden a los años normales, por lo que su uso en estudios de benchmarking en CCRRs con escasez de agua debe ser manejado con cautela, especialmente cuando los datos disponibles son de unos pocos años. Por otra parte, los indicadores definidos como un ratio con la superficie regada varían de forma directamente proporcional a VsSr. Algunos de ellos presentan una correlación moderada con funciones lineales (CMSSr y CENSr), mientras que otros (VPSr y MBSr) no presentaron prácticamente correlación. Por lo tanto los indicadores financieros se muestran los más estables ante variaciones del suministro de agua.

\subsubsection{Patrón de cultivo y manejo del agua a nivel de parcela}

En este apartado se analiza el padrón de cultivos y manejo del agua de la zona regable de la CRCC a nivel de parcela en los periodos con restricciones de agua. En la Fig. 5.10 se muestra la evolución de la superficie total regada $(\mathrm{Sr})$, de la superficie de 
cada grupo de cultivos y el VsSr durante el periodo de estudio en la CRCC. Ningún año se alcanzó el suministro máximo teórico de agua $\left(3.500 \mathrm{~m}^{3} \mathrm{ha}^{-1}\right)$. El periodo de estudio comenzó con tres "años normales" (2002-2004), pero rápidamente y con sólo un "año seco", hubo un período de sequía severa de tres "años muy secos" (2006-2008). Posteriormente, el suministro de agua se recuperó progresivamente y alcanzó otra vez un "año normal" en 2011. Entre 2004 y 2009 se produjo una reducción de Sr cercana al $10 \%$, debido a la continuidad de años secos y muy secos durante ese período. Está reducción de $\mathrm{Sr}$ afectó principalmente a los cultivos hortícolas de invierno y verano. Sin embargo, la mejora del suministro de agua en los últimos dos años produjo una rápida recuperación de Sr, principalmente debido al incremento en los cultivos de hortícolas de verano.

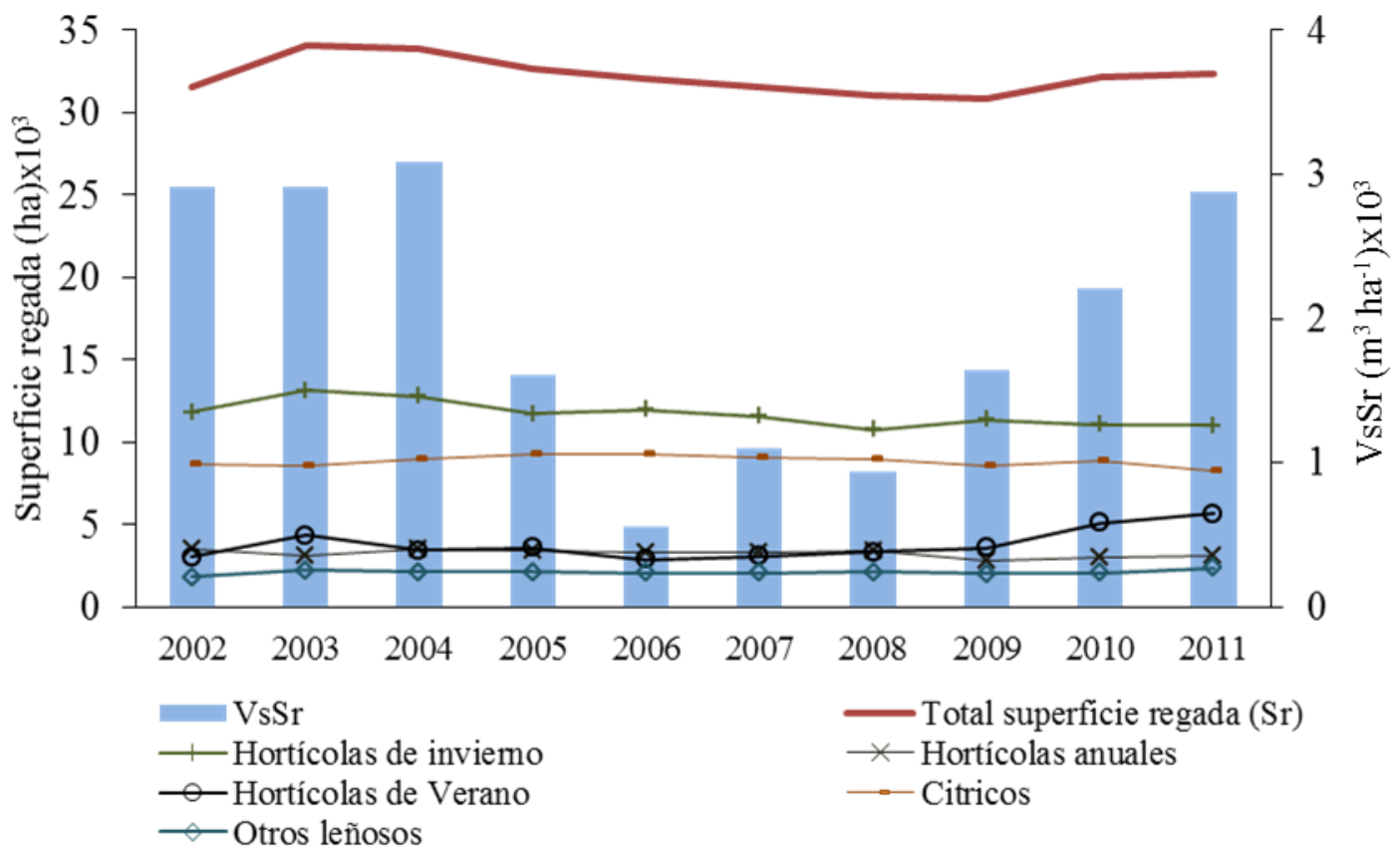

Figura 5.10. Evolución de la superficie total regada $(\mathrm{Sr})$ y por grupos de cultivos en la CRCC durante el período 2002-2011.

Al contrario que en otras regiones españolas (Playán y Mateos, 2006; GarcíaVila et al, 2008; Moreno-Pérez y Roldán-Cañas, 2013) el patrón de cultivo no presentó una tendencia clara durante el periodo de estudio. Todos los grupos de cultivos 
mantuvieron su porcentaje, con la única excepción del aumento, ya mencionado, de los hortícolas de verano en los últimos dos años, a costa de una reducción de los cítricos y hortícolas de invierno. Este resultado pone de manifiesto que la actividad agrícola en la CRCC es estable y se encuentra consolidada, ya que se basa en cultivos muy rentables y no se encuentra influenciada por las reformas agrarias basadas en subvenciones. En ese sentido la reforma de 2003 de la Política Agrícola Común no supuso ningún cambio en las prácticas culturales y en los patrones de cultivo, a diferencia de otras regiones (Perry et al., 2009).

Resulta sorprendente que en el período de años más secos “2006-2008” apenas se redujo la superficie total cultivada (Fig. 5.10), este hecho se puede justificar con la Fig. 5.11, donde se analiza para la CRCC los datos globales relativos al manejo del agua en parcela.

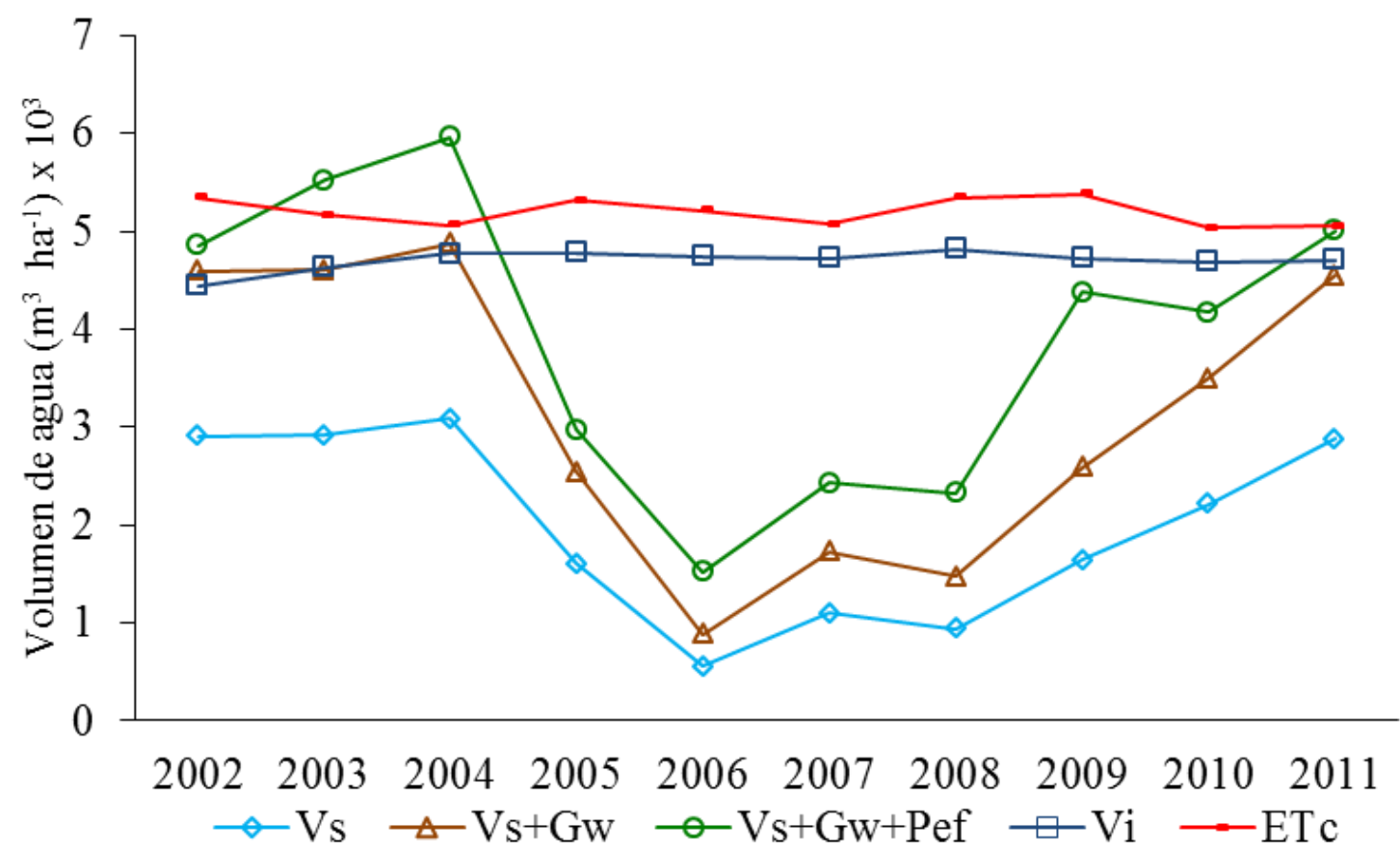

Figura 5.11. Evolución de: (a) el volumen anual de agua suministrada por la CRCC (Vs), (b) la evapotranspiración total anual de los cultivos (ETc), (c) el volumen total anual de agua de riego aplicada (Vi), (d) el agua en las explotaciones agrícolas disponible (Vs $+\mathrm{Gw})$, y (e) el volumen total anual de agua aplicada a los cultivos (Vs+ Gw + Pef). 
La línea inferior de la Fig. 5.11 representa el volumen de agua de riego anual suministrado a los agricultores por la CRCC (Vs), la superior es la evapotranspiración anual de los cultivos (ETc), y una tercera línea representa el volumen total anual de agua de riego aplicada (Vi), que se ha calculado según lo indicado por los agricultores en la encuesta realizada. Esta estimación de Vi es real sólo en 2011 y teórica en el resto de años, donde se consideró la misma pauta de funcionamiento de los agricultores en lo referente al agua aplicada para los cultivo que en 2011 (año normal).

De lo indicado por los agricultores se desprende que el agua de riego total aplicada en 2011 fue ligeramente inferior a la ETc, lo cual es razonable al considerar la precipitación efectiva (Pef) o si se hizo riego deficitario a nivel parcela.

Los agricultores también señalaron en la encuesta que aplican un volumen de aguas subterráneas, a nivel de parcela, del 50-60\% del Vs, esta afirmación es razonable si tenemos en cuenta la posibilidad que tienen de obtener aguas subterráneas $(\mathrm{Gw})$ para mezclarlas con Vs, consiguiendo un agua para riego con una salinidad media de $2 \mathrm{dS} \mathrm{m}^{-}$ 1. La línea Vs + Gw muestra el volumen disponible de agua para riego en las explotaciones agrícolas teniendo en cuenta el promedio del 55\% de las aguas subterráneas mezcladas, en base a lo expresado por los agricultores. Por lo tanto el volumen de agua disponible a nivel parcela $(\mathrm{Vs}+\mathrm{Gw})$ está en consonancia con volumen total anual de agua de riego aplicada (Vi) en los "años normales" (2002, 2003, 2004 y 2011), lo que representa el funcionamiento normal del riego en la CCRR. La Fig. 5.11 también muestra que si se considera la Pef, el volumen total de agua aplicado a los cultivos (Vs + Gw + Pef) en algunos años superó a la ETc, permitiendo que se pudiera realizar un lavado de sales.

El razonamiento anterior deja claro que para los años secos y muy secos, se deben considerar otras estrategias específicas por parte de los agricultores para el 
mantenimiento de la superficie regada, dado que el volumen disponible (Vs+Gw) está muy por debajo de la ETc.

\subsubsection{Estrategias de los agricultores bajo restricciones de agua}

En este apartado se analiza la estrategia de los agricultores de la CRCC frente a la escasez de agua. El periodo de sequía 2006-2008 produjo una disminución del valor de la producción (Fig. 5.9a), pero apenas afectó la superficie de cada grupo de cultivos (Fig. 5.10), lo que indica que los agricultores aplicaron estrategias de adaptación para hacer frente a las limitaciones del suministro de agua. De las encuestas realizadas a los agricultores se obtuvo el agua aplicada a los cultivos en un año normal (2011), que se muestra en la Fig. 5.12 por grupo de cultivos.

La Fig. 5.12 muestra también cómo las necesidades brutas de agua de riego $(\mathrm{Nb})$ eran ligeramente superiores a la ETc para todos los grupos de cultivos. Esto se debió a que la Pef en la zona semiárida estudiada no es significativa, donde por lo general se suele despreciar en los cálculos de riego (Pef rara vez es superior a $100 \mathrm{~mm}$ año ${ }^{-1}$ ).

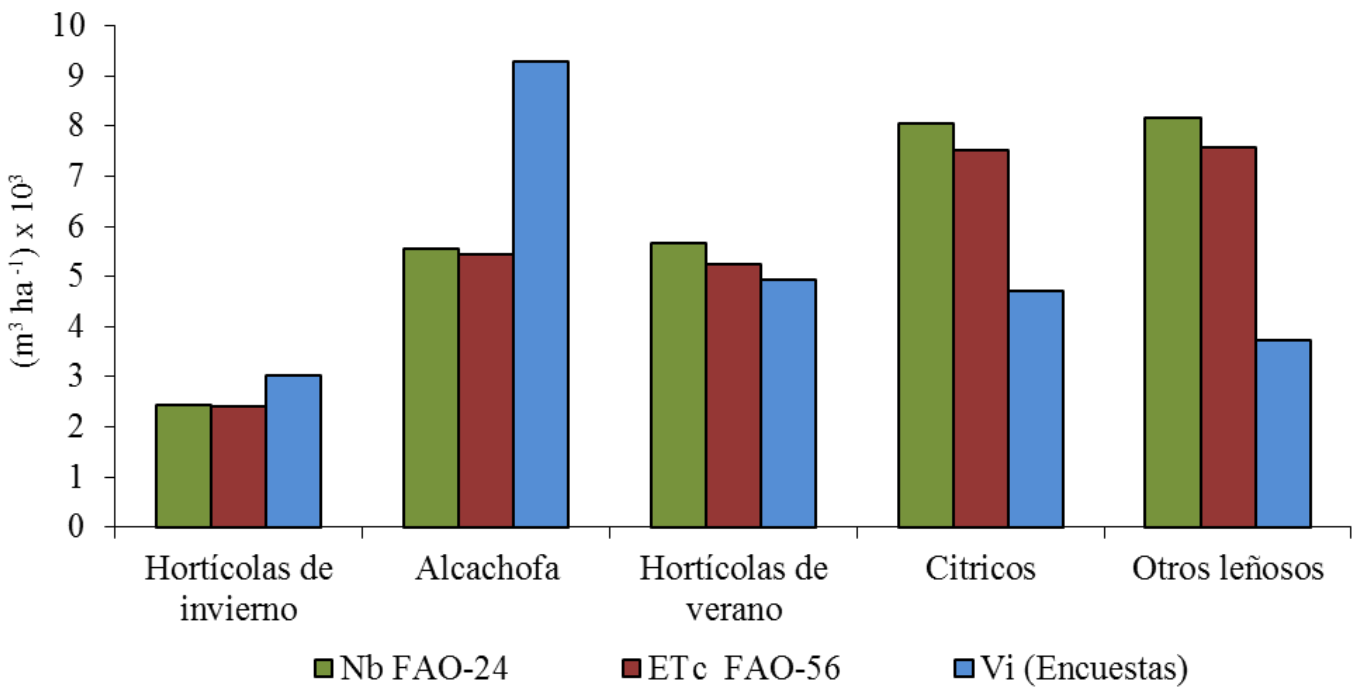

Figura 5.12. Necesidades brutas de agua de riego calculadas según FAO-24 (Nb FAO-24); evapotranspiración del cultivo calculada según FAO-56 (ETc FAO-56), y agua de riego aplicada según las encuestas de los agricultores por grupos de cultivos en 2011(Vi encuestas). 
El volumen total de agua de riego aplicada (Vi) presentó diferente relación con la ETc para cada grupo de cultivos. Para hortícolas de invierno, Vi fue mayor que la ETc, debido a que después del trasplante de las plántulas el suelo se mantiene a la capacidad de campo mediante riego por aspersión para favorecer el arraigo y la lixiviación de la sales en la capa de suelo superficial. Este riego excesivo con respecto a las necesidades de agua de los cultivos tiene una duración de unas tres semanas y provoca que Vi supere sobre un $20 \%$ a la ETc. Los hortícolas de verano (melón y sandía) se suelen cultivar con un film de plástico acolchado y la fila se cubre con los objetivos de conservar la humedad del suelo y promover la precocidad. El riego se suele reducir generalmente en la fase final del cultivo (frutos maduros), dando como resultado que Vi sea ligeramente inferior a la ETc. La alcachofa (hortícolas anuales) es un cultivo muy especial en cuanto al manejo del riego. Se requiere que el suelo se encuentre a capacidad de campo durante toda la época de cosecha (de diciembre a abril) para evitar la floración de su yema comestible, resultando los valores de Vi casi el doble de la ETc. La alcachofa es también tolerante a la salinidad del agua de riego (Rhoades et al., 1992), y se podría estar regando directamente con las aguas subterráneas salobres del acuífero $\left(4 \mathrm{dS} \mathrm{m}^{-1}\right)$, sin efectos importantes en el rendimiento del cultivo, pero si a la calidad del fruto debido a una reducción de su tamaño.

Los cítricos y otros leñosos (almendro y olivo) se manejan de una manera similar, los agricultores en base a su experiencia reducen el riego en esas etapas que el cultivo es menos sensible al déficit hídrico. Esta técnica podría ser denominada como riego deficitario sin control específico y su aplicación es más restrictiva para el almendro y el olivo $\left(\mathrm{V}_{\mathrm{i}} \approx 50 \% \mathrm{ETc}\right)$ que para los cítricos $\left(\mathrm{V}_{\mathrm{i}} \approx 70 \% \mathrm{ETc}\right)$.

En los últimos bloques de preguntas, en las entrevistas a los agricultores, se les preguntó sobre sus estrategias más habituales frente a las restricciones en el suministro 
de agua. Las respuestas de los agricultores fueron en cierto modo heterogéneas e imprecisas, basándose principalmente en su experiencia pasada. En general, la mayoría de los agricultores destacaron un importante aumento en la extracción de aguas subterráneas, que incrementó su proporción en el agua de riego y consiguientemente su salinidad. Esto dio lugar a dos desventajas principales: (i) las necesidades del riego aumentaron debido al incremento de la fracción de lavado, y (ii) a una disminución del rendimiento de los cultivos. Aunque los agricultores generalmente trataron de reducir los efectos negativos mediante la incorporación de enmiendas y fertilizantes especiales por la salinidad del agua, las consecuencias fueron un aumento en los costes del cultivo y una disminución inevitable en los rendimientos de los cultivos, con una reducción de la calidad de los mismos, que finalmente dio lugar a un margen bruto menor de sus explotaciones.

Por grupos de cultivos se siguieron las siguientes estrategias bajo restricciones en el suministro de agua. El uso principal del agua suministrada por la CRCC fue para los hortícolas de invierno, ya que (i) la mayoría de ellos son sensibles a la salinidad del agua, (ii) sus necesidades de agua son inferiores (Fig. 5.12), y (iii) presentan una menor variación interanual en el precio agrícola, ya que muchos agricultores los plantan con un precio previo pactado, lo que representa la base de la actividad agrícola en la zona. En anteriores situaciones de escasez de agua, la disponibilidad de agua solía ser suficiente para el mantenimiento de estos cultivos y la adaptación sólo era reducir la dosis de riego y aumentar la salinidad del agua de riego hasta donde era posible.

La alcachofa es un cultivo bianual, su tolerancia a la salinidad hace posible su riego directo con las aguas subterráneas. En este caso se aplica más agua que la indicada en la Fig. 5.12, con el fin de mantener el contenido de agua del suelo cerca de la capacidad de campo y se aumenta la fracción de lavado. 
El riego de hortícolas de verano, durante los periodos de escasez de agua, se realiza de manera similar a las hortícolas de invierno en las primeras etapas del cultivo y en el resto de etapas se realiza como la alcachofa. El melón y sandía son sensibles a la salinidad durante la etapa de plántula, siendo el agua procedente de la CRCC esencial para el correcto desarrollo del cultivo, pero su tolerancia hacia la salinidad aumenta a medida que se va desarrollando el cultivo y el riego directo con las aguas subterráneas es posible en las últimas fases. Pero a pesar de esto, la Fig. 5.10 muestra una disminución del 30\% en la superficie cultivada de hortícolas verano entre 2004 (año normal) y 2006 (año seco), lo que indica que debido a la gran escasez de agua algunos agricultores se vieron obligados a abandonar este cultivo.

Los cítricos son los más sensibles a la escasez de agua ya que la supervivencia de los mismos está en juego durante los periodos en los que la escasez de agua es más severa. Esta razón justifica estrategias más específicas, tales como la instalación de pequeñas plantas desalobradoras en las explotaciones agrícolas, siendo su fuente el agua salobre de los acuíferos. Las plantas desalobradoras empezaron a instalarse principalmente durante la gran sequía que se produjo sobre 1995, en esta época muchos agricultores decidieron instalarlas en sus fincas para resolver el problema de las limitaciones de agua. Desde entonces se estima que sobre 100 explotaciones agrícolas han adoptado esta solución basada en la tecnología de desalinización por ósmosis inversa, la producción de estas plantas se suele encontrar entre 500 y $5.000 \mathrm{~m}^{3}$ día $^{-1}$. Esta estrategia también parece estar extendiéndose a explotaciones dedicadas a cultivos de invernadero y hortícolas de invierno.

Por tanto la combinación del riego deficitario sin control específico y la desalinización de agua salobre es la estrategia habitual de los cítricos frente a la escasez de agua. En cuanto a otros cultivos leñosos, la alta resistencia de almendro y olivo a la 
sequía hace posible aumentar la intensidad del riego deficitario, realizándose incluso solo riegos de socorro, hay que tener en cuenta que estos cultivos también se cultivan en secano.

\subsection{DISCUSIÓN}

En este Capítulo se ha evaluado la sensibilidad de los indicadores de gestión en las CCRRs sometidas a restricciones en el uso del agua a lo largo del tiempo. El estudio de los indicadores en general muestra una gran variabilidad durante el periodo analizado, siendo la escasez un factor determinante en esta variación.

Los efectos más destacables de la escasez de agua sobre los indicadores de gestión en las CCRRs estudiadas fueron: (a) una reducción de la intensidad de cultivo (SrSa), de la eficiencia de distribución (ED) y del aporte relativo de agua de riego (ARIS); (b) un aumento de los costes de manejo del sistema (CMSVs) y energéticos (CENVs) por unidad de agua de riego suministrada; y (c) una disminución en el valor de la producción agrícola (VPSr) y margen bruto (MBSr) por unidad de superficie regada. Hay que significar, que al contrario de lo esperado, en algunas CCRRs han aumentado los costes energéticos (CENSr) por unidad de superficie regada con la disminución de $\mathrm{VsSr}$, debido al empleo de las aguas subterráneas para paliar la reducción de sus recursos disponibles de otras fuentes.

Por último, las encuestas realizadas a los agricultores de la CRCC revelaron que están bien adaptados a la escasez de agua gracias a la disponibilidad de las aguas subterráneas salobres. Sin embargo, las estrategias adoptadas implican varias prácticas desaconsejables como la gestión del agua de riego de alta salinidad, la producción de salmuera sin control en las plantas desalobradoras, o un aumento importante en el consumo de energía en las explotaciones agrarias debido a la extracción y tratamiento 
de las aguas subterráneas salobres. Además, el coste de los cultivos se incrementa significativamente en situaciones de escasez de agua (captación de aguas subterráneas, desalinización, uso de fertilizantes especiales, etc), mientras que los rendimientos de los mismos disminuyen debido a la mayor salinidad del suelo, ocasionando menores márgenes brutos, que pueden llegar a ser incluso negativos. Por lo tanto, la perseverancia de las situaciones de escasez de agua implica inconvenientes ambientales y económicos que podrían hacer insostenible el mantenimiento de la actividad agrícola en la zona. 


\section{Capítulo 6}

\section{EFECTOS DE LA MODERNIZACIÓN}

Este Capítulo se centra en los efectos de la modernización sobre las comunidades de regantes, analizando el papel de las tecnologías de la información y la comunicación en la gestión moderna de estas organizaciones, así como el efecto de los nuevos servicios proporcionados por las mismas sobre el regante.

\subsection{INTRODUCCIÓN}

La Directiva Marco del Agua exige que: “los Estados miembros, a más tardar en 2010, tendrán en cuenta el principio de la recuperación de los costes de los servicios relacionados con el agua, incluidos los costes medioambientales y los relativos a los recursos", por lo que se hace necesario un control de los caudales consumidos en el regadío.

La modernización de las comunidades de regantes (CCRRs) ha sido promovida fundamentalmente para controlar los volúmenes suministrados, mejorar la gestión y la eficiencia del uso del agua en sus zonas regables (López-Gunn et al., 2012). Estos procesos de modernización se han caracterizado principalmente por la sustitución de los tradicionales sistemas de distribución de canales abiertos por conducciones presurizadas, y la incorporación de las tecnologías de la información y la comunicación (TICs) a la gestión de las CCRRs (Playán y Mateos, 2006; García-Vila et al., 2008; Rodríguez et al., 2011a). La incorporación de estas nuevas tecnologías ofrece muchas oportunidades a los gestores de las CCRRs para optimizar el uso de los recursos hídricos y energéticos. Dado que pueden contar con nuevas herramientas: sistemas de supervisión y adquisición de datos (SCADA); sistemas de soporte a la decisión (SSD); 
sistemas de información geográfica (GIS); y aplicaciones Web y para la telefonía móvil. Estas herramientas han sido descritas en el apartado 2.6.2 del Capítulo 2.

Algunos estudios ya han analizado la situación antes y después de actuaciones de modernización. Por ejemplo, Lecina et al. (2010) compararon el efecto de la modernización en diversos escenarios; y Rodríguez et al. (2011a) analizaron las ventajas y limitaciones relativas a la modernización basado en los datos de campo recogidos antes y después de la realización de la misma. Los estudios dejan claro que la valoración de la efectividad de las medidas aplicadas por medio de técnicas de benchmarking es esencial para identificar las cuestiones clave para la mejora de la gestión del agua.

En nuestro caso para poder evaluar los efectos de la modernización y el papel de las TICs en las CCRRs de la Región de Murcia, se ha analizado a la Comunidad de Regantes del Campo de Cartagena (CRCC) que está aplicando estas herramientas en la gestión de su zona regable desde 1999, incluyendo: SCADA, SSD, GIS, aplicaciones Web y para telefonía móvil.

\subsection{METODOLOGÍA}

La metodología llevada a cabo en el presente Capítulo ha sido estructurada en varios pasos. En primer lugar se seleccionaron una serie de indicadores de gestión para poder caracterizar los efectos de la modernización en la CRCC mediante el análisis del antes y el después de la modernización. Los datos para poder calcular estos indicadores se tomaron directamente de las bases de datos de la CRCC y de sus memorias anuales. A continuación se describe la zona de estudio y el sistema de distribución de agua, mostrando la arquitectura del sistema con sus diferentes aplicaciones y el SCADA.

Para finalizar se presentan los efectos de la modernización sobre los indicadores de gestión y los efectos de las TICs en el funcionamiento de la CCRR y la adaptación de 
los agricultores a los nuevos servicios. Por último se realiza la discusión de los resultados obtenidos.

\subsubsection{Indicadores seleccionados}

El efecto de la modernización se cuantificó comparando el valor de los indicadores de gestión entre el año 2002 (antes de la modernización) y el año 2011 (después de la modernización), años que presentaron una cantidad similar en cuanto al suministro de agua por unidad de área regada. Se seleccionaron años con un volumen suministrado de agua similar debido a que, como se indica en el Capítulo anterior, ésta puede interferir en el valor de los indicadores. De esta forma la variabilidad en los resultados obtenidos se puede atribuir principalmente al efecto de la modernización.

En la Tabla 6.1 se describe el conjunto de indicadores seleccionados y cómo se calcularon para su aplicación en este Capítulo. Los indicadores de rendimiento seleccionados fueron $\mathrm{VsSr}, \mathrm{SrSa}$ y $\mathrm{ED}$, que permiten evaluar el efecto de la modernización sobre la superficie cultivada y la mejora sobre la eficiencia de distribución del sistema. Hay que tener en cuenta que uno de los objetivos principales de la modernización es reducir las pérdidas de agua mediante la mejora en la ED. Con los indicadores financieros (GGVs, GGSr, CPVs, CPSr, CMVs, CMSr, CENVs y CENSr) se pretende evaluar cómo afecta la modernización a los costes de funcionamiento de la CCRR. Por último con los indicadores de la eficiencia de la producción (VPVs y VPSr) se pretende ver cómo afecta este proceso al valor de la producción agrícola de la zona de estudio.

Todos los valores monetarios relacionados con los indicadores financieros y de eficiencia de la producción se han actualizado a 2011 mediante el IPC para evitar los efectos de la inflación. 
Tabla 6.1. Descripción y método de cálculo de los indicadores de gestión empleados.

\begin{tabular}{|c|c|c|c|}
\hline $\begin{array}{l}\text { Nombre del indicador y } \\
\text { acrónimo }\end{array}$ & Unidad & Clasificación & Descripción y cálculo \\
\hline $\begin{array}{l}\text { Suministro de agua por } \\
\text { unidad de área regada ( } \mathrm{VsSr})\end{array}$ & $\mathrm{m}^{3} \mathrm{ha}^{-1}$ & De rendimiento & $\begin{array}{l}\text { Vs/Sr } \\
\text { donde Vs es el volumen total anual } \\
\text { suministrado a los usuarios y } \mathrm{Sr} \text { es la } \\
\text { superficie total regada. }\end{array}$ \\
\hline Intensidad de cultivo ( $\mathrm{SrSa}$ ) & $\%$ & De rendimiento & $\begin{array}{l}100 \cdot \mathrm{Sr} / \mathrm{Sa} \\
\text { donde } \mathrm{Sr} \text { es la superficie total regada y Sa es } \\
\text { la superficie regable. }\end{array}$ \\
\hline $\begin{array}{l}\text { Eficiencia de distribución } \\
\text { (ED) }\end{array}$ & $\%$ & De rendimiento & $\begin{array}{l}100 \cdot \mathrm{Vs} / \mathrm{VT} \\
\text { donde Vs es el volumen total anual } \\
\text { suministrado a los usuarios y VT el volumen } \\
\text { anual que entra al sistema de la CCRR }\end{array}$ \\
\hline $\begin{array}{l}\text { Gastos generales del sistema } \\
\text { por unidad de agua de riego } \\
\text { suministrada (GGVs) }\end{array}$ & $€ \mathrm{~m}^{-3}$ & Financieros & $\begin{array}{l}\text { GG/Vs } \\
\text { donde GG son los gastos generales anuales y } \\
\text { Vs es el volumen total anual suministrado a } \\
\text { los usuarios }\end{array}$ \\
\hline $\begin{array}{l}\text { Gastos generales del sistema } \\
\text { por unidad de área regada } \\
\text { (GGSr) }\end{array}$ & $€ \mathrm{ha}^{-1}$ & Financieros & $\begin{array}{l}\mathrm{GG} / \mathrm{Sr} \\
\text { donde GG son los gastos generales anuales y } \\
\text { Sr es la superficie total regada }\end{array}$ \\
\hline $\begin{array}{l}\text { Costes personal por unidad de } \\
\text { agua de riego suministrada } \\
\text { (CPVs) }\end{array}$ & $€ \mathrm{~m}^{-3}$ & Financieros & $\begin{array}{l}\mathrm{CP} / \mathrm{Vs} \\
\text { donde CP son los costes de personal anuales y } \\
\text { Vs es el volumen total anual suministrado a } \\
\text { los usuarios }\end{array}$ \\
\hline $\begin{array}{l}\text { Costes personal por unidad de } \\
\text { área regada (CPSr) }\end{array}$ & $€ \mathrm{ha}^{-1}$ & Financieros & $\begin{array}{l}\mathrm{CP} / \mathrm{Sr} \\
\text { donde } \mathrm{CP} \text { son los costes de personal anuales y } \\
\mathrm{Sr} \text { es la superficie total regada }\end{array}$ \\
\hline $\begin{array}{l}\text { Costes mantenimiento por } \\
\text { unidad de agua de riego } \\
\text { suministrada }(\mathrm{CMVs})\end{array}$ & $€ \mathrm{~m}^{-3}$ & Financieros & $\begin{array}{l}\mathrm{CM} / \mathrm{Vs} \\
\text { donde CM son los costes de mantenimiento } \\
\text { anuales y Vs es el volumen total anual } \\
\text { suministrado a los usuarios }\end{array}$ \\
\hline $\begin{array}{l}\text { Costes mantenimiento por } \\
\text { unidad de área regada (CMSr) }\end{array}$ & $€ \mathrm{ha}^{-1}$ & Financieros & $\begin{array}{l}\mathrm{CM} / \mathrm{Sr} \\
\text { donde } \mathrm{CM} \text { son los costes de mantenimiento } \\
\text { anuales y Sr es la superficie total regada }\end{array}$ \\
\hline $\begin{array}{l}\text { Coste energético por unidad } \\
\text { de agua de riego suministrada } \\
\text { (CENVs) }\end{array}$ & $€ \mathrm{~m}^{-3}$ & Financieros & $\begin{array}{l}\text { CEN/Vs } \\
\text { donde CEN son los costes energéticos anuales } \\
\text { facturados y Vs es el volumen total anual } \\
\text { suministrado a los usuarios }\end{array}$ \\
\hline $\begin{array}{l}\text { Coste energético por unidad } \\
\text { de área regada (CENSr) }\end{array}$ & $€ \mathrm{ha}^{-1}$ & Financieros & $\begin{array}{l}\text { CEN/Sr } \\
\text { donde CEN son los costes energéticos anuales } \\
\text { facturados y Sr es la superficie total regada. }\end{array}$ \\
\hline $\begin{array}{l}\text { Valor producción agrícola por } \\
\text { unidad de agua de riego } \\
\text { suministrada (VPVs) }\end{array}$ & $€ \mathrm{~m}^{-3}$ & $\begin{array}{l}\text { De eficiencia de } \\
\text { producción }\end{array}$ & $\begin{array}{l}\text { VP/Vs } \\
\text { donde VP es el valor total de la producción } \\
\text { agrícola y Vs es el volumen total anual } \\
\text { suministrado a los usuarios. }\end{array}$ \\
\hline $\begin{array}{l}\text { Valor producción agrícola por } \\
\text { unidad de superficie regada } \\
\text { (VPSr) }\end{array}$ & $€$ ha $^{-1}$ & $\begin{array}{l}\text { De eficiencia de } \\
\text { producción }\end{array}$ & $\begin{array}{l}\mathrm{VP} / \mathrm{Sr} \\
\text { donde VP es el valor total de la producción } \\
\text { agrícola y } \mathrm{Sr} \text { es la superficie total regada. }\end{array}$ \\
\hline
\end{tabular}

\subsubsection{Zona de estudio}

Las características principales de la CRCC han sido descritas en el Capítulo 2. Las actividades principales de esta CCRR son: (a) adaptar la oferta disponible, dentro de lo posible en cada momento, a la demanda del agua de los cultivos de su zona regable; (b) la distribución del agua; (c) las actividades de mantenimiento; (d) la supervisión de las actividades de la operación y de mantenimiento; (e) y el servicio de asistencia al 
riego. La CRCC cuenta con 33 sectores de riego hidráulicamente independientes, 18 en la Zona Regable Oriental, 3 en la Zona Regable Occidental y 12 en la Zona Regable Cota 120. En 2012 se suministró agua a 23.498 parcelas, con 2.962 regantes.

La modernización ha consistido principalmente en: (a) la sustitución de elementos de control y de medida por otros preparados para el telecontrol; (b) la instalación de equipos de medida en las tuberías principales, primarias y secundarías, así como en las balsas de riego; (c) agrupación de las estaciones de bombeo; (d) aumento de la capacidad de almacenamiento de agua y de la red de distribución; (e) incorporación de las TICs a la gestión de la CRCC, mediante el uso de CENTUR (una aplicación de gestión), GIS, aplicaciones Web, aplicaciones para telefonía móvil, y el SCADA.

Antes de la modernización, la distribución de agua se llevaba a cabo de la siguiente manera: (i) el regante indicaba al celador el volumen de agua y el día que quería efectuar el riego; (ii) el celador, dependiendo de los recursos disponibles, y de los turnos que ya tenía asignados a otros agricultores previamente, le indicaba al regante el día, las horas del riego y el volumen de agua que podía tomar; (iii) antes de iniciar el riego, el agricultor tomaba la lectura de manera visual del contador instalado en la conducción, después de haber realizado el riego, el agricultor volvía a tomar lectura de nuevo; (iv) el consumo de agua considerado era la diferencia entre ambas lecturas, la verificación de la exactitud de estas lecturas era realizada por los agricultores sucesivos bajo la atenta supervisión del celador de cada sector; (v) el celador realizaba un talón con el volumen suministrado en base al consumo y las lecturas del contador facilitadas por el agricultor, dando una copia al agricultor y otra era enviada a las oficinas principales de la CRCC para realizar la facturación correspondiente. 
Con la modernización, todas estas tareas se han automatizado mediante el uso de las TICs, que son las encargadas de todos los procesos que se describen en el siguiente apartado.

\subsubsection{Sistema de asignación y distribución del agua}

Las asignaciones de agua a los agricultores se realizan por cupos $\left(\mathrm{m}^{3} \mathrm{ha}^{-1}\right)$, ya que el volumen de agua disponible es por lo general inferior a las necesidades hídricas de los cultivos de la zona regable, y de esta manera se reduce la conflictividad entre los agricultores al ser tratados todos por igual. Por tanto el volumen de agua asignado para cada agricultor es función de la superficie de sus parcelas y los cupos dados por la CRCC. Cada agricultor administra su asignación de agua, que irá disminuyendo en función del volumen que consuma. Por todo ello, como primera actuación previa a la modernización, para poder realizar correctamente la asignación y distribución de agua fue necesario realizar el censo de todas las parcelas ubicadas dentro del perímetro de la zona regable. La fuente del censo fue el catastro, dado que esta información tiene carácter legal y es actualizada por el Estado continuamente (Playán et al., 2007).

CENTUR es la aplicación encargada de la gestión del censo, con el apoyo del GIS para el tratamiento de la información espacial. Dado que la distribución del agua se organiza mediante el sistema de turnos, CENTUR es además el SSD en la asignación y en la distribución del agua, en base a las peticiones semanales efectuadas por los agricultores. En la Fig. 6.1 se presenta el diagrama del flujo de cómo se realiza la distribución del agua. Los agricultores pueden pedir agua cuando tienen volumen asignado y saldo en sus cuentas, en el pedido indican cuando quieren efectuar el riego, el volumen y la duración del mismo. Los miércoles se realiza el cálculo de los turnos de 
riego de toda la semana, en función de (a) los pedidos realizados, (b) los recursos disponibles y (c) las limitaciones hidráulicas de las infraestructuras de la CCRR.

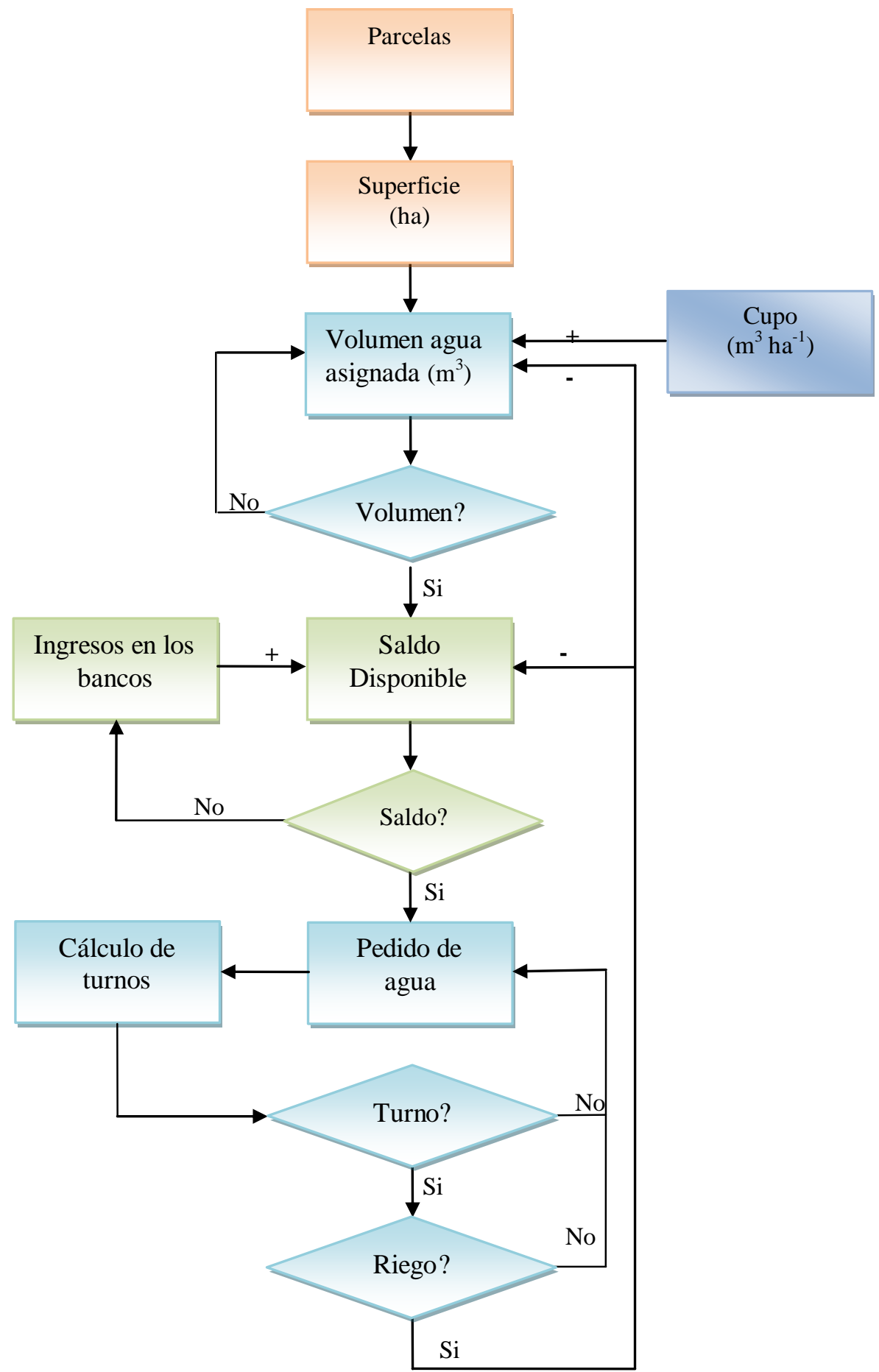

Figura 6.1. Diagrama de flujo de la distribución de agua. 
Una vez calculada la programación semanal de los turnos de riego por CENTUR, las operaciones necesarias en la infraestructura hidráulica para poder efectuar los riegos también se definen por este SSD. A continuación, las órdenes para el manejo del sistema hidráulico se envían al SCADA, para que este efectúe la operación sobre la red de riego con el fin de realizar correctamente los suministros de agua programados a los agricultores y controlar cualquier incidencia que se produzca. Los agricultores consultan la programación y la ejecución de su turno en tiempo real a través de las aplicaciones Web y aplicaciones para el móvil.

La infraestructura hidráulica controlada por el SCADA consiste principalmente en: (a) la red de tuberías $(1.033 \mathrm{~km})$, (b) balsas con una capacidad total de $2,5 \mathrm{hm}^{3}$; (c) siete estaciones de bombeo; (d) 1.310 válvulas hidráulicas, y (e) 1.351 contadores.

Los celadores se encargan de la vigilancia y supervisión de la infraestructura hidráulica y de los elementos de control. Para ello cuentan con acceso a la monitorización de la red de riego proporcionada por el SCADA a través de aplicaciones Web y para telefonía móvil, y pueden actuar sobre la red de riego de forma remota en caso de emergencia (por ejemplo cerrar una válvula hidráulica cuando se produce la rotura de una tubería).

\subsubsection{Arquitectura del sistema de gestión}

El sistema de gestión de la CRCC está formado por varias unidades hardware / software, que se encuentran estrechamente relacionadas y que se comunican a través de una sofisticada red de bases de datos y aplicaciones (Fig. 6.2). Las principales aplicaciones que forman el sistema de gestión de la CRCC son: CENTUR (censo y gestión del riego), AutoCAD Map (edición GIS), iFIX (control SCADA), BASE (gestión contable), aplicaciones Web (Aplicación de la gestión y distribución del agua, 
Aplicación celadores, Aplicación Gestión de Incidencias, WikiCRCC y WebGIS) y las aplicaciones para móviles.

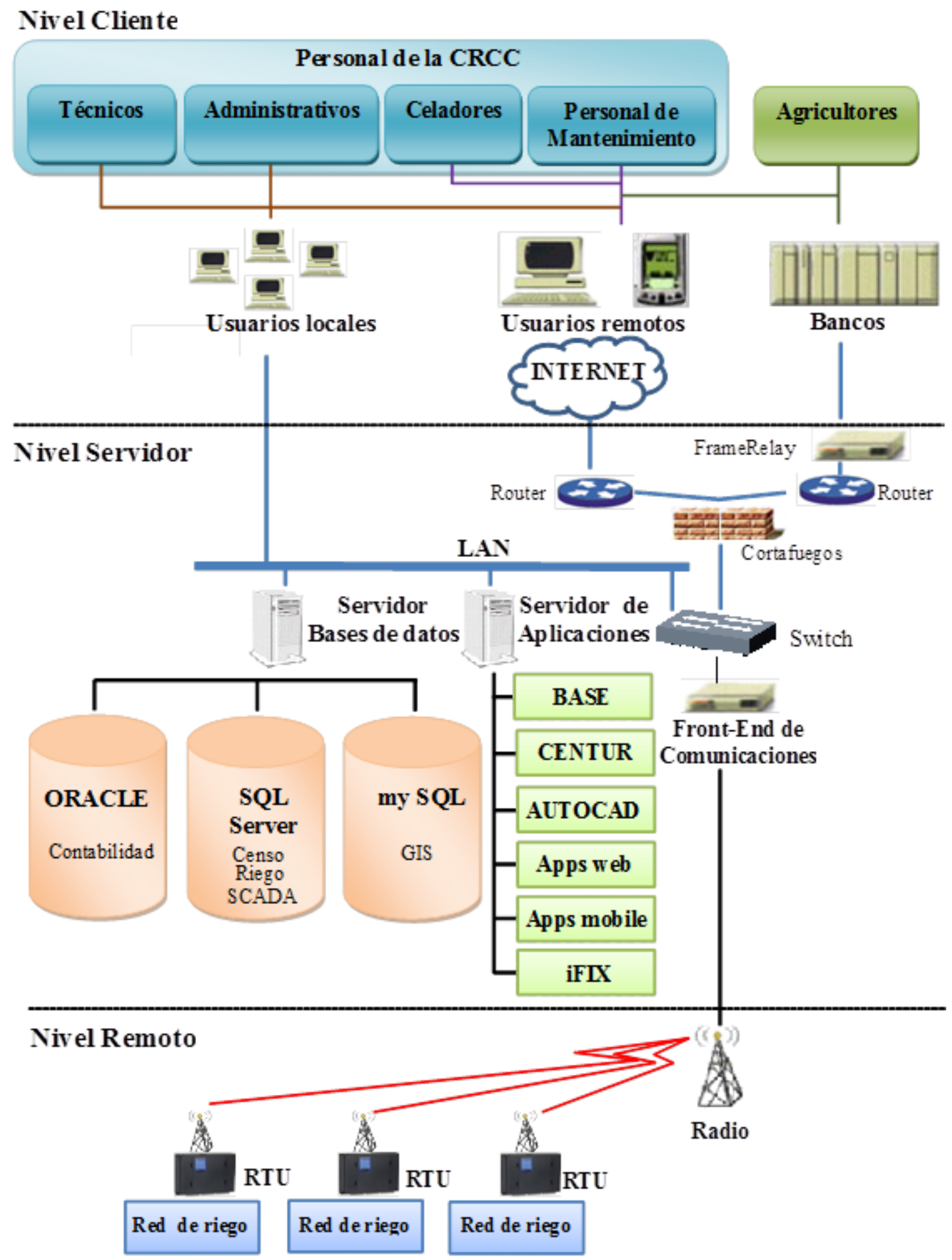

Figura 6.2. Los tres niveles del sistema de gestión de la CRCC. 
La arquitectura del sistema de gestión está organizada en capas o niveles (Fig. 6.2). Los diferentes niveles son:

1. El nivel Cliente es el responsable del intercambio de información entre los diferentes usuarios y el sistema. Proporciona a los usuarios un interfaz "amigable", que recibe la entrada de datos de los agricultores y el personal de la CRCC, y muestra la información proporcionada por el sistema. Todos los usuarios tienen acceso remoto al sistema mediante las aplicaciones Web y para telefonía móvil. Los técnicos como usuarios locales emplean las aplicaciones CENTUR, AutoCAD Map, iFIX, mientras que el personal administrativo maneja las aplicaciones CENTUR y BASE.

2. El nivel Servidor conecta a los usuarios con los nodos remotos, y consiste en las diferentes aplicaciones y en las bases de datos del sistema. Las bases de datos empleadas son bases de datos relacionales, en las que se produce el almacenamiento de toda la información, incluyendo datos espaciales e históricos. Las bases de datos utilizadas son SQL Server (censo, gestión de la distribución del agua y el SCADA), MySQL (GIS) y Oracle (gestión contable). El propósito de estas herramientas o aplicaciones es llevar la información al interfaz de usuario, proporcionando acceso a toda la información disponible y facilitando la ejecución de las diferentes tareas de la CRCC. En este nivel se incluye un software que conecta con los bancos, para recibir la relación de los ingresos realizados por los agricultores para poder efectuar sus riegos.

3. El nivel Remoto permite realizar el telecontrol y la supervisión remota de las infraestructuras de riego. Su función es la de garantizar las comunicaciones entre el software del sistema y las más de 1.000 unidades de terminal remoto (RTUs) instaladas junto a los elementos de control. Además monitoriza la red de riego, 
controlando los reintentos y la integridad del flujo de datos, así como la activación o desconexión de equipos remotos de manera automática o a solicitud del usuario. Los Front-End de comunicaciones actúan como enrutadores de las comunicaciones entre las RTUs y el iFIX, hacen de interfaz entre los distintos medios de comunicación disponibles, entre la red Ethernet (LAN) del centro de control y la red de radio que da cobertura a las RTUs.

\subsubsection{Aplicaciones para los usuarios en local}

Los técnicos y el personal administrativo son los usuarios de las siguientes aplicaciones en modo local:

1. CENTUR es la encargada de la gestión del censo, de la asignación y distribución del agua. CENTUR fija el volumen de agua asignado a cada agricultor en función de los cupos y de la superficie de sus parcelas. Recibe las peticiones de riego de los agricultores, estableciendo los turnos de riego en base al protocolo establecido (cálculo de turnos), existiendo la posibilidad de reasignación inmediata de turnos en caso de avería en el sistema hidráulico. Envía al SCADA la programación de los turnos y una vez ejecutados, recibe los datos de los volúmenes suministrados para poder hacer la facturación a cada agricultor, descontando el agua consumida y el dinero de su saldo. Esta aplicación tiene integrado un módulo GIS que permite consultar gráficamente las parcelas de un agricultor y la información sobre la infraestructura hidráulica.

2. En AutoCAD Map se realiza la edición de información gráfica de las parcelas e infraestructuras, así como las consultas y mapas temáticos de toda la información disponible, proporcionando a los técnicos toda la funcionalidad de los GIS. Se trata de un programa comercial conectado a una base de datos 
geoespacial MySQL y a distintos servidores Web Map Server (WMS) que proporcionan información de catastro, ortofotomapas, mapas de suelos, cartografía medioambiental, actuaciones urbanas, etc. El GIS permite una visualización global de toda la zona regable, relacionando toda la información alfanumérica disponible con la información espacial.

3. IFix es la aplicación de control del SCADA, que es la encargada de llevar la información hacia y desde los elementos de operación hidráulica, así como de mostrar el estado de funcionamiento de la red de riego y de la propia red de comunicaciones. La información es presentada mediante un mapa interactivo con los elementos de control. Recibe las ordenes de CENTUR, efectúa las operaciones de telecontrol encargadas y devuelve la información del normal desenvolvimiento de los suministros o de los eventos que se hayan producido (consumos, averías, etc.), que CENTUR transmitirá finalmente a los agricultores afectados.

4. BASE es la aplicación encargada de la gestión contable. Gestiona los ingresos realizados por los agricultores en las entidades bancarias y cajeros, que quedan automáticamente reflejados en las cuentas de los mismos en la CRCC.

\subsubsection{Aplicaciones para los usuarios en remoto}

El acceso remoto al sistema se realiza a través de las aplicaciones Web y para telefonía móvil. Estas aplicaciones presentan tres tipos de accesos: abierto, aplicaciones para los agricultores, y aplicaciones para el personal de la CCRR (técnicos, celadores, personal de mantenimiento y administrativos). Desde el año 2000 es posible el acceso a la Aplicación de la gestión y distribución del agua a través del portal Web de la CRCC (http://www.crcc.es). Esta aplicación permite a los agricultores acceder a su 
información y gestionar todas sus tareas relacionadas con los volúmenes de agua suministrados por la CRCC. El personal de la CRCC tiene disponibles diferentes aplicaciones Web para: (a) dar servicio a los agricultores, (b) poder supervisar y controlar la distribución del agua, y (c) registrar las operaciones de mantenimiento. Estas aplicaciones son:

- Aplicación celadores. Esta aplicación permite que los celadores puedan atender a los agricultores y supervisar remotamente los riegos programados y toda la infraestructura que tienen a su cargo. El acceso por Internet permite una conexión directa con las bases de datos del sistema.

- Aplicación de incidencias. Esta aplicación registra las operaciones de mantenimiento preventivo, normativo y de reposición de la infraestructura realizadas por los celadores y el personal de mantenimiento. Esto permite a los técnicos, celadores y personal de mantenimiento un seguimiento histórico de las operaciones de mantenimiento, así como en los elementos que se producen las mismas. El acceso puede ser a través de Web o aplicación para telefonía móvil.

○ WikiCRCC. Se trata de un sistema de gestión documental compartido, que recoge toda la información de gestión técnica de las infraestructuras, con objeto de compartir y mejorar las comunicaciones y procesos internos entre el personal de la CRCC. En esta aplicación participa todo el personal. Este sistema se emplea a través de la Web.

○ WebGIS (http://gis.crcc.es). En el WebGIS se integran los mapas propios de la CRCC con ortofotomapas, mapas topográficos y catastrales de otros servidores.

La tecnología aplicada para el desarrollo de las aplicaciones para los teléfonos móviles fue Wireless Application Protocol (WAP). En su desarrollo se tuvieron en cuenta los limitados recursos de presentación e interacción de un terminal móvil, por lo 
que se creó un interfaz sencillo y de acceso universal que permitiese su funcionamiento en la mayoría de móviles. Este sistema ofrece dos tipos de acceso en función del perfil del usuario que se conecta: personal de la CRCC y agricultores (Del Amor, 2006).

\subsubsection{SCADA}

El SCADA permite realizar el telecontrol y supervisión de la red de riego. Cada dispositivo que controla el SCADA está conectado a una RTU compuesta por un autómata, sensores de intrusismo, un sistema de comunicaciones vía radio UHF y un sistema de alimentación compuesto por un panel solar. El sistema de comunicaciones empleado por el SCADA cuenta con 4 repetidores y más de 1.000 RTUs. En la Fig. 6.3 se muestra el esquema general de comunicaciones con las RTUs, que tienen un código de identificación único y una asignación de medio de comunicación para cada zona. En este esquema se muestran los 33 sectores de riego que forman la CRCC y la localización de las oficinas de atención al regante.

El sistema de comunicaciones tiene una estructura ramificada, formada por las RTUs y por las estaciones repetidoras, que concentran las señales de un grupo de RTUs y hacen de puente con el centro de control. Las estaciones repetidoras son elementos transparentes a las comunicaciones lógicas y su funcionalidad es la de aumentar la cobertura de la red de radio. Cada estación repetidora cuenta con dos equipos de radio que comunican con los sectores asignados, que en la Fig. 6.3 corresponde al color indicado en la leyenda. Los modos de comunicaciones, a seleccionar por el usuario en cada RTU son: (a) polling con alarmas y eventos, (b) polling con alarmas, (c) alarmas y (d) remota silenciada. El centro de control está compuesto por los siguientes elementos: (a) clúster de servidores, (b) frontales de comunicaciones (Front-End), (c) Sistema de Alimentación Ininterrumpida (SAI), y (d) panel sinóptico. 


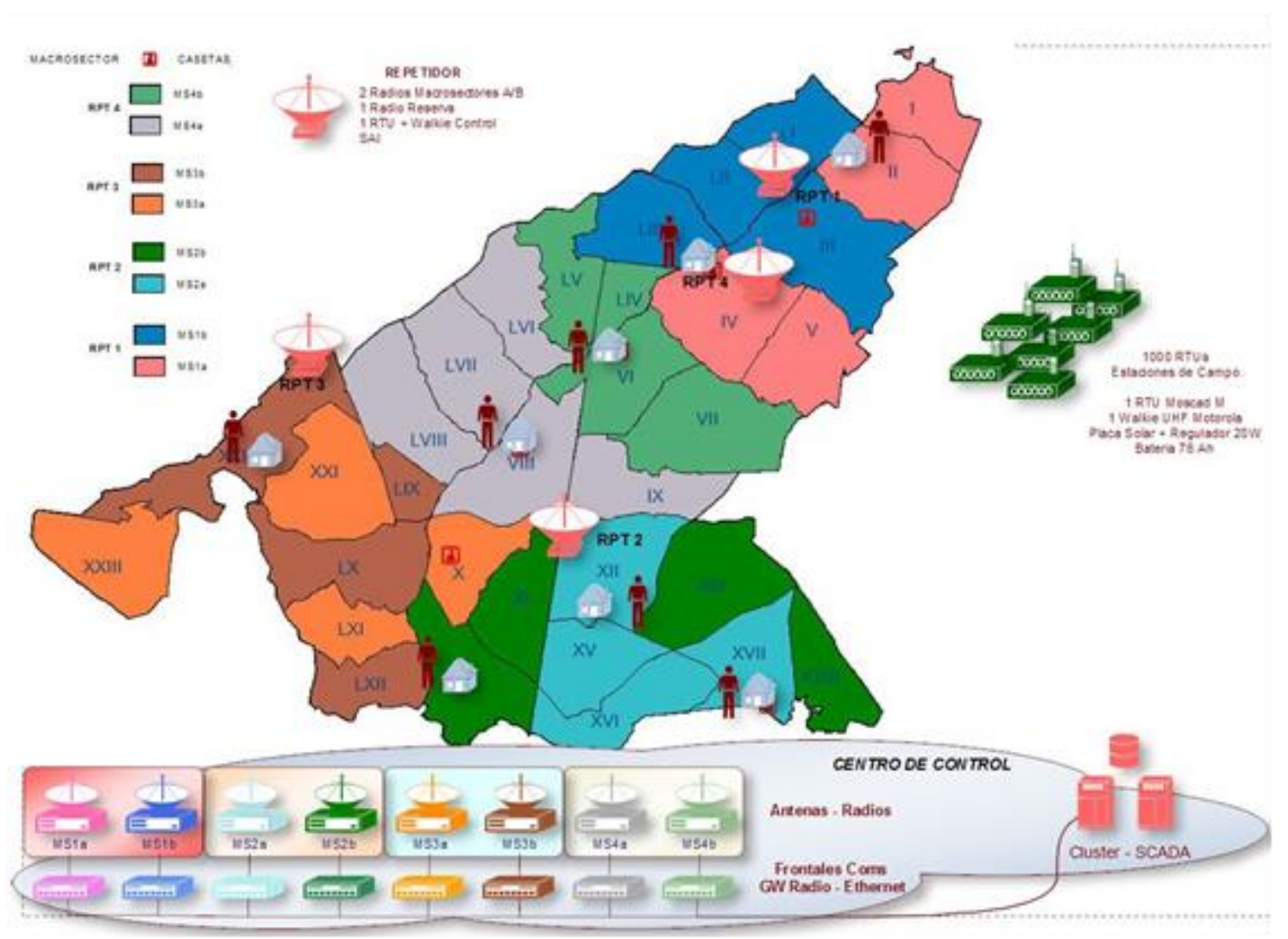

Figura 6.3. Esquema general de comunicaciones entre el centro de control y las RTUs. Las oficinas de atención al regante en el campo están representadas como una persona y una caseta.

\subsection{RESULTADOS}

\subsubsection{Efecto de la modernización sobre los indicadores de gestión}

Como se ha comentado en la Introducción, varios estudios han analizado la situación del antes y después de la modernización en CCRRs españolas. En estos casos, por lo general, la modernización ha consistido en la sustitución de los tradicionales canales de distribución por redes presurizadas mucho más eficientes. Las principales conclusiones de estos estudios han sido que, aunque el consumo de agua se redujo considerablemente, la demanda de energía se incrementó drásticamente. Con la modernización, además del aumento de los costes energéticos, se produjo un incremento considerable de los costes de gestión, operación y mantenimiento, provocando un mayor coste del agua para el agricultor. Este incremento en el precio del agua supuso una limitación en la viabilidad económica de algunos cultivos. También se produjo la 
paradoja en algunos casos en los que aunque se consiguió un ahorro de agua por la mejora en la eficiencia de distribución, la modernización produjo un cambio de cultivos en busca de una mayor productividad agrícola, que llevó asociado un aumento en el consumo de agua de la zona regable en comparación con la situación anterior (Lecina et al., 2010; Rodríguez et al., 2011a).

La modernización efectuada en la CRCC difiere bastante de lo indicado en el párrafo anterior, ya que el sistema de distribución se encontraba presurizado antes de iniciar los procesos de modernización. El efecto de este tipo de modernización se evaluó comparando el valor de los indicadores de gestión antes y después de estos procesos.

La Fig. 6.4 presenta la variación de los indicadores de gestión entre el año 2002 (antes de la modernización) y 2011 (después de la modernización). Cabe señalar que el volumen suministrado de agua por unidad de superficie regada ( $\mathrm{VsSr}$ ) fue prácticamente el mismo en esos años (-1,1\% de variación), por lo tanto el efecto de la escasez de agua puede despreciarse y la variación de estos indicadores se puede atribuir principalmente al proceso de modernización.

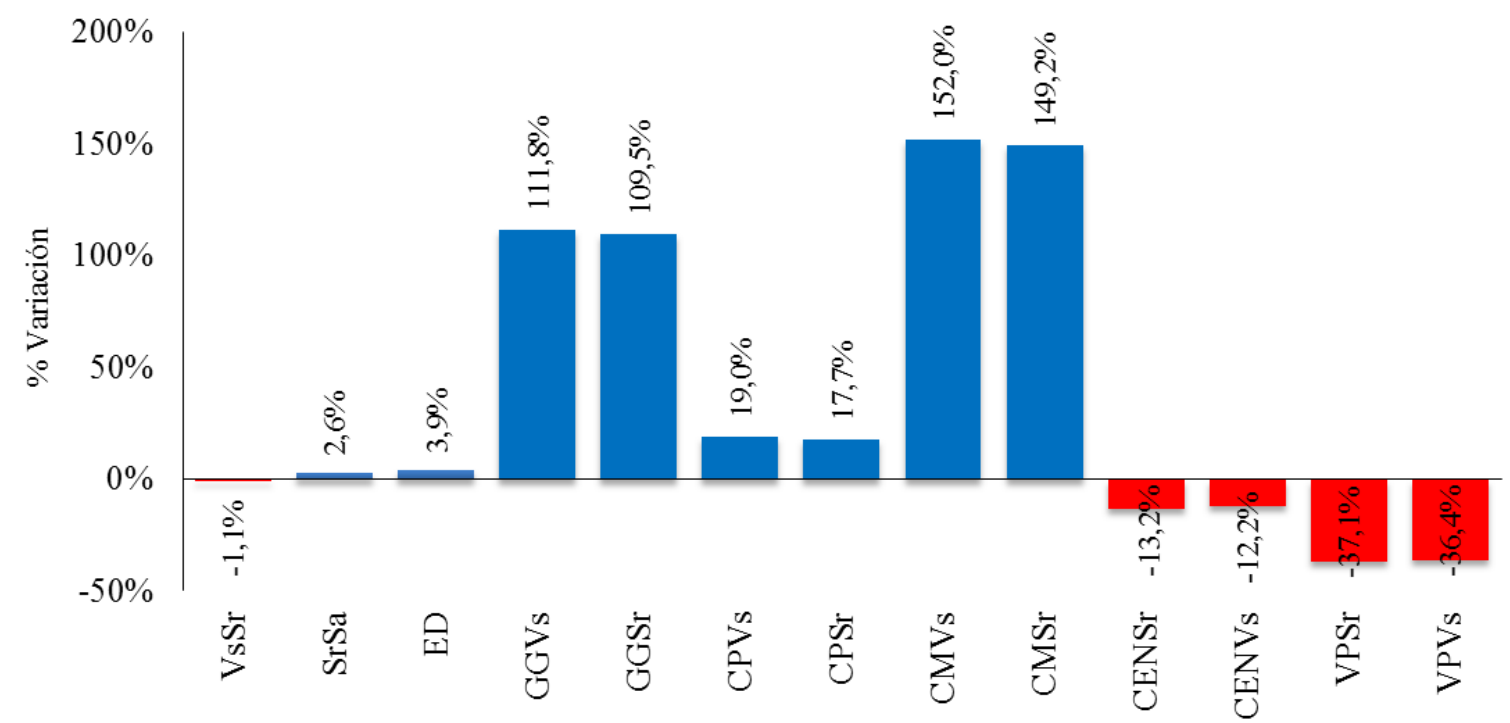

Figura 6.4. Variación de los indicadores de gestión en la CRCC antes (2002) y después (2011) de la modernización. 
La intensidad de cultivo ( $\mathrm{SrSa}$ ) no presentó ninguna variación significativa como consecuencia de la modernización, de la misma manera no se cambió el patrón de cultivos hacia otros cultivos más rentables, probablemente porque no había otros mejores para implantar en la zona. La eficiencia de distribución (ED) ya presentaba un valor muy alto antes de la modernización $(96,2 \%)$, y su valor se elevó después de la modernización hasta el 99,8\%. Esta mejora está relacionada principalmente con la implementación del SCADA que permite un seguimiento en tiempo real de cada metro cúbico distribuido, con un sistema de alarmas para detectar cualquier pérdida de agua en la infraestructura de distribución, lo que permite que se actúe rápidamente consiguiendo una ED casi perfecta.

Los gastos generales del sistema (GG) se incrementaron sobre un $110 \%$, tanto por unidad de agua de riego suministrada como por unidad de área regada. Este incremento está relacionado con el aumento de los costes de mantenimiento y personal, sobre un $150 \%$ y un $18 \%$ respectivamente. Los costes energéticos se redujeron más de un $12 \%$ entre 2002 y 2011, a pesar del fuerte incremento de las tarifas eléctricas para riego en los últimos años. Estos resultados contrastan con lo indicado por Rodríguez et al. (2011a), que analizaron varios procesos de modernización de CCRRs en Andalucía. Estas modernizaciones consistieron principalmente en la presurización de la red de distribución de agua, dando lugar a un fuerte aumento de los costes de manejo del sistema (400\%), debido principalmente al que el coste de la energía de las impulsiones de los sistemas de riego presurizados es mucho mayor ahora en comparación con los sistemas alimentados por gravedad utilizados previamente.

El valor de la producción agrícola por unidad de superficie regada (VPSr) y el valor de la producción agrícola por unidad de agua de riego suministrada (VPVs) se redujo aproximadamente un $37 \%$. Esta disminución significativa no está relacionada 
con una reducción de la producción, sino con la importante caída de los precios provocada por el brote de la bacteria E. coli en Alemania en el verano de 2011. El tratamiento desafortunado de este incidente, ya que en un principio se relacionó incorrectamente con pepinos españoles (Sandman y Lanard, 2011), afectó muy negativamente al valor de la producción agrícola española del área mediterránea.

En resumen, las principales ventajas de la modernización en la CRCC, detectadas por el empleo de los indicadores de gestión, fueron un aumento significativo en la optimización energética y una ligera mejora en la eficiencia de distribución. Por otro lado la principal desventaja fue un aumento de los gastos generales, aunque este valor es considerablemente menor a lo indicado por otros procesos de modernización estudiados. La variación negativa de los indicadores de eficiencia de producción (VPSr y VPVs) se debió a factores externos que afectaron a los precios agrícolas.

\subsubsection{Efectos sobre la gestión y el servicio de la CRCC}

El GIS es una potente herramienta que permite acceder rápidamente a la información de las parcelas que forman la CCRR, como su localización, propiedad, regante, cultivos implantados, etc. Su uso combinado con CENTUR proporciona conocer la disponibilidad de agua en todo momento en cada parcela de la zona regable. En este sentido, la Fig. 6.5 muestra, a modo de ejemplo, un mapa del volumen de agua disponible por parcela para un instante determinado.

El empleo de SCADA ha permitido controlar la trazabilidad del agua en tiempo real, ayudando a detectar las posibles pérdidas de agua o manipulaciones no autorizadas de la red de riego. Como consecuencia se ha conseguido aumentar la ED, tal como se ha comentado en el apartado anterior. En la Fig. 6.6 se recoge una consulta gráfica de la aplicación iFIX, donde se muestra el registro de datos de un contador obtenido a través 
del SCADA durante un periodo de dos semanas. La línea verde representa el caudal instantáneo, mientras que la línea azul presenta el volumen acumulado suministrado por el hidrante. Esta información es de gran utilidad para: (i) comprobar la facturación correcta de los riegos; (ii) contrastar cualquier reclamación de los agricultores, y (iii) detectar posibles anomalías que se hubieran producido durante el suministro.

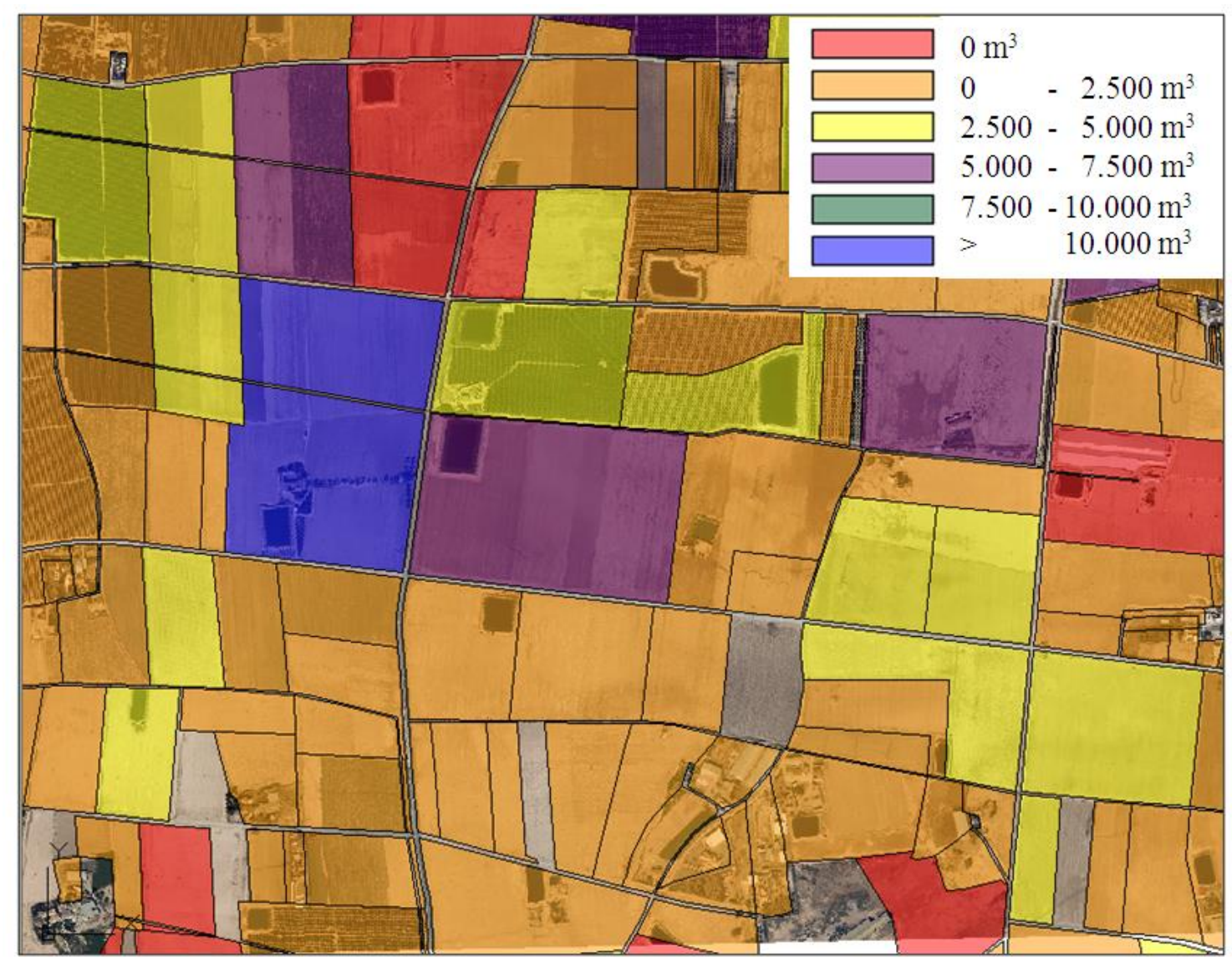

Figura 6.5. Ejemplo de la aplicación GIS donde se muestra la distribución del agua disponible $\left(\mathrm{m}^{3}\right)$ por parcela. El color de la parcela indica el volumen de agua disponible.

La aplicación de las TICs ha reducido la conflictividad entre los agricultores por el reparto del agua. La conflictividad era un problema de especial importancia en los periodos de escasez de agua, y los celadores no disponían de las herramientas adecuadas para garantizar la equidad entre los regantes. El empleo de la aplicación CENTUR ha conseguido que el proceso de reparto del agua sea equitativo y transparente, pudiendo 
verificarse el proceso de distribución del agua, desde su asignación hasta su aplicación, en cualquier momento e hidrante de la CRCC.

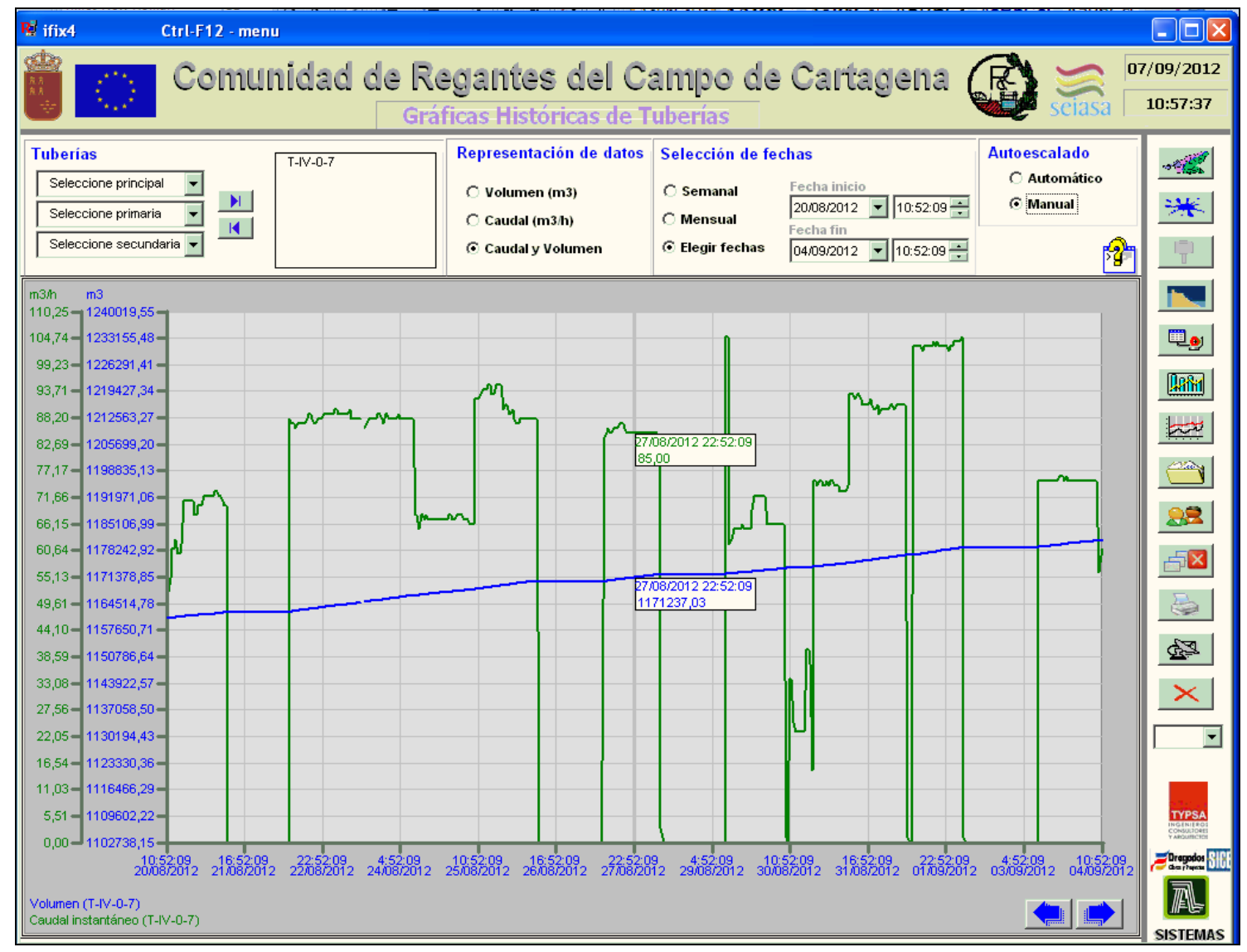

Figura 6.6. Consulta de los datos registrados en un contador de una toma de riego a través del SCADA. Se representa caudal (línea verde) y volumen de agua suministrado (línea azul).

La optimización del consumo energético es otro beneficio de la modernización con la incorporación de las TICs en la CCRR, ya que permite llevar un control estricto sobre el cumplimiento de la programación de los grupos de bombeo, realizada en base a los turnos asignados a los agricultores. Esto ha permitido una disminución de los costes energéticos, tal como se ha mostrado en el apartado anterior. La información proporcionada por el SCADA también permite realizar auditorías energéticas (Abadía et al., 2008a) de forma fácil y rápida en la CCRR.

La reducción de tiempo de actuación es otro aspecto que ha mejorado considerablemente. En la Tabla 6.2 se muestra un análisis comparativo del tiempo 
empleado para la realización de diferentes tareas, antes y después de la modernización. Se observa como las tareas propias de los celadores han pasado a realizarse de forma casi instantánea, incorporándose además nuevas capacidades no disponibles anteriormente. Esta notable mejora en la productividad de los celadores ha conllevado una reducción del $30 \%$ en este tipo de personal, mientras que el personal de mantenimiento fue incrementado un $100 \%$, y los técnicos y el personal administrativo un $25 \%$. Como resultado el número de empleados se ha mantenido constante desde el año 2000, aunque su cualificación profesional ha aumentado considerablemente.

Tabla 6.2. Análisis comparativo de tiempo empleado para la realización de diferentes tareas antes y después de la modernización.

\begin{tabular}{lrr}
\hline Tarea & Tiempo requerido & Después \\
\cline { 2 - 3 } & Antes & $15-30$ min \\
\hline Tiempo entre el riego y la facturación & $>5$ días & $<5$ min \\
Apertura/cierre de válvulas & 15 min $-1 \mathrm{~h}$ & $<5$ min \\
Arranque/parada grupos de bombeo & $20 \mathrm{~min}-1 \mathrm{~h}$ & $<2$ min \\
Conocer la lectura de un contador & 15 min $-1 \mathrm{~h}$ & $<2$ min \\
Conocer el nivel de las balsas & $20 \mathrm{~min}-1 \mathrm{~h}$ & Tiempo real \\
Identificar un acto de vandalismo en la red de riego & $10-30 \mathrm{~min}$ & Tiempo real \\
Identificar las parcelas de un regantes & $1-2 \mathrm{~h}$ & Tiempo real \\
Conocer los riegos de una toma & - & 30 min $-1 \mathrm{~h}$ \\
Programar los turnos de riego de una semana & - & $<2$ min \\
Identificar unas parcelas con una serie de atributos & - & Tiempo real \\
Conocer la superficie regada de la CRCC & - & Tiempo real \\
Conocer la demanda de la CRCC & - & $<2$ min \\
Conocer la evolución de la superficie de cada cultivo & - & $5-15$ min \\
Mapas temáticos en función diferentes atributos
\end{tabular}

El número de oficinas de riego, distribuidas por la zona regable para la atención al agricultor, también ha disminuido con la modernización, pasando de catorce oficinas en 2001 a ocho oficinas en 2011 (Fig. 6.3). En general, el uso de las TICs ha permitido mejorar la calidad del servicio a los agricultores, a pesar de reducir el personal y los puntos de atención dedicados a este fin. 


\subsubsection{Adaptación de los agricultores a las TICs}

El sistema de gestión implantado en la CRCC tiene como objetivo a medio plazo conseguir que la mayoría de los agricultores realicen todas sus gestiones relacionadas con el riego mediante aplicaciones Web y para telefonía móvil. Sin embargo, los gestores de esta CCRR también son conscientes de los condicionantes de la masa social a la que van dirigidos los nuevos servicios (nivel de formación, avanzada edad, dificultades para acceder a Internet, etc.), por lo que se mantienen la atención personal en las ocho oficinas que la CCRR tiene distribuidas por toda la zona regable (Fig. 6.3).

Los nuevos servicios asociados al uso de las TICs han permitido mejorar la información a los agricultores sobre las normas y criterios de reparto del agua, los cupos vigentes en cada año hidrológico, los precios del agua, los volúmenes asignados y consumidos por cada regante, etc. Este nivel de transparencia, junto a la posibilidad de verificar cada una de las operaciones de riego realizadas, ha aumentado la confianza de los agricultores en el sistema, resultando en la casi total desaparición de reclamaciones y conflictos asociados a la distribución del agua de riego.

La posibilidad de conocer el volumen asignado para cada agricultor ha supuesto una gran mejora en la gestión del agua a nivel de parcela, ya que los agricultores pueden planificar la rotación de sus cultivos en función del agua disponible. De esta forma se minimizan las pérdidas asociadas a la escasez imprevista de agua.

Las aplicaciones Web permiten a los agricultores un acceso en tiempo real (las 24 horas del día, los 7 días de la semana) desde cualquier lugar a los servicios proporcionados por la CRCC, evitando desplazamientos a las oficinas de riego para realizar las diferentes gestiones relacionadas con el suministro de agua a sus parcelas. Esta mejora en la eficiencia en las tareas administrativas a los agricultores les 
proporciona más tiempo para la gestión de sus explotaciones u otras actividades, representando una mejora en la calidad de vida de los mismos.
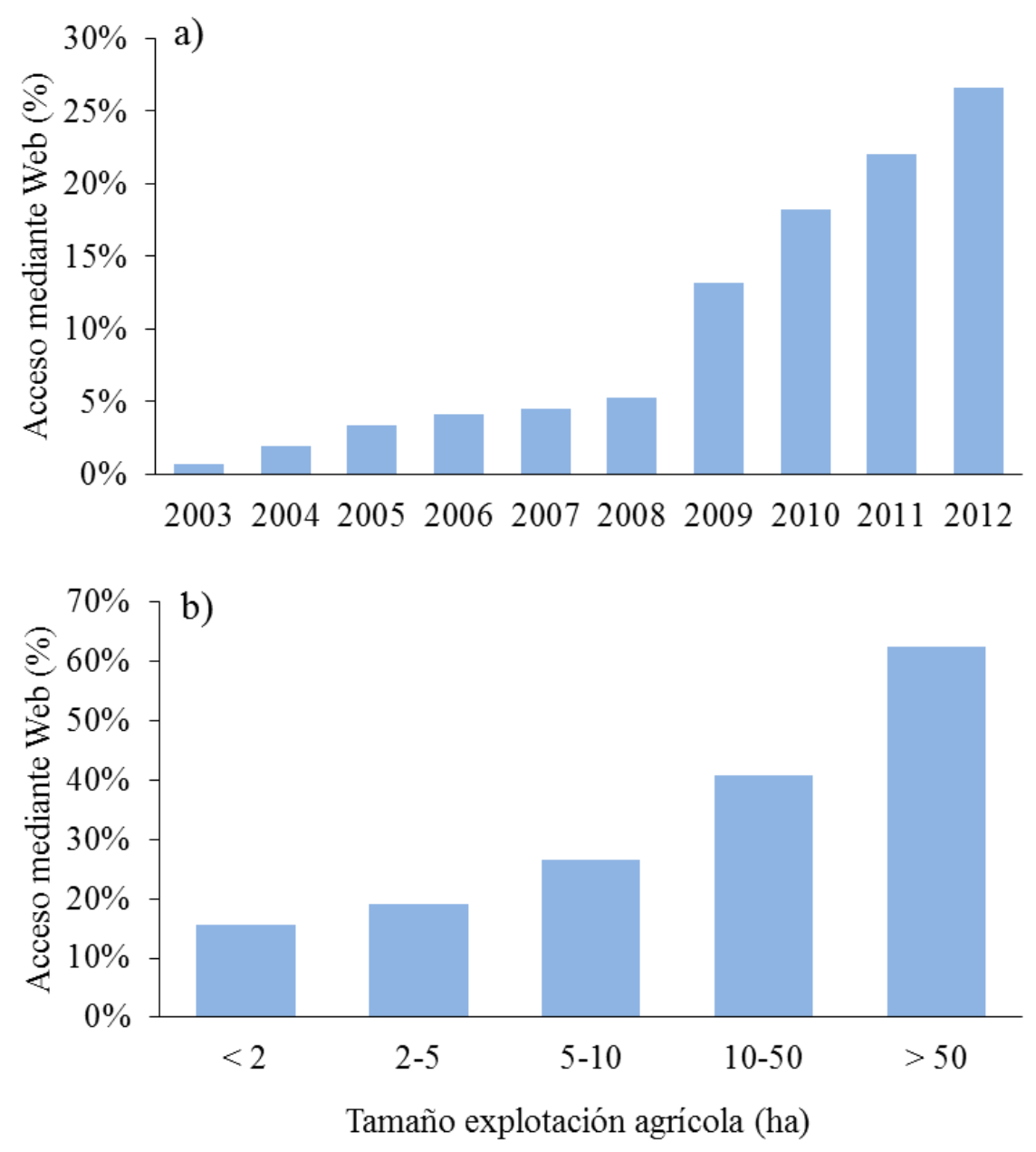

Figura 6.7. Evolución del uso de las aplicaciones Web: a) porcentaje de agricultores que usaron el servicio Web entre 2003 y 2012, y b) porcentaje que usaron el servicio Web en 2012 por tamaño de explotación agrícola.

Las aplicaciones Web y para móviles están siendo bien aceptadas por los agricultores. La Fig. 6.7a muestra la evolución de los agricultores que utilizan aplicaciones Web entre 2003 y 2012. Mostrando un incremento progresivo desde el 1\% en 2003 al 27\% en 2012. Este incremento se relaciona tanto con el creciente interés del regante en las TICs como con la calidad de la información y los servicios proporcionados, que ha ido mejorando tanto en cantidad como calidad a lo largo del periodo de estudio. Por tamaño de explotación agrícola (Fig. 6.7b), cuanto mayor es la 
explotación mayor es el empleo de Internet. Así en 2012 el 63\% de las explotaciones agrícolas con una superficie superior a 50 ha empleaban las aplicaciones Web. Como consecuencia de lo indicado el 52\% del agua suministrada por la CRCC en 2012 fue gestionada por los regantes a través de Internet.

De forma contraria, los regantes que utilizan la aplicación para telefonía móvil apenas han aumentado en el periodo de estudio, alcanzando un 6\% en 2012. Este resultado es debido a que con los Smartphone, Smart TV y Tablet es posible acceder al portal Web de la CRCC, con lo que no emplean la aplicación específica para móvil.

Por último, señalar que las TICs están proporcionando un canal directo para asesorar técnica y agronómicamente a los agricultores, por lo que es de esperar que se produzca una mejora en la gestión hídrica y energética de sus explotaciones a medio plazo.

\subsection{DISCUSIÓN}

Este Capítulo destaca la existencia de dos tipos diferentes de procesos de modernización: los denominados de modernización "primera generación", caracterizada por la presurización de las redes de distribución, así como las modernizaciones de "segunda generación", que se caracterizan por centrarse en la automatización de la infraestructura hidráulica presurizada existente previamente a la modernización y a los servicios de la CCRR.

La modernizaciones de "primera generación" por lo general han dado como resultado: (a) una reducción de las pérdidas del agua suministrada por la red de riego, como consecuencia de la mejora en la eficiencia de distribución debido a la sustitución de los canales abiertos de distribución por sistemas presurizados; (b) un incremento muy importante de los costes de manejo del sistema, debido a un aumento considerable 
de los costes energéticos por una mayor demanda energética en relación con la situación previa a la modernización; y (c) un cambio progresivo en los patrones de cultivo hacia cultivos más rentables. Estos hechos provocan cambios muy importantes en los valores de los indicadores de gestión. Las modernizaciones de "segunda generación”, como es el caso de la CRCC, debido a que la red de distribución ya se encontraba presurizada antes de realizar la modernización, presentan variaciones moderadas de los indicadores de gestión: un reducido impacto sobre el ahorro de agua y una disminución notable de los costes energéticos. Presentado sobre todo las ventajas provocadas por la aplicación de las TICs, que con los indicadores de gestión tradicionales no quedan reflejadas. Por lo tanto, son necesarios nuevos indicadores para caracterizar correctamente la modernización de "segunda generación" en relación con su mejora en la gestión y en los servicios prestados a los agricultores. Por ejemplo se propone considerar el tiempo empleado para varias tareas de gestión en la CCRR, como el intervalo de tiempo entre el suministro de agua y de facturación, el tiempo necesario para conocer la lectura de un contador, y el tiempo necesario para hacer mapas temáticos sobre el agua disponible en parcela u otras características. La incorporación de las TICs también podría ser evaluada por el porcentaje de agricultores que llevan a cabo todas sus actividades relacionadas con la CCRR a través de Internet, o el porcentaje de agua suministrada por la CCRR que se maneja a través de las aplicaciones Web y para telefonía móvil.

La incorporación de las TICs a la gestión de las CCRRs ha tenido una repercusión de enorme trascendencia en las prestaciones de estas instituciones colectivas. En el caso de la CRCC el avance tecnológico que suponen las TICs ha permitido: (a) mejorar la eficiencia de distribución; (b) hacer un reparto equitativo del agua; (c) conocer la trazabilidad del agua; (d) un ahorro de agua; (e) tener una gestión transparente; (f) reducir la conflictividad de los agricultores; (g) disminuir el consumo y 
coste energético; (h) reducir las oficinas de atención al agricultor y el número de celadores, y (i) tener una rápida actuación para evitar actos de vandalismo. Por el contrario, ha supuesto un incremento en los costes de personal y de mantenimiento, debido principalmente a la incorporación de personal más cualificado y a la complejidad intrínseca asociada a la infraestructura necesaria para la aplicación de las TICs en la gestión de la CCRR.

Además, la incorporación de las TICs ha permitido mejorar los servicios que la CRCC ofrece a sus agricultores, tanto en cantidad como calidad. La disponibilidad de acceso a estos servicios mediante Internet y telefonía móvil 24 horas al día y 7 días a la semana ofrece notables ventajas como: (a) facilitar el uso de criterios de optimización en la gestión del agua y la energía a nivel parcela y (b) proporcionar una mejor calidad de vida a los agricultores. El uso de Internet para la gestión del agua de riego ha tenido una buena aceptación por parte de los mismos, tal y como se demuestra por el progresivo aumento del número de usuarios.

El mundo de las TICs está en continua evolución, por lo que aunque ya apenas se producen mejoras relativas a la infraestructura hidráulica de la CCRR, el personal de la CRCC trabaja de forma continua en el desarrollo de nuevas aplicaciones y herramientas para satisfacer los requerimientos de la propia CCRR y de sus comuneros. En este sentido se están desarrollando nuevas herramientas para: (a) la optimización del consumo energético mediante el control en tiempo real del rendimiento de los grupos de bombeo, (b) la mejora de los servicios de asesoramiento de riego en parcela, con acceso a los datos meteorológicos en tiempo real y con aplicaciones para la programación del riego; (c) mejorar el asesoramiento al agricultor sobre el consumo de energía en parcela; (d) desarrollo de nuevas aplicaciones en el entorno WebGIS y (e) mejorar los procesos administrativos y técnicos de la CCRR. 


\section{Capítulo 7}

\section{CONCLUSIONES}

\subsection{CONCLUSIONES}

Las principales conclusiones de la presente tesis son las siguientes:

1. Las comunidades de regantes (CCRRs) de la Región de Murcia se caracterizan por: presentar una alta eficiencia de distribución; tener unos elevados costes de manejo del sistema; sufrir unas grandes variaciones en cuanto a los recursos hídricos disponibles; no satisfacer las necesidades hídricas de sus cultivos; presentar un valor de la producción agrícola muy alto; y tener una actividad agrícola estable, que se encuentra limitada principalmente por la disponibilidad de agua.

2. Los indicadores de gestión pueden sufrir una gran variación interanual como consecuencia de las fluctuaciones en la cantidad de agua distribuida. Por lo tanto el enfoque tradicional, que maneja indicadores como valores fijos característicos de una zona regable, no es adecuado en zonas con estrés hídrico. Por tanto debe plantearse la caracterización de las CCRRs en estas áreas en periodos de duración suficientemente amplios para que sean representativos.

3. Para determinar el consumo total de energía asociada al agua de riego, es necesario conocer el consumo energético en los tres niveles de gestión del regadío. En la zona de estudio, el mayor consumo de energía se produce a nivel de cuenca (71-82\%), siendo la fuente del agua el factor que más influye: superficial $\left(0,04-0,10 \mathrm{kWh} \mathrm{m}^{-3}\right)$, reutilizada $\left(0,72-0,86 \mathrm{kWh} \mathrm{m}^{-3}\right)$, subterránea $\left(0,80-0,96 \mathrm{kWh} \mathrm{m}^{-3}\right)$, del Trasvase Tajo-Segura $(0,94-1,01 \mathrm{kWh}$ $\left.\mathrm{m}^{-3}\right)$, y agua salobre desalada $\left(0,83-1,69 \mathrm{kWh} \mathrm{m}^{-3}\right)$. 
4. Los efectos principales de la escasez de agua sobre las zonas regables son una reducción: (a) de la superficie cultivada, (b) de la eficiencia de distribución y (c) del aporte relativo de agua de riego (ARIS). Estos efectos provocan un aumento del consumo de energía específica y una disminución del valor de la producción agrícola. Aunque los agricultores aplican estrategias para adaptarse a la escasez de agua, la perseverancia de este tipo de situaciones a lo largo del tiempo implica inconvenientes ambientales y económicos que pueden hacer insostenible la actividad agrícola en la zona a medio y largo plazo.

5. Este estudio ha permitido diferenciar dos tipos de procesos de modernización: los de "primera generación", caracterizados por la presurización de las redes de distribución; y los de "segunda generación", que se caracterizan por centrarse en la automatización de la infraestructura hidráulica presurizada existente previamente y en los servicios que la CCRR ofrece al regante. Los efectos de ambos tipos de modernizaciones sobre los indicadores de gestión son marcadamente diferentes.

6. La incorporación de las tecnologías de la información y la comunicación a la gestión de las CCRRs ha proporcionado: un mejor servicio al regante; conocer la trazabilidad del agua; y una distribución de agua transparente, eficiente y equitativa. Sin embargo, los indicadores tradicionales no han sido capaces de reflejar estas mejoras, por ello se proponen nuevos indicadores para poder cuantificarlas como: el tiempo empleado para realizar varias tareas de gestión en la CCRR, el porcentaje de agricultores que llevan a cabo todas sus actividades relacionadas con la CCRR a través de Internet, o el 
porcentaje de agua suministrada por la CCRR que se maneja a través de las aplicaciones Web y por telefonía móvil.

\subsection{PROPUESTA PARA FUTUROS TRABAJOS DE INVESTIGACIÓN QUE SE PUEDEN DERIVAR DE ESTA TESIS}

En base a los resultados obtenidos se proponen las siguientes líneas de investigación:

1. Extender este tipo de trabajos a todas las regiones españolas, o a cualquier otro ambito geográfico, con el fin de desarrollar un amplio proceso de benchmarking que permita una mejora continua de las CCRRs.

2. Desarrollar metodologías para la auditoria y seguimiento del consumo energético. Debido a la interrelación entre el consumo de agua y energía, es necesario seguir trabajando en esta línea de investigación mediante el empleo de indicadores específicos, con el objetivo de gestionar de una manera conjunta y más eficiente los recursos hídricos y energéticos en los tres niveles de gestión del regadío, y así asegurar la sostenibilidad de la agricultura de regadío.

3. Analizar los efectos de la escasez de agua a nivel de parcela, mediante el empleo de indicadores de gestión específicos, con el objetivo final de establecer recomendaciones que permita a los agricultores una producción sostenible.

4. Desarrollar y evaluar nuevos indicadores para caracterizar correctamente la modernización de "segunda generación" en relación con las mejoras introducidas por las tecnologías de la información y la comunicación. 
5. Plantear indicadores ambientales para incorporarlos a la gestión de las CCRRs que sean fiables y fáciles de obtener. Actualmente el empleo de este tipo de indicadores en las CCRRs suele ser prácticamente inexistente. 


\section{Bibliografía}

Abadía, R., Rocamora, M.C., Ruiz, A., 2008a. Protocolo de Auditoría Energética en Comunidades de Regantes. Volumen 10 de Eficiencia y Ahorro Energético. Agricultura Instituto para Diversificación y Ahorro de la Energía, IDAE. 68 pp.

Abadía, R., Rocamora, M.C., Ruiz, A., Puerto, H., 2008b. Energy efficiency in irrigation distribution networks I: Theory. Biosystems Engineering 101: 21-27.

Abadía, R., Rocamora, M.C., Córcoles J.I., Ruiz-Canales, A., Martinez-Romero, A., Moreno, M.A., 2010. Comparative analysis of energy efficiency in water users associations. Spanish Journal of Agricultural Research 8: 134-142.

Abadía, R., Rocamora, M.C., Vera, J., 2012. Energy efficiency in irrigation distribution networks II: Applications. Biosystems Engineering 111: 398-411.

Acosta, J.A., Faz, A., Jansen, B., Kalbitz, K., Martínez-Martínez, S., 2011. Assessment of salinity status in intensively cultivated soils under semiarid climate, Murcia, SE Spain. Journal of Arid Environments 75: 1056-1066.

Ahmad, A., Khan, S., 2009. On comparison of water and energy productivities in pressurized irrigation systems. In Anderssen, R.S., R.D. Braddock and L.T.H. Newham 18th World IMACS Congress and MODSIM09 International Congress on Modelling and Simulation. Modelling and Simulation Society of Australia and New Zealand and International Association for Mathematics and Computers in Simulation: 2776-2782.

Al-Ismaily, H., Probert, D., 1998. Water-resource facilities and management strategy for Oman. Applied Energy 61: 125-146.

Alcalá, F., Sancho, I. 2002. Agua y producción agrícola: un análisis econométrico del caso de Murcia. Estudios Agrosociales y Pesqueros 197: 129-157.

Alcón, F., De Miguel, M.D., Fernánez-Zamudio, M.A. 2006. Modelización de la difusión de la tecnología de riego localizado en el Campo de Cartagena. Estudios Agrosociales y Pesqueros 210: 227-245.

Alcón, F., 2007. Adopción y difusión de tecnologías de riego en la Región de Murcia. Seríe Técnica de Estudios no 33. Consejería de Agricultura y Agua de la Región de Murcia. 223 pp.

Alcón, F., De Miguel, M.D., Burton, M., 2011. Duration analysis of adoption of drip irrigation technology in southeastern Spain. Technological Forecasting and Social Change 78: 991-1001. 
Alcón, F., Atenza, J., Erena, M. Alarcon, J.J.,2012. Capítulo: Soil salinity prospects based on the quality of irrigation water used in the Segura basin, 223-229. In: Options mediterraneennes: The use of remote sensing and geographic information systems for irrigation management in Southwest Europe. CIHEAM. $239 \mathrm{pp}$.

Allen, R.A., Pereira, L.S., Raes, D., Smith, M., 1998. Crop evapotranspiration Guidelines for computing crop water requirements - FAO Irrigation and Drainage paper 56. 300 pp.

APQC. El código de conducta del Benchmarking. 2006. www.apqc.org. Acceso enero 2012.

Arcas, N., Alcón. F., 2007. Contribución de las entidades de "economía social" a la gestión eficiente del agua para uso agrícola. Revista de Estudios Cooperativos 91: 7-33.

Awan, U.K., Tischbein, B., Conrad, C., Martius, C., Hafeez, M., 2011. Remote Sensing and Hydrological Measurements for Irrigation Performance Assessments in a Water User Association in the Lower Amu Darya River Basin. Water Resources Management 25: 2467-2485.

Bailey, D., Wright, E., 2003. Practical SCADA for industry. Elsevier. Amsterdam. 344 pp.

Barros, R., Isidoro, D., Aragüés, R., 2011. Long-term water balances in La Violada irrigation district (Spain): I. Sequential assessment and minimization of closing errors. Agricultural Water Management 102: 35-45.

Barros, R., Isidoro, D., Aragüés, R., 2012. Three study decades on irrigation performance and salt concentrations and loads in the irrigation return flows of La Violada irrigation district (Spain). Agriculture, Ecosystems and Environment 151: 44-52.

Berbel, J., Calatrava, J., Garrido, A., 2007. Water Pricing and Irrigation: A Review of the european experience, 295-327. In: Irrigation Water Pricing. The Gap Between Theory And Practice. Ed. Molle, T. and Berkoff, J. CAB International, Oxfordshire, UK. 357 pp.

Berbel, J., Mesa-Jurado, M.A., Pistón, J.M., 2011. Value of irrigation water in Guadalquivir basin (Spain) by residual value method. Water Resources Management 25: 1565-1579.

Bescós, M., Cameo, D., Castillo, R., Citoler, J., Santafé, L.J., 2008. Alternativas para la reducción de costes energéticos en el diseño de redes de riego a presión mediante bombeo directo. Congreso de Huesca AERYD.

BOE (Boletín Oficial del Estado), 2001. Real Decreto Legislativo 1/2001, de 20 de julio, por el que se aprueba el texto refundido de la Ley de Aguas. $\mathrm{N}^{\circ} 176$ de 24 Julio 2001, p. 26791. 
BOE (Boletín Oficial del Estado), 2007. Real Decreto 1620/2007, de 7 diciembre por el que se establece el régimen jurídico de la reutilización de las aguas depuradas. $\mathrm{N}^{\circ} 294$ de 8 diciembre 2007, p. 50639.

Borgia, C., García-Bolaños, M., Li, T., Gómez-Macpherson, H., Comas, J., Connor, D., Mateos, L., 2013. Benchmarking for performance assessment of small and large irrigation schemes along the Senegal Valley in Mauritania. Agricultural Water Management 121: 19-26.

Brouwer, C., Heibloem, M., 1986. Irrigation Water Management: Irrigation Water Needs. - FAO Training Manual no. 3. 102 pp.

Burt, C.; Clemmens, T.S.; Strelkoff, K.H.; Solomon, R.D.; Bliesner, L.A.; Ardí, T.A. Howell, T.A., D.E. Eisenhauer. 1997. Irrigation Performance MeasuresEfficiency and Uniformity. Journal of Irrigation and Drainage Engineering. ASCE 123:423-442.

Burt, C., 2001. Proceso de Evaluación Rápida (RAP) y comparación con el patrón de referencia (benchmarking). Explicación y herramientas. Irrigation Training and Research Center. 55 pp. http://www.fao.org/nr/water/docs/RAPespanol.pdf.

Burt, C.M., Anderson, S.S., 2005. SCADA and Related Technologies for Irrigation District Modernization. In Proceedings USCID Water Management Conference, Vancouver, WA, Oct. 26-29. USCID Denver. Colorado. 356 pp.

Cabrera, E., 2011. El binomio agua-energía. ¿un asunto de moda o de interés real?. Fundación Ciudadanía y Valores. 21pp.

Cakmak, B., Beyribey, Y., Yildirim, E., Modal, S., 2004. Benchmarking performance of irrigation schemes: a case study from Turkey. Irrigation and Drainage 53: 155163.

Calatrava, J., Martinez-Granados, D., 2012. El valor de uso del agua en el regadío de la cuenca del Segura y en las zonas regables del trasvase Tajo-Segura.Economía Agraria y Recursos Naturales 12, 1: 5-32.

Campalans, R. 2001. ¿Qué es el Benchmarking?. Area temática nº 2. Fundación Rafael Campalans. Barcelona. 8 pp.

CARM, 2013.Comunidad Autonoma Región de Murcia. http://www.carm.es. Acceso enero 2013.

Carrillo-Cobo, M.T., Rodríguez, J.A., Camacho, E., 2010. The role of energy audits in irrigated areas. The case of 'Fuente Palmera' irrigation district (Spain). Spanish Journal of Agricultural Research 8: 152-161.

Carrillo-Cobo, M.T., Rodríguez, J.A., Montesinos, P., López, R., Camacho, E., 2011. Low energy consumption seasonal calendar for sectoring operation in pressurized irrigation networks. Irrigation Science 29: 157-169. 
Castañón, G., 2009. Agua y regadío sostenible. Cuaderno Interdisciplinar de Desarrollo Sostenible 2: 33-58.

CHS, 2013. Confederación Hidrográfica del Segura. http://www.chsegura.es. Acceso enero 2013.

Clothier, B., 2008. Wise use of water and nutrients in agriculture. SciTopics. http://www.scitopics.com/Wise_use_of_water_and_nutrients_in_agriculture.htm Acceso marzo 2013.

Córcoles, J.I., 2009. La gestión del agua y la energía en el regadío mediante técnicas de Benchmarking. Tesis Doctoral. Universidad de Castilla La Mancha. Albacete. $521 \mathrm{pp}$.

Córcoles, J.I., De Juan, J.A., Ortega, J.F., Tarjuelo, J.M., Moreno, M.A., 2010. Management evaluation of Water Users Associations using benchmarking techniques. Agricultural Water Management 98: 1-11.

Corominas, J., 2009. Agua y energía en el riego, en la época de la sostenibilidad. Comunicaciones de los invitados especiales. Jornadas de Ingeniería del Agua. Madrid.

CRCC, 2013. Comunidad de Regantes del Campo de Cartagena. http://www.crcc.es/. Acceso enero 2013.

CRLORCA, 2013. Comunidad de Regantes de Lorca. http://www.crlorca.org. Acceso enero 2013.

De Stafano, L., Llamas, M. R., 2013. Water, Agriculture and the Environment in Spain: can we square the circle?. CRC Press. Taylor and Francis. 316 pp.

Dechmi, F., Burguete, J., Skhiri, A., 2012. SWAT application in intensive irrigation systems: Model modification, calibration and validation. Journal of Hydrology 470-471: 227-238.

Del Amor, F., Gomez, J., Sanchez, M.I., 1998. Modernización de los Regadíos Tradicionales de Mula. Cajamurcia. Murcia. 99 pp.

Del Amor, P.L. 2006. Sistema de acceso móvil para la gestión de servicios de riegos en comunidades de regantes. Riegos y Drenajes XXI 147: 70-73.

Del Campo, A., 2008. Las comunidades de regantes y su federación nacional. FENACORE. 69 pp.

Dickie, P., 2007. Making Water-Desalination: Option or Distraction for a Thirsty World? Report for the WWF Global Freshwater Programme; World Wildlife Fund: Switzerland. 53 pp.

Doorenbos, J., Pruitt, W.O., 1977. Crop water requirements. FAO Irrigation and Drainage Paper No. 24 (rev.). FAO, Rome. 
Droogers, P., Kite, G., 1999. Water productivity from integrated basin modeling. Irrigation and Drainage Systems 13: 275-290.

Dubreuil, A., Assoumou, E., Bouckaert, S., Selosse, S., Maïzi, N., 2013. Water modeling in an energy optimization framework - The water-scarce middle east context. Applied Energy 101: 268-279.

Dursun, M., Ozden, S., 2012. Application of solar powered automatic water pumping in Turkey. International Journal of Computer and Electrical Engineering 4: 161164.

ECONET, 2013. Centro Regional de Estadística de Murcia.http://www.carm.es/econet/. Acceso enero 2013.

Ederra, I., Murugarren, N., 2010. La nueva tarifa eléctrica: la escalada de precios del agua. S.A: Servicio de Asesoramiento al Regante. Riegos de Navarra. 47 pp.

Erena, M., Rincon , L., Arcas, N., Perez, P., Soto-García, M, Garcia, P, Alcon, F., 2008. La Gestión del Agua en el Campo de Cartagena. IV Congreso mundial de Ingenieros Agrónomos y Profesionales de la Agronomía. Madrid.

ESAMUR, 2013. http://esamur.com/. Acceso enero 2013.

ESYRCE, 2011. Encuesta sobre Superficies y Rendimientos de Cultivos (ESYRCE). Años 2002-2011. Informe sobre los regadíos en España. Ministerio de Agricultura, Alimentación y Medio Ambiente.

ETI, 2008. Esquema provisional de temas importantes. Demarcación Hidrográfica del Segura.http://www.chsegura.es/export/descargas/planificacionydma/planificacio n/docsdescarga/ETI_v6_29julio2008.pdf. Acceso marzo 2013.

FAO, 1997. Modernization of irrigation schemes: past experiences and future options. FAO-RAP 1997/22, Water Report Series 12, Bangkok.

Fernández, M.A, Soria, A., 2011. La contaminación de las aguas por nitratos procedentes de fuentes de origen agrario. Volumen 34 de Formación Agroalimentaria. Consejería de Agricultura y Agua. 13 pp.

Fernández, M.D., González, A.M., Carreño, J., Pérez, C., Bonachela, S., 2007. Analysis of on-farm irrigation performance in Mediterranean greenhouses. Agricultural Water Management 89: 251-260.

Gallego-Elvira, B. 2011. Análisis de la evaporación en embalses de riego y su reducción con coberturas de sombreo. Tesis Doctoral. Universidad Politécnica de Cartagena. Cartagena. 204 pp.

García, C., Olivares, P., 1968. La huerta de Murcia en los siglos XII y XIII. Murcia: Universidad, Secretariado de Publicaciones. 33 pp. 
García, J., 2007. Evaluación económica y eficiencia del agua de riego en frutales de regadío. Volumen 3 de Serie Técnica y de Estudios. Consejería de Agricultura y Agua. 115 pp.

García, V., Casañas, A., 2010. Reverse osmosis, a key technology in combating water scarcity in Spain. Desalination 250: 950-955.

García-Ruiz, J.M., López-Moreno, J.I., Vicente-Serrano, S.M., Lasanta-Martínez, T., Beguería, S., 2011. Mediterranean water resources in a global change scenario. Earth-Science Reviews 105: 121-139.

García-Vila, M., Lorite, I.J., Soriano, M.A., Fereres, E., 2008. Management trends and responses to water scarcity in an irrigation scheme of southern Spain. Agricultural Water Management 95:458-468.

García-Vila, M., Fereres, E., 2012. Combining the simulation crop model AquaCrop with an economic model for the optimization of irrigation management at farm level. European Journal of Agronomy 36: 21-31.

Geerts, S., Raes, D., 2009. Deficit irrigation as an on-farm strategy to maximize crop water productivity in dry areas. Agricultural Water Management 96: 1275-1284.

Ghazalli, M.A., 2004. Benchmarking of irrigation projects in Malaysia: Initial implementation stages and preliminary results. Irrigation and Drainage 53: 195212.

Gil, E., 2006. Los paisajes agrarios de la Región de Murcia. Papeles de Geografía, 43: 19-30.

Gil, E., 2010. La Región de Murcia, un laboratorio de experiencias de ahorro y eficiencia en el uso del agua: La modernización de sus regadíos, entre la política agraria y ambiental de la Unión Europea. Papeles de Geografía 51-52: 131-145.

Giménez, M., Perez, I., Baños, P., Pedreño, A., 2010. Las comunidades de regantes: Análisis multidisciplinar sobre los marcos institucionales, reglas y fórmulas de participación social entorno a los manantiales de la Comarca del Noroeste (Región de Murcia, España). Primer Congreso Red de Investigadores Sociales Sobre Agua. México. 22 pp.

Gómez, J.M., 1997. El regadío en el umbral del siglo XXI: Planes de mejora y modernización. Papeles de Geografía 25: 75-102.

Gómez, J.M., Gil, E., García, R., 2005. Insuficiencias hídricas y modernización de los regadíos en la Cuenca de Mula. Papeles de Geografía 41-42: 101-121.

Gómez, J.M., García, R., Gil, E., 2007. Modernización de regadíos con aguas subterráneas en ámbitos semiáridos. M+A. Revista Electrónic@ de Medioambiente 3: 1-22. 
Gómez, J.M., Lopez, J.A., Montaner Salas, M.E., 2011. Modernización de regadíos: Sostenibilidad social y económica. La sigularidad de los regadíos del Trasvase Tajo-Segura. Universidad de Murcia. 439 pp.

Gonçalves, J.M., Pereira, L.S., 2009. A decision support system for surface irrigation design. Journal of Irrigation and Drainage Engineering 135: 343-356.

Grindlay, A.L., Zamorano, M., Rodríguez, M.I., Molero, E., Urrea, M.A., 2011. Implementation of the European Water Framework Directive: Integration of hydrological and regional planning at the Segura River Basin, southeast Spain. Land Use Policy 28: 242-256

Gurutze, M., Ochoa, C.,2005. Una revisión teórica de la herramienta de benchmarking. Revista de Dirección y Administración de Empresas 12: 73-103.

Hardy, L., Garrido A., 2010. Análisis y evaluación de las relaciones entre el agua y la energía en España. Papeles del Agua Virtual nº 6. Fundación Botín. 208 pp.

Hardy, L., Garrido, A., Juana, L., 2012. Evaluation of Spain's Water-Energy Nexus. International Journal of Water Resources Development 28: 151-170.

Hernández-Sancho, F., Molinos-Senante, M., Sala-Garrido, R., 2010. Economic valuation of environmental benefits from wastewater treatment process: an empirical approach for Spain. Science of the Total Environment 408: 953-957.

Hsiao, T., Steduto, P., Fereres, E., 2007. A systematic and quantitative approach to improve water use efficiency in agriculture. Irrigation Science 25: 209-231.

Huang, Y., Li, Y.P., Chen, X., Ma, Y.G., 2012. Optimization of the irrigation water resources for agricultural sustainability in Tarim River Basin, China. Agricultural Water Management 107: 74-85.

IDAE. 2005. Ahorro y Eficiencia Energética en Agricultura de Regadío. Instituto para Diversificación y Ahorro de la Energía, IDAE. Serie divulgación Ahorro y Eficiencia Energética en Agricultura 2. 36 pp.

IEA (International Energy Agency), 2007. World Energy Outlook 2007: 674.

Iglesias, A., Garrote, L., Flores, F., Moneo, M., 2007. Challenges to manage the risk of water scarcity and climate change in the Mediterranean. Water Resources Management 21: 775-788.

Iglesias, R., Ortega, E., 2008. Present and future of wastewater reuse in Spain. Desalination 218: 105-119.

Iglesias, R., Ortega, E., Batanero, G., Quintas, L., 2010. Water reuse in Spain: Data overview and costs estimation of suitable treatment trains. Desalination 263: 110.

INE (Instituto Nacional de Estadística), 2012. http://www.ine.es. Acceso Junio 2012. 
Jackson,T.M., Khan, S., Hafeez, M., 2010. A comparative analysis of water application and energy consumption at the irrigated field level. Agricultural Water Management 97: 1477-1485.

Jacobsen, S.E., Jensen, C.R., Liu, F., 2012. Improving crop production in the arid Mediterranean climate. Field Crops Research 128: 34-47.

Jayatillake, H.M., 2004. Application of performance assessment and benchmarking tool to help improve irrigation system performance in Sri Lanka. Irrigation and Drainage 53: 185-193.

Jebaraj, S., Iniyan, S., 2006. A review of energy models. Renewable and Sustainable Energy Reviews 10: 281-311.

Jiménez-Bello, M.A., Martínez-Alzamora, F., Bou, V, Bartolí, H.J., 2010. Methodology for grouping intakes of pressurised irrigation networks into sectors to minimise energy consumption. Biosystems Engineering 105: 429-438.

Jiménez-Bello, M.A., Martínez-Alzamora, F., Castel, J.R., Intrigliolo, D.S., 2011. Validation of a methodology for grouping intakes of pressurized irrigation networks into sectors to minimize energy consumption. Agricultural Water Management 102: 46-53.

Jiménez-Martínez, J., Skaggs, T.H., Van Genuchten, M. Th., Candela, L., 2009. A root zone modelling approach to estimating groundwater recharge from irrigated áreas. Journal of Hydrologic 367: 138-149.

Kazbekov, J., Abdullaev, I., Manthrithilake, H., Qureshi, A., Jumaboev, K., 2009. Evaluating planning and delivery performance of Water User Associations (WUAs) in Osh Province, Kyrgyzstan. Agricultural Water Management 96: 1259-1267.

Kim, Y., Evans, R.G., 2009. Software design for wireless sensor-based site-specific irrigation. Computers and Electronics in Agriculture 66: 159-165.

Kizilaslan H., 2009. Input-output energy analysis of cherries production in Tokat Province of Turkey. Applied Energy 86: 1354-1358.

Koutroulis, A.G., Tsanis, I.K., Daliakopoulos, I.N., Jacob, D., 2013. Impact of climate change on water resources status: a case study for Crete Island, Greece. Journal of Hydrology 479: 146-158.

Lacy, J., 2011. Cropcheck: Farmer benchmarking participatory model to improve productivity. Agricultural Systems 104: 562-571.

Lal, R., 2004. Carbon emission from farm operations. Environment International 30: 981-90.

Lamaddalena, N., Khila, S., 2012. Energy saving with variable speed pumps in ondemand irrigation systems. Irrigation Science 30: 157-166. 
Lecina, S., Isidoro, D., Playán, E., Aragüés, R., 2010. Irrigation Modernisation and Water Conservation in Spain: the case of Riegos del Alto Aragón. Agricultural Water Management 97: 1663-1675.

Lee, W.S., Burks, T.F., Schueller, J.K., 2002. Silage yield monitoring system. Paper 021165. ASABE. St. Joseph.

López, J., 2006. La transformación del paisaje en el regadío tradicional de la Huerta de Mula. Papeles de Geografía 44: 59-72.

López-Gunn, E., Zorrilla, P., Prietod, F., Llamase, M.R., 2012. Lost in translation? Water efficiency in Spanish agriculture. Agricultural Water Management 108: 83-95.

Lorite, I.J., Mateos, L., Fereres, E., 2004. Evaluating irrigation performance in a Mediterranean environment. II. Variability among crops and farmers. Irrigation Science 23: 85-92.

Luc, J. P., Tarhouni, J., Calvez, R., Messaoud, L., Sablayrolles, C., 2006. Performance indicators of irrigation pumping stations:application to drill holes of minor irrigated areas in the kairouan plains (tunisia) and impact of malfunction on the price of water. Irrigation and Drainage 55: 85-98.

Maestre-Valero, J.F., 2011. Efectos de la aplicación de coberturas de sombreo suspendidas sobre balsas de riego. Tesis Doctoral. Universidad Politécnica de Cartagena. $141 \mathrm{pp}$.

MAGRAMA. 2013. Ministerio de Agricultura, Alimentación y Medio Ambiente. http://www.magrama.gob.es. Acceso enero de 2013.

Malano, H., Burton, M., 2001. Guidelines for benchmarking performance in the irrigation and drainage sector. In: International Programmefor Technology and Research in Irrigation and Drainage (IPTRID), Rome, Italy. 44 pp.

Malano, H., Burton, M., Makin, I., 2004. Benchmarking performance in the irrigation and drainage sector: a tool for change. Irrigation and Drainage 53: 119-133.

Martínez, R., Gómez, J.M., 2008. Modernización de regadíos en el Valle del Guadalentín. XIV Coloquio de Geográfia Rural: Los Espacios Rurales Españoles en el Nuevo Siglo. Murcia.

Martínez-Alvarez, V., Baille, A., Molina Martínez, J.M., González-Real, M.M., 2006. Efficiency of shading materials in reducing evaporation from free water surfaces. Agricultural Water Management 84: 229-239.

Martínez-Alvarez, V., González-Real, M.M., Baille, A., Maestre Valero, J.F., Gallego Elvira, B., 2008. Regional assessment of evaporation from agricultural irrigation reservoirs in a semiarid climate. Agricultural Water Management 95: 1056-1066. 
Martínez-Alvarez, V., Calatrava, J., Maestre-Valero, J.F., Martin-Gorriz, B., 2009. Economic assessment of shade-cloth covers for agricultural irrigation reservoirs in a semi-arid climate. Agricultural Water Management 96: 1351-59.

Martínez-Carrasco, F., Martínez, J.M., 2011. El cluster agroalimentario de la Región de Murcia. Cuadernos de Estudios Agroalimentarios 2: 175-198.

Martínez-Fernández, J., Esteve-Selma, M.A., Baños-González, I., Carreño, F., Moreno, A., 2013. Sustainability of Mediterranean irrigated agro-landscapes. Ecological Modelling 248: 11-19.

Martínez-Granados, D., Maestre-Valero, J.F., Calatrava, J., Martínez-Alvarez, V., 2011. The economic impact of water evaporation losses from water reservoirs in the Segura basin, SE Spain. Water Resources Management 25: 3153-3175.

Mathiyalagan, V., Grunwald, S., Reddy, K.R., Bloom, S.A., 2005. A WebGIS and geodatabase for Florida's wetlands. Computers and Electronics in Agriculture 47: 69-75.

MedWSD, 2007. Mediterranean water scarcity and drought report. Mediterranean water scarcity \& drought working group, European Commission Technical Report 009-2007. http:www.emwis.net/topics/WaterScarcity.

Melgarejo, J., Molina, A., Del Villar, A., 2009. La responsabilidad patrimonial del estado ante la hipotética reducción o cancelación del Trasvase Tajo-Segura. Fundación Agua y Progreso de la Comunidad Valenciana. 144 pp.

Melgarejo, J., 2009. El Trasvase Tajo-Segura: Repercusiones económicas, sociales y ambientales en la Cuenca del Segura. Caja Mediterráneo. 635 pp.

Melgarejo, J., Montaño, B., 2009. La eficiencia energética en el trasvase Tajo-Segura. In: Cuides, Cuaderno Interdisciplinar de Desarrollo Sostenible, 3. Fundación CajaMar: 173-193.

Melgarejo, J., Molina, A., Del Villar, A., 2010. El valor socioeconómico del Trasvase Tajo-Segura. Análisis jurídico y económico ante la hipótesis de su reducción y cancelación. COEPA y Fundación Agua y Progreso de la Comunidad Valenciana. $175 \mathrm{pp}$.

Melián-Navarro, A., Canatario-Duarte, A., Ruiz-Canales, A., 2010. Aplicación de indicadores de benchmarking en comunidades de regantes. Evaluación comparativa de dos realidades de la península Ibérica. Riegos y drenajes XXI 175: 14-19.

Mo, W., Zhang, Q., Mihelcic, J.R., Hokanson, D.R., 2011. Embodied energy comparison of surface and groundwater supply options. Water Research 45: 5577-5586. 
Molina, J.L., García-Aróstegui, J.L., Benavente, J.,Varela,C., De la Hera, A., López, J.A., 2009. Aquifers Overexploitation in SE Spain: A Proposal for the Integrated Analysis of Water Management. Water Resources Management 23: 2737-2760.

Molina, J.L., García-Aróstegui, J.L., Bromley, J., Benavente, J., 2011. Integrated Assessment of the European WFD Implementation in Extremely Overexploited Aquifers Through Participatory Modelling. Water Resources Management 25: 3343-3370.

Montaner, M.E., 1992. La sequía, freno inevitable al desarrollo de la Región?. Papeles de Geografía 18: 185-193.

Montoro, A., López-Fuster, P., Fereres, E., 2011. Improving on-farm water management through an irrigation scheduling service. Irrigation Science 29: 311-319.

Morales, A., Rico, A.M., Hernández, M., 2005. El trasvase Tajo-Segura. Observatorio Medioambiental 8: 73-110.

Moreno, M.A., Ortega, J.F., Corcoles, J.I., Martínez, A., Tarjuelo, J.M., 2010a. Energy analysis of irrigation delivery systems: monitoring and evaluation of proposed measures for improving energy. Irrigation Science 28: 445-460.

Moreno, M.A., Córcoles, J.I., Tarjuelo, J.M., Ortega, J.F., 2010b. Energy efficiency of pressurised irrigation networks managed on-demand and under a rotation schedule. Biosystems engineering 107: 349-63.

Moreno-Pérez, M.F., Roldán-Cañas, J., 2013. Assessment of irrigation water management in the Genil-Cabra (Córdoba, Spain) irrigation district using irrigation indicators. Agricultural Water Management 120: 98-106.

Nelson, E., 2002. Low cost options for creating a GIS. American City and County, 10.

Nicolás, E., Pedrero, F., Alarcon, J.J., Mounzer, O., Martínez-Álvarez, V., Nortes, P.A., Alcon, F., Egea, G., De Miguel, M.M., 2012. Estudio de la viabilidad del uso de las aguas regeneradas procedentes de la EDAR de Jumilla en la Comunidad de Regantes Miraflores. Universidad Politécnica de Cartagena. 55 pp.

Oksanen, T., Ohman, M., Miettinen, M., Visala, A., 2004. Open configurable control system for precision farming. Paper 701P1004. ASABE, St. Joseph, USA.

Orellana, F.J., Del Sagrado, J., Del Aguila, M.I., 2011. SAIFA: A Web-based system for Integrated Production of olive cultivation. Computers and Electronics in Agriculture 78: 231-237.

Pavan, W., Fraisse C.W., Peres, N.A., 2011. Development of a Web-based disease forecasting system for strawberries. Computers and Electronics in Agriculture 75: $169-175$. 
Pedrero, F., Kalavrouziotis, I., Alarcón J.J., Koukoulakis P., Asano T., 2010. Use of treated municipal wastewater in irrigated agriculture-Review of some practices in Spain and Greece. Agricultural Water Management 97: 1233-1241.

Pereira, L.S., Oweis, T., Zairi, A., 2002. Irrigation management under water scarcity. Agricultural Water Management 57: 175-206.

Pereira, L.S., 2004. Trends for Irrigated Agriculture in the Mediterranean Region: Coping With Water Scarcity. European Water 7/8: 47-64.

Pereira, L.S., Cordery, I., Iacovides, I., 2012. Improved indicators of water use performance and productivity for sustainable water conservation and saving. Agricultural Water Management 108: 39-51.

Pérez-Blanco, C.D., Gómez, C.M., Del Villar, A., 2011. El riesgo de disponibilidad de agua en la agricultura: una aplicación a las cuencas del Guadalquivir y del Segura. Estudios de Economía Aplicada 29-1: 333-358.

Pérez-Sirvent, C., Martínez-Sánchez, M.J., Vidal, J., Sánchez, A., 2003. The role of low-quality irrigation water in the desertification of semi-arid zones in Murcia, SE Spain. Geoderma 113: 109-125.

Perry, C., Steduto, P., Allen, R.G., Burt, C.M., 2009. Increasing productivity in irrigated agriculture: agronomic constraints and hydrological realities. Agricultural Water Manage 96: 1517-1524.

Plappally, A.K., Lienhard, J.H., 2012. Energy requirements for water production, treatment, end use, reclamation, and disposal. Renewable and Sustainable Energy Reviews 16: 4818-4848.

Playán, E., Mateos L., 2006. Modernization and optimization of irrigation systems to increase water productivity. Agricultural Water Management 80: 100-116.

Playán, E., Cavero, J., Mantero, I., Salvador, R., Lecina, S., Faci, J.M., Andres, J., Salvador, V., Cardeña, G., Ramon, S., Lacueva, J.L., Tejero, M., Ferri, J., Martínez- Cob, A., 2007. A database program for enhancing irrigation district management in the Ebro Valley (Spain). Agricultural Water Management 87: 209-216.

Plusquellec, H., 2009. Modernisation of large-scale irrigation systems: Is it an achievable objective or a lost cause? Irrigation and Drainage 58: 104-120.

Pulido, I., Gutiérrez, J., Roldán, J., López, R., 2006. Depósitos de regulación en cabecera de redes hidráulicas a presión. Revista Iberoamericana de Ingeniería Mecánica 10, 2: 81-96.

Rasouliazar, S. 2011. A Study of Factors Influencing Development of Pressurized Irrigation Systems in Iran (Case Study in West Azerbaijan Province). AmericanEurasian Journal of Agricultural \& Environmental Sciences 10: 928-933. 
Rhoades, J.D., Kandiah, A., Mashali, A.M., 1992. The use of saline waters for crop production. Irrigation and Drainage Paper 48. FAO. Roma. 133 pp.

Richards, Q.D., Bange, M.P., Johnston, S.B., 2008. HydroLOGIC: An irrigation management system for Australian cotton. Agricultural Systems 98: 40-49.

Rocamora, M.C., Abadia, R., Ruiz, A. 2008. Ahorro y Eficiencia Energética en Comunidades de Regantes. Instituto para Diversificación y Ahorro de la Energía, IDAE. Serie divulgación Ahorro y Eficiencia Energética en Agricultura 9. $42 \mathrm{pp}$.

Rodríguez, J.A., 2003. Análisis de la gestión del agua de riego y aplicación de las técnicas de benchmarking a las zonas regables de Andalucía. Tesis doctoral. Universidad de Córdoba, Córdoba. 332 pp.

Rodríguez, J.A., Pérez, L., Camacho, E., López, R., 2005. IGRA. A tool for applying the benchmarking initiative to irrigated areas. Irrigation and Drainage 54: 307319.

Rodríguez, J.A., Camacho, E., López, R., Pérez, L., 2008. Benchmarking and multivariate data analysis techniques for improving the efficiency of irrigation districts: an application in Spain. Agricultural Systems 96: 250-259.

Rodríguez, J.A, López, R., Carrillo, M.T., Montesinos, P., Camacho, E., 2009. Exploring energy saving scenarios for on-demand pressurised irrigation networks. Biosystems Engineering 104: 552-561.

Rodríguez, J.A., Pérez, L., Camacho, E., Montesinos, P., 2011a. The paradox of irrigation scheme modernization: more efficient water use linked to higher energy demand. Spanish Journal of Agricultural Research 9: 1000-1008.

Rodríguez, J. A., Camacho-Poyato E., Blanco-Pérez M. 2011b. Evaluation of Water and Energy Use in Pressurized Irrigation Networks in Southern Spain. Journal of Irrigation and Drainage Engineering 137: 644-650.

Romero, R., Muriel, J.L., García, I., Muñoz de la Peña, D., 2012. Research on automatic irrigation control: State of the art and recent results. Agricultural Water Management 114: 59- 66.

Rossman, L. A., 2000. EPANET 2. Users Manual. US Environmental Protection Agency (EPA), USA. 200 pp.

Ruiz, A., Molina, J.M., 2010. Automatización y telecontrol de sistemas de riego. Marcombo. $426 \mathrm{pp}$.

Sagardoy, J.A., Bottrall, A., Uittenbogaard, G.O., 1982. Organization, operation and maintenance of irrigation schemes. FAO Irrigation and Drainage paper 40. Roma.174 pp. 
Salvador, R., Martínez-Cob, A., Cavero, J., Playan, E., 2011. Seasonal on farm irrigation performance in the Ebro basin (Spain): Crops and irrigation systems. Agricultural Water Management 98: 577-587.

San Martín, E. 2011. Un análisis económico de los trasvases de agua intercuencas: El Trasvase Tajo Segura. Tesis doctoral. Universidad Nacional de Educación a Distancia. 525 pp.

Sánchez-Moreno, S., Ferris, H., Young-Mathews, A., Culman, S., Jackson, L., 2011. Abundance, diversity and connectance of soil food web channels along environmental gradients in an agricultural landscape. Soil Biology \& Biochemistry 43: 2374-2383.

Sandman, P., Lanard, J., 2011. Explaining and Proclaiming Uncertainty: Risk Communication Lessons from Germany's Deadly E. coli Outbreak. Peter Sandman website. http://www.psandman.com/col/GermanEcoli.htm.

Schaldach, R., Koch, J., Aus der Beek, T., Kynast,E., Flörke M., 2012. Current and future irrigation water requirements in pan-Europe: An integrated analysis of socio-economic and climate scenarios. Global and Planetary Change 94-95: 3345.

SCRATS (Sindicato Central de Regantes del Acueducto Tajo-Segura), 2013. http://www.scrats.com/. Acceso enero 2013.

Serrano, S., Jiménez-Hornero, F.J., Gutiérrez de Ravé, E., Jodral, M.L., 2008. GIS design application for "Sierra Morena Honey" designation of origin. Computers and Electronics in Agriculture 64: 307-317.

SIAM, 2013. Sistema de Información Agraria de Murcia. http://siam.imida.es. Acceso enero 2013.

Siddiqi, A, Diaz, L., 2011.The water-energy nexus in Middle East and North Africa. Energy Policy 39: 4529-4540.

SIRRIMED, 2013. Sustainable use of IRRigation water in the MEDiterranean region. http://www.sirrrimed.org. Acceso marzo 2013.

Skhiri, A., Dechmi, F., 2012. Impact of sprinkler irrigation management on the Del Reguero river (Spain). I: Water balance and irrigation performance. Agricultural Water Management 103: 120-129.

Soto-García, M., Martínez-Alvarez, V., Valiente, M., Del Amor, F. 2007. Modernización de la Zona Regable del Campo de Cartagena. Riegos y Drenajes XXI 157: 2835 .

Soto-García, M., Martínez-Alvarez, V., García-Bastida, P.A., Alcón, F., Martin-Gorriz, B., 2013a. Effect of water scarcity and modernisation on the performance of irrigation districts in south-eastern Spain. Agricultural Water Management 124: 11-19. 
Soto-García, M., Martin-Gorriz, B., García-Bastida, P.A., Alcón, F., Martínez-Alvarez, V., 2013b. Energy consumption for crop irrigation in a semiarid climate (southeastern Spain). Energy 55: 1084-1093.

Stokes, J.R., Horvath, A., 2009. Energy and air emission effects of water supply. Environmental Science \& Technology 43: 2680-2687.

Styczen, M., Poulsen, R.N., Falk, A.K., Jørgensen, G.H., 2010. Management model for decision support when applying low quality water in irrigation. Agricultural Water Management 98: 472-481.

Tanaka, Y., Sato, Y., 2005. Farmers managed irrigation districts in Japan: Assessing how fairness may contribute to sustainability. Agricultural Water Management 77: 196-209.

Tarjuelo, J.M., De-Juan, J. A., Moreno, M. A., Ortega, J. F., 2010. Review. Water resources deficit and water engineering. Spanish Journal of Agricultural Research 8: 102-121.

Tobarra, M.A., Castros, J.P., 2011. Incertidumbre hídrica y prima de riesgo en la agricultura de la Cuenca del Segura. Revista Atlántica de Economía 2: 1-17.

USAID (United States Agency for International Development), 2001. USAID Global Environment Center Environment Notes, The Water-Energy Nexus: Opportunities for Integrated Environmental Management. Washington DC.

Uysal, O., Atis, E., 2010. Assessing the performance of participatory irrigation management over time: a case study from Turkey. Agricultural Water Management 97: 1017-1025.

Vera, P., 2005. Murcia y el agua: Historia de una pasión. Comisión mixta Asamblea Regional de Murcia, Real Academia Alfonso X el Sabio. Murcia. 240 pp.

Vermillion, D.L., Sagardoy, J.A., 2001. La transferencia de la gestión del riego: Directrices. Estudio FAO Riego y Drenaje, 58. FAO. Roma. 102 pp.

Werner, A.D., Zhang, Q., Xue, L., Smerdon, B.D., Li X., Zhu, X., Yu, L., Li, L., 2013. An Initial Inventory and Indexation of Groundwater Mega-Depletion Cases. Water Resources Management 27: 507-533.

WWAP (World Water Assessment Programme), 2012. The United Nations World Water Development Report 4: Managing Water under Uncertainty and Risk. Paris, UNESCO.

Xu, L., Chen, L., Chen, T., Gao, Y., 2011. SOA-based precision irrigation decision support system. Mathematical and Computer Modelling 54: 944-949.

Younos, T., 2005.The Economics of Desalination. Journal of Contemporary Water Research \& Education 132: 39-45. 
Zazueta, F.S., Xin, J., Pereira, L.S., Musy, A., 2006. Information technologies in water management. In: Munack, A. CIGR Handbook of Agricultural Engineering, Vol. VI: Information Technologies. ASABE: 314-324.

Zhang, Z., 2004. Investigation of wireless sensor networks for precision agriculture. Paper 041154. ASABE. St. Joseph.

Zwart, S.J., Bastiaanssen, W.G.M., Fraiture, C., Molden, D.J., 2010. A global benchmarkmap of water productivity for rainfed and irrigated wheat. Agricultural Water Management 97: 1617-1627. 